\title{
MODELO HIDROGEOQUÍMICO DO AQÜÍFERO ADAMANTINA EM URÂNIA - SP
}

\section{ANGÉLICA SOUZA GUTIERREZ}

Orientador: Prof. Dr. Ricardo César Aoki Hirata

DISSERTAÇÃO DE MESTRADO

Nome

Presidente: Prof. Dr. Ricardo César Aoki Hirta

Examinadores: Profa. Dra. Maria Cristina Motta de Toledo

Dr. Reginaldo Antonio Bertolo

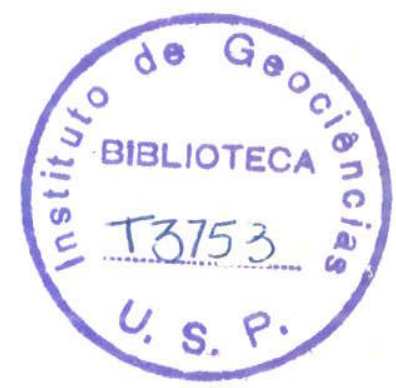

Assinatura

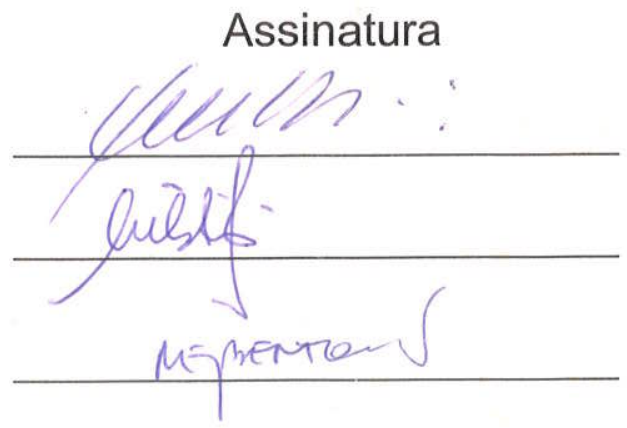

SÃO PAULO

2003 


\section{UNIVERSIDADE DE SÃO PAULO INSTITUTO DE GEOCIENCIAS}

\section{MODELO HIDROGEOQUÍMICO DO AQÜÍFERO ADAMANTINA EM URÂNIA - SP}

Angélica Souza Gutierrez

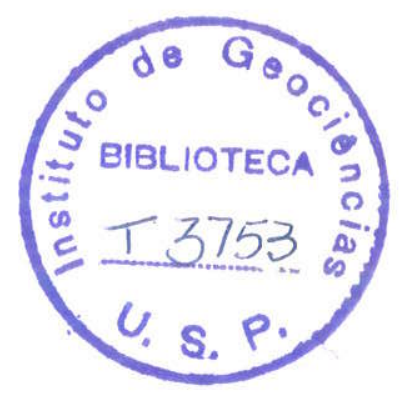

Orientador: Prof. Dr. Ricardo César Aoki Hirata

\section{DISSERTAÇÃO DE MESTRADO}

Programa de Pós-Graduação em Recursos Minerais e Hidrogeologia

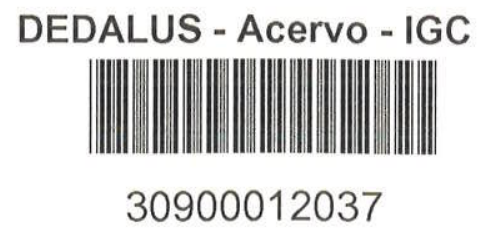

SÃo PAULO

2003 
Aos meus pais. 


\section{SUMÁRIO}

SUMÁRIO

AGRADECIMENTOS

LISTA DE FIGURAS III

LISTA DE TABELAS V

LISTA DE ANEXOS .. VII

LISTA DE ANEXOS VIII

RESUMO

ABSTRACT

1.INTRODUÇÃO $\mathrm{X}$

2.OBJETIVO

3.CARACTERISTICA DA ÁREA DE ESTUDO

3.1. LOCALIZAÇÃO ........................................................................... 3

3.2. ASPECTOS FISIOGRÁFICOS ...................................................... 3

3.3. ASPECTOS SOCIO-ECONÓMICOS …............................................... 5

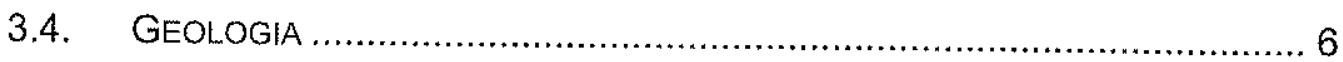

3.4.1. Geologia da cidade de Urânia.......................................... 8

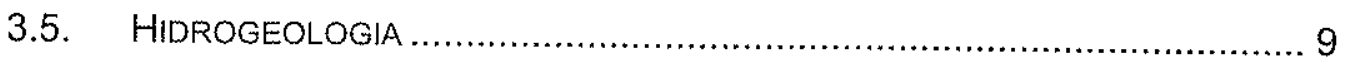

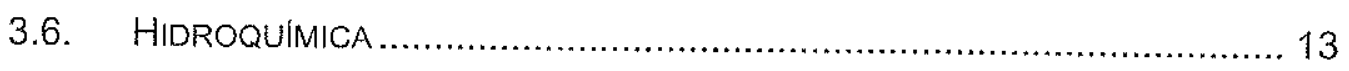

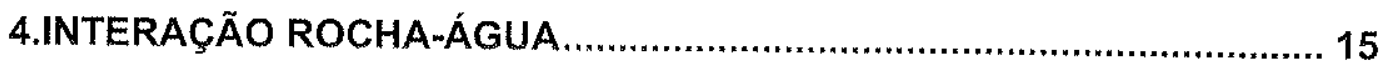

4.1. INTEMPERISMO QUIMICO E QUIMICA DA ÁGUA SUBTERRÂNEA …............ 15

4.1.1. Intemperismo de minerais silicáticos..................................... 16

4.1.2. Intemperismo de minerais carbonáticos................................. 19

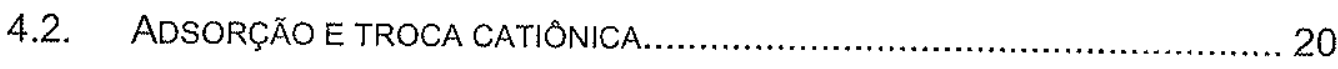

5.MODELOS HIDROGEOQUÍMICOS ...................................................... 23

6.MATERIAIS E MÉTODOS................................................................. 26

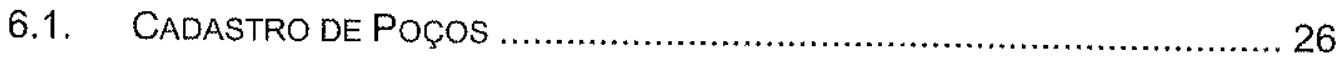

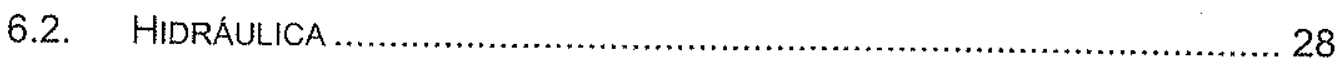

6.3. COLETA E ANÁLISE DE AMOSTRAS DE SEDIMENTOS ............................ 28

6.3.1. Coleta de amostras de sedimentos.................................. 28

6.3.2. Estudos petrográficos .................................................. 29

6.3.3. Análise granulométrica....................................................... 29

6.3.4. Análise mineralógica por difração de raio-X .......................... 31 
6.3.5. Análise por microscopia eletrônica de varredura (MEV) ............. 32

6.3.6. Análise química por ICP/AES-Plasma ................................... 32

6.3.7. Capacidade de troca de cátions e pH do solo......................... 33

6.4. Coleta E ANÁlises quimicas de AMOSTRAS de ÁGUA SUBTERRÂNEA ... 35

6.4.1. Programa de Amostragem ................................................. 35

6.4.2. Coletas de Água ............................................................ 35

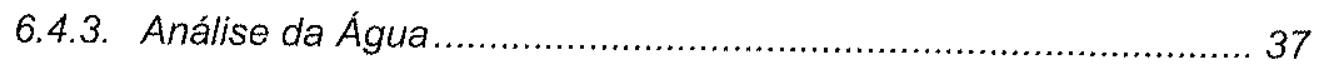

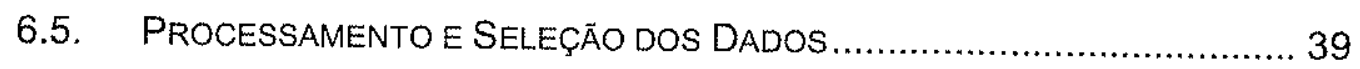

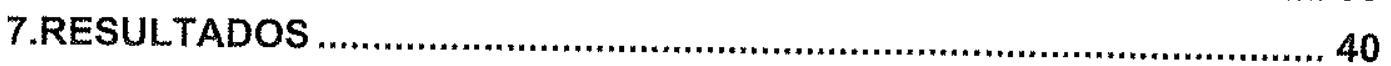

7.1. MODELO HIDRAULIICO CONCEITUAL ................................................ 40

7.2. CARACTERIZAÇÃO DA FASE SÓLIDA ........................................... 43

7.2.1. Descrição macroscópica e microscópica da petrográfia ............ 43

7.2.2. Análise granulométrica................................................... 44

7.2.3. Análise mineralógica por difração de raio-X........................... 44

7.2.4. Análise de microscopia eletrônica de varredura (MEV) ............ 48

7.2.5. Análise química por ICP/AES - Plasma ................................. 50

7.2.6. Análise de capacidade de troca catiônica, pHe matéria orgânic 54

7.3. CARACTERIZAÇÃO DA ÁGUA SUBTERRÂNEA ...................................... 61

7.3.1. Resultados das análises físicomquímicas ..............................62

7.3.2. Classificação hidrogeoquímica ..........................................6 64

7.3.3. Variações da composição química com a profundidade ............ 66

7.3.4. Amostragem em diferentes tempos de bombeamento $e$ estratificada

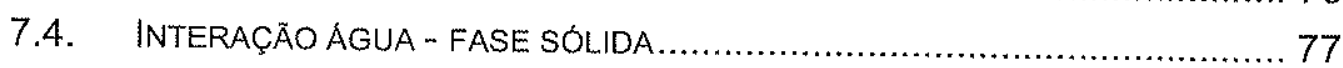

7.4.1. Diagramas de estabilidade........................................... 77

7.4.2. Cálculo dos índices de saturação .................................... 82

7.5. MODELO CONCEITUAL HIDROGEOQUIMICO ................................... 84

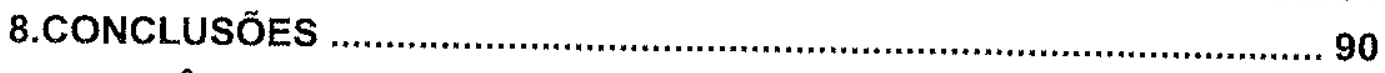

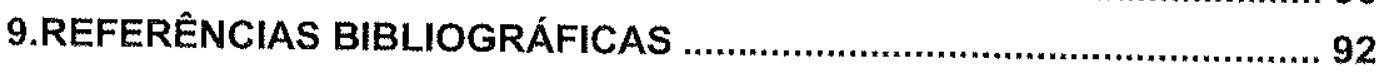




\section{AGRADECIMENTOS}

A elaboração desta dissertação de mestrado contou com a participação de várias pessoas e instituiçōes, sem as quais a sua realização não seria possivel. Desta forma, registro os meus agradecimentos:

Ao Prof. Dr. Ricardo César Aoki Hirata, pelo oferecimento desta oportunidade que sem dúvida foi de grande importância para o meu amadurecimento profissional, orientação, discussão, paciência, apoio e confiança ao longo desse tempo.

Ao Instituto de Geociências da Universidade de São Paulo, em especial aos Departamentos de Geologia Sedimentar e Ambiental (GSA), de Mineralogia e Geotectônica (GMG) e do Centro de Pesquisa de Águas Subterrâneas (CEPAS) pelo uso de seus equipamentos e infra-estrutura.

À Fundação de Amparo à Pesquisa do Estado de São Paulo - FAPESP pelo auxílio financeiro à pesquisa (processos 97/13879-6 e 00/10345-5) e concessão da bolsa de estudo (processo 99/12473-1).

À Companhia de Saneamento Básico de São Paulo (SABESP), em especial ao Sérgio Donizete Giovanini pelo suporte ao longo dos trabalhos de campo em Urânia.

Aos funcionários do IGc-USP: Ana Paula Cabanal e Magali P. F. Rizzo, Lúcia Helena da Silva, Sandra Andrade, Flávio M. S. de Carvalho, Isaac, Elaine, Miltonete Soares de Araújo e Mauro Marcos Lopes.

Ao Prof. Dr. Chang Hung Kiang (Universidade Estadual de São Paulo - Rio Claro), Jesse Stimson (Universidade de Waterloo - Canadá), Ondrej Sracek (Universidade de Laval - Canadá) e Lucy Sant'Anna, pelas sugestões.

Aos meus amigos do laboratório de Modelos Físicos Marta Almodovar pela companhia nos trabalhos de campo e Reginaldo Antônio Bertolo por toda a ajuda ao longo da realização deste trabalho. Aos demais colegas, Claudia Varnier, Alessandro Cesarino (Gummy), Luiz Carlos Ferrari (Louis), Jeane Gláucia Santos Penoff (Manah), Fabíola Rossato (Joleveta), Fabiana Cagnon, Marcos Mondi (Zeca), Alexandra Suhogusoff, Liliana Oltavaro, Cristiano Chiessi, pelo 
companheirismo, carinho, discussões, apoio, galhos quebrados, revisões, enfim pela agradável convivência ao longo desses anos.

Ao meu noivo e futuro marido Carlos Alberto Cutrim, por toda a ajuda e paciência na elaboração desta dissertação.

Aos meus pais Cicinha e André pelo carinho e confiança, irmão André pelo apoio, avós André e Lola e tios Margarida e Plínio. 


\section{LISTA DE FIGURAS}

Figura 3.1.: Localização da cidade de Urânia. 04

Figura 3.2.: Potenciometria da cidade de Urânia e arredores (Rossato, 1999) ......11

Figura 3.3.: Potenciometria da cidade de Urânia e arredores com a operação dos poços profundos da SABESP (Rossato, 1999). 12

Figura 4.1: Seqüência de intemperismo mineral de Goldich (Appelo \& Postma, 1993)

Figura 6.1: Mapa da cidade de Urânia com a localização poços cadastrados, coletados e pontos de coleta de sedimento.

Figura 7.1: Mapa potenciométrico. 41

Figura 7.2: Perfil esquemático de fluxo. 42

Figura 7.3: Gráfico de barras e curva acumulada da análise granulométrica. ........44

Figura 7.4.: Difratograma de minerais pesados da amostra EXP 56 ..................46 46

Figura 7.5.: Difratograma de minerais magnéticos da amostra EXP 44-48.

Figura 7.6.: Difratograma da amostra EXP 32 nas formas natural, glicolada e aquecida.

Figura 7.7.: Imagens de microscopia eletrônica de varredura (MEV) e EDS correspondentes.

Figura 7.8.: Variação da composição química do perfil EXP com a profundidade.. 51

Figura 7.9.: Variação da composição química do perfil ESC com a profundidade.. 52

Figura 7.10.: Resultado da análise de CTC na perfuração EXP. 56

Figura 7.11.: Resultado da análise de CTC na perfuração ESC. 57

Figura 7.12.: Relação entre ions adsorvidos e CTC na perfuração EXP. 59

Figura 7.13.: Relação entre ions adsorvidos e CTC na perfuração ESC 60

Figura 7.14.: Diagrama de classificação de Piper. 65

Figura 7.15.: Perfis de isoconcentração para cálcio, sódio, potássio e magnésio $(\mathrm{mg} / \mathrm{L})$

Figura 7.16.: Perfis de isoconcentração para bicarbonato, nitrato, cloreto e sílica $(\mathrm{mg} / \mathrm{L})$.

Figura 7.17.: Perfis de isoconcentração para $\mathrm{pH}$, condutividade elétrica e Eh. 69 
Figura 7.18.: Gráficos das coletas em diferentes tempos de bombeamento para o PP-2.

Figura 7.19.: Gráficos das coletas em diferentes tempos de bombeamento para o PP-4.

Figura 7.20.: Coleta estratificada nos poços PP-1, 6 e 8 em junho de 1999. .76

Figura 7.21.: Diagrama de estabilidade $\mathrm{K}_{2} \mathrm{O}-\mathrm{Al}_{2} \mathrm{O}_{3}-\mathrm{SiO}_{2}-\mathrm{H}_{2} \mathrm{O}$ a $25^{\circ} \mathrm{C}$ 79

Figura 7.22.: Diagrama de estabilidade $\mathrm{Na}_{2} \mathrm{O}-\mathrm{Al}_{2} \mathrm{O}_{3}-\mathrm{SiO}_{2}-\mathrm{H}_{2} \mathrm{O}$ a $25^{\circ} \mathrm{C}$ 80

Figura 7.23.: Diagrama de estabilidade $\mathrm{CaO}-\mathrm{Al}_{2} \mathrm{O}_{3}-\mathrm{SiO}_{2}-\mathrm{H}_{2} \mathrm{O}$ a $25^{\circ} \mathrm{C}$. 81

Figura 7.24.: Perfis de índices de saturação para o quartzo, calcita e dolomita. ....83

Figura 7.25.: Perfil da taxa de dispersão do cloreto, nitrato e sódio. 86 


\section{LISTA DE TABELAS}

Tabela 4.1.: Reações de intemperismo para alguns minerais silicáticos (Drever, 1988 e Appelo \& Postma, 1993)

Tabela 4.2.: Medidas de capacidade de troca de cátions de alguns materiais normaimente encontrados no meio ambiente (Appelo \& Postma, 1993) 22

Tabela 7.1.: Resultados das análises de difração de raio-X nas amostras de fração total das perfurações EXP e ESC 45

Tabela 7.2.: Matriz de correlação da análise química da perfuração EXP. 53

Tabela 7.3.: Matriz de correlação da análise química da perfuração ESC. 54

Tabela 7.4.: Matriz de correlação da análise de capacidade de troca de cátions para a perfuração EXP. 58

Tabela 7.5.: Matriz de correlação da análise de capacidade de troca de cátions para a perfuração ESC 61

Tabela 7.6.: Correlação de Pearson da Zona Rasa.... 71

Tabela 7.7.: Correlação de Pearson da Zona Intermediária 72

Tabela 7.8.: Correlação de Pearson da Zona Profunda. 72

Tabela 7.9.: Resultados do cálculo de troca de base (icb) 88

Tabela 7.10.: Resumo dos processos identificados nos três diferentes tipos de zonas identificadas. 89 


\section{LISTA DE ANEXOS}

Anexo 1 - Cadastro dos poços e medição de nível d'água .96

Anexo 2 - Resultados analíticos dos sedimentos 102

Anexo 3 - Resultados analíticos da água subterrânea. 130

Anexo 4 - Análise estatística. 


\section{RESUMO}

O objetivo desta pesquisa é estabelecer a evolução hidrogeoquimica do Aqüifero Adamantina na cidade de Urânia, noroeste do Estado de São Paulo, definindo as relações químicas entre a água subterrânea e a rocha hospedeira desde a zona de recarga até a descarga.

Durante a realização deste trabalho foram coletadas amostras de água em 14 poços cacimbas (PC), 10 poços tubulares particulares (PT) e 7 poços profundos da SABESP (PP), distribuídos na área de estudo, por um período de três anos, para análises físico-químicas de metais, $\mathrm{pH}$, Eh, condutividade elétrica e alcalinidade. Sedimentos da Formação Adamantina de dois poços tubulares também foram amostrados para análise mineralógica (microscopia óptica, difração de raio-X $\mathrm{e}$ microscopia eletrônica de varredura), granulométrica (peneiramento e pipetagem) e química (ICP/AES-Plasma). Os resultados obtidos indicaram que a água subterrânea encontra-se em contato com sedimentos arenosos compostos principalmente por quartzo, feldspato (K-feldspato, albita e anortita), anfibólio e piroxênios cálcicos magnesianos, granada, calcita, goetita, hematita, montmorilonita cálcica e caulinita. Quimicamente o sedimento é composto por $\mathrm{SiO} 2(76 \%$ a $78 \%$ da massa), seguido pelo ferro e alumínio (4\% a $10 \%), \mathrm{CaO}(3,4 \%), \mathrm{MgO}(1,5 \%), \mathrm{K} 2 \mathrm{O}$ $(1 \%)$ e $\mathrm{Na} 2 \mathrm{O}(0,3 \%)$.

As águas subterrâneas do Aqüifero Adamantina na área de estudo foram divididas em três zonas hidroquímicas dominantes. A zona rasa e de recarga (profundidades de 2,0 a 16,0 m) é caracterizada por águas cloretadas sódicas devido à presença de contaminação por fossas sépticas e negras, vazamentos da rede de esgoto e/ou fertilizantes nitrogenados. Na zona intermediária (profundidades de 8,0 a $100,0 \mathrm{~m}$ ) predominam águas bicarbonatada cálcica, causada pela dissolução de minerais carbonáticos e aluminossilicáticos, porém ainda observa-se influência da contaminação. A zona profunda (profundidade de 60,0 a 160,0 m) e de descarga é caracterizada por água bicarbonatadas cálcicas, porém foi observada a presença de sódio em poços próximos à zona de descarga, indicando uma possível troca deste cátion com o cálcio. 


\begin{abstract}
The objective of this study is that of establishing the hydrogeochemical evolution of the Adamantina Aquifer in the city of Urânia, located in the northwest of the state of São Paulo, defining chemical relationships between groundwater and the rock holding this water, from the recharge zone to the discharge zone.

During this work, water samples were collected over a period of three years from 14 hand-dug wells (PC), 10 private deep groundwater wells (PT) and 7 SABESP deep groundwater wells (PP), distributed throughout the area under study, with a view to conducting physical-chemical analyses of metals, $\mathrm{pH}$, Eh, electrical conductivity and alkalinity. Adamantina Formation sediments in two of the deep groundwater wells were also sampled for mineralogical analysis (optical microscope, $X$-ray diffraction and scanning electron microscope), granulometric analysis (sieving and pipeting) and chemical analysis (ICP/AES-Plasma). The results obtained showed that groundwater is to be found in contact with sandy sediments principally composed of quartz, feldspar (K-feldspar, albite and anortite), calcium-magnesium amphibole and pyroxenes, garnet, calcite, goethite, hematite, calcium montmorilonite and caulinite. In chemical terms, this sediment is composed of $\mathrm{SiO} 2(76 \%$ to $78 \%$ by mass), followed by iron and aluminum (4\% to $10 \%)$, $\mathrm{CaO}(3.4 \%), \mathrm{MgO}(1.5 \%), \mathrm{K} 2 \mathrm{O}$ $(1 \%)$ and $\mathrm{Na} 2 \mathrm{O}(0.3 \%)$.

The groundwater of the Adamantina Aquifer in the area under study was divided into three predominant hydrochemical zones. The shallow recharge zone (depths ranging from 2.0 to $16.0 \mathrm{~m}$ ) is characterized by sodium-chloride waters, due to the presence of contamination from septic tanks and cesspits, leaks from the sewage collection network and/or nitrogenated fertilizers. In the intermediate zone (depths ranging from 8.0 to $100.0 \mathrm{~m}$ ) there is a predominance of calcium-bicarbonate waters, brought about by dissolved carbonate and aluminosilicate minerals, although the influence of contamination can still be seen. The deep discharge zone (depths ranging from 60.0 to $160 \mathrm{~m}$ ) is characterized by calcium-bicarbonate waters, however, the presence of sodium was detected in wells located close to the discharge zone, indicating the possible exchange of this cation with calcium.
\end{abstract}




\section{INTRODUÇÃO}

A área de estudo encontra-se nos domínios do Aqüifero Adamantina pertencente ao Sistema Aqüifero Bauru que é um dos mais importantes reservatórios subterrâneos naturais de água no Estado de São Paulo, ocupando uma área de $104.000 \mathrm{~km}^{2}$, cerca de $40 \%$ do território paulista. Os sedimentos presentes neste aqüifero são de idade cretácica com litologia variável, recobrindo discordantemente o basalto da Formação Serra Geral.

Segundo São Paulo (1990), a distribuição dos núcleos urbanos por tipos de mananciais explotados mostra que em média $80 \%$ dos municípios dos sistemas públicos de abastecimento na região oeste do Estado são supridos por aqüíferos, sendo predominante o Sistema Bauru.

A despeito de sua grande importância, o Sistema Aqüífero Bauru ainda é pouco estudado. A exceção dos relatórios regionais do DAEE (1974, 1976, 1979) e de outros estudos decorrentes destes trabalhos (Rocha et al., 1982; Campos, 1987, 1993), ainda é bastante restrita a pesquisa sobre a sua hidrogeoquímica, sobretudo para estudos de detalhe.

Desta forma, a presente dissertação apresenta uma pesquisa de caráter local sobre a evolução hidroqueoquímica da água subterrânea, através de sua relação rocha-água, na área do perímetro urbano da cidade de Urânia localizada a noroeste do Estado de São Paulo. Foram realizados estudos sobre as modificações sofridas pela água subterrânea local ao fluir das porções mais rasas do aqüifero até as mais profundas ou de descarga.

A área de estudo desta dissertação foi escolhida a partir da presença de concentrações anômalas de cromo na água subterrânea da cidade de Urânia, que deu origem a um projeto de pesquisa financiado pela FAPESP, no qual o presente trabalho fez parte. 


\section{OBJETIVO}

O principal objetivo deste trabalho é a caracterização da evolução hidrogeoquimica do Aqüífero Adamantina, pertencente ao Sistema Aqüífero Bauru, no perímetro urbano da cidade de Urânia localizada no noroeste do Estado de São Paulo.

O objetivo principal desta dissertação foi obtido a partir da realização e integração das seguintes etapas:

- realização de estudo sobre a hidráulica local do Aqüifero Adamantino, para obtenção de dados sobre a direção e tempo de fluxo da água subterrânea;

- caracterização da composição química da água subterrânea em diferentes zonas do aqüífero local, através de coletas periódicas em poços com diferentes profundidades distribuídos ao longo de toda a cidade de Urânia;

- caracterização química e mineralógica dos sedimentos da zona saturada, através da análise de amostras coletadas até a profundidade máxima de 80 $m$ em dois pontos distintos da área de estudo; $e$

- interações entre a composição química da água subterrânea e dos sedimentos da zona saturada estabelecendo um modelo da evolução hidrogeoquímica do local. 


\section{CARACTERÍSTICA DA ÁREA DE ESTUDO}

\subsection{Localização}

A área de estudo localiza-se na cidade de Urânia, região noroeste do Estado de São Paulo, cerca de $600 \mathrm{~km}$ da capital. A partir de São Paulo, o acesso à cidade é feito pela Rodovia Anhanguera até Limeira, seguido pela Rodovia Washington Luís até Mirassol e finalmente a Rodovia Euclides da Cunha até o município de Urânia (Figura 3.1.).

\subsection{Aspectos Fisiográficos}

O município de Urânia encontra-se na unidade morfoestrutural do Planalto Centro Ocidental Paulista (Ross \& Moroz, 1997), que é caracterizado por colinas amplas e baixas com topos convexos e aplanados ou tabulares, entalhamento médio dos vales inferiores a $20 \mathrm{~m}$ interflúvios com dimensões médias entre 1750 e $3750 \mathrm{~m}$, densidades de drenagem baixa, altimetria variando entre 400 a $700 \mathrm{~m}$ e declividades médias das vertentes entre 2 a $10 \%$. Com isso a cidade de Urânia possui relevo monótono com a presença de pequenos morrotes, cujas cotas variam de 430 a $470 \mathrm{~m}$.

O município de Urânia situa-se sobre o divisor hidrográfico das unidades 18 (São José dos Dourados) e 15 (Turvo, Grande) (IGC-DAEE, 1996). Na cidade de Urânia estão presentes as nascentes que fazem parte do Córrego da Porteira e do Ribeirão Comprido.

De acordo com o balanço hídrico do posto 8B-002, no Rio São José dos Dourados (DAEE, 1976), a chuva na região de estudo foi de $1430 \mathrm{~mm}$ em 1974, sendo que deste total, $83,6 \%$ participou dos processos de evapotranspiração, $7,4 \%$ corresponderam ao escoamento superficial e apenas $9,0 \%$ compreenderam à recarga subterrânea. 


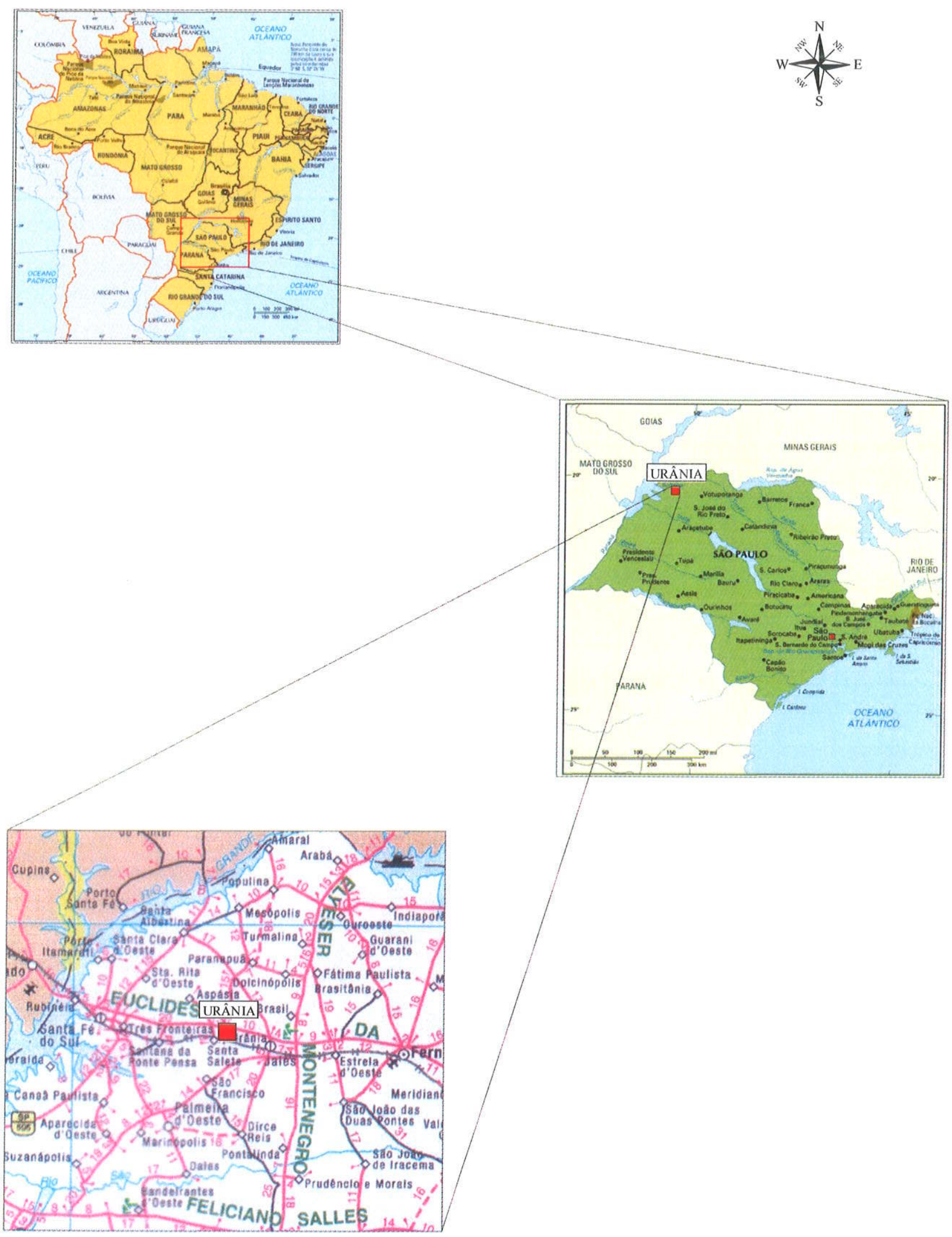

Figura 3.1.: Localização da cidade de Urânia 
Por se encontrar nos domínios do Planalto Centro Ocidental, Urânia sofre influência da massa equatorial continental, continental tropical e, secundariamente, das massas polares. Há alternância de períodos úmidos e secos, onde as chuvas ocorrem no verão (dezembro e março) e a seca no inverno (abril e setembro). De 1959 a 1999, o posto pluviométrico B7-006 do DAEE em Urânia indicou que os meses de dezembro, janeiro e fevereiro apresentaram os maiores índices pluviométricos (196, 234 e $179 \mathrm{~mm}$, respectivamente), enquanto que os meses de julho, agosto e setembro registraram os menores índices (30, 16 e $17 \mathrm{~mm}$, respectivamente).

\subsection{Aspectos Sócio-Econômicos}

Segundo o IBGE (dados preliminares do censo de 2000), a população do município de Urânia é de 8614 pessoas, residentes em uma área de $209 \mathrm{~km}^{2}$.

Embora a Companhia de Saneamento Básico do Estado de São Paulo (SABESP) seja a responsável pela distribuição de água para a cidade de Urânia, há residências que possuem poços particulares do tipo cacimba e tubular para o consumo doméstico.

A SABESP possui sete poços distribuídos na cidade de Urânia, sendo que apenas três encontram-se equipados com bombas, porém não são utilizados devido às concentrações anômalas de cromo na água subterrânea, tornando-a imprópria para o consumo humano. Desta forma, a água distribuida na cidade provém do Aqüífero Guarani extraída em Jales (cidade vizinha).

Mesmo se tratando de uma área urbanizada, há presença de atividades agrícolas (café, uva, manga, verduras e legumes) e pecuárias (bovinos, suínos e aves), principalmente nas porções noroeste e sul da cidade.

Há alguma atividade industrial, representada pelo beneficiamento de arroz, construção de charretes e fábrica de móveis. 


\subsection{Geologia}

$\mathrm{Na}$ área de estudo afloram os sedimentos da Formação Adamantina (Cretáceo Superior), que é a de mais ampla distribuição aflorante entre as outras formações do Grupo Bauru no estado, recobrindo os basaltos da Formação Serra Geral (Juro-Cretáceo).

A Formação Adamantina foi formalmente proposta por Soares et al. (1980), como denominação a um conjunto de fácies cuja principal caracteristica era a presença de bancos de arenitos com estratificação cruzada, espessura variando de 2 a $20 \mathrm{~m}$, granulação fina a muito fina e cor rósea a castanha. A estratificação cruzada apresentava-se alternada com bancos de lamitos, siltitos e arenitos lamíticos, de cor castanha-avermelhada a cinza-castanho e estrutura maciça ou com acamamento plano-paralelo grosseiro, apresentando freqüentemente marcas de onda e micro-estratificação cruzada. Os sedimentos são bem selecionados, finos, freqüentemente compostos por mica e mais raramente feldspato, opacos e grande variedade de estruturas sedimentares.

As maiores espessuras da formação ocorrem geralmente nas porções ocidentais dos espigões entre os grandes rios. Atingem $160 \mathrm{~m}$ entre os rios São José dos Dourados e Peixe, $190 \mathrm{~m}$ entre os rios Santo Anastácio e Paranapanema, e 100 a $150 \mathrm{~m}$ entre os rios Peixe e Turvo, adelgaçando-se dessas regiões em direção a leste e noroeste (Soares et al., 1980). Almodovar (1995) identificou como sendo $208 \mathrm{~m}$ a maior espessura do pacote de sedimentos da Formação Adamantina na cidade de Guzolândia. Em Urânia os sedimentos desta formação foram encontrados até $160 \mathrm{~m}$, em Fernandópolis $130 \mathrm{~m}$ e em Jales $85 \mathrm{~m}$.

Brandt Neto (1977) estudando a Formação Adamantina na região de Araçatuba e Penápolis no Baixo Tietê, observou, em 38 amostras de sedimentos que a ocorrência de minerais pesados se concentrava em turmalina e estaurolita, predominantemente, e granada, zircão, rutilo e perovskita, secundariamente. Os argilominerais reconhecidos por Brandt Neto et al. (1985) foram caulinita, montmorilonita e palygorskita. 
Brandt Neto et al. (1987) identificaram e caracterizaram, pela primeira vez nesta formação, o mineral analcima em sondagem efetuada na cidade de Macedônia, localizada a $20 \mathrm{~km}$ de Fernandópolis. Segundo os autores, este mineral se originou a partir de processos hidrotermais.

Coimbra (1976) indicou como área fonte da Formação Adamantina os sedimentos fanerozóicos pré-existentes, áreas de rochas básicas do Grupo São Bento, as rochas metamórficas do Grupo Araxá e Canastra e as rochas alcalinas presentes no Triângulo Mineiro. As conclusões deste autor basearam-se principalmente na análise da distribuição de parâmetros granulométricos e da freqüência relativa de minerais pesados, entre eles zircão, turmalina, rutilo, perovskita, augita e titano-augita, anatásio, granada (almandina), cianita, estaurolita e epídoto.

Segundo Fernandes (1998), dentro de sua nova proposta litoestratigráfica, em Urânia aflora a Formação Vale do Rio do Peixe. A unidade é constituída por arenito muito fino a fino de cores marrom-claro, rosado a alaranjado, de seleção moderada a boa (predominantemente), com intercalações de siltitos de cores creme a marrom. Os arenitos formam estratos tabulares de aspecto maciço, com zonas de estratificação/laminação plano-paralela, grosseira, e estratos, também tabulares, com estratificação cruzada tabular e acanalada em geral de médio a pequeno porte. A formação está associada a sedimentos essencialmente eólicos. Provavelmente, estes depósitos foram fixados em corpos aquosos rasos e efêmeros, formados nas zonas mais baixas, em períodos de elevação do nivel freático. $O$ autor propõe que o contato inferior da Formação Vale do Rio do Peixe é gradual com a Formação Santo Anastácio ou, conforme ocorre na cidade de Urânia, discordante e diretamente sobre os basaltos da Formação Serra Geral, e que o contato superior é interdigitado e transgressivo com a Formação Araçatuba. 


\subsubsection{Geologia da cidade de Urânia}

$\mathrm{Na}$ cidade de Urânia os sedimentos da Formação Adamantina são caracterizados por arenitos finos siltosos a muito argilosos, de cor marrom, variando as tonalidades de mais clara a escura e avermelhada. Os grãos são subarredondados e bem selecionados.

A análise granulométrica realizada por Almodovar (2000) em 12 amostras do solo da área de estudo, concluiu que a faixa granulométrica presente no local era representada por areias, argilas e cascalhos.

Em Almodovar (2000) também foram realizadas análises mineralógicas do solo, através de DRX - difração de raio X e MEV - microscopia eletrônica de varredura.

O DRX foi realizado em diversas frações das amostras, sendo possivel identificar os seguintes minerais:

- fração total - quartzo, goetita, muscovita e argilas do grupo da caulinita e ilita;

- minerais pesados não magnéticos, fração grossa - hematita, goetita, quartzo e braunita;

- minerais pesados não magnéticos, fração fina - hematita, goetita, quartzo e microclínio;

- minerais pesados magnéticos, fração grossa - magnetita, ilmenita e hematita e

- minerais pesados magnéticos, fração fina - magnetita, ilmenita e hematita.

A microscopia eletrônica de varredura foi utilizada para a identificação de minerais que apresentassem cromo, sendo possivel determinar os seguintes minerais: cromita $\left(\mathrm{FeCr}_{2} \mathrm{O}_{4}\right)$, hematita $\left(\mathrm{Fe}_{2} \mathrm{O}_{3}\right)$, magnetita $\left(\mathrm{FeFe}_{2} \mathrm{O}_{4}\right)$ e ilmenita $\left(\mathrm{FeTiO}_{3}\right)$.

$\mathrm{Na}$ área de estudo, o contato inferior da Formação Adamantina se dá com os basaltos da Formação Serra Geral de forma direta e discordante. A espessura local dos sedimentos varia de 66 a $160 \mathrm{~m}$, sendo as maiores espessuras localizadas do lado oeste da cidade de Urânia (Almodovar, 2000). 


\subsection{Hidrogeologia}

O Sistema Aqüífero Bauru é regionalmente do tipo livre e localmente semi-confinado, com espessura média de $100 \mathrm{~m}$ podendo chegar a $250 \mathrm{~m}$ (Campos, 1987).

A velocidade de circulação das águas no aqüífero é de $0,04 \mathrm{~m} /$ dia e transmissividade de 10 a $100 \mathrm{~m}^{2} /$ dia. Há um zoneamento do potencial explotável do Sistema Aqüífero Bauru: a faixa de vazão entre 5 e $20 \mathrm{~m}^{3} / \mathrm{h}$ é predominante em área; as faixas de $20-30$ e de $30-50 \mathrm{~m}^{3} / \mathrm{h}$ ocorrem em áreas menores, sobretudo quando a espessura é maior (DAEE, 1976, 1988).

Rocha et al. (1982) subdividiram este sistema em duas unidades distintas, em função das diferentes litofácies, expressão geomorfológica e dos parâmetros hidráulicos e hidroquímicos. A unidade 1 correspondia às formações Marilia e Adamantina e seria caracterizada por um potencial explotável médio a baixo, com águas relativamente mais salinizadas, fortemente bicarbonatadas cálcicas, potencialmente incrustantes ou corrosivas. A unidade II correspondia às formações Santo Anastácio e Caiuá e seria caracterizada por um potencial explotável médio a elevado, onde as águas possuem teores salinos muito baixos, sendo bicarbonatadas cálcio-magnesianas e potencialmente corrosivas.

Quanto ao comportamento hidráulico, Rocha et al. (1982) concluíram que:

- os valores médios de capacidade específica compreendidos no intervalo de 0,5 a $10 \mathrm{~m}^{3} / \mathrm{h} / \mathrm{m}$ eram mais característicos de uma faixa de terrenos a oeste, ao longo do Rio Paraná, correspondendo, aproximadamente, às áreas de ocorrência da Formação Santo Anastácio e de sua transição à sudeste, com a Formação Caiuá. Este intervalo também ocorre à sudeste, na região de Racharia, onde há uma litofácie mais permeável da parte inferior da Formação Adamantina. Áreas com valores abaixo de $0,5 \mathrm{~m}^{3} / \mathrm{h} / \mathrm{m}$ ocorrem a sudoeste, devido à pequena espessura saturada, e a norte, na margem esquerda do Rio Grande, onde a litofácie da Formação Adamantina é menos permeável. Valores acima de $2 \mathrm{~m}^{3} / \mathrm{h} / \mathrm{m}$ são característicos da Formação Caiuá; 
- os valores médios de transmissividade predominantes em áreas são da ordem de 30 a $50 \mathrm{~m}^{2} /$ dia e estão situados nos domínios da Formação Adamantina. O intervalo de 50 a $100 \mathrm{~m}^{2} /$ dia é mais freqüente na área de ocorrência da Formação Santo Anastácio; estes valores também são encontrados nas regiões de São José do Rio Preto e Racharia. A faixa de 100 a $200 \mathrm{~m}^{2} /$ dia é característica da Formação Caiuá; e

- os valores de condutividade hidráulica média aparente variam de 0,1 a 1,0 $\mathrm{m} /$ dia. O intervalo de 0,1 a $0,3 \mathrm{~m} /$ dia é predominante em área, abrangendo o domínio da Formação Adamantina. Valores entre 0,3 a $1,0 \mathrm{~m} /$ dia estão distribuídos nas Formações Santo Anastácio, Caiuá e na parte inferior da Formação Adamantina, à sudoeste.

A recarga natural do aqüifero é dada diretamente por águas pluviais. As superfícies potenciométricas mostram linhas de fluxo convergindo para as calhas dos rios e os divisores de águas subterrâneas coincidindo com os divisores das bacias hidrográficas.

Quanto à porosidade efetiva do Sistema Aqüifero Bauru, Barcha (1980) , a partir do estudo de 350 amostras de 13 poços, chegou a índices bastante variados de porosidade efetiva, com valores médios entre 16 e $26 \%$.

Recentemente, a Formação Adamantina vem sendo individualizada como unidade hidrogeológica independente, o Aqüífero Adamantina, assim como as demais unidades do Sistema Bauru (Hirata et al., 1997). Este aqüifero possui extensão regional e tem comportamento livre a semi-confinado. A recarga ocorre naturalmente pela infiltração da água da chuva e as superfícies potenciométricas são freqüentemente influenciadas pela geomorfologia da área, onde os divisores de águas subterrâneas coincidem com os divisores das bacias hidrográficas. As linhas de fluxo convergem para os rios, tendo desta forma, um caráter efluente. É provável, embora nunca tenha sido comprovado, que exista um sistema de circulação de maior profundidade, com tempos de trânsito maiores. Este sistema poderia transpassar várias bacias e teria características regionais. 
Do ponto de vista hidrogeológico, os poços tubulares de Urânia, Aspásia e Santa Salete mostram espessura saturada média de $100 \mathrm{~m}$, capacidade específica de $0,24 \mathrm{~m}^{3} / \mathrm{h} / \mathrm{m}$ e transmissividade de $6,31 \mathrm{~m}^{2} /$ dia (Hirata \& Rodolfi, 1993). Os perfis litológicos dos poços perfurados na cidade de Urânia mostram profundidades que variam de 70 a $270 \mathrm{~m}$, níveis estáticos variando de 4,56 a 50 m e vazão entre 2,2 a 18,8 $\mathrm{m}^{3} / \mathrm{h}$ (Almodóvar, 1995).

Rossato (1999) realizou o modelamento matemático preliminar do fluxo de água subterrânea do Aqüífero Adamantina na cidade de Urânia e arredores. As Figuras 3.2. e 3.3. apresentam os resultados dos mapas potenciométricos, com e sem os poços profundos da cidade em funcionamento. Nota-se que a mancha urbana do município situa-se sobre um divisor de bacias hidrogeológicas e que o bombeamento conjunto dos poços profundos da SABESP gera um único cone de rebaixamento sob a cidade. A mesma autora sugere que a área de recarga do aqüífero corresponde a toda área de exposição dos sedimentos, enquanto que a descarga seria as calhas dos rios.

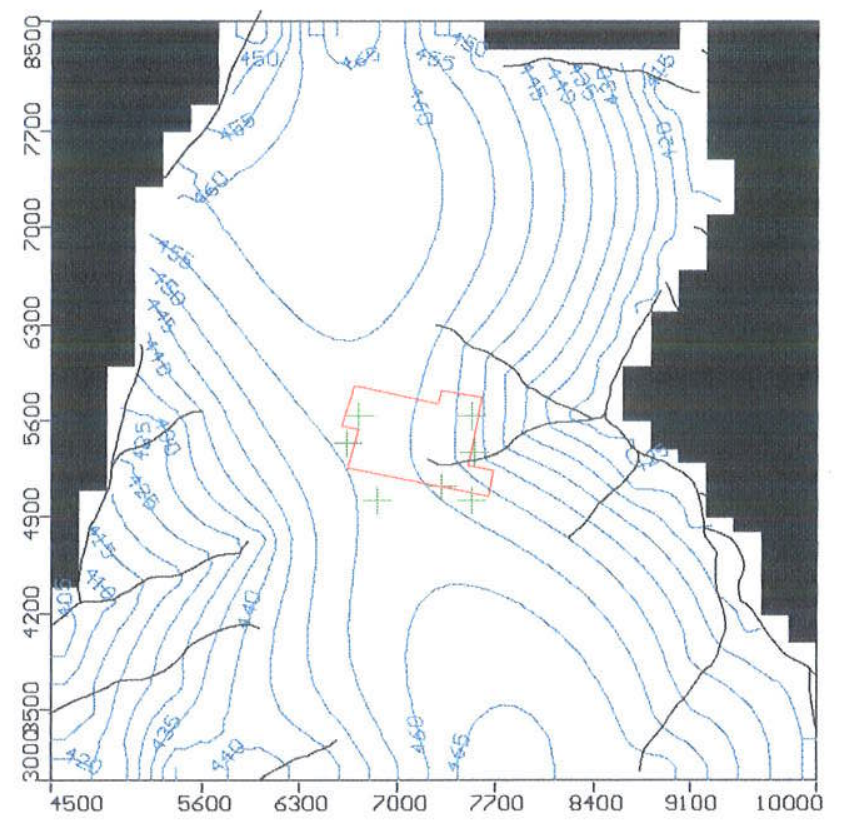

Figura 3.2.: Potenciometria da cidade de Urânia e arredores (Rossato, 1999) 


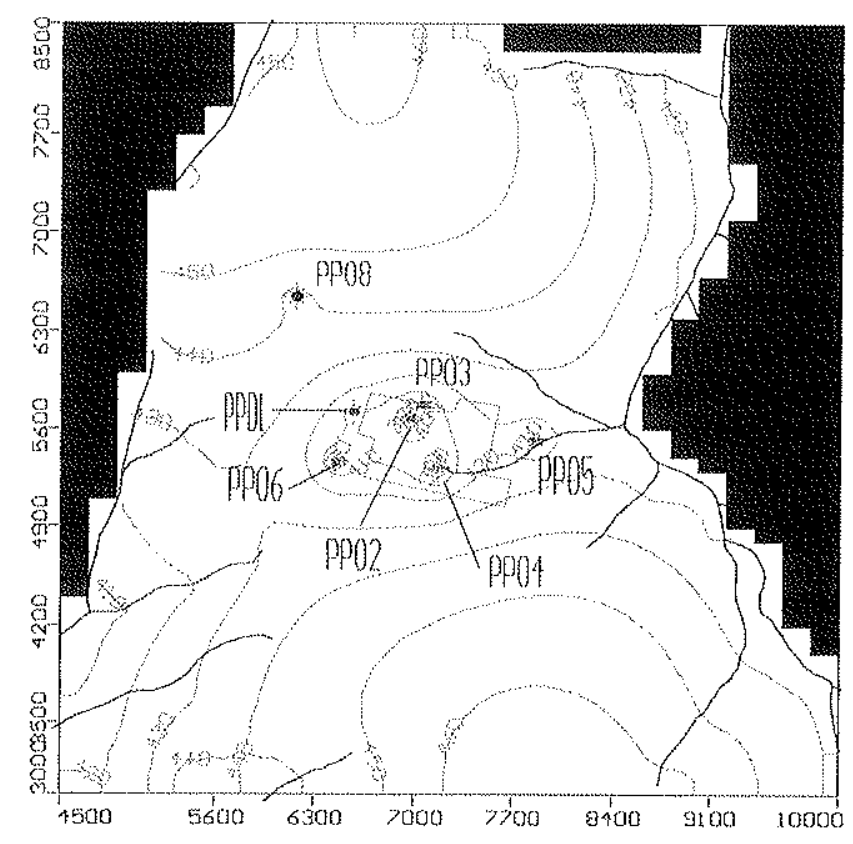

Figura 3.3.: Potenciometria da cidade de Urânia e arredores com a operação dos poços profundos da SABESP (Rossato, 1999) 


\subsection{Hidroquímica}

Um dos primeiros estudos sobre a hidroquímica do Sistema Aqüífero Bauru no Estado de São Paulo foi realizado por Taltasse (1968). O autor distinguiu duas fácies hidrogeoquímicas para os arenitos cretácicos do Bauru: a das águas bicarbonatadas cálcicas e a das águas bicarbonatadas magnesianas.

Segundo DAEE (1974), na região de São José do Rio Preto distinguem-se dois grupos hidrogeoquímicos em terrenos do Grupo Bauru:

- as águas bicarbonatadas cálcio-magnesianas, de baixo teor salino, onde ions majores têm a seguinte proporção: $r \mathrm{Mg}>\mathrm{rCa}>\mathrm{rNa}$; $\mathrm{Na}>>\mathrm{rCl}$ e

- as águas bicarbonatadas cálcicas, de alto teor salino, onde os íons maiores têm a seguinte proporção: $\mathrm{rCa}>\mathrm{rMg}>\mathrm{rNa}$; $\mathrm{Na}>>\mathrm{rCl}$.

DAEE $(1976,1979)$, estudando a região de Bauru, São José do Rio Preto, Araçatuba, Presidente Prudente e Marilia, identificou dois grupos hidrogeoquímicos principais:

- águas bicarbonatadas cálcicas secundariamente magnesianas ou sódicas; $\mathrm{rCa}>\mathrm{rMg}>\mathrm{rNa}$ e $\mathrm{rHCO}_{3}>\mathrm{rCl}$. Para as águas pertencentes ao Bauru Superior e

- águas bicarbonatadas sódicas secundariamente cálcicas; rNa>rCa>rMg e $\mathrm{rHCO} 3>>\mathrm{rCl}$, refletindo um enriquecimento em sódio, provenientes de aqüíferos mais profundos.

No estudo da bacia do Rio São José dos Dourados, realizado por Mezzalira et al. (1979), foram analisados ${ }^{18} \mathrm{O}, \mathrm{D}, \mathrm{P}, \mathrm{Cl}, \mathrm{Mg}, \mathrm{NH}_{4}$ e $\mathrm{NO}_{3}$. A conclusão destes autores foi que as águas não apresentam fortes sinais de evaporação durante a recarga, o que indica um sistema de infiltração rápida de alta condutividade hidráulica.

Rocha et al. (1982) sugerem um zoneamento hidrogeoquímico do Sistema Aqüífero Bauru. Dois domínios são indicados: águas bicarbonatadas cálcicas e águas bicarbonatadas cálcio-magnesianas. Nos espigões e planaltos, correspondentes aos arenitos da parte superior da Formação Adamantina e Formação Marília, as águas apresentam concentrações salinas mais elevadas, fortemente bicarbonatadas cálcicas. A partir dos espigões, nos vales, as 
concentrações salinas diminuem, às vezes na mesma formação e as águas são do tipo bicarbonatadas cálcio-magnesianas. Nesta progressão, a ocorrência de águas bicarbonatadas sódicas no extremo sudoeste sugere uma evolução hidrogeoquímica no sentido $\mathrm{Ca} \rightarrow \mathrm{Mg} \rightarrow \mathrm{Na}$, de montante para jusante dos principais rios interiores que percolam o Grupo Bauru.

Segundo Campos (1987), as águas do Sistema Aqüifero Bauru apresentam dois tipos químicos dominantes: águas bicarbonatadas cálciomagnesianas e águas bicarbonatadas cálcicas. Os estudos estatísticos mostram que os íons $\mathrm{HCO}_{3}{ }^{-}, \mathrm{Ca}^{2+}$ e $\mathrm{Mg}^{2+}$ são os principais responsáveis no processo de enriquecimento salino das águas. A composição mineralógica dos sedimentos das distintas formações do Grupo Bauru (à exceção da Formação Caiuá) parece contribuir significativamente para a predominância destes ions maiores. 0 carbonato de cálcio (calcrete) e os argilominerais, constituintes dos cimentos das litofácies, devem ser as principais fontes de enriquecimento iônico do meio aqüífero. 


\section{INTERAÇÃO ROCHA-ÁGUA}

A qualidade da água subterrânea pode ser controlada a partir de mecanismos como: evaporação e evapotranspiração; influências da biomassa; decaimento da matéria orgânica; dissolução e precipitação de minerais; reações de troca iônica e misturas entre diferentes tipos de água.

Dos mecanismos citados anteriormente, apenas a dissolução e precipitação de minerais e as reações de troca iônica serão mencionados, por serem considerados os mecanismos que mais influenciam o aqüifero estudado.

\subsection{Intemperismo químico e química da água subterrânea}

A composição química de uma determinada água subterrânea é definida a partir da interação de vários fatores ambientais, como tipo de rocha, clima, relevo, vegetação e tempo. Apesar de todos estes fatores terem grande importância para a definição química da água subterrânea, o fator mais atuante é a interação da água da chuva com um determinado tipo de rocha. Essa interação é denominada de intemperismo químico e consiste na dissolução ou alteração de minerais presentes nas rochas, liberando íns para água.

Ao se infiltrar no solo, a água percola através de diferentes tipos de solo e rocha, e conseqüentemente a sua composição química está diretamente relacionada ao tipo de material percolado. Em rochas carbonáticas, o efeito da sua dissolução é facilmente observado a partir do aumento significativo de carbonato dissolvido na água, porém o efeito da dissolução de minerais silicáticos é menos aparente devido à sua grande resistência ao intemperismo. 


\subsubsection{Intemperismo de minerais silicáticos}

Ao observar o perfil de alteração de uma determinada rocha silicática notamse que alguns minerais desaparecem relativamente mais rápido que outros em direção à base do perfil. Essa diferença no tempo de alteração dos minerais é função de suas diferentes taxas de dissolução. Em 1934, Goldich apresentou uma seqüência empírica de intemperismos dos minerais silicáticos primários, onde os minerais mais susceptiveis ao intemperismo são a olivina e o plagioclásio cálcico, enquanto que o quartzo é o mineral mais resistente (Figura 4.1.).

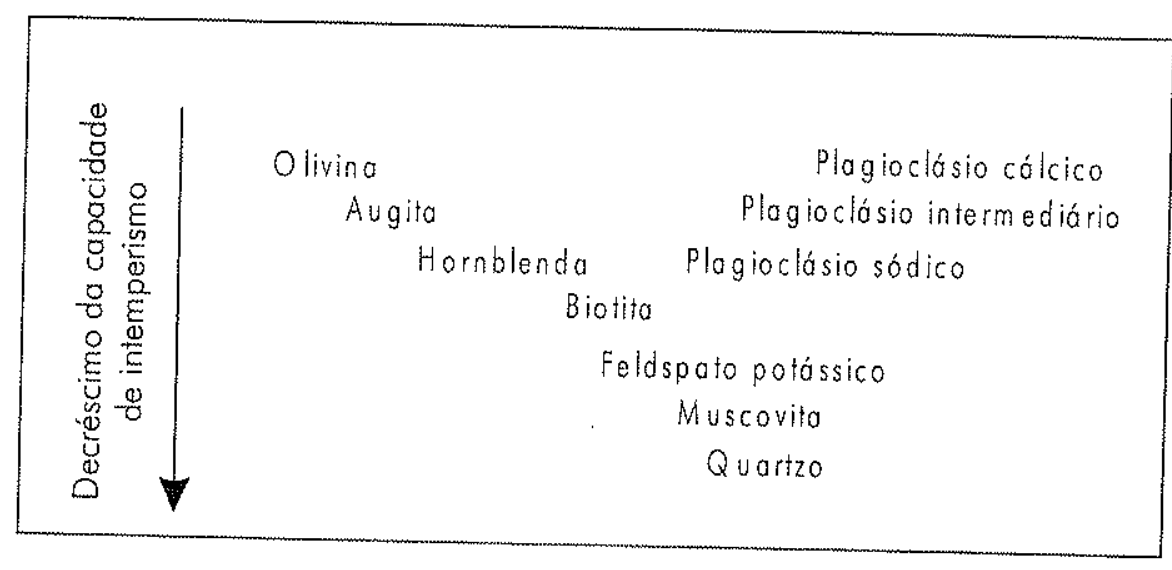

Figura 4.1: Seqüência de intemperismo mineral de Goldich (Appelo \& Postma, 1993)

Outra observação importante a ser feita no perfil de alteração de rochas silicáticas é que com a alteração dos minerais primários alguns minerais secundários, como argilominerais e óxidos de ferro, são formados. Os minerais secundários constituem a parte insolúvel da alteração dos minerais primários formados a partir de reações incongruentes e composta por compostos de alumínio.

O efeito da dissolução de minerais silicáticos na água subterrânea é o aumento da concentração de sílica e cátions. As reações de intemperismo desse tipo de mineral consomem ácido e dessa forma possuem um efeito tampão. Em locais onde não ocorre a influência de contaminantes, o ácido carbônico é a 
mais importante fonte de próton, e como demonstrado pela equação $11 \mathrm{da}$ Tabela 4.1., o bicarbonato será produzido durante a alteração de silicatos. ferro presente nesses minerais irá formar óxidos de ferro como produto de intemperismo insolúvel. A Tabela 4.1. apresenta algumas reações de intemperismo em alguns minerais silicáticos.

\begin{tabular}{|c|c|}
\hline \multicolumn{2}{|c|}{ 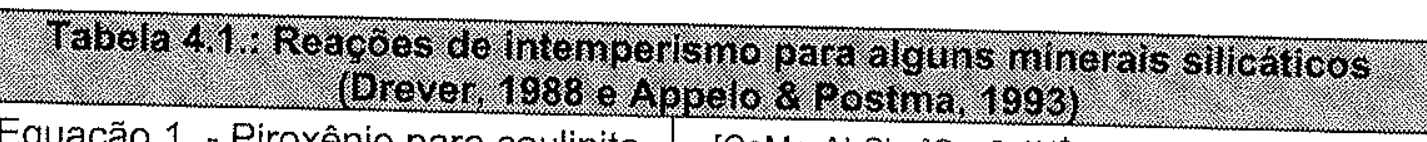 } \\
\hline - yuazar t. - riruxemo para caulnita & $\begin{array}{c}{\left[\mathrm{CaMg} \mathrm{Al}_{3} \mathrm{Si}_{1,7}\right] \mathrm{O}_{6}+3,4 \mathrm{H}^{+}+1,1 \mathrm{H}_{2} \mathrm{O} \rightarrow 0,3 \mathrm{Al}_{2} \mathrm{Si}_{2} \mathrm{O}_{5}} \\
(\mathrm{OH})_{4}+\mathrm{Ca}^{2+}+0,7 \mathrm{Mg}^{2+}+1,1 \mathrm{H}_{4} \mathrm{SiO}_{4} \\
\end{array}$ \\
\hline $\begin{array}{l}\text { Equação 2. - Na-montmorilonita para } \\
\text { caulinita }\end{array}$ & $\begin{array}{c}\mathrm{Na}_{0.33} \mathrm{Al}_{2} \mathrm{Si}_{3 \cdot 67} \mathrm{O}_{40}(\mathrm{OH})_{2}+1 / 3 \mathrm{H}^{+}+23 / 2 \mathrm{H}_{2} \mathrm{O} \rightarrow 7 / 6 \mathrm{Al}_{2} \mathrm{~S} \\
\mathrm{i}_{2} \mathrm{O}_{5}(\mathrm{OH})_{4}+1 / 3 \mathrm{Na}^{+}+4 / 3 \mathrm{Si}(\mathrm{OH})_{4}\end{array}$ \\
\hline $\begin{array}{l}\text { Equação 3. - Ca-montmorilonita para } \\
\text { caulinita }\end{array}$ & $\begin{array}{c}\mathrm{Ca}_{0 \cdot 33} \mathrm{Al}_{2} \mathrm{Si}_{3 \cdot 67} \mathrm{O}_{10}(\mathrm{OH})_{2}+1 / 3 \mathrm{H}^{+}+23 / 2 \mathrm{H}_{2} \mathrm{O} \rightarrow 23 / 20 \mathrm{Al} \\
{ }_{2} \mathrm{Si}_{2} \mathrm{O}_{5}(\mathrm{OH})_{4}+3 / 5 \mathrm{~K}^{+}+1 / 4 \mathrm{Mg}^{2+}+6 / 3 \mathrm{Si}(\mathrm{OH})_{4}\end{array}$ \\
\hline Equação 4. - Illita para caulinita & $\begin{array}{c}\mathrm{K}_{0 \cdot 6} \mathrm{Mg}_{0 \cdot 25} \mathrm{Al}_{2 \cdot 30} \mathrm{Si}_{3 \cdot 5} \mathrm{O}_{10}(\mathrm{OH})_{2}+11 / 10 \mathrm{H}^{+}+63 / 60 \mathrm{H}_{2} \mathrm{O} \\
\rightarrow 23 / 2 \mathrm{Al}_{2} \mathrm{Si}_{2} \mathrm{O}_{5}(\mathrm{OH})_{4}+3 / 5 \mathrm{~K}^{+}+1 / 4 \mathrm{Mg}^{2+}+6 / 3 \\
\mathrm{Si}(\mathrm{OH})_{4}\end{array}$ \\
\hline Equação 5. - Albita para caulinita & $\begin{array}{c}\mathrm{NaAlSi}_{3} \mathrm{O}_{8}+\mathrm{H}^{+}+9 / 2 \mathrm{H}_{2} \mathrm{O} \rightarrow 1 / 2 \mathrm{Al}_{2} \mathrm{Si}_{2} \mathrm{O}_{5}(\mathrm{OH})_{4}+\mathrm{Na}^{+}+2 \\
\mathrm{Si}(\mathrm{OH})\end{array}$ \\
\hline $\begin{array}{l}\text { Equação 6. - Albita para } \\
\text { Na-montmorilonita }\end{array}$ & $\begin{array}{l}\mathrm{NaAlSi}_{3} \mathrm{O}_{8}+6 / 7 \mathrm{H}^{+}+20 / 7 \mathrm{H}_{2} \mathrm{O} \rightarrow 3 / 7 \mathrm{Na}_{0.33} \mathrm{Al}_{\cdot 33} \mathrm{Si}_{3} \\
\quad 67 \mathrm{O}_{0}(\mathrm{OH})_{2}+6 / 7 \mathrm{Na}^{+}+10 / 7 \mathrm{Si}(\mathrm{OH})_{4}\end{array}$ \\
\hline $\begin{array}{l}\text { Equação } 7 . \text { - Microclínio para } \\
\text { caulinita }\end{array}$ & $\mathrm{KAl}_{2} \mathrm{Si}_{3} \mathrm{O}_{8}+2 \mathrm{H}^{+}+\mathrm{H}_{2} \mathrm{O} \rightarrow \mathrm{Al}_{2} \mathrm{Si}_{2} \mathrm{O}_{5}(\mathrm{OH})_{4}+\mathrm{K}^{2+}$ \\
\hline Equação 8. - Anortita para caulinita & $\mathrm{CaAl}_{2} \mathrm{Si}_{3} \mathrm{O}_{8}+2 \mathrm{H}^{+}+\mathrm{H}_{2} \mathrm{O} \rightarrow \mathrm{Al}_{2} \mathrm{Si}_{2} \mathrm{O}_{5}(\mathrm{OH})_{4}+\mathrm{Ca}^{2+}$ \\
\hline Equação 9. - Andesita para caulinita & $\begin{array}{c}\mathrm{Na}_{0.5} \mathrm{Ca}_{0.5} \mathrm{Al}_{1 \cdot 5} \mathrm{Si}_{2 \cdot 5} \mathrm{O}_{8}+3 / 2 \mathrm{H}^{+}+11 / 4 \mathrm{H}_{2} \mathrm{O} \rightarrow 3 / 4 \mathrm{Al}_{2} \\
\mathrm{Si}_{2} \mathrm{O}_{5}(\mathrm{OH})_{4}+1 / 2 \mathrm{Na}^{+}+1 / 2 \mathrm{Ca}^{2 \cdot+}+\mathrm{Si}(\mathrm{OH})_{4}\end{array}$ \\
\hline Equação 10. - Biotita para caulinita & $\begin{array}{c}\mathrm{KMg}_{3} \mathrm{AlSi}_{3} \mathrm{O}_{10}(\mathrm{OH})_{2}+7 \mathrm{H}^{+}+1 / 2 \mathrm{H}_{2} \mathrm{O} \rightarrow 1 / 2 \mathrm{Al}_{2} \mathrm{Si}_{2} \mathrm{O}_{5} \\
(\mathrm{OH})_{4}+\mathrm{K}^{+}+3 \mathrm{Mg}^{2+}+2 \mathrm{Si}(\mathrm{OH})_{4}\end{array}$ \\
\hline $\begin{array}{l}\text { Equação 11. - Formação ácido } \\
\text { carbônico }\end{array}$ & $\mathrm{CO}_{2}+\mathrm{H}_{2} \mathrm{O} \rightarrow \mathrm{H}^{+}+\mathrm{HCO}_{3}$ \\
\hline
\end{tabular}

As reações de intemperismo ocorrem não somente em perfis de alteração mas também em rochas percoladas por água subterrâneas, contudo as transformações minerais são mais dificeis de serem detectadas do que no perfil (Appelo \& Postma, 1993). 
Os principais minerais secundários formados a partir do intemperismos de silicatos são a caulinita, a montmorilonita e a gibsita. A alteração de minerais silicáticos para esses produtos depende da capacidade de lixiviação, que está relacionada à retirada de uma determinada quantidade de sílica e cátions do mineral, das condições hidrogeológicas e da taxa de intemperismo do mineral. A montmorilonita é formada preferencialmente em climas relativamente secos, onde a lixiviação do solo é baixa e quando a dissolução dos minerais é rápida como os das rochas vulcânicas. A gibsita é formada em locais tipicamente tropicais, com chuvas intensas e boas condições de drenagem. A formação da caulinita esta relacionada a um ambiente intermediário aos outros dois (Appelo \& Postma, 1993).

Segundo Drever (1988) e Appelo \& Postma (1993), a solubilidade de minerais secundários, que possuem alumínio, é bastante baixa na faixa de $\mathrm{pH}$ da água subterrânea, estando abaixo do limite de detecção dos equipamentos que determinam a concentração de alumínio na água.

Os fenômenos de dissolução e precipitação de aluminossilicáticos podem ser estudados a partir de diagramas de estabilidade mineral, pois é comum a não detecção do alumínio nas análises químicas de águas subterrâneas, impedindo a realização de cálculos de índices de saturação para esses minerais. Tais diagramas contém campos de predomínio de minerais, separados por linhas que expressam a situação de equilibrio químico entre as diferentes fases. As posições das linhas nos diagramas são estabelecidas através da relação do $\mathrm{pH}$ e as atividades da silica, do cálcio, do sódio ou do potássio da solução, onde todo o alumínio é completamente preservado na fase sólida, não havendo lixiviação para a água. 


\subsubsection{Intemperismo de minerais carbonáticos}

As reações que envolvem carbonatos são de grande importância no controle da composição da água subterrânea. Os principais minerais que compõem este tipo de rocha são os carbonatos de cálcio e magnésio que reagem facilmente com a água subterrânea e dando a ela a característica da água dura.

Os minerais carbonáticos podem estar presentes não somente em rochas carbonáticas, mas em sedimentos arenosos na forma de minerais secundários e/ou cimento envolvendo os grãos. Mesmo em pequenas quantidades, devido a sua grande reatividade, os minerais carbonáticos ainda possuem grande influência na composição química da água subterrânea.

Água subterrânea em aqüíferos carbonáticos geralmente possui $\mathrm{Ca}^{2+\cdot} \mathrm{e}$ $\mathrm{HCO}_{3}{ }^{n}$ como íons maiores dissolvidos e geralmente apresenta equilíbrio próximo ao da calcita. Segundo Drever (1988) a concentração de $\mathrm{Ca}^{2+}$ depende da pressão de $\mathrm{CO}_{2}$ da água, que é geralmente controlada pelo solo e pela atmosfera na zona de recarga, através do mecanismo descrito abaixo.

A água da chuva que chega no solo está em equilíbrio com o dióxido de carbono da atmosfera, que possui pressão parcial de $10^{-3,5} \mathrm{~atm}$. Os gases no solo possuem mais $\mathrm{CO}_{2}$ (normalmente $10^{-2,5}$ a $10^{-1,5} \mathrm{~atm}$ ) do que a atmosfera, como conseqüência da respiração e decaimento da matéria orgânica. Quando a chuva percola o solo a quantidade de $\mathrm{CO}_{2}$ aumenta para $10^{-2}$ ou mais. $\mathrm{O} \mathrm{CO}_{2}$ adicional irá aumentar a capacidade da água em dissolver $\mathrm{CaCO}_{3}$. A quantidade de $\mathrm{CaCO}_{3}$ dissolvido por litro de água percolada (e com isso a concentração de $\mathrm{Ca}^{2+}$ na água) depende da concentração inicial de $\mathrm{CO}_{2}$ e na extensão em que o $\mathrm{CO}_{2}$ pode ser reposto na água através da troca com a fase gasosa. Se o $\mathrm{CO}_{2}$ não for reposto a quantidade de calcita que a água pode dissolver é limitada pela quantidade de $\mathrm{CO}_{2}$ presente inicialmente, através da equação:

$$
\mathrm{CaCO}_{3}+\mathrm{H}_{2} \mathrm{O}+\mathrm{CO}_{2}=\mathrm{Ca}^{2+}+2 \mathrm{HCO}_{3} \quad \text { Equação } 12
$$


Caso o sistema seja aberto (ocorre reposição de $\mathrm{CO}_{2}$ ) a pressão de $\mathrm{CO}_{2}$ no sistema permanecerá constante e $\mathrm{CO}_{2}$ será transferido da fase gasosa para repor o $\mathrm{CO}_{2}$ consumido pela dissolução da calcita. Dessa forma, a dissolução da calcita não é limitada pela disponibilidade inicial de $\mathrm{CO}_{2}$ e mais calcita será dissolvida em condições de sistema aberto do que no fechado.

O intemperismo da dolomita é parecido com o da caulinita, com exceção da taxa de dissolução que é menor, e parte do $\mathrm{HCO}_{3}{ }^{-}$é mais balanceado para $\mathrm{Mg}^{2+}$ do que para $\mathrm{Ca}^{2+}$. Dolomita normalmente possui dissolução congruente.

Quando as rochas percoladas pela água subterrânea contem calcita e dolomita, essa água normalmente conterá mais cálcio do que magnésio, uma vez que a calcita dissolve-se mais rapidamente que a dolomita. Depois de centenas de anos a razão magnésio/cálcio da água pode chegar ao equilíbrio (Appelo \& Postma, 1993).

\subsection{Adsorção e troca catiônica}

A fase sólida presente nos aqüiferos possui grande capacidade de modificar sua concentração através da transferência de massa entre a água subterrânea e os minerais presentes no aqüifero. Os processos responsáveis pela troca de massa são: adsorção (quando o íon encontra-se aderido à superfície do sólido) e troca iônica (quando ocorre a reposição de um ion por outro).

Segundo Appelo \& Postma (1993), os processos acima mencionados são modelados a partir de equações derivadas da leí de ação das massas. A principal diferença entre a adsorção e troca iônica é que o modelo de equações do primeiro usa as concentrações de apenas um ín enquanto que o outro considera todos os íons capazes de serem trocados, dificultando o cálculo, uma vez que a água subterrânea possui vários íons dissolvidos. 
Também é bastante complicada a distinção dos processos de adsorção e troca iônica dos processos de precipitação e dissolução de minerais, sendo que a principal diferença é que o sólido (argilominerais, matéria orgânica e óxidos e hidróxidos de ferro) possui uma capacidade específica de adsorção e troca iônica.

A adsorção corresponde a um fenômeno de aderência de íons ou moléculas presentes numa solução a uma fase sólida que apresenta elevada superficie especifica. Esse processo ocorre normalmente quando os argilominerais, matéria orgânica e/ou óxidos e hidróxidos de ferro encontram-se negativamente carregados, atraindo cátions a fim de que ocorra estabilidade elétrica. Há situações inversas, onde a fase sólida apresenta-se positivamente carregada, atraindo ânions. O controle do tipo de adsorção (se cátion ou ânions) este relacionado ao tipo de material adsorvente e o $\mathrm{pH}$ da solução percolante. Desta forma, se o $\mathrm{pH}$ da solução percolante for mais elevado que o do material adsorvente, no qual a carga elétrica da sua superfície seja zero (definido como $\mathrm{pH}_{z \mathrm{pc}}$, ou $\mathrm{pH}$ de zero point of change), haverá condições para a adsorção de cátions, e vice-versa. Segundo Deutsch (1997), os argilominerais são os minerais que mais sofrem estes tipos de processos nos solos e aqüiferos.

Uma forma de se medir quantativamente a ocorrência de retenção de ions para diferentes tipos de material é através do cálculo da capacidade de troca de cátions (CTC), normalmente expresso em equivalentes de cargas positivas por massa de material adsorvente. Os valores de CTC variam de material para material, em função das suas diferentes superfícies especificas (minerais com superfície específica maior adsorvem mais). A Tabela 4.2. apresenta os valores de CTC e de $\mathrm{pH}_{z p c}$ de alguns materiais normalmente encontrados no meio ambiente (Appelo \& Postma, 1993). 


\begin{tabular}{|c|c|c|}
\hline 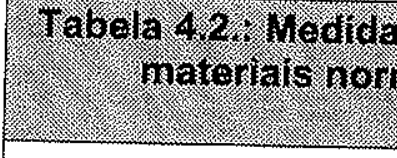 & 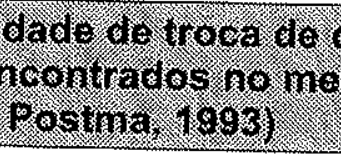 & s do alguns \\
\hline Material & CTC (meq/100g) & $\mathrm{pH}_{z p c}$ \\
\hline Caulinita & $1-15$ & 4 a 5 \\
\hline Montmorilonita & $80-120$ & 2,5 \\
\hline Goetita e Hematita & até 100 & 7 a 8 \\
\hline
\end{tabular}

Os principais cátions trocáveis são cálcio, magnésio, potássio, sódio, hidrogênio e alumínio, sendo que a soma da concentração destes íons em situação de adsorção representa uma boa aproximação da medida de capacidade de troca de cátions (Wutke \& Camargo, 1972). Normalmente, os materiais retêm com maior intensidade os íns de maior valência e de menor raio iônico. A afinidade pela adsorção decresce na seguinte ordem: $\mathrm{Al}^{3+}>\mathrm{Ca}^{2+}>$ $\mathrm{Mg}^{2+}>\mathrm{K}^{+}>\mathrm{Na}^{+}$(Hem, 1985). O hidrogênio possui comportamento característico, assemelhando-se ao de um cátion bivalente, sendo mais fortemente retido pela caulinita que o cálcio, ocorrendo o inverso com a montmorilonita (Wutke \& Camargo, 1972). Isso acontece devido aos diferentes tipos de ligações químicas que o hidrogênio realiza com os diversos materiais trocadores. 


\section{MODELOS HIDROGEOQUÍMICOS}

Os modelos computacionais hidrogeoquímicos compreendem uma ferramenta que auxilia no entendimento de modelos hidrogeoquímicos conceituais através da interação das características químicas da água-rocha-gás do sistema. Estes programas também realizam previsões de respostas do sistema a partir de mudanças nas condiçōes químicas do meio (Deutcsh, 1997).

Os modelos hidrogeoquímicos podem ser divididos, basicamente, em três tipos:

- Modelos de especiação

Calculam, a partir do resultado da composição química da água, a distribuição e as atividades das espécies dissolvidas entre ions livres e os seus diferentes complexos, assim como o índice de saturação de diferentes minerais, levando-se em conta a força iônica da solução. Os cálculos dos parâmetros mencionados são baseados no princípio da lei de ação de massas e utilizam-se de bancos de dados termodinâmicos e de constantes de equilíbrio das principais reações químicas.

O cálculo do índice de saturação por esses modelos é útil para o desenvolvimento de modelos conceituais, pois mede o desequilibrio existente entre a solução e os minerais da rocha, através da relação entre o produto das atividades dos ions formadores de um mineral (IAP), obtido com os resultados das análises químicas da água e das constantes de equilibrio químico dos minerais $(\mathrm{K})$, de acordo com a seguinte equação:

$$
I S=\log \frac{I A P}{K} \quad \text { Equação } 13
$$

Valores positivos de índice de saturação (IS) indicam que a solução está supersaturada com relação a determinado mineral, o que leva à precipitação. Valores negativos sinalizam que o mineral encontra-se em processo de dissolução e valores próximos de zero indicam que a solução está em equilibrio químico com o mineral. 
- Modelos de previsão

O modelo de previsão consiste em apresentar ao programa a composição de uma água de montante e fazer a previsão da composição de uma água de jusante em um mesmo sistema de fluxo, após a primeira ter entrado em contato com uma ou várias fases minerais e/ou gasosas ou sofrido alguma alteração nas condições ambientais (temperatura, $\mathrm{pH}$ ou Eh). Como resultado, o programa fornece a especiação e os índices de saturação da água de jusante, bem como as quantidades de massa transferidas de uma fase para outra. Vários tipos de reações químicas entre fases podem ser modeladas por estes programas, tais como dissolução/precipitação, óxido/redução, troca iônica, adsorção e complexação de superfícies sólidas.

- Modelos inversos ou de balanço de massa

Nestes modelos, fornece-se ao programa as concentrações químicas de suas amostras de água coletadas à montante e jusante de um mesmo sistema de fluxo, enumeramse os tipos de fases sólidas entre os dois pontos e um índice de incerteza dos resultados das análises químicas, devido a erros analíticos e de amostragem. A saída do programa corresponde a uma série de sugestões de reações químicas que justificam as mudanças de composição química da água entre os dois pontos. Estes programas utilizam-se apenas da estequiometria das reações na resolução do problema, não utilizando constantes de equilíbrio químicos e dados termodinâmicos.

Dentre os programas de modelagem hidrogeoquímica disponíveis, os mais conhecidos são o Wateq (Truesdel et al., 1973), desenvolvido pela USGS, - MinteqA2 (Allison et al., 1991), desenvolvido pela USEPA e Phreeqc (Parkhurst, 1995), desenvolvido pela USGS. Através do programa Wateq pode-se calcular especiação iônica, constante de equilibrio ajustada com a temperatura do sistema, equilibrio redox, equilíbrio da fase gás e índice de saturação. Com o MinteqA2 além dos parâmetros calculados pela Wateq, podese obter transferência de massas, troca iônica, adsorção e complexação de superfície. O Phreeqc é o mais completo dos três, onde ainda pode-se realizar a modelação inversa, modelação de mistura e transporte advectivo. 
A habilidade de um modelo hidrogeoquímico em simular de forma precisa os sistemas naturais é limitada por uma série de fatores, tais como exatidão dos dados de campo e laboratório, a extensão e precisão da base de dados termodinâmicos, mas principalmente com relação à velocidade das reações químicas. 


\section{MATERIAIS E MÉTODOS}

\subsection{Cadastro de Poços}

O cadastro dos poços existentes na cidade de Urânia teve como objetivo reunir informações sobre a quantidade, tipos e características dos poços existentes na área de estudo, com a finalidade de se caracterizar a hidrogeologia da cidade. Foram cadastrados 8 poços tubulares da SABESP, 16 poços tubulares particulares e 28 poços cacimbas (Anexo 1).

Para a realização do cadastro recorreu-se à SABESP da cidade de Urânia, onde foram adquiridos os "Relatórios Finais de Poços" dos sete poços tubulares profundos da SABESP e a localização de alguns poços tubulares e cacimbas existentes na área. O cadastramento dos poços que não estavam registrados na SABESP foram realizadas através de visitas a cada uma das captações, localizadas em pontos estratégicos ao longo da cidade de Urânia.

Cada poço cadastrado recebeu uma numeração de acordo com o tipo de poço (tubular profundo da SABESP $=$ PP-00, tubular particular $=$ PT-00 e cacimba $=\mathrm{PC}-00)$, foram também reunidas informações como nome do proprietário, endereço e localização do poço, profundidade, diâmetro, nível d'água, equipamento utilizado para extração da água (baide, bomba, etc.), ano de perfuração, uso da água, vazão da bomba quando presente, tipo de revestimento e formação geológica perfurada (Figura 6.1.). 


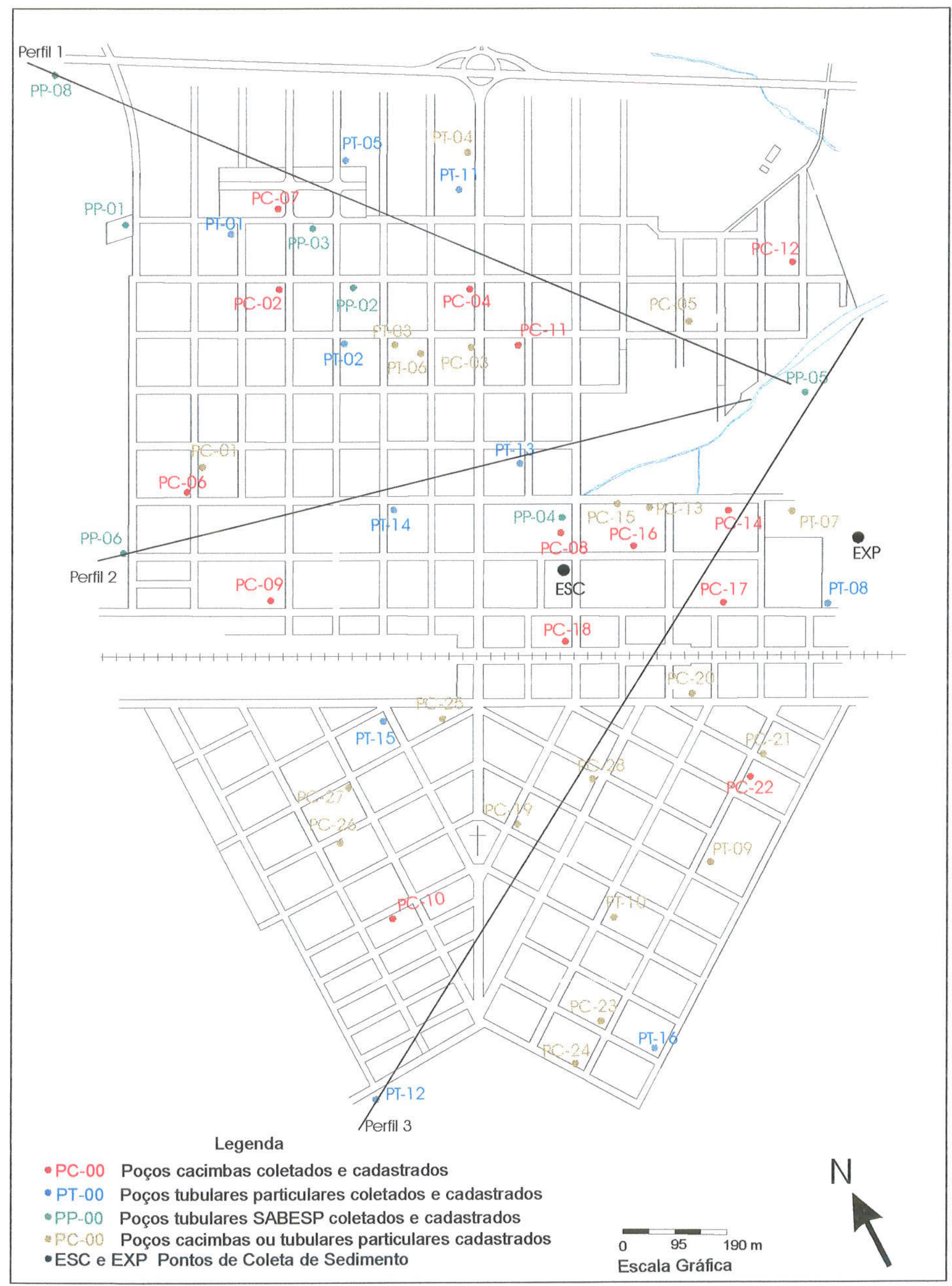

Figura 6.1: Mapa da cidade de Urânia com a localização dos poços cadastrados e coletados e pontos de coleta de sedimentos 


\subsection{Hidráulica}

Com finalidade de se definir um modelo conceitual da hidráulica da zona saturada no Aqüifero Adamantina na cidade de Urânia, foram coletados dados sobre o nivel d'água durante o cadastramento dos poços e ao longo de uma campanha de medição realizada no mês de setembro de 2001 em 20 poços cacimbas distribuídos em toda a cidade. Antes das medições foi solicitado aos proprietários dos poços que os mesmo não fossem bombeados no período de 24 horas. Os dados destas medições estão apresentados no Anexo 1.

A partir de medições dos niveis d'água nos poços, foi confeccionado um mapa potenciométrico para os poços cacimbas e um perfil esquemático de fluxo entre os poços PP-8 e PP-5. Para a elaboração do perfil de fluxo foram realizadas medições de nível d'água em alguns poços tubulares (PT) $\mathrm{e}$ profundos da SABESP (PP).

\subsection{Coleta e análise de amostras de sedimentos}

\subsubsection{Coleta de amostras de sedimentos}

As amostras de sedimentos foram coletadas durante a escavação de dois poços tubulares por sondagem rotativa. Essas sondagens foram realizadas com hastes de seis polegadas, dotadas de uma peça triangular com vídias em sua ponta, que perfurou o terreno através de sua rotação. Para o resfriamento do equipamento foi um utilizado um sistema fechado de circulação de água.

As amostras foram coletadas em intervalos de dois a quatro metros de profundidade e que consistiram de uma mistura de sedimentos desagregados e/ou triturados com água. 
Um dos poços perfurados está localizado na escola municipal, dentro do perímetro urbano da cidade de Urânia (ESC), e o outro no recinto de exposições agropecuárias, há menos de $1 \mathrm{~km}$ da cidade (EXP). A perfuração ESC possui 60 $m$ de profundidade e os intervalos coletados foram os de $10,14,17,20,24,28$, $32,36,40,44,52$ e $60 \mathrm{~m}$, enquanto que a EXP possui $80 \mathrm{~m}$ e intervalos coletados de 22, 26, 30, 40, 43, 44-48, 52, 56, 60, 64, 78 e 80m (Figura 6.1.). 0 único intervalo testemunhado foi de $44-48 \mathrm{~m}$.

\subsubsection{Estudos petrográficos}

Os estudos petrográficos foram realizados na amostra indeformada EXP $44-48 \mathrm{~m}$, que inicialmente, foi descrita macroscopicamente, ressaltando-se parâmetros como cor, granulometria, estrutura e mineralogia.

Em seguida, foram realizados estudos de microscopia óptica de lâminas delgadas. Esse estudo visou o detalhamento da mineralogia dos sedimentos coletados.

A preparação da lâmina delgada foi efetuada de acordo com os procedimentos adotados pela Seção de Laminação do IGc-USP.

\subsubsection{Análise granulométrica}

A análise granulométrica foi realizada a partir do método de peneiramento e pipetagem, no Laboratório de Sedimentologia do instituto de Geociências da Universidade de São Paulo (IGc-USP).

Essa análise foi executada na amostra de testemunho EXP 44-48m, após sua desagregação em almofariz de porcelana e secagem a $30^{\circ} \mathrm{C}$. Em seguida foram peneiradas as faixas granulométricas maiores que o silte grosso $(0,02 \mathrm{~mm}$ de diâmetro) e pipetadas as frações granulométricas menores (argila e silte fino) após o tempo padrão de sedimentação segundo a lei de Stokes, utilizando-se a pipeta de Robinson. Os resultados apresentados consideram as seguintes faixas granulométricas: argila $(<2 \mu \mathrm{m})$, silte fino (2 a $20 \mu \mathrm{m})$, silte grosso (20 a $50 \mu \mathrm{m})$, areia fina $(50$ a $200 \mu \mathrm{m})$ e areia média e grossa $(>200 \mu \mathrm{m})$. 


\section{- Separação da fração $<0,004 \mathrm{~mm}$}

Para estudos mineralógicos dos argilominerais foi utilizada a fração $<0,004 \mathrm{~mm}$, cuja separação foi efetuada via pipetagem. As amostras foram secas a $30^{\circ} \mathrm{C}$, desagregadas naturalmente e dispersas em água destilada com defloculante (pirofosfato de sódio). Após 2 horas e 3 minutos de repouso (decantação), foi pipetada uma única vez a coluna de água de $10 \mathrm{~cm}$ em uma proveta de $1000 \mathrm{~mL}$, que continha material em suspensão. A separação deste material foi feita no Laboratório de Sedimentologia do IGc USP.

Segundo Alves (1990), acredita-se que nesta fração ocorram as maiores concentrações de argilominerais e desta forma a separação granulométrica representa essencialmente um fracionamento mineralógico.

\section{- Separação de minerais pesados e magnéticos}

A separação de minerais pesados foi realizada através do bromofórmio que se trata de um líquido de densidade conhecida $(2,9035 \mathrm{~g} / \mathrm{L})$ próxima aos dos minerais aluminossilicáticos que é de aproximadamente $2,65 \mathrm{~g} / \mathrm{L}$.

Inicialmente as amostras foram secas em estufa a $30^{\circ} \mathrm{C}$, desagregadas em almofariz de cerâmica com água destilada. Essas amostras foram lavadas para a retirada de materiais argilosos. Após essa lavagem as amostras foram novamente secas em estufa a $30^{\circ} \mathrm{C}$.

Depois da secagem, as amostras foram colocadas em funis que continham bromofórmio. Desta forma, foram considerados minerais leves os sobrenadantes e pesados os afundados.

Os minerais magnéticos foram separados através da utilização de um ímä. 


\subsubsection{Análise mineralógica por difração de raio-X}

A difração de raio-X (DRX) foi empregada para os estudos mineralógicos qualitativos em amostras totais, fração $<0,004 \mathrm{~mm}$, minerais pesados e magnéticos.

As amostras totais, de minerais pesados e magnéticos foram desagregadas naturalmente e homogeneizadas através de moagem em almofariz de ágata. Em seguida as lâminas foram preparadas pela técnica da prensagem. Foram realizadas análises de amostras totais em todos os pontos coletados, porém as análises de minerais pesados e magnéticos foram efetuadas apenas nas amostras ESC 20, 32 e 52m e EXP 44-48, 56 e 80m, escolhidas devido ao seu grande volume.

As amostras da fração $<0,004 \mathrm{~mm}$ foram umedecidas com água destilada e espalhadas uniformemente pelas lâminas. Depois de sua secagem natural foram analisadas em sua forma natural, glicolada (exposta ao etilenoglicol durante 12 horas) e aquecida (aquecidas durante 3 horas a temperaturas de aproximadamente $500^{\circ} \mathrm{C}$ ). Esta técnica foi utilizada para a determinação de argilas expansivas, sendo desta forma, escolhidas para essa análise, as amostras ESC 20, 32 e 52m e EXP 44-48, 56 e 80m, por apresentarem maior volume de amostra e pico intenso de argilominerais expansivos no difratograma de amostras totais.

Utilizoumse o difratômetro (Siemens-Bruker, modelo D5000) do Laboratório de Difração de Raio-X do IGc-USP, que possui tubos de raios $X$ de cobre, operando em condições rotineiras com voltagem de $40 \mathrm{KV}$, corrente de $40 \mu \AA$ e varredura $2 \theta$ variando de $3^{\circ}$ a $65^{\circ}$, com $0,05^{\circ}$ num tempo de dois segundos. $A$ identificação dos minerais foi realizada através do programa DIFRAC-plus e pela comparação com o Powder Diffraction File-PDF do ICDD (1995). 


\subsubsection{Análise por microscopia eletrônica de varredura (MEV)}

Para a identificação dos minerais presentes nos sedimentos da Formação Adamantina na área de estudo, foi efetuada a análise por Microscopia Eletrônica de Varredura, com microanálise pontual de energia dispersiva acoplada (MEV/EDS), em um fragmento da amostra EXP 44-48 $\mathrm{m}$ e em suas frações pesadas e leves.

O EDS acoplado ao MEV permite identificar os elementos quimicos presentes nos minerais da rocha analisada através da ionização de átomos da amostra que ejetam elétrons de suas camadas mais internas ao ser atingido por um feixe de eletrônico. Para recuperar a estabilidade, os elétrons de outras camadas substituem as vacâncias geradas, emitindo quantias específicas de energia que são medidas e desta forma, permitindo identificar os elementos presentes no material analisado.

O MEV utilizado foi o Leo 440i da OXFORD, do IGc-USP. Este é composto por detectores de elétrons secundários (morfologia dos grãos), e elétrons retroespalhados (contraste dos grãos), catodoluminescência e espectrômetro de energia dispersiva EDS (Energy Dispersive Systems).

O fragmento da amostra EXP 44-48 m e os seus grãos da fração leve e pesada foram fixados em um suporte e recoberto por ouro. Inicialmente, foi analisado o fragmento de rocha sendo possivel analisar a interação entre os minerais, suas superfícies além de caracterizar qualitativamente as suas composições quimicas. Em seguida foram analisadas as frações leves $e$ pesadas da amostra na tentativa de uma melhor identificação mineralógica.

\subsubsection{Análise química por ICPIAES-Plasma}

As análises químicas por ICP/AES-Plasma foram executadas em amostras totais de todos os pontos coletados nas perfurações EXP e ESC.

As amostras foram previamente moidas até uma granulação menor que 200 mesh em uma panela de carbeto de tungstênio. Então, foram separadas parcelas de amostra para a análise dos parâmetros de umidade e perda de elementos voláteis ao fogo. Essas duas análises são feitas a partir da diferença 
entre as amostras total e seca a $60^{\circ} \mathrm{C}$ e a $1000^{\circ} \mathrm{C}$, respectivamente. Em seguida elas foram submetidas a uma fusão alcalina, que consiste em fundir a amostra em cadinhos contendo fundente de metaborato e tetraborato de lítio a uma temperatura de $1000^{\circ} \mathrm{C}$, e logo após foram transformadas em soluções aquosas utilizando-se ácido nítrico e fluorídrico. As soluções aquosas foram obtidas a partir do método elaborado por Janasi et al. (1996).

Tais soluções aquosas foram analisadas no ICP/AES, que consistem em um espectômetro seqüencial de emissão atômica, com plasma induzido acoplado.

No Laboratório de Química e ICP/AES do IGc-USP foram analisados os seguintes parâmetros:

- em porcentagem - $\mathrm{SiO}_{2}, \mathrm{Al}_{2} \mathrm{O}_{3}, \mathrm{Fe}_{2} \mathrm{O}_{3}, \mathrm{MgO}, \mathrm{CaO}, \mathrm{Na}_{2} \mathrm{O}, \mathrm{K}_{2} \mathrm{O}, \mathrm{P}_{2} \mathrm{O}_{5}, \mathrm{MnO}$, $\mathrm{TiO}_{2}$, perda ao fogo e $\mathrm{H}_{2} \mathrm{O}$; e

- em ppm - Ba, La, Sr, V, Y e Zr.

O laboratório realizou três tipos de controle de qualidade das amostras: duplicatas - amostras EXP 78 e ESC 52 apresentando ótima reprodutibilidade com diferenças abaixo de $10 \%$ (que é considerado o limite de aceitação); branco de laboratório, onde não foi detectada a concentração de nenhum composto, indicando a não ocorrência de contaminação no laboratório; e soluções padrões - JG-1a, JB-1a e GS-N que apresentaram ótima reprodutibilidade dos resultados obtidos e certificados. A partir das três checagens acredita-se que os resultados possuíram uma boa confiabilidade.

\subsubsection{Capacidade de troca de cátions e pH do solo}

As análises químicas de troca de cátions (CTC), pH e matéria orgânica do solo foram realizadas em todas as amostras coletas de sedimentos, pelo laboratório de Análise Química de Solo e Planta da Universidade Federal de São Carlos (Araras - SP). De acordo com o responsável pelo laboratório o procedimento utilizado nas análises é basicamente o proposto por Raiji \& Quaggio (1983), porém o laboratório realizou algumas modificações. 
A capacidade de troca catiônica (CTC) representa a somatória dos principais cátions tocáveis que estão adsorvidos no solo $\left(\mathrm{Na}^{+}, \mathrm{K}^{+}, \mathrm{Ca}^{2+}, \mathrm{Mg}^{2+}\right.$, $\left.\mathrm{Al}^{3+} \in \mathrm{H}^{+}\right)$. Outros cátions podem estar adsorvidos, porém em concentraçōes menores. Desta forma, a somatória dos cátions descritos a cima constituem uma razoável aproximação da capacidade de troca catiônica total do solo,

Inicialmente as amostras são secas, desagregadas e homogeneizadas. $O$ $\mathrm{pH}$ do solo é medido $\left(10 \mathrm{~cm}^{3}\right)$ misturando-se a ele, $\mathrm{CaCl}_{2}(25 \mathrm{~mL})$; enquanto que o teor de matéria orgânica é obtido a partir da oxidação da matéria orgânica contida no solo, com uma mistura de dicromato e ácido sulfúrico, seguida de titulação do resultante com solução de sulfato ferroso amoniacal, após adição de $\mathrm{H}_{3} \mathrm{PO}_{4}$.

A determinação do sódio é feita a partir da solução do solo com ácido clorídrico $0,1 \mathrm{~N}$, que após a troca iônica do sódio pelo hidrogênio a solução é analisada por espectrofotometria de chamas.

O potássio é determinado a partir da mistura do solo com uma resina trocadora de cátions saturada em sódio, que permanece em agitador por 16 horas, até que todo os cátions da resina se transfiram para o solo. A resina é separada do solo por lavagem com água deionizada e atacada com solução de $50 \mathrm{~mL}$ de $\mathrm{NH}_{4} \mathrm{Cl}(0,8 \mathrm{~N})$ e $\mathrm{HCl}(0,2 \mathrm{~N})$, sendo o extrato resultante analisado para potássio por espectrofotometria de chama.

O processo de extração do cálcio e magnésio ocorre a partir da mistura do solo com o sal $\mathrm{KCl}(1 \mathrm{~N})$ até que ocorra a troca dos dois cátions pelo potássio. A solução sobrenadante é separada e analisada por espectrofotometria de absorção atômica.

A determinação do Al trocável é feita a partir de uma solução do solo com $\mathrm{KCl}(1 \mathrm{~N})$. Após um determinado tempo, o extrato sobrenadante é titulado com uma solução $0,025 \mathrm{~N}$ de $\mathrm{NaOH}$, cujo volume é utilizado para o cálculo da concentração de $\mathrm{Al}$ trocável. $\mathrm{O} \mathrm{H}^{+}$trocável é determinado através da solução tampão SMP, que consiste de uma mistura de sais neutros com vários tampões. A análise é realizada adicionando-se à solução SMP a suspensão onde foi determinado o pH em $\mathrm{CaCl}_{2}$. Após um determinado tempo de agitação e 
repouso é realizada a leitura do $\mathrm{pH}$ da nova suspensão tampão. A concentração de $\mathrm{H}^{+}+\mathrm{Al}^{-}$é obtida a partir de uma curva de regressão, dado $\mathrm{o} \mathrm{pH}$ da suspensão tampão. A determinação do $\mathrm{H}^{+}$é feita a partir da subtração do Al calculado na soma $\mathrm{H}^{+}+\mathrm{Al}^{-}$.

\subsection{Coleta e análises químicas de amostras de água subterrânea}

\subsubsection{Programa de Amostragem}

Primeiramente foram selecionados para a amostragem 31 poços cadastrados distribuídos uniformemente pela área de estudo. Foram programadas seis campanhas de amostragem no período de três anos.

As coletas foram realizadas em junho de 1998, novembro de 1998, março de 1999, junho de 1999, abril de 2000 e outubro de 2000.

Além destas seis campanhas de coleta houve a necessidade de mais duas, sendo a primeira em maio de 1999 para as coletas estratificadas e em diferentes tempos de bombeamento, outra em setembro de 2001 para checagem das concentrações de sílica.

\subsubsection{Coletas de Água}

Nos trabalhos de campo foram utilizadas quatro formas de coleta de água com a finalidade de melhor entender as variaçōes hidrogeoquímicas do Sistema Aqüifero Bauru na cidade de Urânia. As formas de coletas foram:

Amostragem de água em poços portadores de bombas

As amostras de água dos poços PPs, PTs e PCs foram retiradas diretamente de suas bocas. A coleta foi executada nos poços que já estavam sendo bombeados há mais de 15 minutos, sem interrupção ou, após o esgotamento do volume do poço, no caso de bombas desligadas.

Amostragem de água em poços desprovidos de bombas

As amostras de água foram coletadas em três poços tubulares profundos da SABESP (PP-1, PP -6 e PP-8). Neste tipo de amostragem utilizou-se garrafas 
amostradoras, pois as captações de água haviam sido desativadas e não possuíam bombas submersas.

Em junho e novembro de 1998 e abril e outubro de 2000 para as coletas de água, foi introduzido um amostrador constituído de um cilindro de PVC. O equipamento possuía uma válvula em uma das extremidades, que fechava quando estava cheio de água e uma corda de nylon na outra, para sua retirada após a coleta.

As coletas de março e junho de 1999 foram efetuadas com uma garrafa amostradora de pressão da marca Solinst Discrete Interval Sampler Mod 425. O funcionamento desta garrafa consiste em bombear para seu interior uma pressão calculada a partir da coluna d'água, introduzi-la dentro do poço até a profundidade prémestabelecida, retirar a pressão para que o ar saia e a água entre, colocar a mesma pressão para que se feche e possa ser retirada. Uma vez fora do poço, a pressão é aliviada e a água pode ser coletada.

$\mathrm{Na}$ amostragem de março de 1999, as águas foram coletadas em duas diferentes profundidades, $20 \mathrm{~m}$ a partir do nível estático e até onde foi possível descer a garrafa amostradora de pressão. Em junho de 1999 os mesmos intervalos de coleta de água foram utilizados para o poço PP-1. Nos outros dois poços coletou-se água em quatro profundidades diferentes, seguindo a coleta estratificada de maio de 1999, descrita a seguir.

Amostragem de água em diferentes profundidades

Para melhor entender as variações hidrogeoquímicas no Aqüifero Adamantina realizou-se coletas de água a diferentes profundidades.

Para esta amostragem estratificada, realizada em maio de 1999, foram selecionados os poços desprovidos de bombas submersas PP-6 e PP-8. Antes da coleta de água foi executada a limpeza destes poços com ar comprimido.

A amostragem foi efetuada em quatro profundidades preestabelecidas a partir dos intervalos de filtros. As coletas foram realizadas 24 horas (PP-6 e PP. 8 A) e 48 horas (PP-6 e PP-8-B) após a limpeza dos poços. Para tanto foi utilizada a garrafa amostradora descrita anteriormente e que nesta amostragem atingiu $130 \mathrm{~m}$ de profundidade. 
A garrafa amostradora possibilitou coletas discretas em profundidades especificas, sem contaminações de outros estratos mais superficiais. O resultado destas análises não permitiu obter as variações das concentrações dos parâmetros físico-químicos com a profundidade do aqüifero, sendo que o motivo será discutido no capítulo dos resultados.

Amostragem de água em diferentes tempos de bombeamento

As amostras de água coletadas em tempos de bombeamento préestabelecidos foram realizadas para verificar a existência de variações nas concentrações dos ions.

Em março de 1999 foi selecionado para esta amostragem o poço PP-4. Foram coletadas duas amostras nos intervalos de dez minutos e seis horas de bombeamento constante.

Em maio de 1999 além do PP-4 também foi escolhido o PP-2. Foram coletadas 7 amostras de água nos períodos de 15 minutos, 1, 6, 12, 18 e 24 horas de constante bombeamento.

Em junho de 1999 amostrou-se também o poço PP-5 por encontrar-se naturalmente jorrante quando retirada a sua tampa. As coletas foram realizadas a 10, 30,60 e 120 minutos de constante derramamento de água.

\subsubsection{Análise dá Água}

Durante a coleta, foram medidos "in situ" os seguintes parâmetros com os devidos equipamentos: temperatura do ar e da água - termômetro do Oxímetro; pH - pHmetro pH 330/SET-1-WTW; Eh - Ehmetro da DIGEMED; oxigênio dissolvido - Oxímetro Oxi 330/SET-WTW; condutividade elétrica Condutivímetro LF330/SET-WTW. O Ehmetro usado no campo possui um eletrodo de cloreto de mercúrio e não de hidrogênio. Por isso, nas medidas de Eh acrescentou-se $250 \mathrm{mV}$ para correção.

As aicalinidades total e parcial também foram medidas em campo, sendo a alcalinidade total determinada por titulação com ácido sulfúrico usando indicador misto e a alcalinidade parcial pela titulação com ácido sulfúrico, usando como indicador a fenoftaleína. Para a medida da alcalinidade parcial, em algumas amostras, usou-se a solução tampão borax $(0,025 \mathrm{M}$-pH8,3) como 
referência (branco), pois a transição entre o incolor para o rosa, não foi de fácil visualização. Foi utilizado ácido sulfúrico $0,1 \mathrm{~N}$ padronizado em laboratório com $\mathrm{Na}_{2} \mathrm{CO}_{3}$.

As amostras destinadas aos laboratórios do Centro de Pesquisa de Águas Subterrâneas - CEPAS do Instituto de Geociências da Universidade de São Paulo - IGC-USP para análises físico-químicas, foram filtradas e armazenadas em três frascos de polietileno, novos e descartáveis com volume de $100 \mathrm{~mL}$. Um dos frascos foi congelado para análises dos ânions, no outro foi adicionado cinco gotas de solução $1: 1$ de $\mathrm{HNO}_{3}$ (aproximadamente $0,25 \mathrm{~mL}$ ) para a determinação dos cátions, exceto sódio e potássio, e no frasco restante foram igualmente colocadas cinco gotas de solução $1: 1$ de $\mathrm{H}_{2} \mathrm{SO}_{4}$ para a determinação dos cátions sódio e potássio.

Para a filtragem da água coletada, foi utilizada uma bomba peristáltica Geopump 2, conectada a um holder com papel de filtro de $0,45 \mu \mathrm{m}$ de acetato de celulose.

Os métodos de análises químicas aplicados nos laboratórios do CEPAS para a determinação química das águas subterrâneas foram: processo de cromatografia líquida no aparelho Dionex 2010 i para a análise dos ânions $\mathrm{F}^{*}, \mathrm{Cl}^{\prime}$, $\mathrm{NO}_{2}{ }^{-}, \mathrm{NO}_{3}{ }^{-}, \mathrm{PO}_{4}{ }^{3-}$ e $\mathrm{SO}_{4}{ }^{2}$; para os cátions $\mathrm{Na}^{+}$e $\mathrm{K}^{+}$foi realizado o processo de fotometria de chama desenvolvido no fotômetro $\mathrm{B} 262$ da Micronal; e nos cátions $\mathrm{Cu}^{2+}, \mathrm{Pb}^{2+}, \mathrm{Zn}^{2+}$, Fe total, Cr total, $\mathrm{Mn}^{2+}, \mathrm{Ni}^{2+}, \mathrm{Cd}^{2+}, \mathrm{Ag}^{+}, \mathrm{Ba}^{2+}, \mathrm{Al}^{3+}, \mathrm{Sr}^{2+}, \mathrm{Ca}^{2+} \mathrm{e}$ $\mathrm{Mg}^{2+}$ foi realizado o processo de espectrometria de Absorção Atômica CG AA7000 BCe.

As análises de sílica foram executadas nos laboratórios da TCA Empresa de Apoio Tecnológico, Consultoria Ambiental e Comércio Ltda, CEIMIC Análises Ambientais S/C LTDA e Alfa Laboratório de Análise e Diagnóstico Ambiental. A análise de sílica foi realizada por colorimetria, baseado na $19^{a}$ edição do "Standard Methods for the Examination of Water and Wastewater". 


\subsection{Processamento e Seleção dos Dados}

Os resultados das análises químicas e mineralógicas dos sedimentos, assim como os resultados físico-químicos das amostras de água, foram tratados de forma que fosse possivel a interpretação da evolução dos processos hidrogeoquímicos que ocorrem no aqüifero estudado.

Os resultados das análises químicas e mineralógicas dos sedimentos foram organizados em planithas eletrônicas a partir das quais foi possivel a confecção de gráficos e matrizes de correlação.

Os dados obtidos nas seis campanhas de amostragem de água subterrânea, também foram organizados em planilhas eletrônicas, onde foi possível a realização do balanço iônico para a verificação da qualidade das análises químicas, admitindo-se erros de 15\%, sendo que análises com erros superiores foram consideradas excepcionalmente quando da ausência de dados ou sabendo a origem do erro, análises estatísticas básicas (média, mediana, desvio padrão e histogramas), matrizes de correlação, diagramas de classificação hidrogeoquímica, diagramas de estabilidade mineral e vários perfis representando a evolução de íons maiores, parâmetros físico-químicos e índices de saturação de minerais.

Após a caracterização individual das fases sólida e líquida, algumas técnicas foram utilizadas para estabelecer o modelo conceitual de hidrogeoquímica do aqüífero, a fim de identificar os processos geoquímicos que definem a relação rocha-água. As técnicas utilizadas foram:

- execução da especiação das análises químicas e do cálculo de indices de saturação de minerais através do modelo hidrogeoquímico MinteqA2 (Allison et al., 1991), cujos resultados foram expressos em forma de perfis;

- utilização de diagramas de aluminossilicatos, com intuito de se determinar quais são os minerais aluminossilicáticos mais estáveis; e

- execução de modelagem hidrogeoquímica inversa, segundo o modelo hidrogeoquímico Phreeqc (Parkhurst, 1995). 


\section{RESULTADOS}

\subsection{Modelo hidráulico conceitual}

O modelo conceitual de circulação da água subterrânea na cidade de Urânia foi baseado no mapa potenciométrico a partir dos niveis estáticos dos poços cacimbas e no perfil esquemático de fluxo elaborado entre os poços PP-8 e PP-5.

Através dos perfis litológicos dos relatórios de construção dos poços da SABESP em Urânia, sabe-se que a cidade é caracterizada pela presença do Sistema Aqüifero Bauru, representado pelo Aqüifero Adamantina, que por sua vez sobrepõe o Sistema Aqüifero Serra Geral.

O Aqüifero Adamantina em Urânia é do tipo livre com porosidade primária e o nivel d'água nos poços cacimbas varia entre 2 e $18 \mathrm{~m}$ de profundidade. $O$ mapa potenciométrico da Figura 7.1. indica que o fluxo da água subterrânea é em direção à parte nordeste da cidade. $O$ perfil esquemático de fluxo da Figura 7.2. demonstra que as linhas de fluxo da água subterrânea convergem para a calha do córrego, demonstrando que o mesmo apresenta um caráter influente. Desta forma pode-se considerar que a zona de recarga do aqüfero corresponde à área aflorante da unidade e a zona de descarga ao Córrego Comprido. 


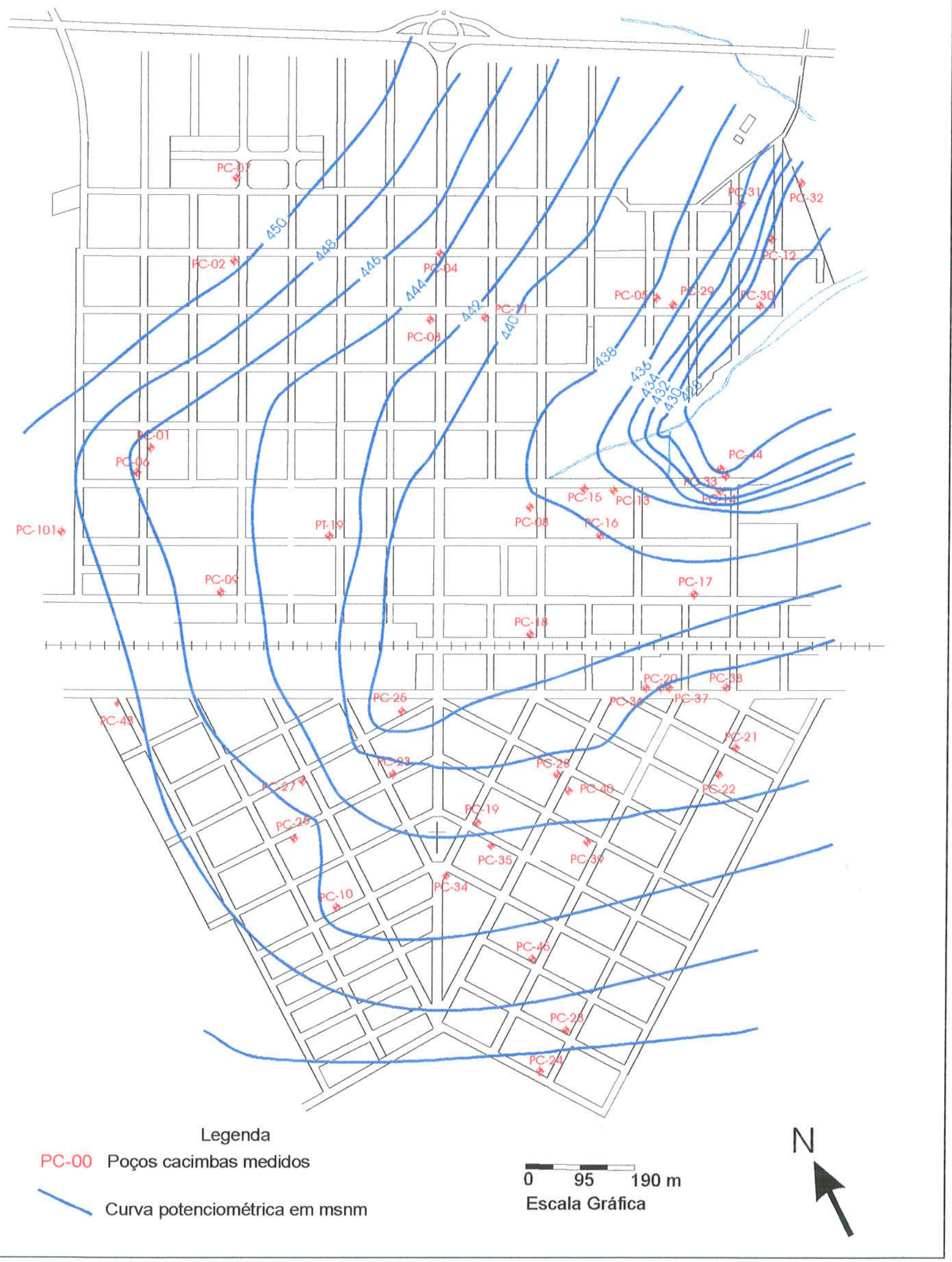

Figura 7.1: Mapa Potenciométrico 


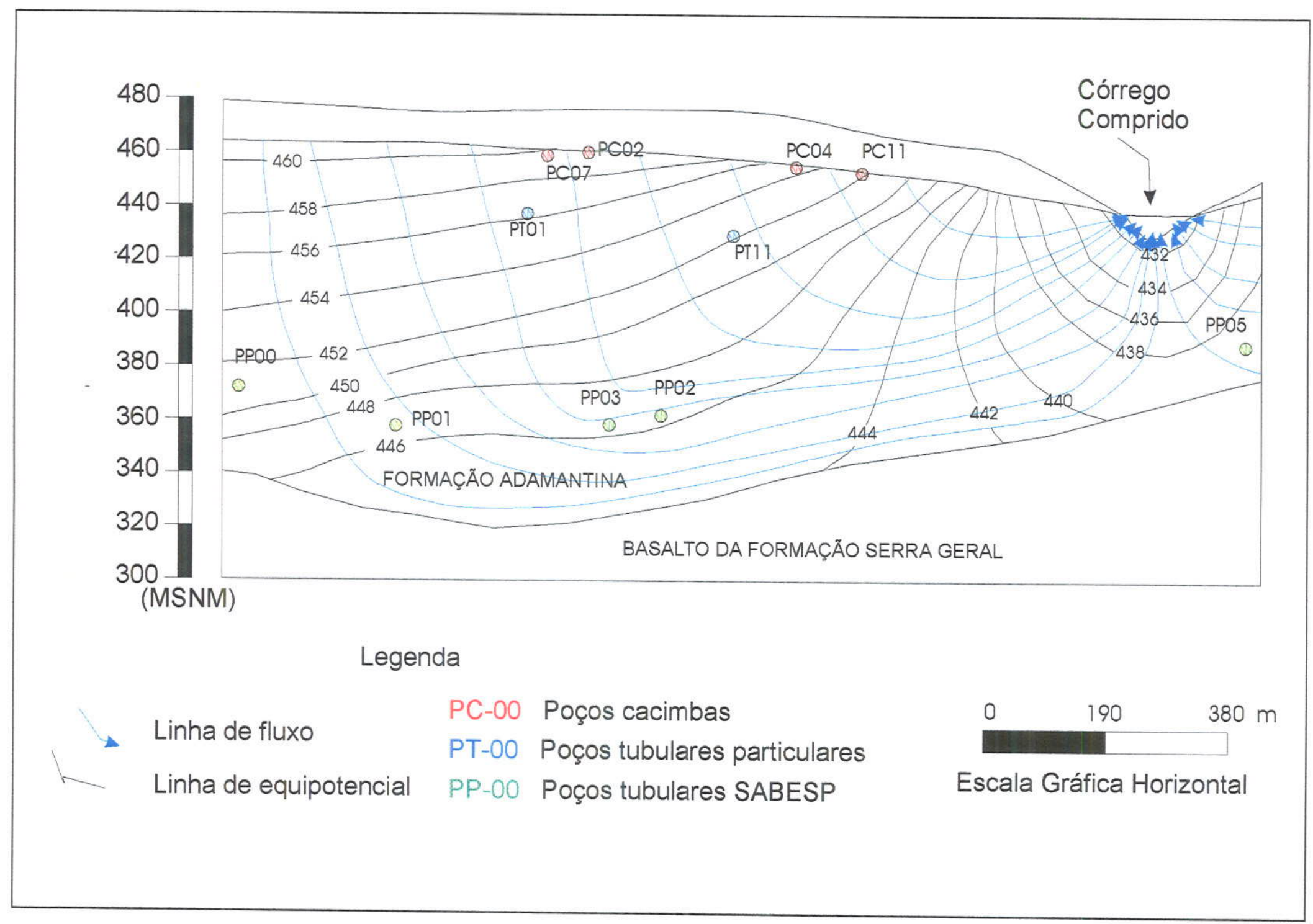

Figura 7.2: Perfil esquemático de fluxo 


\subsection{Caracterização da fase sólida}

\subsubsection{Descrição macroscópica e microscópica da petrográfica}

As descrições petrográficas foram realizadas a partir da amostra EXP 44$48 \mathrm{~m}$, por ser o único intervalo indeformado coletado. Macroscopicamente, a amostra foi descrita como sendo uma rocha sedimentar de cor vermelha escura, com partes centimétricas irregulares de cor branca que efervescem em contato com ácido clorídrico. É composta por um arenito duro de granulometria média, sem qualquer tipo de estrutura visivel a oho nu. Os minerais possiveis de serem identificados macroscopicamente são o quartzo e algum tipo de mineral carbonático (provavelmente calcita), devido à efervescência das partes brancas. Os grãos de quartzo do arenito estão envolvidos em uma matriz composta provavelmente por óxidos e hidróxidos de ferro de cor vermelha e também por um cimento carbonático, devido à dureza e efervescência da toda a amostra.

Ao analisar microscopicamente as duas lâminas petrográficas confeccionadas a partir da amostra EXP 44-48 m, observou-se que a rocha apresentava-se alterada, onde na maioria dos casos os óxidos e hidróxidos de ferro envolviam os grãos da rocha, que representavam cerca de $50 \%$ da amostra Os grãos encontravam-se soltos na matriz e/ou no cimento sem contato com uns aos outros e são do tipo sub-arredondados a arredondados. Não foi observado nenhum tipo de estrutura e orientação da amostra.

Mineralogicamente a amostra apresenta principalmente grãos de quartzo com fraturas conchoidais e microclinio em processo de alteração para sericita ou caulim. Ocorrem, em menores quantidades, plagioclásios com clivagens bem marcadas se alterando também para sericita ou caulim; piroxênios da série diopsídio - enderbejita e egirina; anfibólio com clivagem bem marcada, identificado como sendo actinolita, granada e zircão. 


\subsubsection{Análise granulométrica}

A análise granulométrica também foi realizada apenas na amostra indeformada EXP 44-48. Pode-se observar que a faixa granulométrica predominante na amostra é a de 0,250 a $0,125 \mathrm{~mm}$, seguida pela faixas de 0,125 a $0,062 \mathrm{~mm}$ e de 0,500 a $0,250 \mathrm{~mm}$ que de acordo com a classificação granulométrica de Wenthwork, correspondem a areias finas, areias muito finas e areia médias, respectivamente (Figura 7.3.).
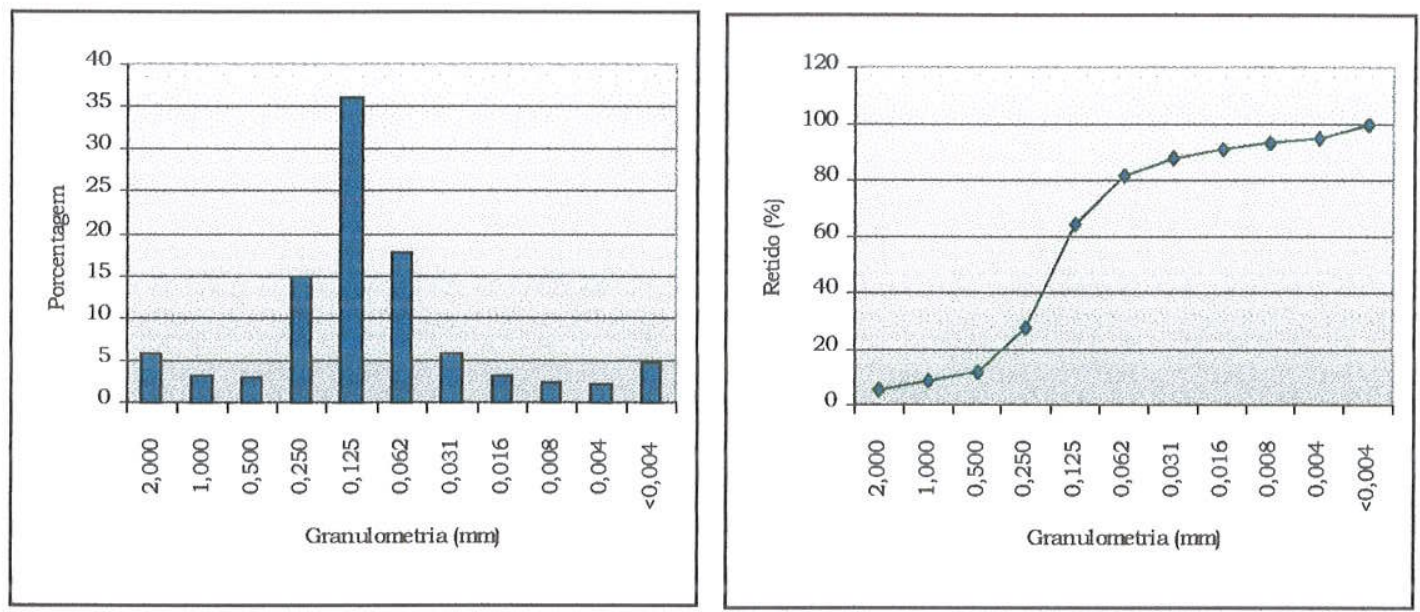

Figura 7.3: Gráfico de barras e curva acumulada da análise granulométrica.

Pode-se observar através da curva acumulada que pouco mais de $80 \%$ da amostra correspondem a frações superiores a areia muito fina, enquanto apenas cerca de $19 \%$ é formada por frações silte e argila.

\subsubsection{Análise mineralógica por difração de raio-X}

Inicialmente foram analisados os difratogramas de raio-X referentes às amostras totais de todos os pontos coletados (Anexo 2). Todas as amostras indicaram a ocorrência de minerais de quartzo, feldspato, um argilomineral com pico de $14 \AA$ e calcita. Os resultados de cada ponto analisado encontram-se na Tabela 7.1.. 


\begin{tabular}{|c|c|c|}
\hline \multicolumn{3}{|c|}{ 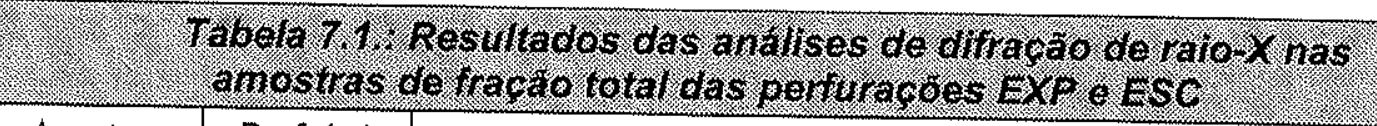 } \\
\hline Amostra & Prof. (m) & Mineralogia \\
\hline EXP 22 & 22 & Quartzo, feldspato, hematita, goetita \\
\hline EXP 26 & 26 & Quartzo, feldspato, argilomineral $14 \AA$, calcita, hematita \\
\hline EXP 30 & 30 & Quartzo, hematita, goetita \\
\hline EXP 34 & 34 & Quartzo, feldspato, argilomineral $14 \mathrm{~A}$, calcita, hematita \\
\hline EXP 40 & 40 & Quartzo, feldspato, argilomineral $14 \AA$, calcita \\
\hline EXP 43 & 43 & Quartzo, feldspato, argilomineral $14 \AA$ \\
\hline EXP 44-48 & $44-48$ & Quartzo, argilomineral $14 \AA$, calcita \\
\hline EXP 52 & 52 & Quartzo, feldspato, argilomineral $14 \AA$, calcita, goetita \\
\hline EXP 56 & 56 & Quartzo, feldspato, argilomineral 14 A, calcita \\
\hline EXP 60 & 60 & Quartzo, feldspato, argilomineral $14 \AA$, calcita \\
\hline EXP 64 & 64 & Quartzo, feldspato, argilomineral $14 \mathrm{~A}$, calcita \\
\hline EXP 78 & 78 & Quartzo, feldspato, argilomineral $14 \mathrm{~A}$, calcita \\
\hline EXP 80 & 80 & Quartzo, feldspato, argilomineral $14 \AA$, calcita \\
\hline ESC 10 & 10 & Quartzo, feldspato \\
\hline ESC 14 & 14 & Quartzo, feldspato \\
\hline ESC 17 & 17 & Quartzo, goetita, hematita \\
\hline ESC 20 & 20 & Quartzo, feldspato, argilomineral $14 \AA$ \\
\hline ESC 24 & 24 & Quartzo, feldspato, argilomineral $14 \AA$, calcita, hematita \\
\hline ESC 28 & 28 & Quartzo, feldspato, argilomineral $14 \AA$, calcita \\
\hline ESC 32 & 32 & Quartzo, feldspato, argilomineral $14 \AA$, calcita \\
\hline ESC 36 & 36 & Quartzo, feldspato, argilomineral $14 \AA$, calcita, hematita \\
\hline ESC 40 & 40 & Quartzo, feldspato, argilomineral $14 \mathrm{~A}$, calcita, hematita, goetita \\
\hline ESC 44 & 44 & Quartzo, feidspato, argilomineral $14 \AA$, calcita \\
\hline ESC 52 & 52 & Quartzo, feldspato, argilomineral 14 A, calcita, hematita, goetita \\
\hline ESC 60 & 60 & Quartzo, feidspato \\
\hline
\end{tabular}

Devido à grande quantidade de quartzo presente nos sedimentos, a intensidade do pico de $3,34 \AA$ das amostras totais apresenta-se bastante pronunciado, podendo mascarar picos de outros minerais existentes na amostra, havendo a necessidade de serem confeccionadas lâminas de frações menos quartzosas. 
Desta forma foram realizadas analisas das frações de minerais pesados e magnéticos, onde foi possível observar com clareza a presença de quartzo, calcita, granada, piroxênio, anfibólio, feldspato, hematita, goetita, ilmenita e rutilo (Figura 7.4. e 7.5.).

Para a identificação do argilomineral com pico de $14 \AA$, foi necessária a separação da fração $<0,004 \mathrm{~mm}$ e análise da sua forma natural, glicolada e aquecida (Figura 11). Para essa análise foram utilizadas apenas as amostras EXP 44-48, 56 e 80 e ESC 20, 32 e 52, pois essas apresentaram picos de $14 \AA$ mais intensos. Os difratogramas restantes encontram-se no Anexo 2.

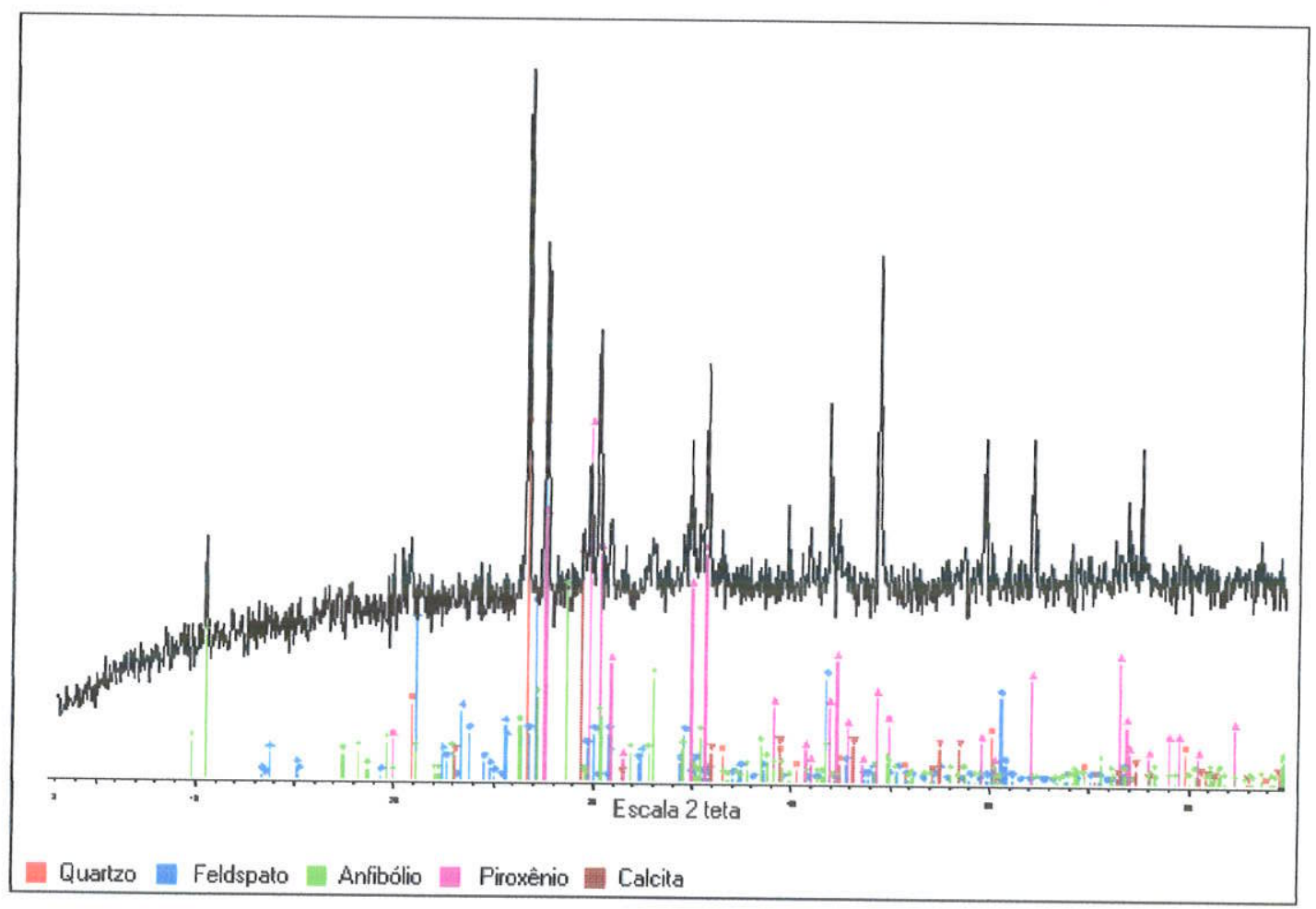

Figura 7.4.: Difratograma de minerais pesados da amostra EXP 56. 


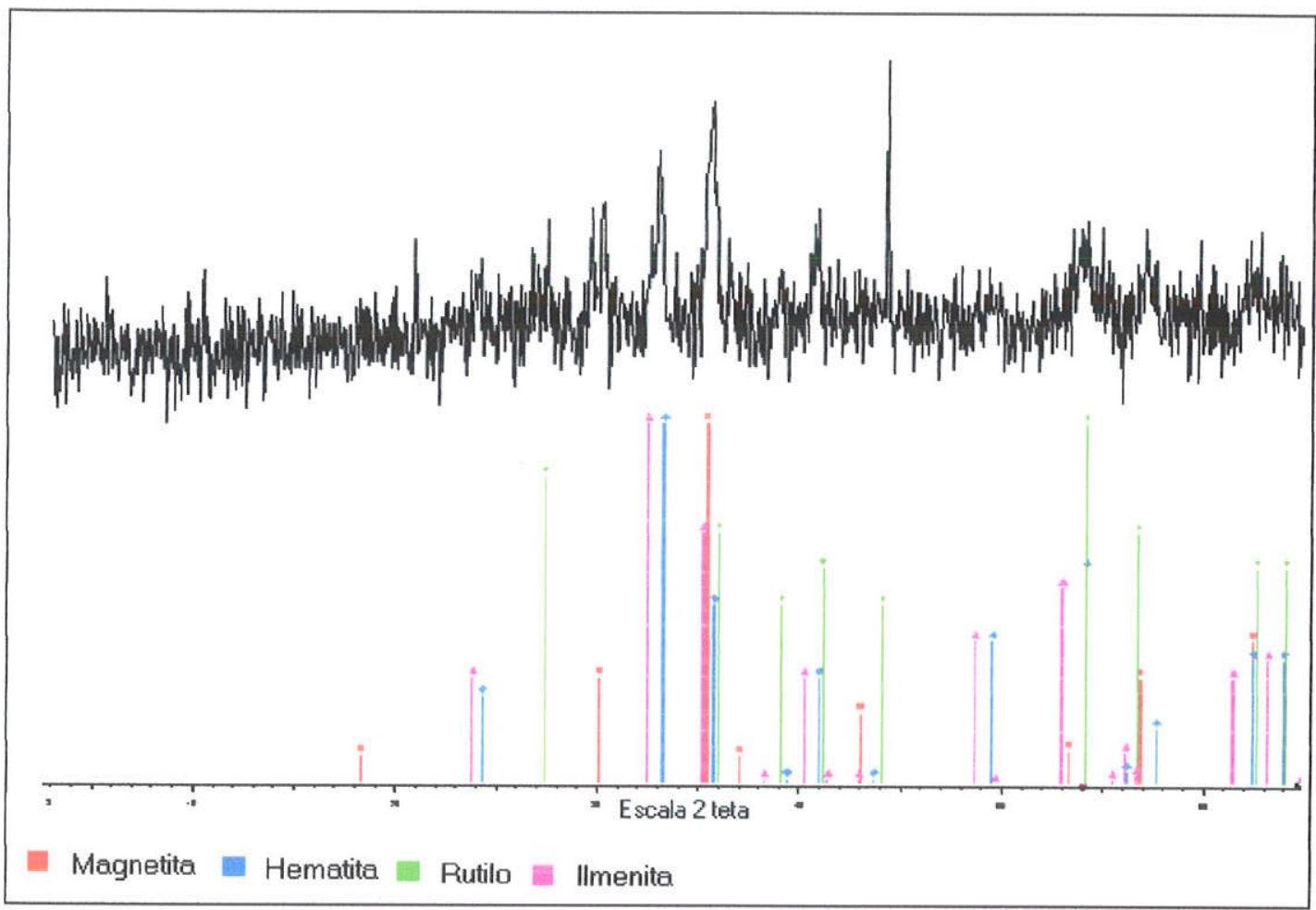

Figura 7.5.: Difratograma de minerais magnéticos da amostra EXP 44-48.

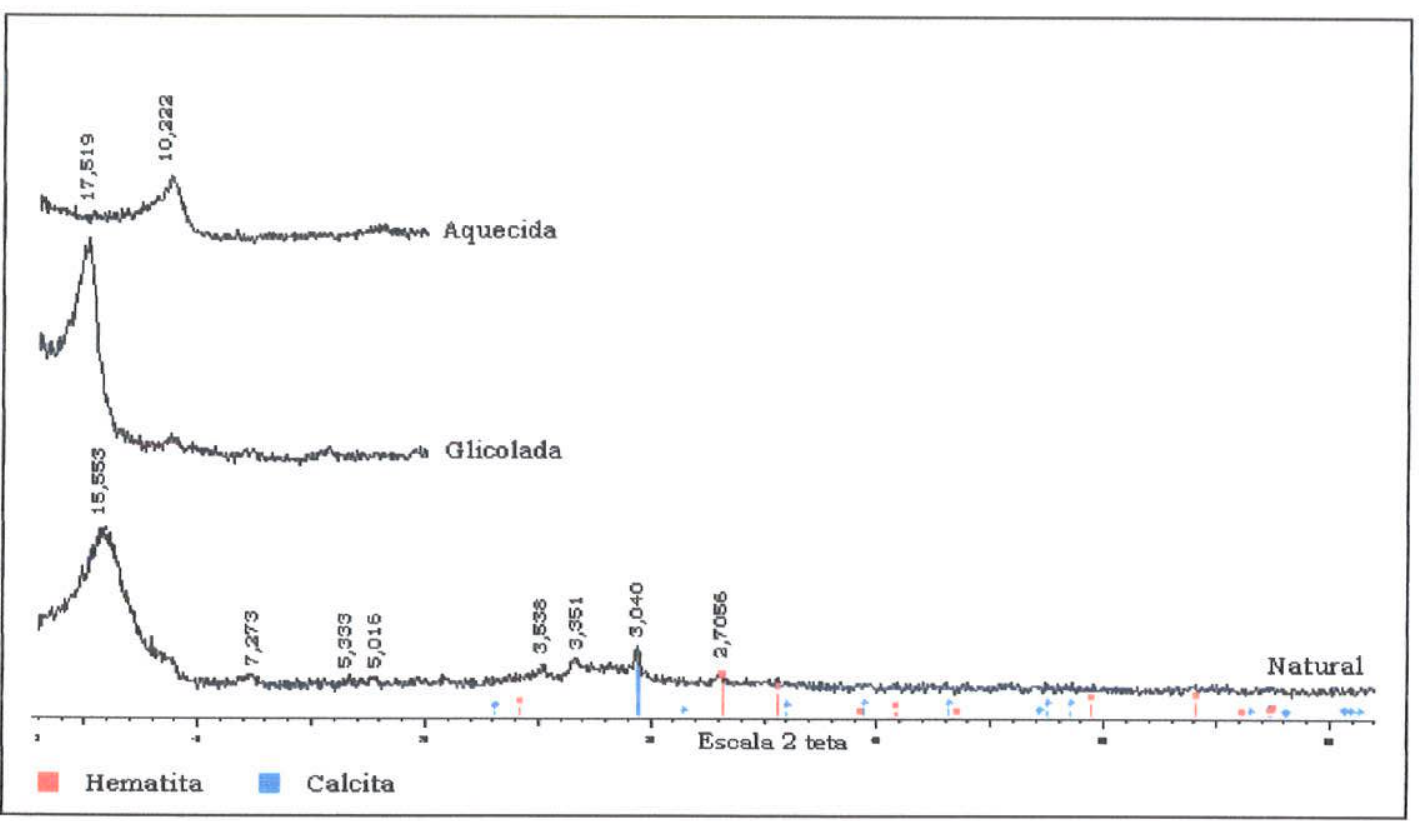

Figura 7.6.: Difratograma da amostra EXP 32 nas formas natural, glicolada e aquecida. 
A partir dos valores dos picos da amostra aquecida $(10,222 \AA)$ e glicolada $(17,519 \AA)$ e bibliografias consultadas sobre os sedimentos da Formação Adamantina, é possível afirmar que o argilomineral presente nas amostras de sedimentos pertence ao grupo das esmectitas (Figura 7.6.).

\subsubsection{Análise de Microscopia Eletrônica de Varredura (MEV)}

A microscopia eletrônica de varredura (MEV) auxiliou na identificação de minerais presentes nos sedimentos da área estudada, através da análise qualitativa da composição química dos grãos.

$\mathrm{Na}$ Figura 7.7. estão apresentadas imagens de cada mineral identificado através do MEV e EDS. A Figura 7.7.A apresenta a textura do argilomineral presente em toda a amostra. Através de comparações com imagens de argilominerais e do EDS pode-se afirmar que o mineral presente trata-se de montmorilonitas magnesianas e cálcicas. A Figura 7.7.B apresenta grão de anfibólios ou piroxênios cálcicos e magnesianos com estruturas de corrosão. A Figura 7.7.C mostra um feldspato sódico enquanto a Figura 7.7.D um feldspato cálcico. Observa-se que as estruturas de corrosäo são mais pronunciadas no feldspato cálcico que no sódico, obedecendo à série de Goldich (Figura 4.1.). Nas figuras onde estão os feldspatos e anfibólio ou piroxênio aparece uma carapaça de montmorilonita ao redor dos grãos indicando o tamanho do mineral antes da corrosão. A Figura 7.7.E apresenta uma calcita ao lado de um anfibólio ou piroxênio.

As Figuras 7.7.F, G e H mostram grãos da fração pesada onde pode-se observar grãos de minerais com superfície de corrosão, de ferro e titânio (ilmenita), titânio, manganês e ferro, manganês e cromo, respectivamente. A presença de sílica nestes grãos provém de possiveis interferências de argilominerais localizados ao redor dos mesmos. 
A

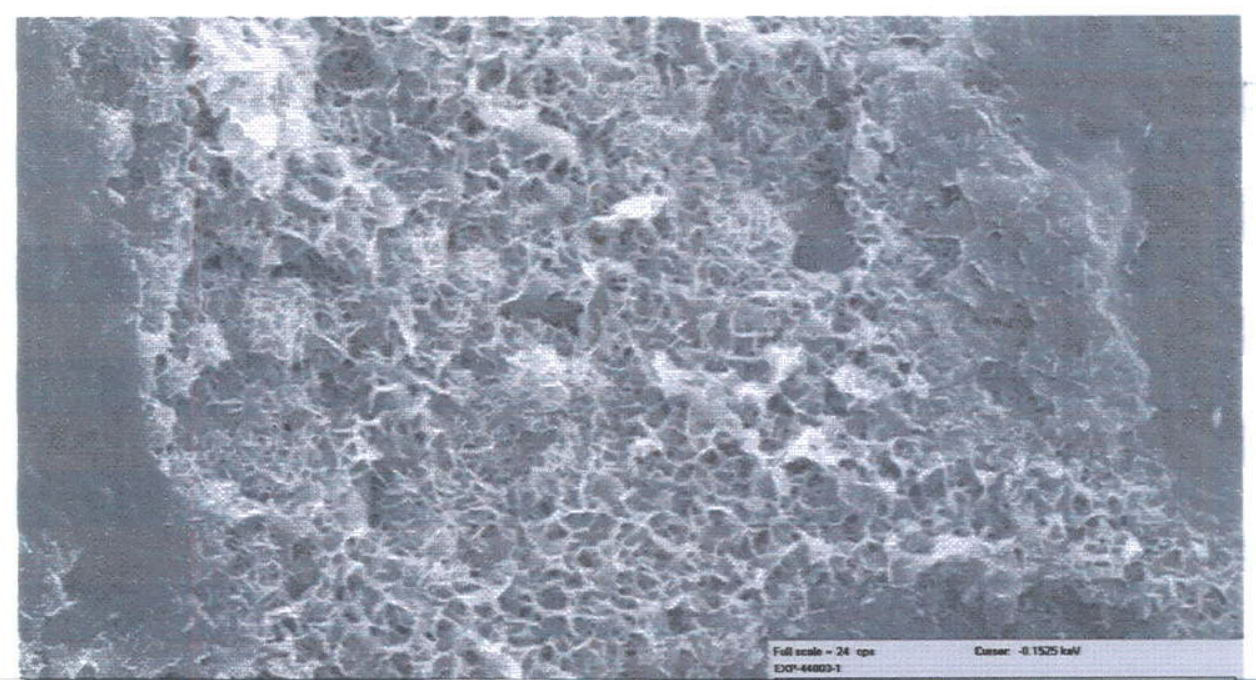

$G$

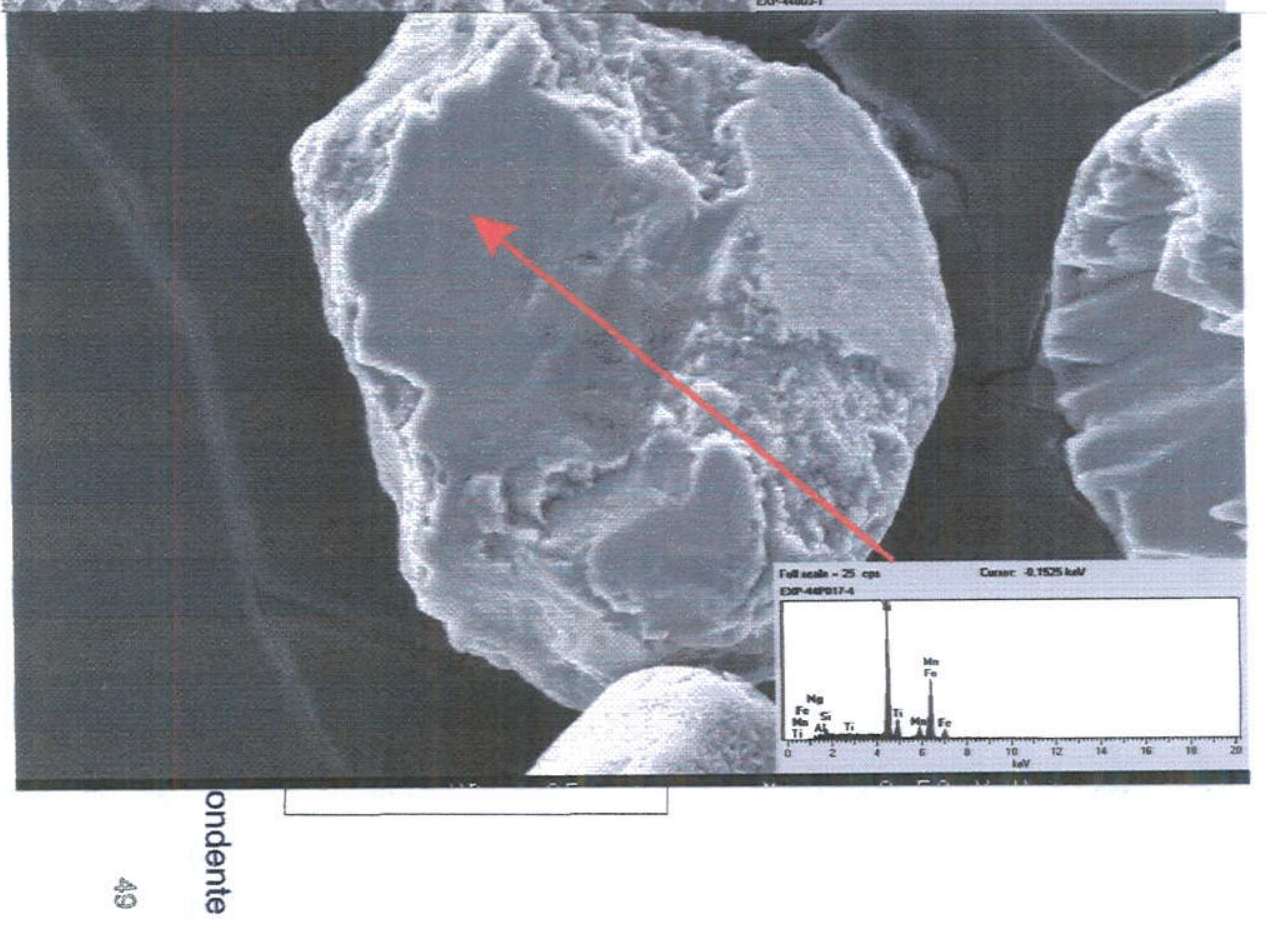

B

$\mathrm{H}$

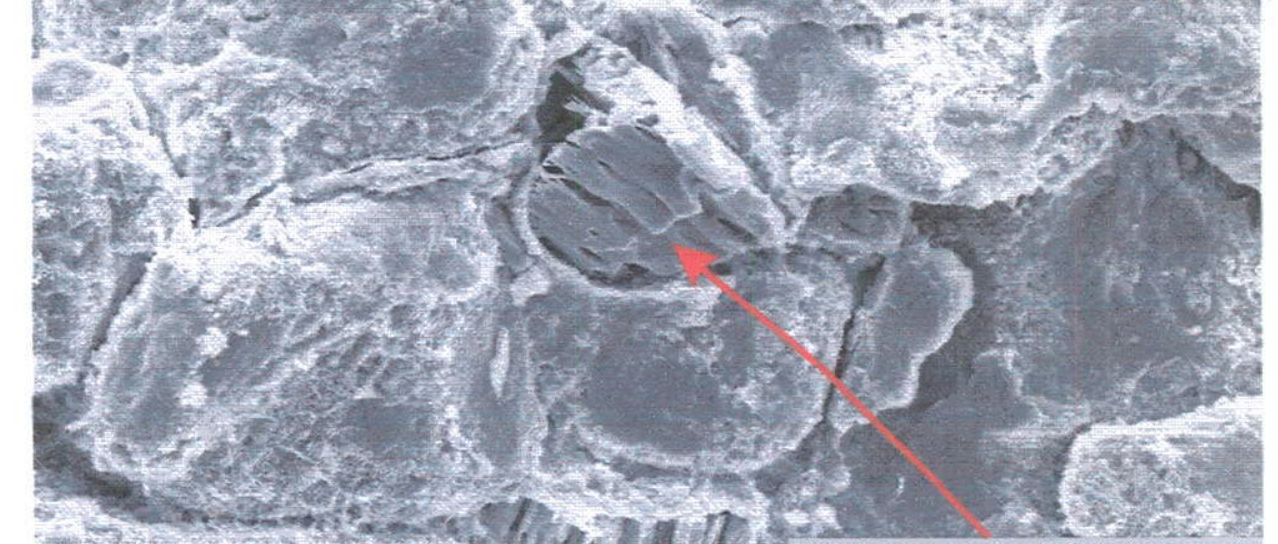

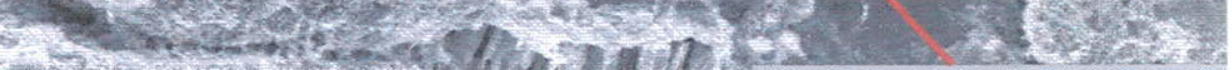

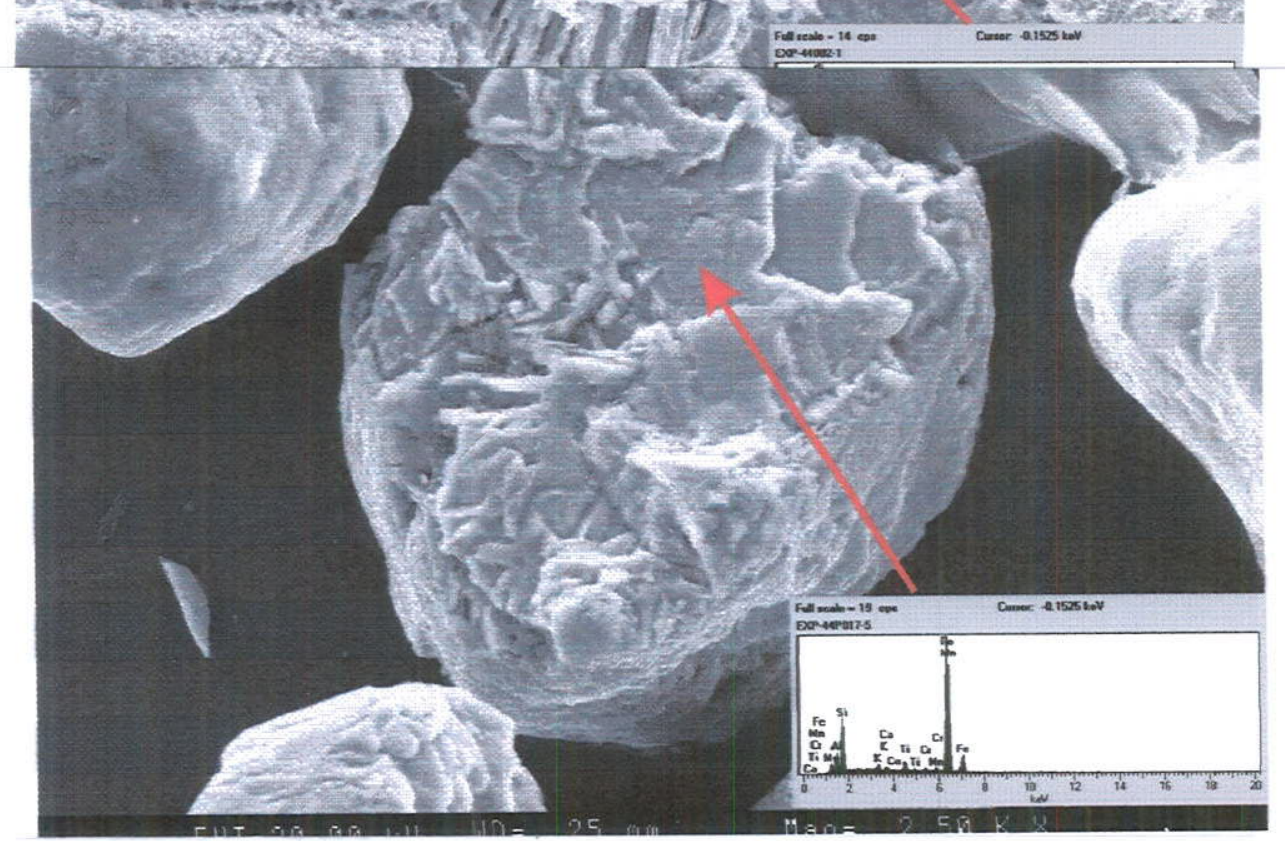


A tow

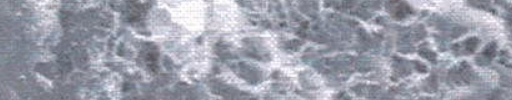

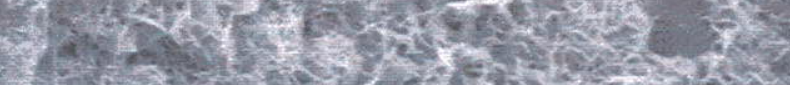

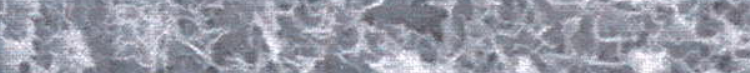

at $x$.

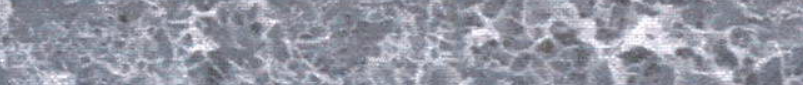

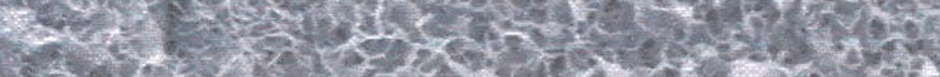

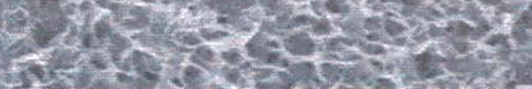

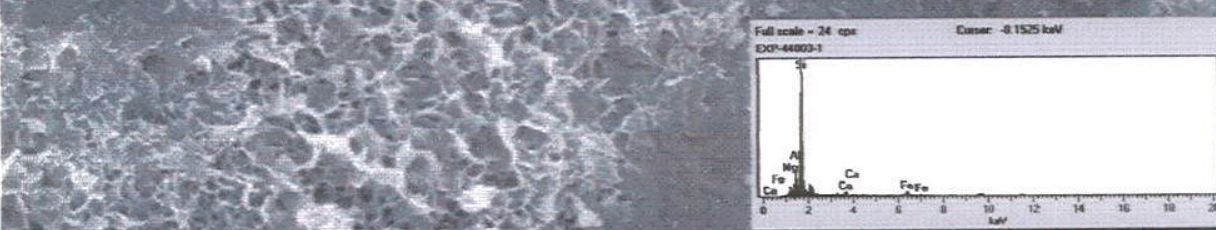
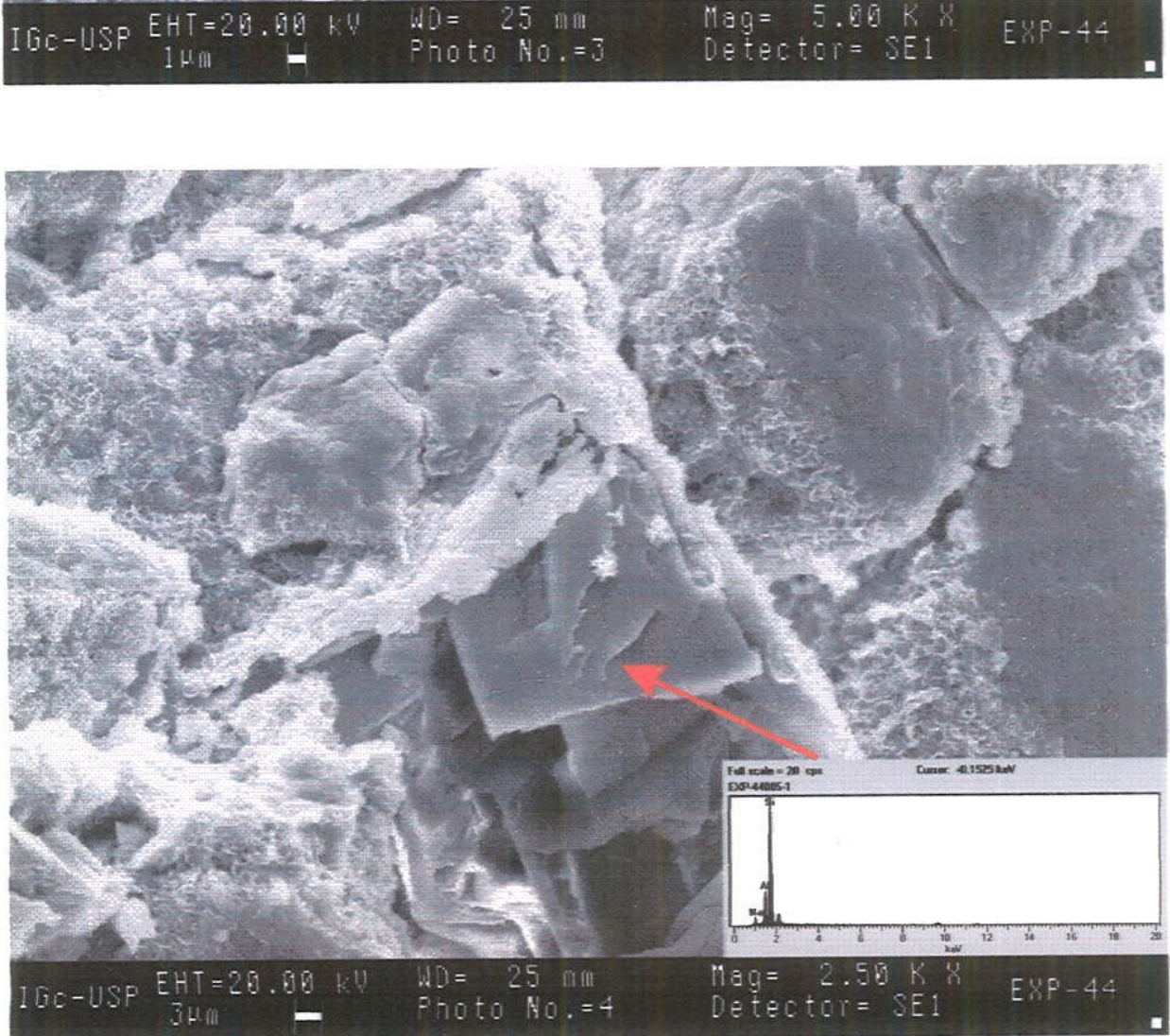

E

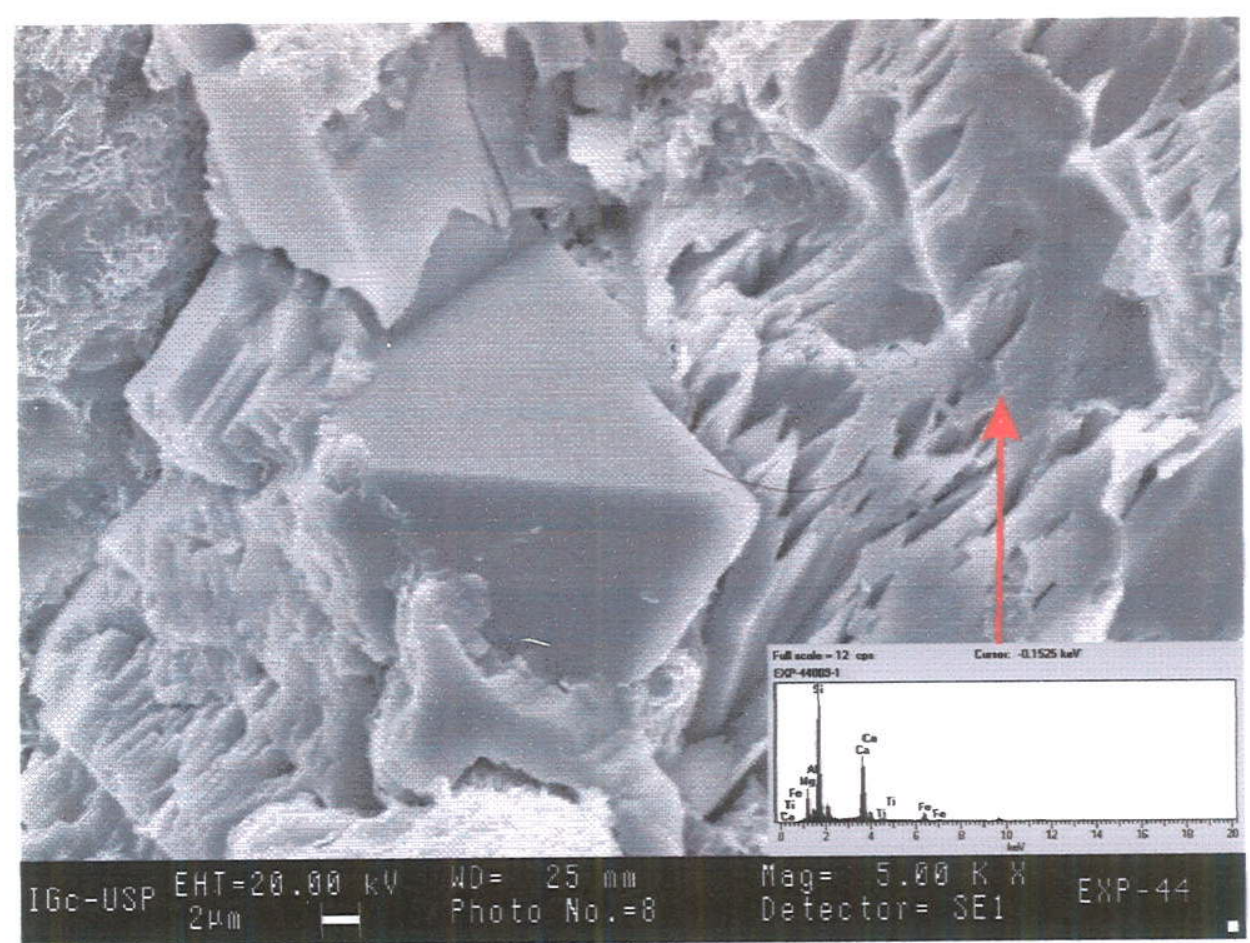

-

G

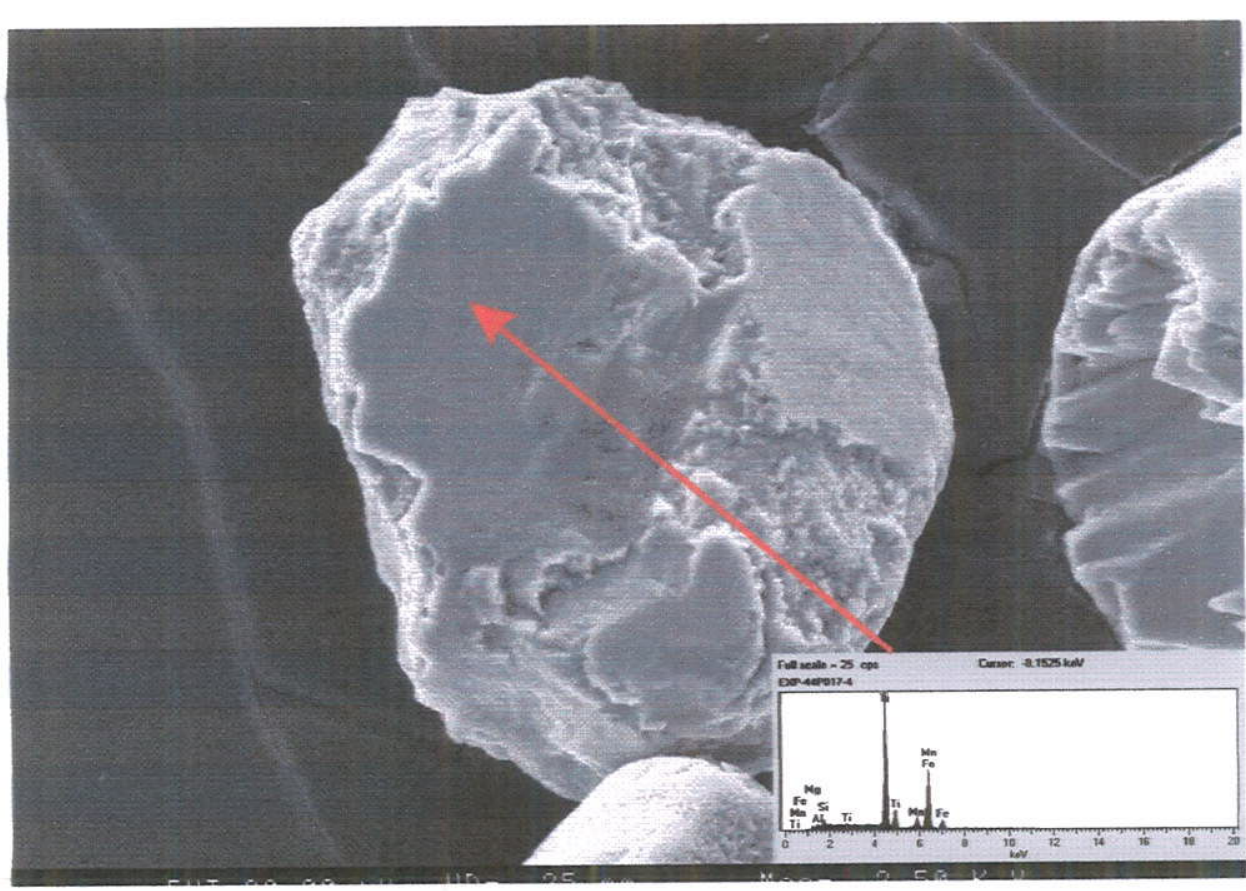

B

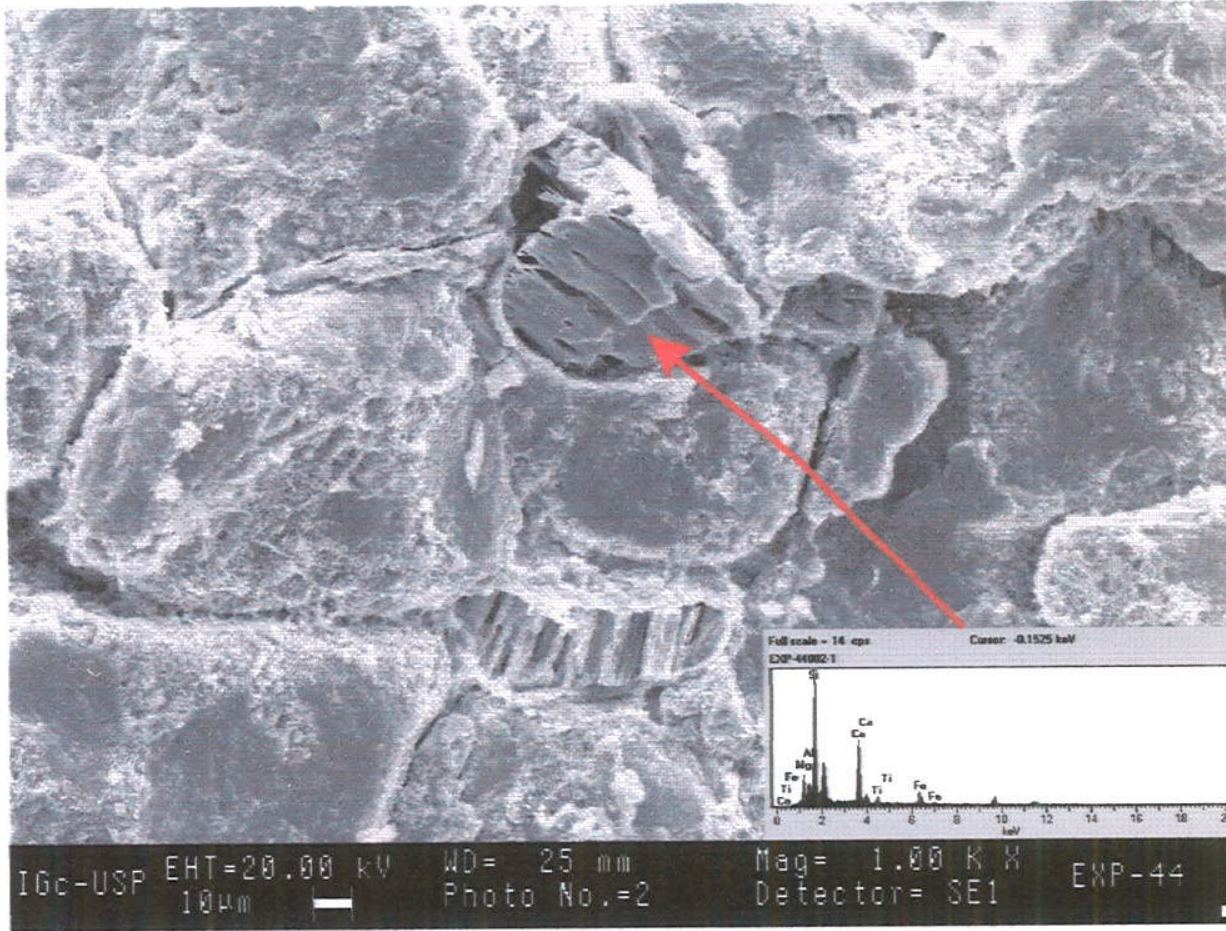

D
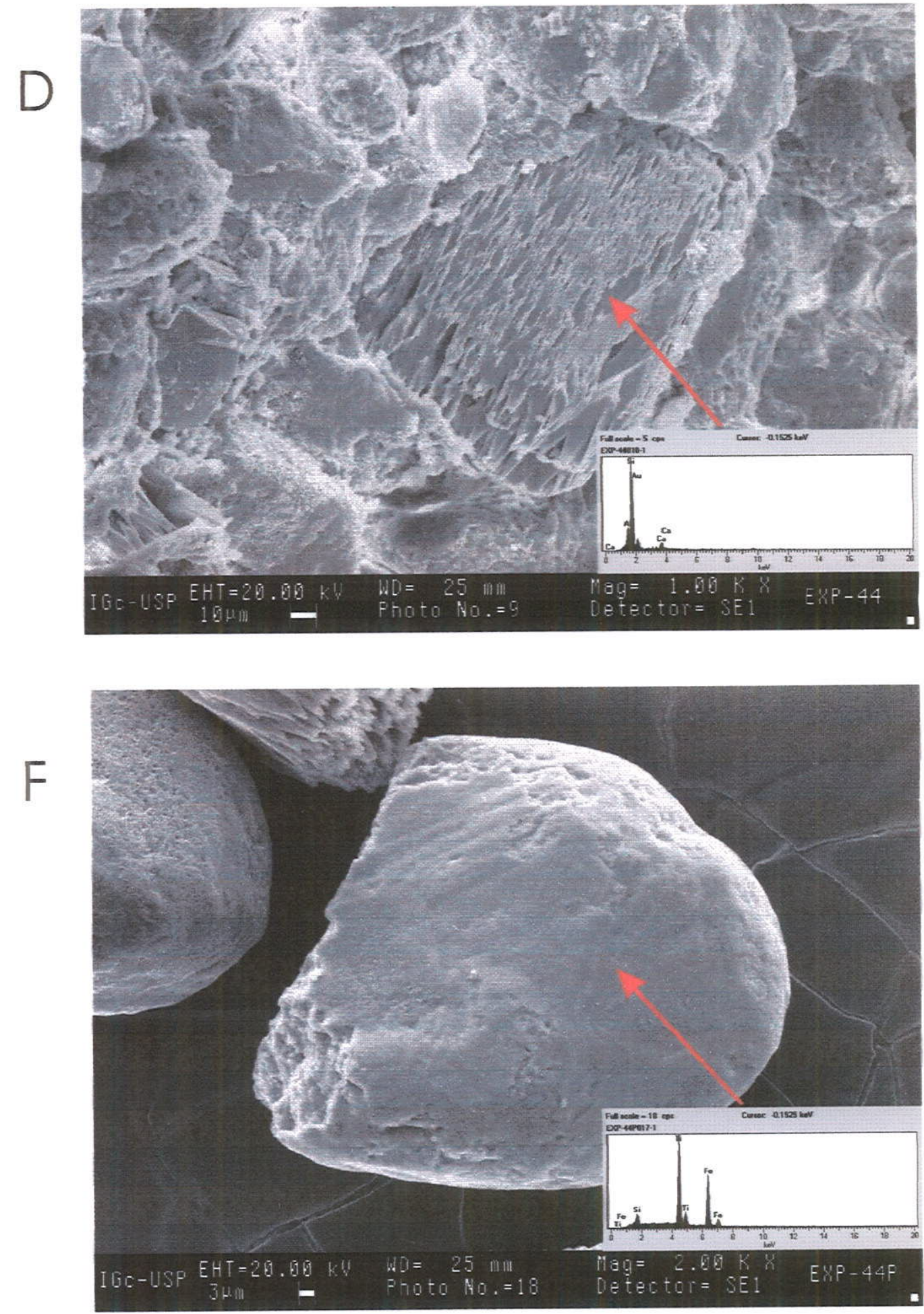

$\mathrm{H}$

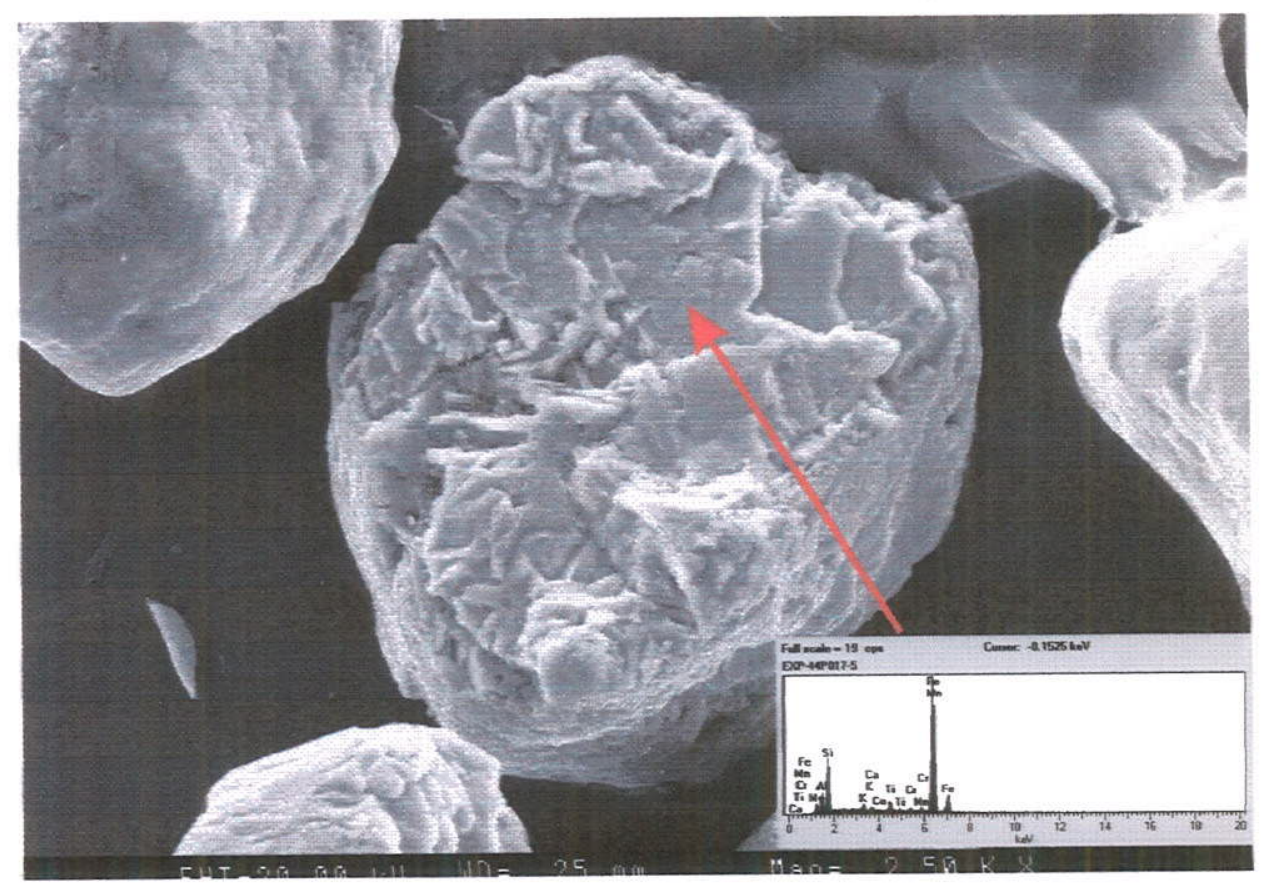


Foto A: Textura do argilomineral presente em toda amostra.

Foto B: Grão de anfibólio ou poroxênio com estrutura de corrosão.

Foto C: Grão de feldspato sódico.

Foto D: Grão de feldspato cálcico.

Foto $E$ : Grão de calcita ao lado de um anfibólio ou piroxênio.

Foto F: Grão de mineral pesado, provável ilmenita.

Foto G: Grão de mineral pesado composto por titânio, ferro e magnésio.

Foto $\mathrm{H}$ : Grão de mineral pesado composto por ferro e manganês.

Figura 7.7.: Imagens de microscopia eletrônica de varredura (MEV) e DES correspondente 


\subsubsection{Análise química por ICPIAES . Plasma}

As Figuras 7.8. 7.9. apresentam os resultados das análises totais de ICP/AES - Plasma em função da profundidade, para as perfurações EXP e ESC, respectivamente.

Os perfis das perfurações EXP e ESC apresentam comportamentos semelhantes. Ambos possuem larga predominância de $\mathrm{SiO}_{2}$, com médias de 76 a $78 \%$ em massa. $O \mathrm{Fe}_{2} \mathrm{O}_{3}$ e $\mathrm{Al}_{2} \mathrm{O}_{3}$ possuem porcentagens de massa semelhantes, porém no perfil EXP, o $\mathrm{Fe}_{2} \mathrm{O}_{3}$ é o segundo mais abundante (média de $5 \%$ em massa) seguido pelo $\mathrm{Al}_{2} \mathrm{O}_{3}$ ( $4 \%$ em massa), enquanto que no perfil ESC, $\circ \mathrm{Al}_{2} \mathrm{O}_{3}$ é o segundo mais abundante (10\% em massa), seguido pelo $\mathrm{Fe}_{2} \mathrm{O}_{3}\left(7 \%\right.$ em massa). As concentrações de $\mathrm{CaO}, \mathrm{MgO}, \mathrm{K}_{2} \mathrm{O}$ e $\mathrm{Na}_{2} \mathrm{O}$ são em geral muito baixas e em alguns casos estão bern próximas do limite de detecção do equipamento. Porém o CaO é o quarto mais abundante com médias de 3,0 a $3,5 \%$ em massa, seguido pelos $\mathrm{MgO}(1,5 \%), \mathrm{K}_{2} \mathrm{O}(1 \%)$ e $\mathrm{Na}_{2} \mathrm{O}(0,3 \%)$.

Nota-se nas Figuras 7.8. 7.9. que o $\mathrm{Fe}_{2} \mathrm{O}_{3}$ e $\mathrm{Al}_{2} \mathrm{O}_{3}$ tendem a diminuir com a profundidade demonstrando que as rochas mais profundas são menos alteradas que as mais rasas. Os cátions aumentam a partir de $18 \mathrm{~m}$ para a perfuração ESC e $30 \mathrm{~m}$ para a perfuração EXP, indicando que os niveis até essas profundidades são mais lixiviados. É possivel notar que quando há um aumento relativo de $\mathrm{SiO}_{2}$ há uma diminuição na porcentagem de cátions e viceversa. Esse fato pode ser explicado a partir da presença de niveis mais arenosos onde predominam grãos de quartzo que são ricos em sílica e pobres em cátions e niveis mais pobres em quartzo com maior diversidade de minerais e conseqüentemente mais ricos ern cátions.

No ponto EXP-44 (Figura 7.8.), observa-se que os valores obtidos para $\mathrm{SiO}_{2}, \mathrm{CaO}$ e MgO são bastante discordantes dos demais. Essa diferença pode ter sido causada pela forma de amostragem deste ponto, sendo este a única amostra indeformada do perfil. Porém apesar das duas formas de amostragem terem gerado dados de concentração diferentes, observa-se que as tendências das curvas dos gráficos apresentam uma certa lógica química, tornando as análises representativas do meio. 


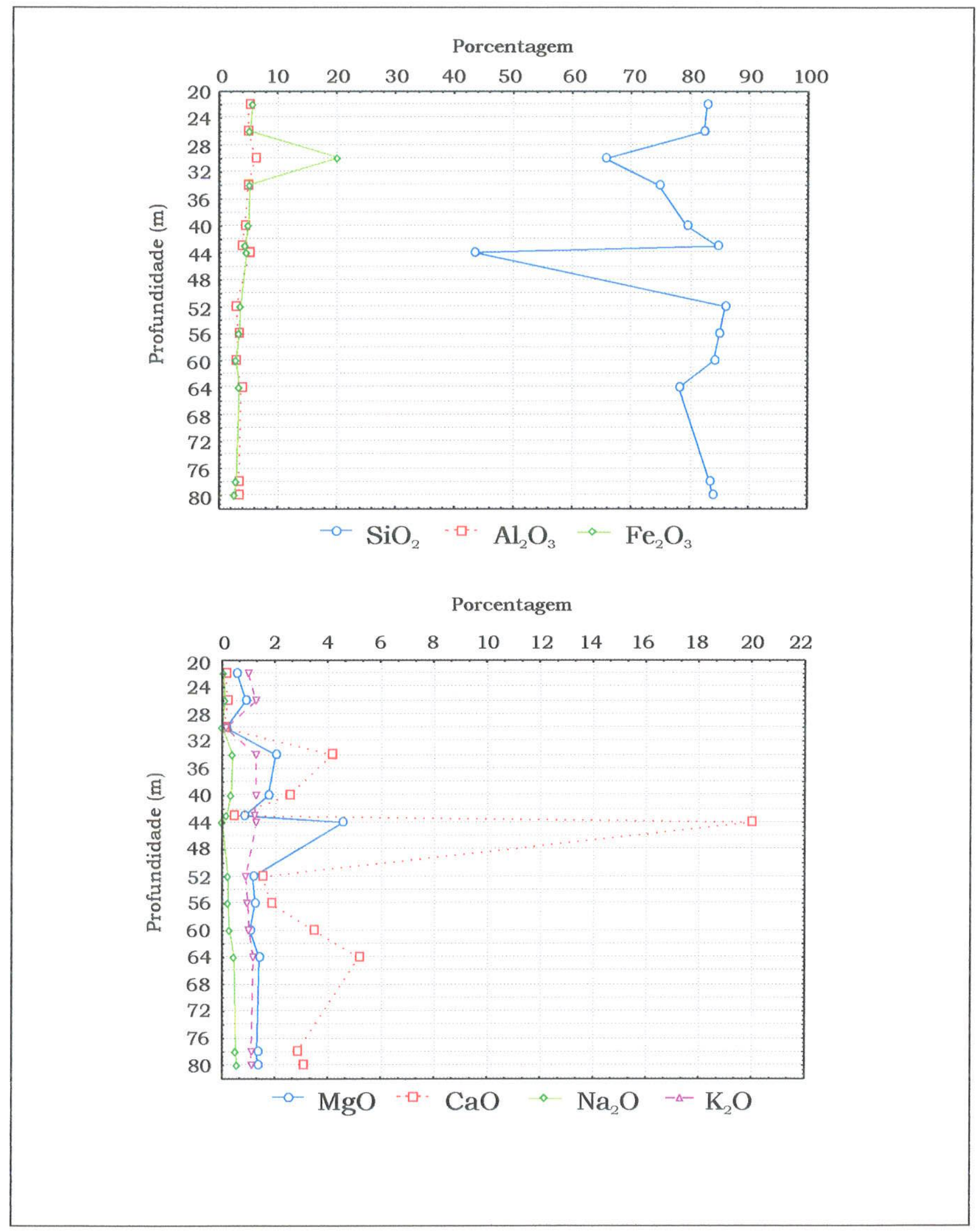

Figura 7.8.: Variação da composição química do perfil EXP com a profundidade 
Porcentagem

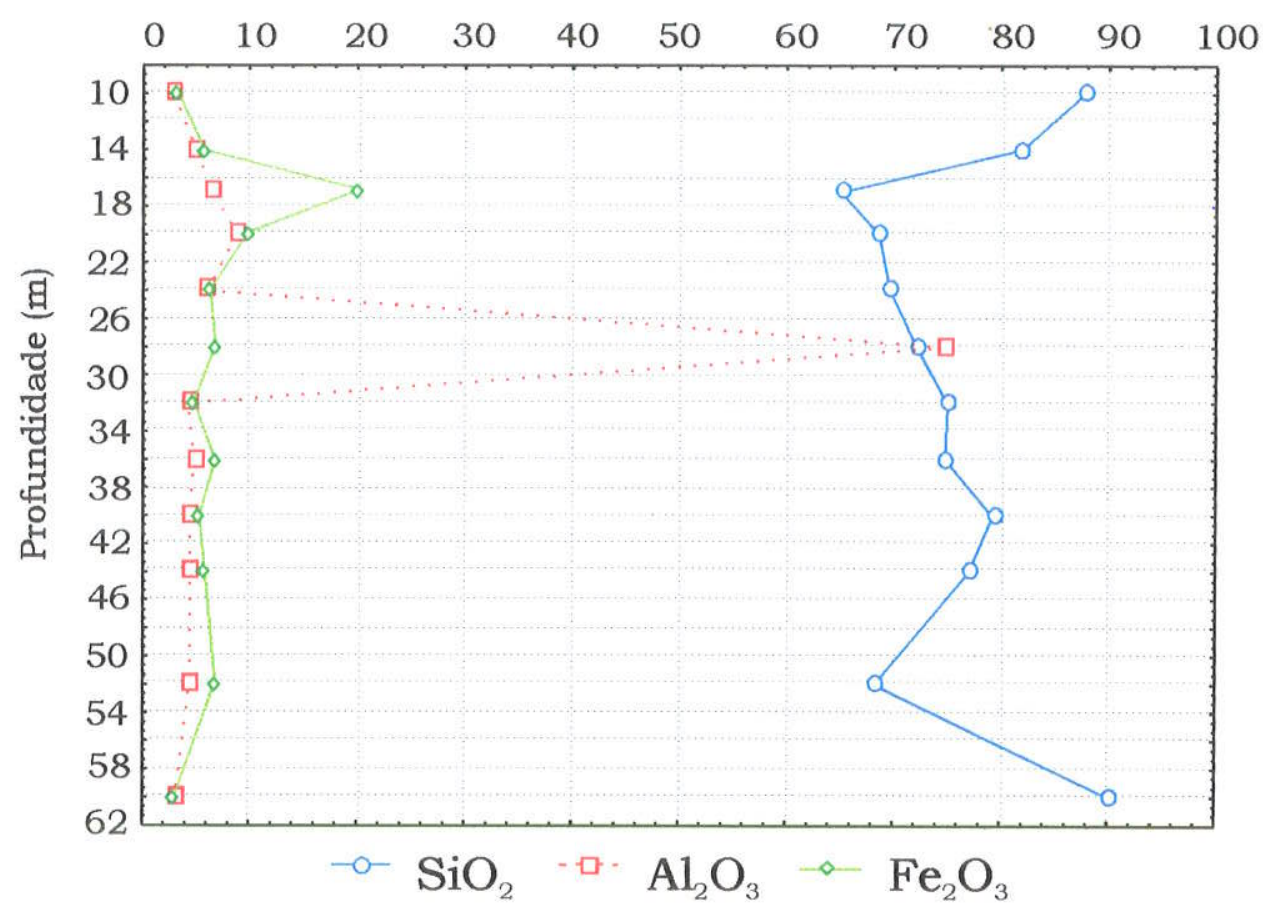

Porcentagem

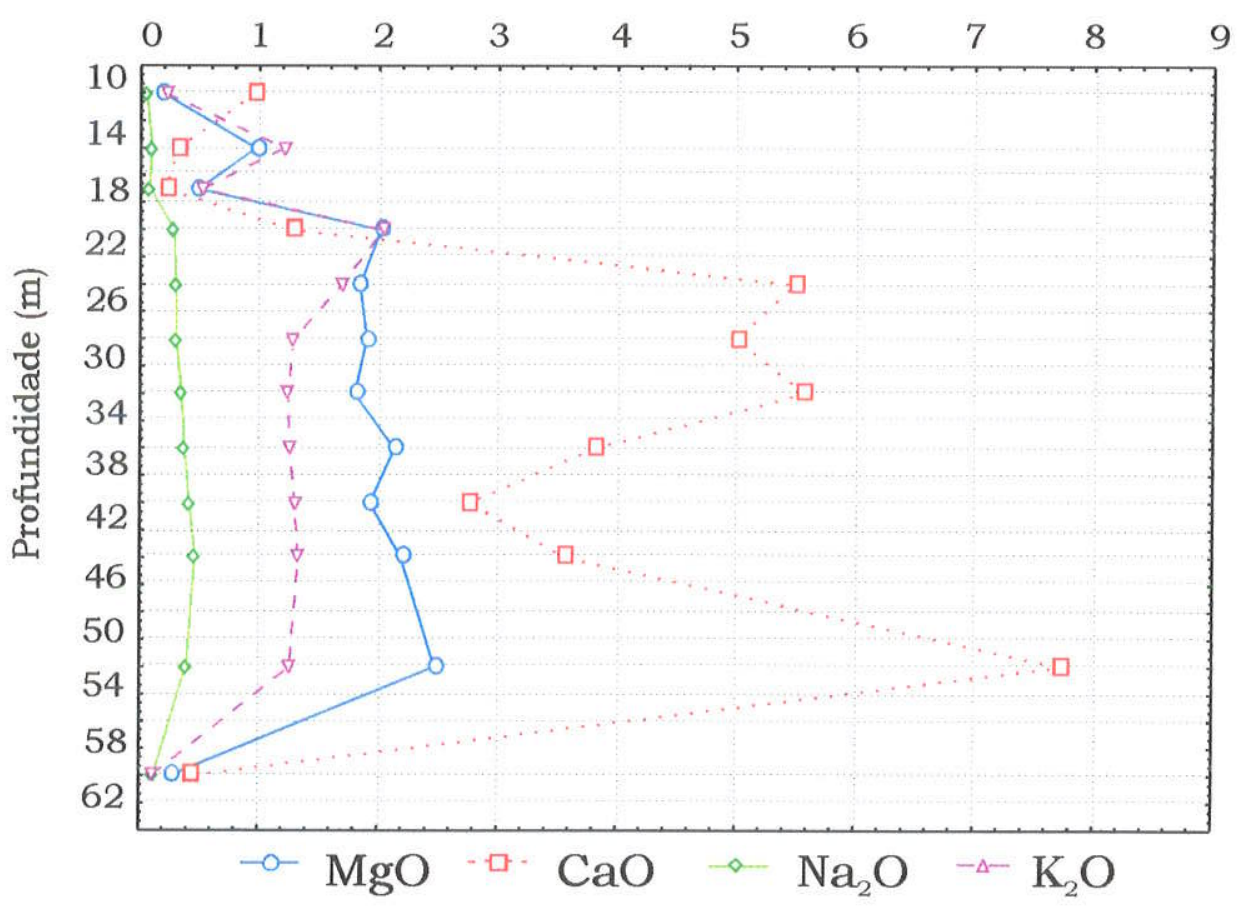

Figura 7.9.: Variação da composição química do perfil ESC com a profundidade 
As Tabelas 7.2. e 7.3. apresentam matrizes de correlação dos resultados de ICP/AES-Plasma para as perfurações EXP e ESC, respectivamente.

Nas duas matrizes de correlação é possível observar que existem correlações negativas do $\mathrm{SiO}_{2}$ com o $\mathrm{Al}_{2} \mathrm{O}_{3}$ e $\mathrm{Fe}_{2} \mathrm{O}_{3}$ indicando prováveis trocas entre esses elementos ou simples alteração dos minerais silicáticos, a $\mathrm{SiO}_{2}$ também apresenta correlação negativa com o $\mathrm{K}_{2} \mathrm{O}, \mathrm{CaO}, \mathrm{MgO}, \mathrm{Ba}$ e $\mathrm{Sr}$, ou seja, os intervalos quartzosos são pobres nesses elementos.

Ocorrem correlações positivas entre $\mathrm{Na}_{2} \mathrm{O}, \mathrm{CaO}, \mathrm{MgO}, \mathrm{K}_{2} \mathrm{O}, \mathrm{Ba}$ e $\mathrm{Sr}$, sendo que, esses elementos, com algumas exceções, possuem correlações positivas com $\circ \mathrm{Al}_{2} \mathrm{O}_{3}$ e negativas com $\circ \mathrm{Fe}_{2} \mathrm{O}_{3}$, indicando que eles estão associados a minerais aluminossilicáticos.

\begin{tabular}{|c|c|c|c|c|c|c|c|c|c|c|c|c|}
\hline & $\mathrm{SiO}_{2}$ & $\mathrm{Al}_{2} \mathrm{O}_{3}$ & $\mathrm{Fe}_{2} \mathrm{O}_{3}$ & $\mathrm{MgO}$ & $\mathrm{CaO}$ & $\mathrm{Na}_{2} \mathrm{O}$ & $\mathrm{K}_{2} \mathrm{O}$ & Mno & $\mathrm{TiO}_{2}$ & $\mathrm{Ba}$ & $\mathrm{Sr}$ & $\mathrm{Zr}$ \\
\hline $\mathrm{SiO}_{2}$ & 1,000 & $-0,617$ & $-0,373$ & $-0,741$ & $-0,836$ & 0,425 & 0,057 & 0,136 & 0,039 & 0,133 & $-0,733$ & 0,193 \\
\hline $\mathrm{Al}_{2} \mathrm{O}_{3}$ & & 1,000 & 0,733 & 0,102 & 0,152 & $-0,590$ & $-0,280$ & 0,232 & 0,474 & $-0,059$ & 0,073 & 0,429 \\
\hline $\mathrm{Fe}_{2} \mathrm{O}_{3}$ & & & 1,000 & $-0,311$ & $-0,180$ & $-0,497$ & $-0,821$ & $-0,272$ & 0,179 & $-0,432$ & $-0,295$ & 0,530 \\
\hline $\mathrm{MgO}$ & & & & 1,000 & 0,954 & $-0,021$ & 0,525 & 0,063 & $-0,087$ & 0,286 & 0,954 & $-0,483$ \\
\hline $\mathrm{CaO}$ & & & & & 1,000 & $-0,120$ & 0,349 & $-0,112$ & $-0,255$ & 0,042 & 0,953 & $-0,570$ \\
\hline $\mathrm{Na}_{2} \mathrm{O}$ & & & & & & 1,000 & 0,333 & $-0,240$ & $-0,377$ & 0,471 & 0,119 & $-0,408$ \\
\hline $\mathrm{K}_{2} \mathrm{O}$ & & & & & & & 1,000 & 0,623 & 0,170 & 0,683 & 0,472 & $-0,379$ \\
\hline MnO & & & & & & & & 1,000 & 0,763 & 0,513 & $-0,093$ & 0,364 \\
\hline $\mathrm{TiO}_{2}$ & & & & & & & & & 1,000 & 0,514 & $-0,239$ & 0,817 \\
\hline $\mathrm{Ba}$ & & & & & & & & & & 1,000 & 0,268 & 0,123 \\
\hline $\mathrm{Sr}$ & & & & & & & & & & & 1,000 & $-0,608$ \\
\hline $\mathrm{Zr}$ & & & & & & & & & & & & 1,000 \\
\hline
\end{tabular}




\begin{tabular}{|c|c|c|c|c|c|c|c|c|c|c|c|c|}
\hline & $\mathrm{SiO}_{2}$ & $\mathrm{Al}_{2} \mathrm{O}_{3}$ & $\mathrm{Fe}_{2} \mathrm{O}_{3}$ & $\mathrm{MgO}$ & $\mathrm{CaO}$ & $\mathrm{Na}_{2} \mathrm{O}$ & $\mathrm{K}_{2} \mathrm{O}$ & $\mathrm{MnO}$ & $\mathrm{TiO}_{2}$ & $\mathrm{Ba}$ & $\mathrm{Sr}$ & $\mathrm{Zr}$ \\
\hline $\mathrm{SiO}_{2}$ & 1,000 & $-0,205$ & $-0,700$ & $-0,555$ & $-0,447$ & $-0,359$ & $-0,602$ & $-0,533$ & $-0,337$ & $-0,576$ & $-0,465$ & 0,147 \\
\hline $\mathrm{Al}_{2} \mathrm{O}_{3}$ & & 1,000 & 0,031 & 0,174 & 0,233 & 0,080 & 0,147 & 0,458 & 0,249 & 0,201 & 0,121 & 0,292 \\
\hline $\mathrm{Fe}_{2} \mathrm{O}_{3}$ & & & 1,000 & $-0,102$ & $-0,242$ & $-0,230$ & 0,032 & 0,014 & $-0,083$ & $-0,062$ & $-0,219$ & $-0,175$ \\
\hline $\mathrm{MgO}$ & & & & 1,000 & 0,766 & 0,933 & 0,839 & 0,818 & 0,765 & 0,940 & 0,871 & 0,076 \\
\hline $\mathrm{CaO}$ & & & & & 1,000 & 0,733 & 0,469 & 0,500 & 0,503 & 0,677 & 0,955 & 0,091 \\
\hline $\mathrm{Na}_{2} \mathrm{O}$ & & & & & & 1,000 & 0,672 & 0,619 & 0,660 & 0,869 & 0,850 & 0,075 \\
\hline $\mathrm{K}_{2} \mathrm{O}$ & & & & & & & 1,000 & 0,836 & 0,534 & 0,912 & 0,572 & $-0,168$ \\
\hline Mno & & & & & & & & 1,000 & 0,782 & 0,787 & 0,552 & 0,173 \\
\hline $\mathrm{TiO}_{2}$ & & & & & & & & & 1,000 & 0,539 & 0,624 & 0,567 \\
\hline $\mathrm{Ba}$ & & & & & & & & & & 1,000 & 0,764 & $-0,172$ \\
\hline $\mathrm{Sr}$ & & & & & & & & & & & 1,000 & 0,094 \\
\hline $\mathrm{Zr}$ & & & & & & & & & & & & 1,000 \\
\hline
\end{tabular}

\subsubsection{Análise de capacidade de troca catiônica, pH e matéria orgânica}

As Figuras 7.10. e 7.11. apresentam os resultados das análises de capacidade de troca de cátions (CTC) e dos principais cátions formadores de CTC em função da profundidade, para as perfurações EXP e ESC, respectivamente.

Observa-se na Figura 7.10. que a CTC tende a aumentar até a profundidade de $44 \mathrm{~m}$, diminui de $44 \mathrm{~m}$ para $52 \mathrm{~m}$, aumenta novamente até $64 \mathrm{~m}$ e diminui novamente. Os cátions $\mathrm{Ca}, \mathrm{Mg}, \mathrm{K}$ e $\mathrm{Na}$ possuem o mesmo comportamento da curva de CTC, enquanto o $\mathrm{Na}$ apresenta essa semelhança apenas até a profundidade de $64 \mathrm{~m}$. O principal cátion adsorvido é o Ca, seguido pelo $\mathrm{Mg}, \mathrm{H}, \mathrm{Na}$ e K. A matéria orgânica apresenta concentração de $5 \mathrm{~g} / \mathrm{dm}^{3}$ na profundidade de $22 \mathrm{~m}$ passando a $3 \mathrm{~g} / \mathrm{dm}^{3}$ a $26 \mathrm{~m}$ e finalmente para $2 \mathrm{~g} / \mathrm{dm}^{3}$ a $30 \mathrm{~m}$, mantendo-se constante até o final do perfil. $\mathrm{O} \mathrm{pH}$ tende a aumentar do início ao final do perfil passando de 5,2 a 7,3. 
Na profundidade de $44 \mathrm{~m}$ ocorre um aumento significativo de CTC e das concentrações $\mathrm{Ca}, \mathrm{Mg}, \mathrm{Na}$ e $\mathrm{K}$. Esse ponto representa à única amostra indeformada coletada em todo o perfil, desta forma acredita-se que a diferença na forma de coleta das amostras deve ter influenciado o resultado.

A Figura 7.10. mostra que no perfil da perfuração ESC a CTC aumenta até a profundidade de $20 \mathrm{~m}$ e depois tende a diminuir em direção à profundidade de $60 \mathrm{~m}$. As curvas dos cátions $\mathrm{Ca}, \mathrm{Mg}$, $\mathrm{Na}$ e $\mathrm{K}$ possuem o mesmo comportamento da curva de CTC. O Al permanece constante ao longo de todo o perfil, com concentração de $0,03 \mathrm{meq} / 100 \mathrm{~g}$. O H aumenta até a profundidade de $17 \mathrm{~m}$ e depois tende a diminuir com valores que variam de 0,57 a 0,67 meq $/ 100 \mathrm{~g}$. Como no perfil da perfuração EXP, o principal cátion adsorvido é o $\mathrm{Ca}$, seguido pelo $\mathrm{Mg}, \mathrm{H}, \mathrm{Na}$ e $\mathrm{K}$. O pH máximo do solo a $10 \mathrm{~m}$ é de 7,3 abaixando para o mínimo de 6,2 a $14 \mathrm{~m}$ e variando entre 7,1 e 7,5 até o final do perfil. A concentração de matéria orgânica permaneceu constante ao longo de todo o perfil, com valor de $2 \mathrm{~g} / \mathrm{dm}^{3}$.

No perfil da perfuração EXP os valores de CTC variam ao redor de 6,7 a $32,3 \mathrm{meq} / 100 \mathrm{~g}$ enquanto que na ESC variam de 3,1 a $25,1 \mathrm{meq} / 100 \mathrm{~g}$. Levandose em conta que toda a CTC é atribuída à fração fina dos sedimentos, e que esta fração corresponde a $19 \%$ da massa total dos sedimentos, calcula-se que a ordem da CTC na fração fina varia de 32 a 169,6 meq/100g na perfuração EXP e de 16,5 a 132,1 meq/100g na ESC. Esses valores de CTC indicam que o provável material adsorvente tem que possuir uma capacidade de troca de cátions entre 16 e $170 \mathrm{meq} / 100 \mathrm{~g}$. Comparando estes valores com os encontrados na literatura, conclui-se que a partir dos minerais descritos na rocha, a montmorilonita é o que melhor se encaixa, sendo ela o principal material adsorvente no meio físico. 
Concentração (meq/100g) ou unidade de pH
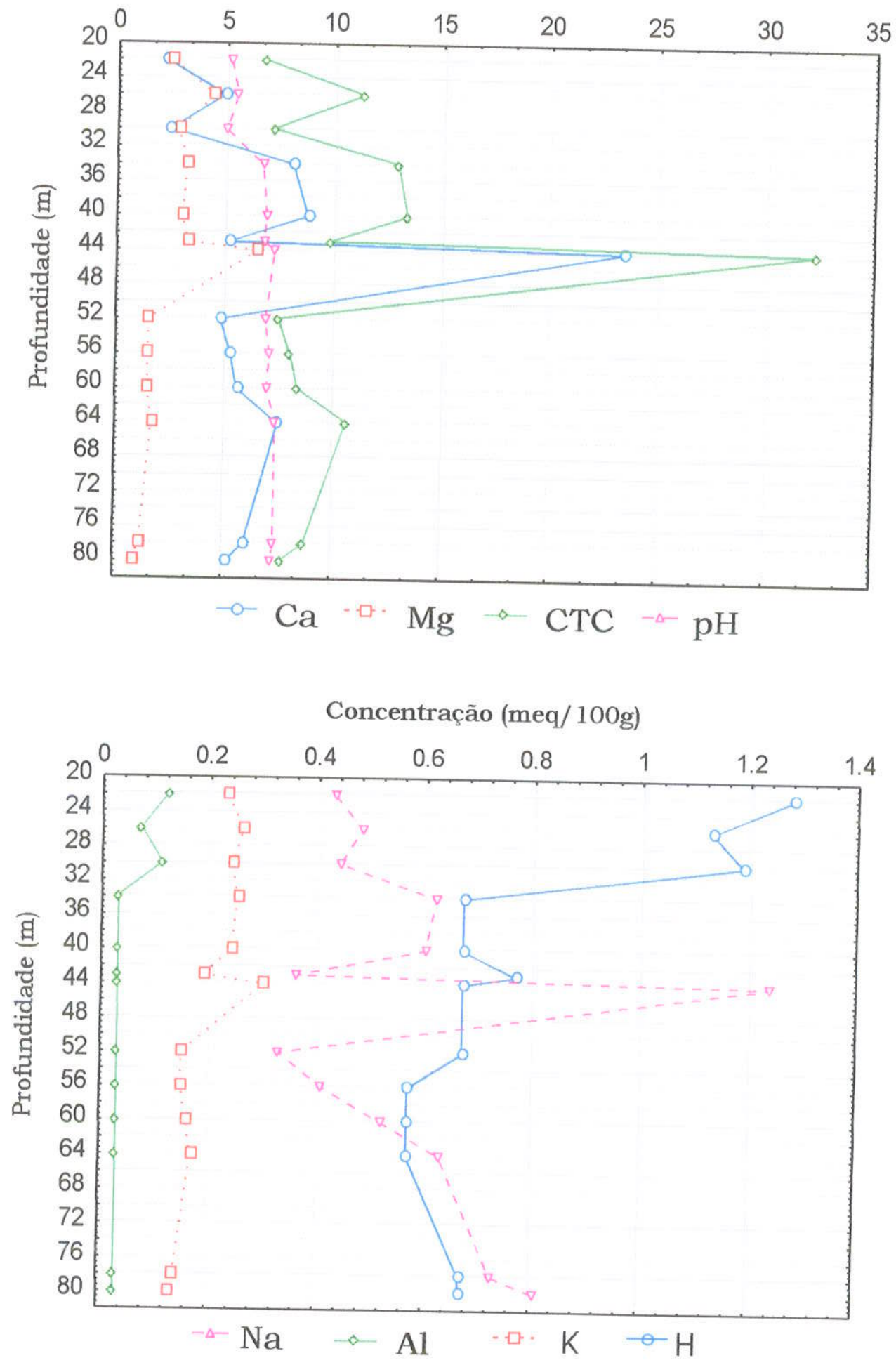

Figura 7. 10::Resultados da análise de CTC na perfuração EXP 

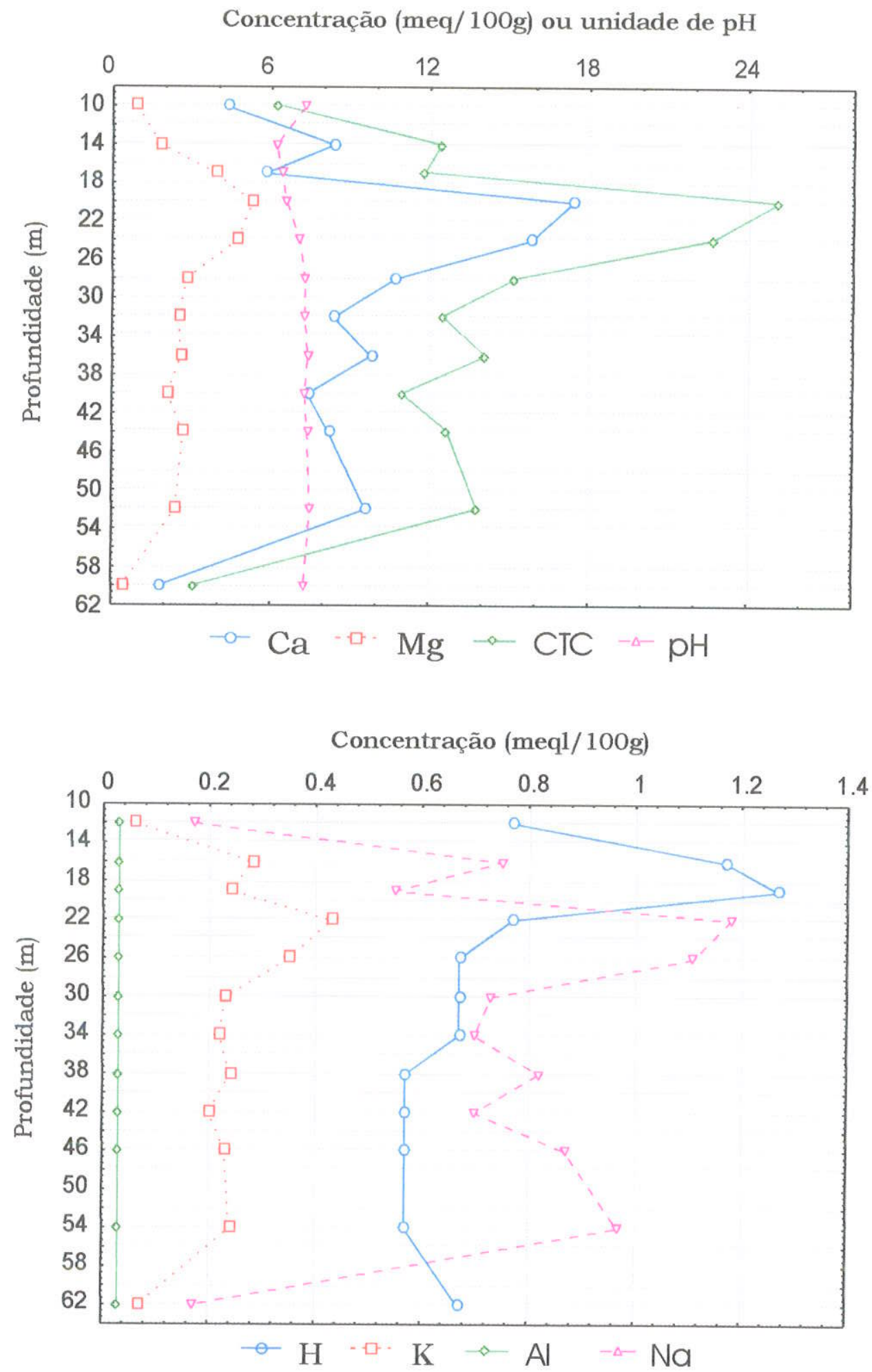

Figura 7.1 1.:Resultados da análise de CTC na perfuração ESC 
As Figuras 7.12. e 7.13. apresentam uma normalização das concentrações dos cátions adsorvidos em relação a CTC ao longo dos perfis EXP e ESC, respectivamente.

Observa-se que na Figura 7.12. a relação $\mathrm{Ca} / \mathrm{CTC}$ tende a aumentar em direção ao fim do perfil, enquanto que a Mg/CTC, a K/CTC, a Al/CTC e a H/CTC possuem comportamentos contrários, indicando uma provável troca desses elementos. A relação $\mathrm{Na} / \mathrm{CTC}$ apresenta comportamento semelhante às relações $\mathrm{Mg}, \mathrm{K}$ e Al/CTC até a profundidade de $43 \mathrm{~m}$, onde a partir do qual apresentas pontos com comportamento contrário. A partir de $64 \mathrm{~m}$ observa-se que o Mg/CTC mostra tendência oposta aos demais parâmetros.

O comportamento das relações entre cátions e CTC para o perfil de perfuração ESC pode ser observado na Figura 7.13., onde também é possivel notar trocas catiônicas do $\mathrm{Ca}$ e $\mathrm{Na}$ com $\mathrm{OH}, \mathrm{Mg}, \mathrm{Al}$ e $\mathrm{K}$, ao longo de mais de $60 \%$ dos pontos analisados.

As Tabelas 7.4. e 7.5. ilustram as matrizes de correlação entre as análises de CTC nas perfurações EXP e ESC. Nota-se que existem correlações positivas entre os cátions trocáveis (cálcio, potássio, magnésio e sódio) e a CTC. $\mathrm{O}$ pH possui correlação negativa com $\circ \mathrm{H}, \mathrm{Al}$ e a matéria orgânica, que por sua vez têm correlação positiva com o $\mathrm{H}$ e o Al. Não foram observadas correlações entre a matéria orgânica e a CTC ou cátions adsorvidos.

\begin{tabular}{|c|c|c|c|c|c|c|c|c|c|}
\hline & MO & $\mathrm{pH}$ & K & $\mathrm{Ca}$ & Mo & & & & \\
\hline MO & 1,000 & & & & & $H$ & Al & CTC & $\mathrm{Na}$ \\
\hline $\mathrm{pH}$ & & & & $-0,290$ & 0,091 & 0,728 & 0,735 & $-0,148$ & $-0,228$ \\
\hline $\mathrm{K}$ & & & $-0,474$ & 0,453 & $-0,22 \uparrow$ & $-0,955$ & $-0,936$ & 0,264 & 0,447 \\
\hline $\mathrm{Ca}$ & & & 1,000 & 0,500 & 0,906 & 0,466 & 0,379 & 0,662 & 0,322 \\
\hline $\mathrm{Mg}$ & & & & 1,000 & 0,706 & $-0,378$ & $-0,412$ & 0,974 & 0,854 \\
\hline$H$ & & & & & 1,000 & 0,265 & 0.125 & 0,843 & 0,473 \\
\hline $\mathrm{Al}$ & & & & & & 1,000 & 0,950 & $-0,186$ & $-0,303$ \\
\hline CTC & & & & & & & 1,000 & $-0,254$ & $-0,312$ \\
\hline $\mathrm{Na}$ & & & & & & & & 1,000 & 0,800 \\
\hline & & & & & & & & & 1,000 \\
\hline
\end{tabular}



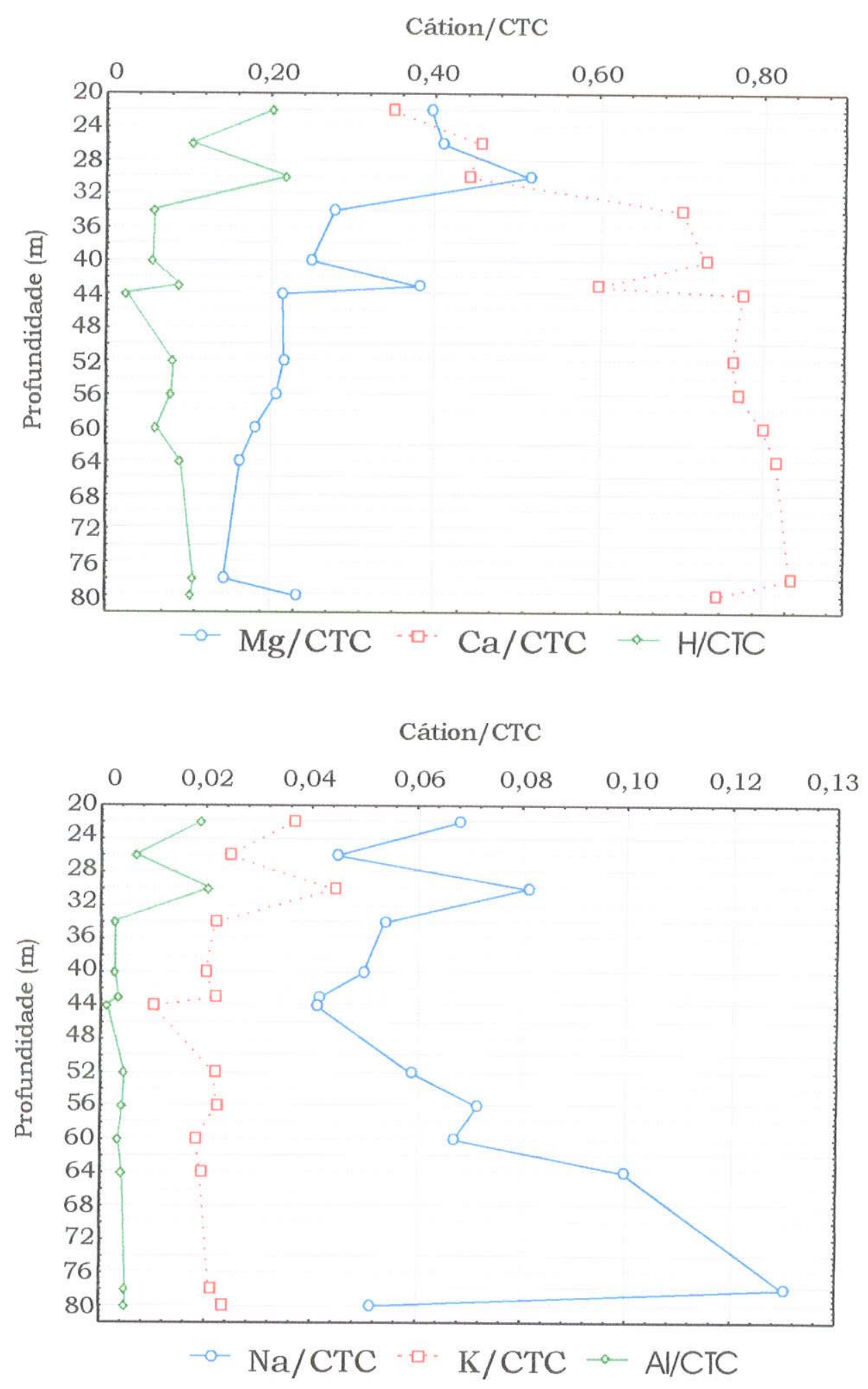

Figura 7.12.: Relação entre íons adsorvidos e CTC na perfuração EXP 
Cátion/CTC

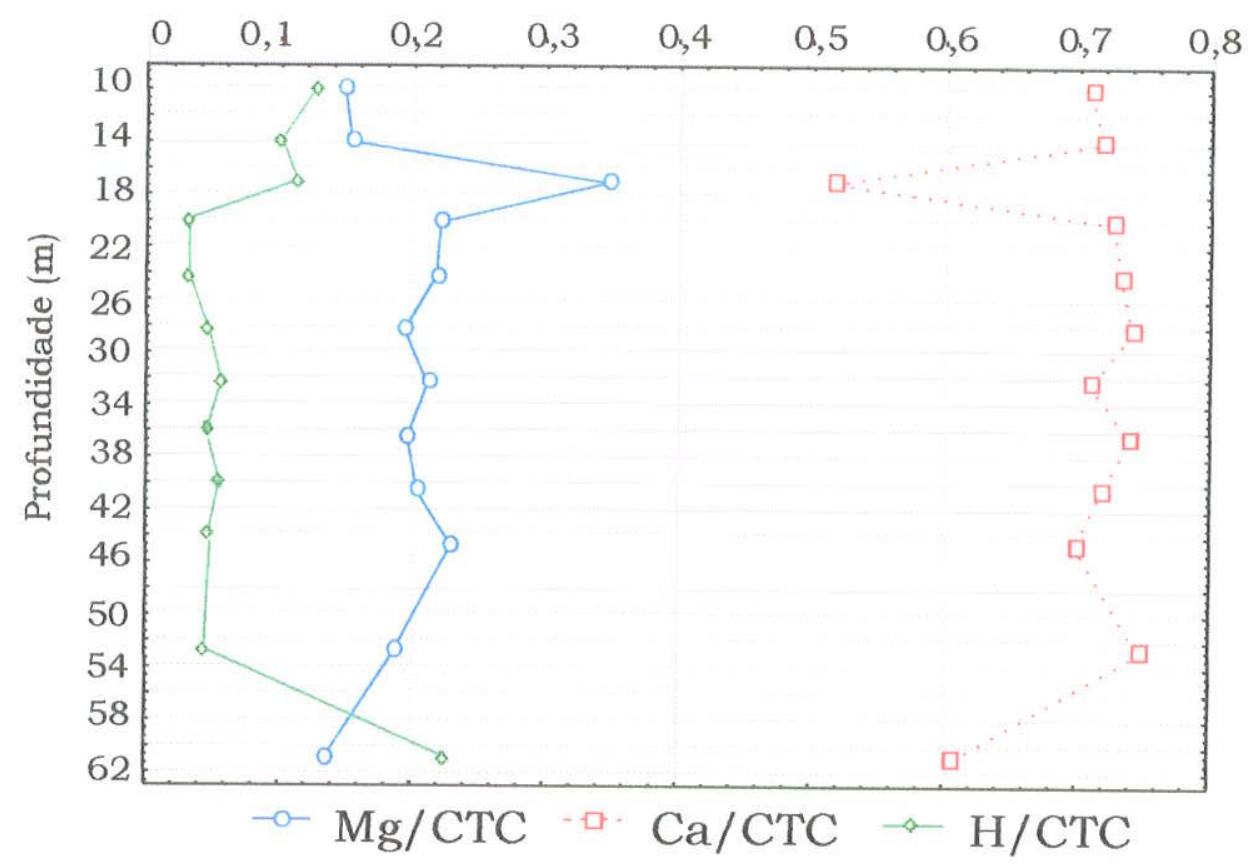

Cátion/CTC

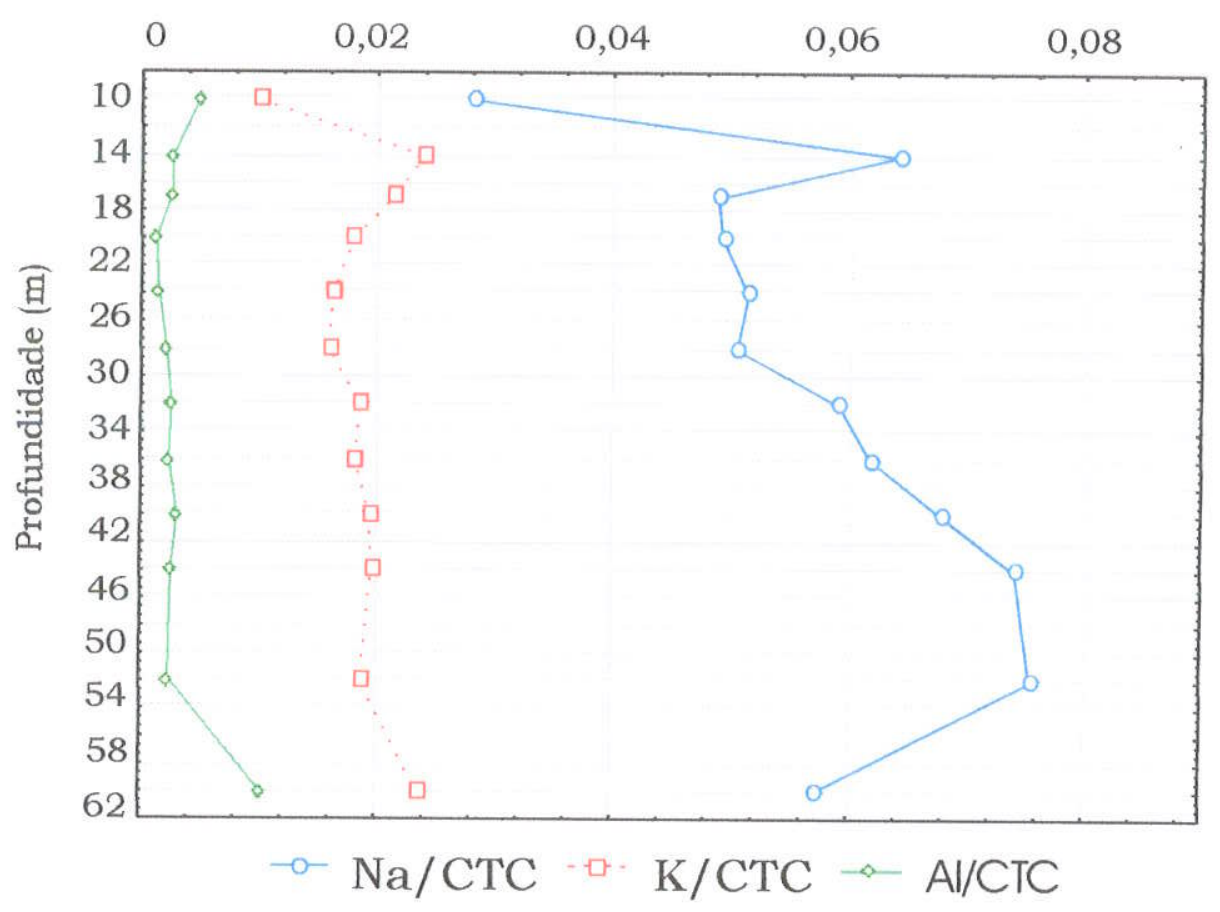

Figura 7.13.: Relação entre íons adsorvidos e CTC na perfuração ESC 


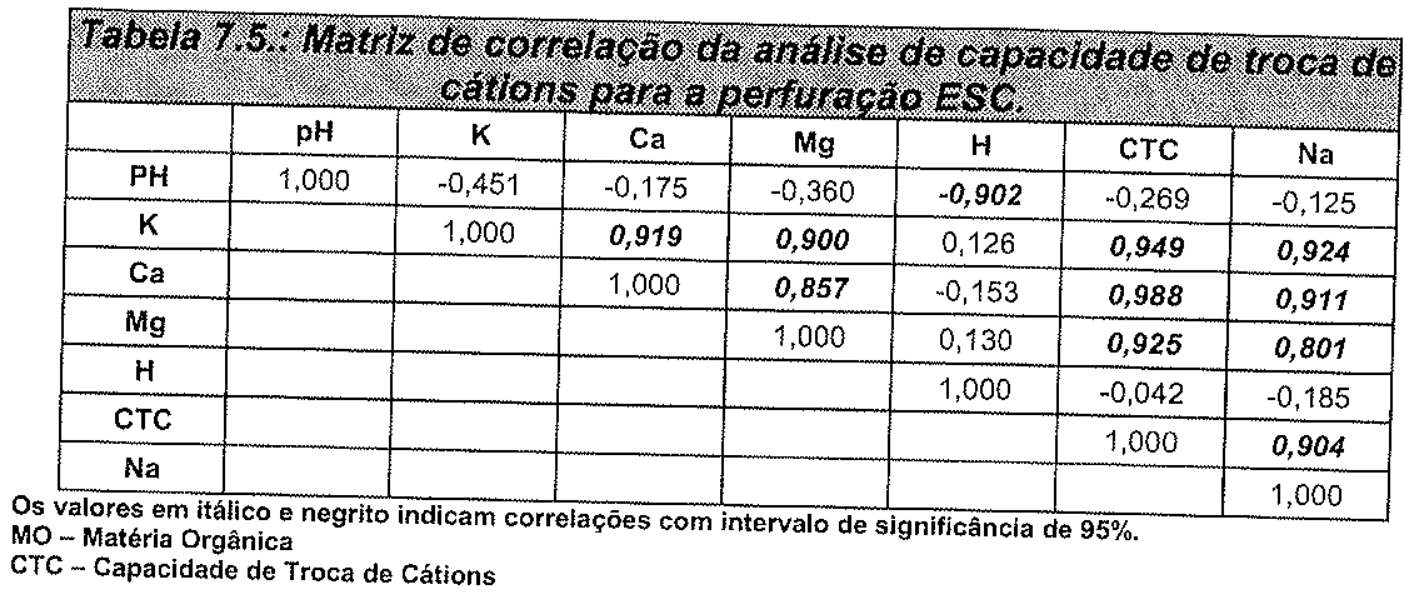

\subsection{Caracterização da água subterrânea}

O Anexo 3 apresenta os resultados das análises químicas para as seis campanhas realizadas ao longo de três anos. Nessas campanhas foram coletadas amostras dos poços cacimbas (PC) de baixa profundidade representando a zona de águas rasas e de recarga $(Z R)$, tubulares profundos da SABESP (PP) de zonas profundas ou de descarga $(Z P)$ e tubulares particulares com profundidades e zonas intermediárias $(\mathrm{ZI})$ aos outros dois citados anteriormente.

Na primeira campanha de amostragem (junho/1998) não foi analisada a alcalinidade nos poços cacimbas e nos poços tubulares particulares, representantes das zonas rasa e intermediária, respectivamente. Enquanto que apenas nas últimas três campanhas (junho/1999, abril/2000 e outubro/2000) foram coletadas amostras de sílica $\left(\mathrm{SiO}_{2}\right)$.

Em março/1999 foram efetuadas amostragens em diferentes tempos de bombeamento nos poços PP-2 e PP-4 e amostras estratificadas (em profundidades determinadas) nos PP-1, PP.6 e PP-8. Na campanha de maio/1999 foram feitas coletas em diferentes tempos de bombeamento, durante 24 horas, nos poços PP-2 e PP-4 e limpeza com coleta estratificada nos poços PP-6 e PP-8. 
Em setembro de 2001 foram coletadas amostras de silica após filtragem em membranas de $0,2 \mu \mathrm{m}$ e $0,1 \mu \mathrm{m}$, para checagem dos resultados coletados anteriormente.

\subsubsection{Resultados das análises físico-químicas}

O Anexo 3 apresenta os resultados das análises químicas de águas e o Anexo 4 os resultados estatísticos básicos destas análises.

Observa-se no Anexo 3 que em geral as amostras de água possuem temperaturas elevadas. Os poços cacimbas (PC) apresentam as maiores temperaturas, seguido pelos poços tubulares (PT) e profundos da SABESP (PP). Ocorrem variações de temperaturas da água subterrânea ao longo das estações do ano, onde elas tende a aumentar no verão e diminuir no inverno, com variações de 13 a $36^{\circ} \mathrm{C}$ e média de $26^{\circ} \mathrm{C}$, especialmente nos poços mais rasos. As maiores temperaturas foram detectados nos poço rasos (PC's) que encontram-se fechados e com uma maior incidência do sol.

O Eh medido em campo apresenta valores médios de 498,7 mi para poços da zona rasa $(Z R), 476,9 \mathrm{mV}$ para poços tubulares particulares da zona intermediária $(Z \mid)$ e $456,4 \mathrm{mV}$ para os poços profundos da SABESP da zona profunda ou de descarga ( $Z P$ ), refletindo um ambiente oxidante para o meio em todo o período monitorado. Nota-se uma diminuição dos valores médios de Eh com a profundidade, porém não são observadas variações temporais, a exceção da última campanha (outubro de 200) que possui valores mais baixos para as três zonas indicando um provável erro de medição.

Ao contrário do Eh, o pH possui um aumento com a profundidade, apresentando valores médios de 5,7 para a zona rasa, 6,5 para a zona intermediária e 7,5 para a zona profunda ou de descarga. A condutividade elétrica (CE) tende a diminuir com a profundidade com valores médios de 225,9 $\mu \mathrm{S} / \mathrm{cm}$ para a $Z R, 213,7 \mu \mathrm{S} / \mathrm{cm}$ para a $\mathrm{Zl}$ e $195,5 \mu \mathrm{S} / \mathrm{cm}$ para a $Z \mathrm{P}$ refletindo uma diminuição de sais dissolvidos das águas rasas para as profundas. Tanto $\circ \mathrm{pH}$ quanto a CE não apresentam variações temporais. 
Nos gráficos e tabelas do Anexo 4 foram calculados os parâmetros estatísticos dos três tipos de poços e suas respectivas zonas para cada campanha de amostragem. Observa-se que para alguns parâmetros o desvio padrão possui valores semelhantes à média, indicando grande variação da concentração do parâmetro na campanha de amostragem. Dos íons o sulfato, o cloreto, o cálcio, o sódio, o fosfato e o flúor são os que mais sofrem variações nas concentrações para a mesma campanha de amostragem.

A partir deste resultado constatou-se que a média não é o valor mais representativo da concentração dos íons em uma determinada campanha e sua utilização torna inconsistente o estudo hidroquímico. Desta forma achou-se necessário à realização de histogramas a fim de se descobrir qual o valor estatístico mais representativo, sendo então confeccionados os histogramas presentes no Anexo 4, onde devido à insuficiência de dados não é possível identificar um padrão. Contudo, as interpretações sobre a evolução dos íons serão feitas a partir do diagrama de Piper e perfis de isoconcentração para cada ion em cada evento de amostragem.

Ainda com relação aos dados das análises químicas do Anexo 3, observa-se que os metais pesados chumbo, cádmio e prata não foram detectados em nenhuma das análises realizadas. Além destes elementos, o nitrito, brometo, ferro total, manganês, alumínio, níquel, zinco, cobre e cromo total foram raramente detectados nas análises e na major parte das vezes muito próximos ou até mesmo abaixo dos limites de detecção. Assim sendo, todos os elementos citados anteriormente não são analisados nas considerações hidrogeoquímicas que se seguem. O fosfato, o bário, o estrôncio e sulfato foram freqüentemente detectados, porém com valores próximos ao limite de detecção. 


\subsubsection{Classificação hidrogeoquímica}

A classifjcação hidrogeoquímica foi feita a partir do diagrama de classificação do tipo Piper para cada campanha de amostragem. A Figura 7.14. mostra a localização das amostras de água analisadas nos diagramas para cinco dos seis eventos de amostragem, uma vez que a primeira amostragem (junho de 1998) não pode ser representada pois não foi analisado o parâmetro alcalinidade.

Observa-se no triângulo dos ânions, que o ín mais abundante nas águas rasas $(Z R)$ é o cloreto, nas águas mais profundas e de descarga (ZP) é o bicarbonato e nas águas intermediárias (ZI) há uma mistura de cloreto e bicarbonato, mas ocorre uma concentração maior de pontos no lado das águas bicarbonatadas. Para os cátions observa-se que nas águas mais rasas ocorre o predomínio do sódio porém também são observados pontos na parte cálcica, nas águas intermediárias há predomino de cálcio e nas águas profundas e de descarga ocorre uma mistura entre o cálcio e o sódio, porém ocorre um predomínio de pontos na parte cálcica. Ainda em correlação aos cátions, nota-se que as água cálcicas possuem maior concentração de magnésio que as sódicas.

Analisando o losango do diagrama de Piper, com algumas exceções, é possivel dizer que as águas intermediárias e rasas mais sódicas tendem a ser mais cloretadas e as mais cálcicas tendem a ser mais bicarbonatada. As águas profundas e de descarga sódicas e cálcicas tendem a ser sempre bicarbonatadas.

Pelos diagramas é possivel identificar três fácies hidrogeoquímicas distintas correlacionada com a profundidade do poço. As águas mais rasas da zona de recarga são classificadas como cloretadas cálcica e secundariamente cloretadas sódicas, as águas da zona intermediária são predominantemente bicarbonatadas cálcica e secundariamente cloretadas cálcica e as águas da zona profunda e de descarga são bicarbonatadas cálcica, secundariamente bicarbonatadas sódicas e por último cloretada cálcica. 

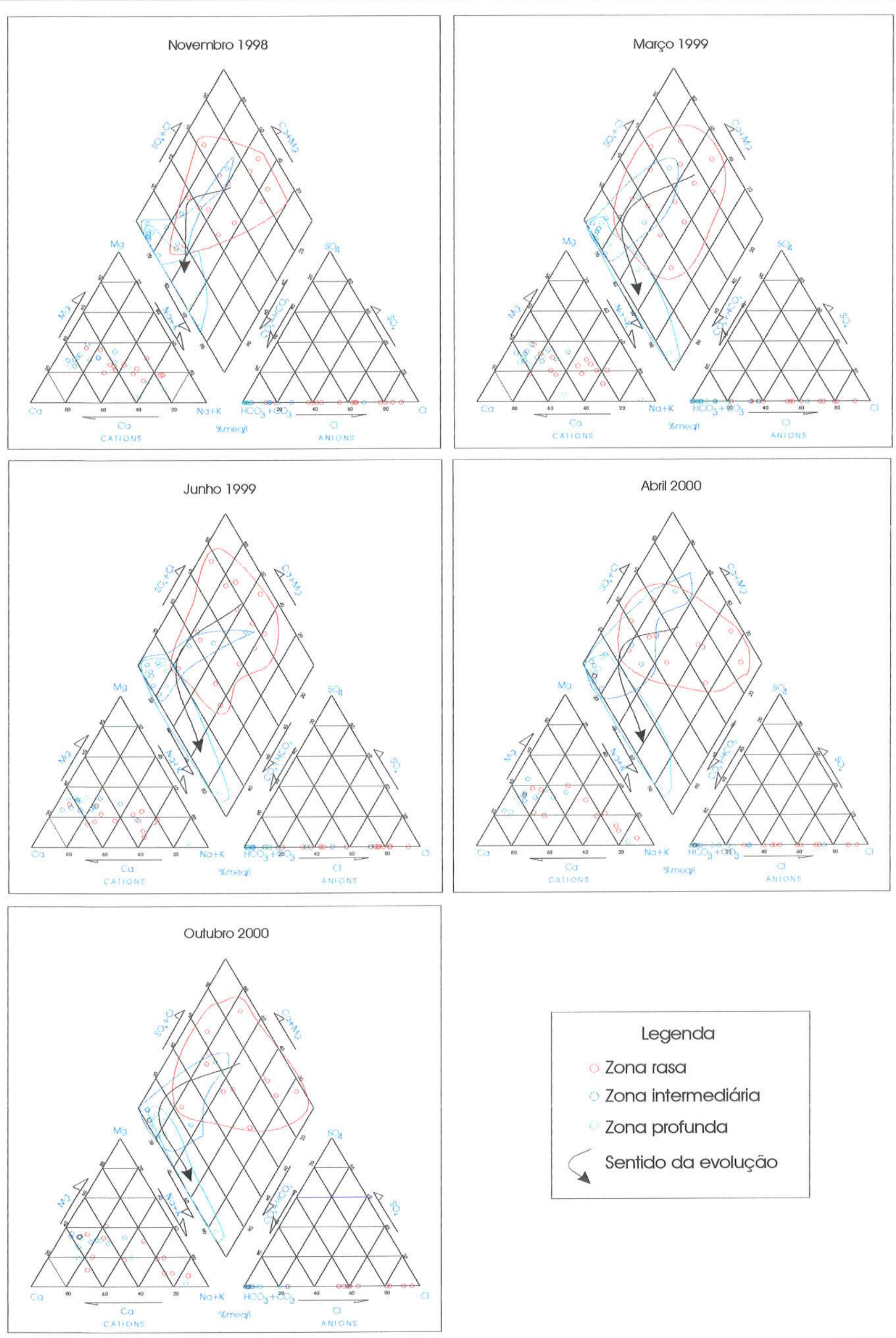

Figura 7.14.: Diagrama de classificação de Piper 
Em síntese, a água subterrânea do Aqüifero Adamantina em Urânia, passa de cloretada cálcica nas porções mais rasas do aqüifero (fluxos locais e área de recarga), para bicarbonatada cálcica nas porções mais profundas do aqüifero (fluxos profundos e áreas de descarga), ocorrendo uma mistura de águas destas duas caracteristicas nas profundidades intermediárias. Porém a água da zona de descarga, representada pelo poço jorrante PP-5, possui característica de bicarbonatada sódica.

\subsubsection{Variações da composição química com a profundidade}

Uma vez que a estatística não apresentou resultados para uma boa análise hidrogeoquímica, foram confeccionados 3 perfis a fim de descrever as variações químicas do aqüífero estudado. A localização de cada perfil pode ser observada na Figura 6.1..

Através dos perfis da Figura 7.15., observa-se que o cálcio é o cátion com maiores concentrações, seguido pelo sódio, magnésio e potássio. Nota-se que nos Perfis 1 e 2 o cálcio e o magnésio tendem a aumentar as suas concentrações com a profundidade e em direção a zona de recarga, já no Perfil 3 o cálcio e o magnésio tendem a aumentar até a zona intermediária e voltam a concentrações menores na zona de descarga representada pelo poço PP.5. 0 sódio e potássio tendem a diminuir com a profundidade, porém no Perfil 3 o sódio tende aumentar da zona intermediária para zona de descarga (PP-5) enquanto o potássio continua a diminuir.

Na Figura 7.16. observa-se que o ânion mais abundante é o bicarbonato, seguido pelo nitrato e por último o cloreto. O cloreto e o nitrato tendem a diminuir com a profundidade enquanto o bicarbonato tende a aumentar. Nota-se que a sílica também tende a aumentar em relação à profundidade.

$\mathrm{Na}$ Figura 7.17. observa-se que o $\mathrm{pH}$ tende a acompanhar a alcalinidade aumentando em relação à profundidade, enquanto que a condutividade elétrica tende a diminuir devido à queda na concentração de cloreto, nitrato, sódio e potássio. O Eh como é de se esperar tende a diminuir com a profundidade devido à diminuição de oxigênio nas partes mais profundas do aqüífero. 

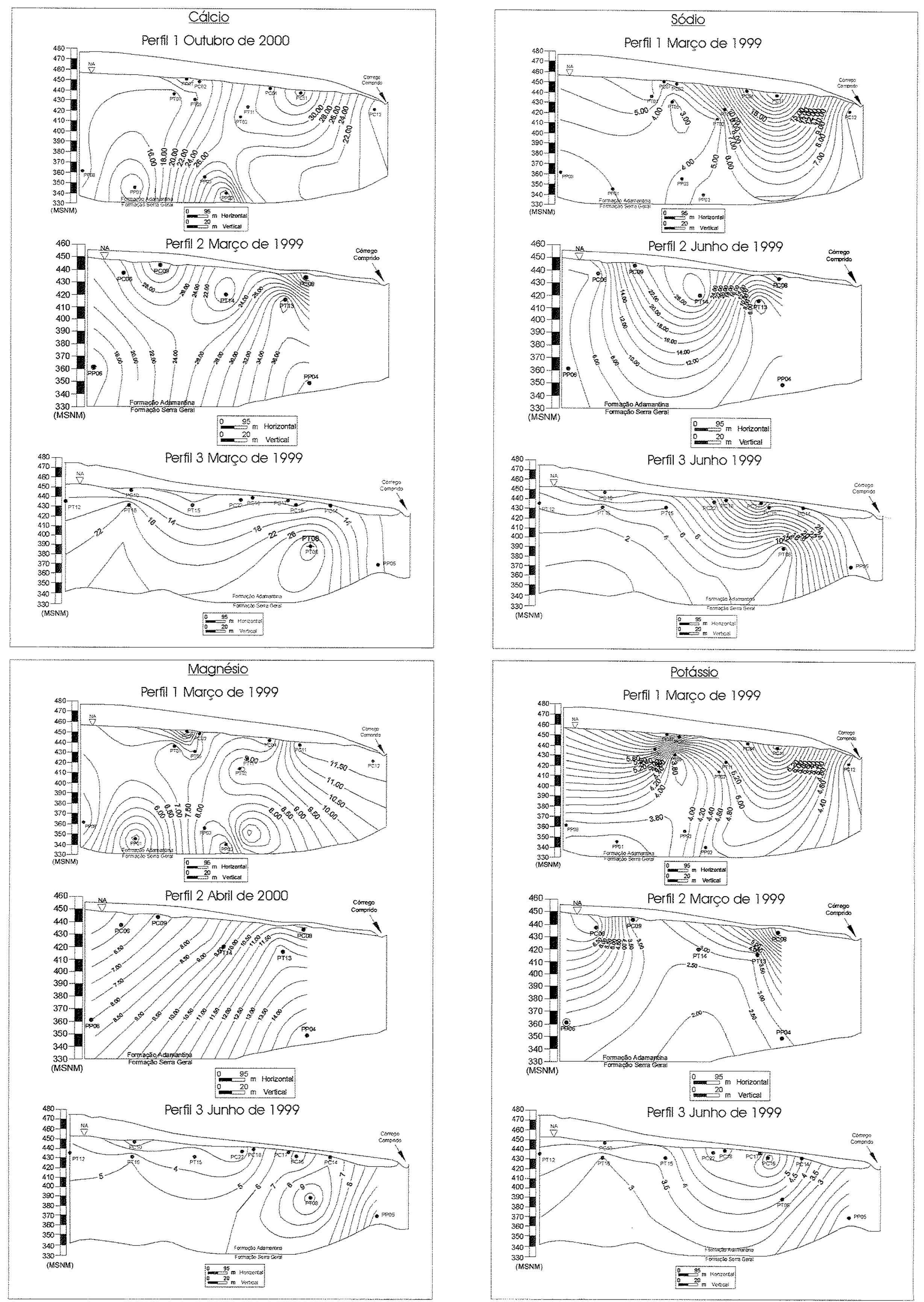

Figura 7.15.: Perfis de isoconcentrações para cálcio, sódio, potássio e magnésio (mg/L) 

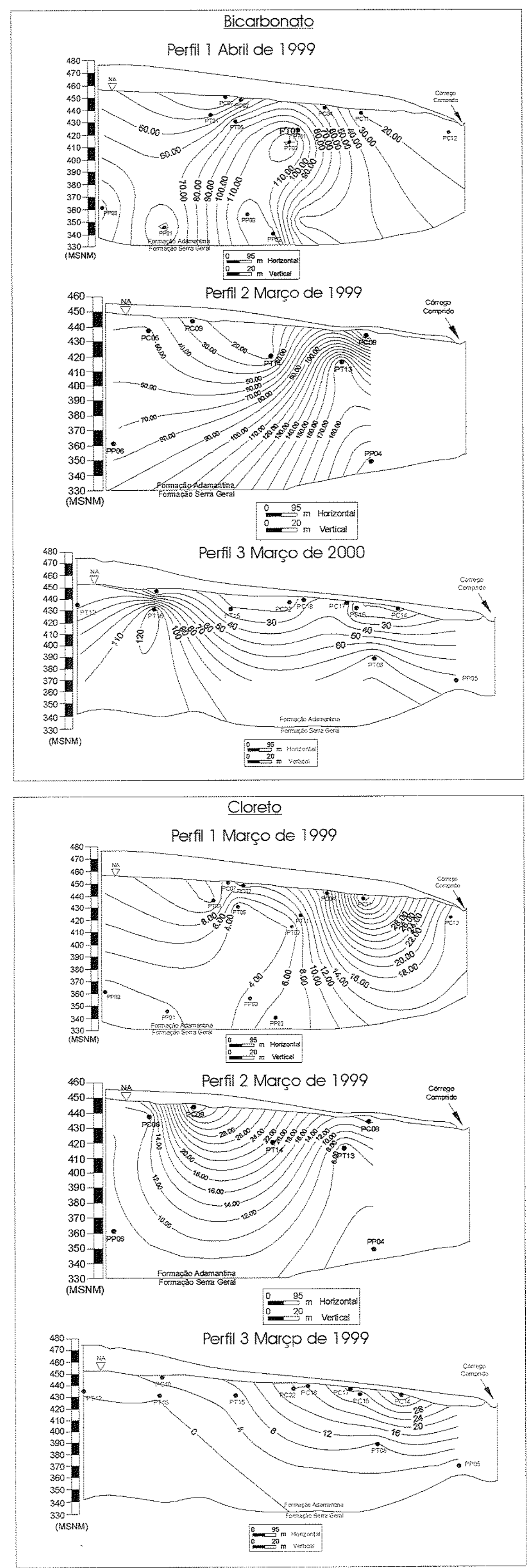
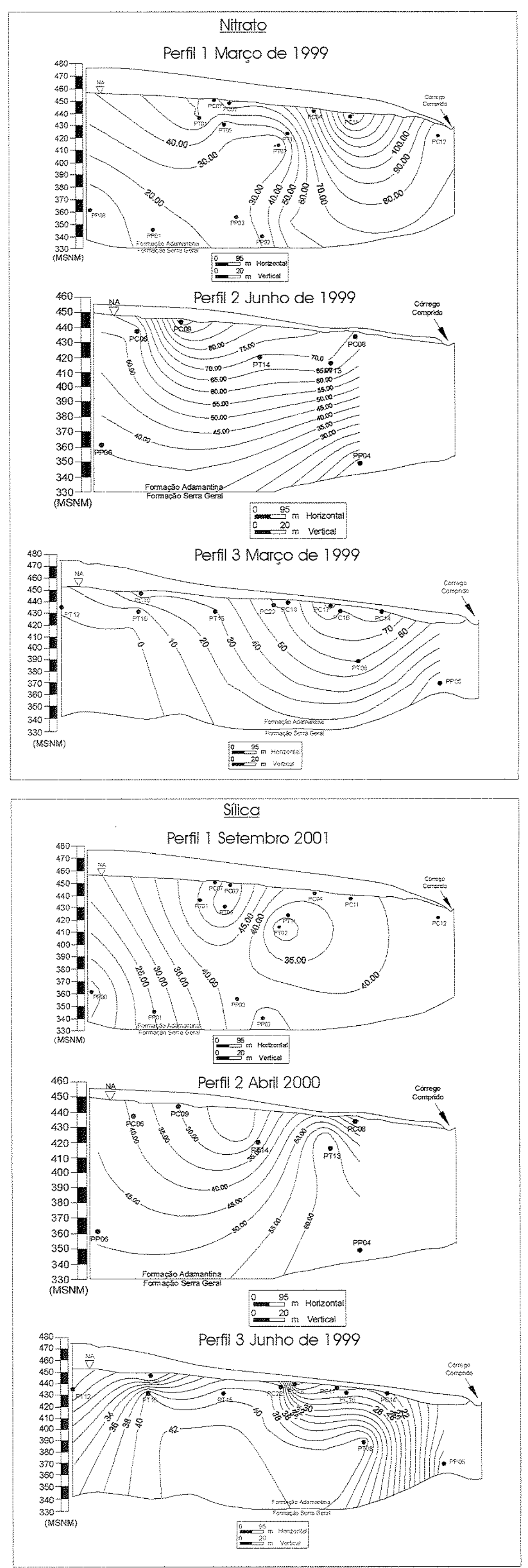

Figura 7.16.: Perfis de isoconcentrações para bicarbonato, nitrało, cloreto e sílica $(\mathrm{mg} / \mathrm{L})$ 

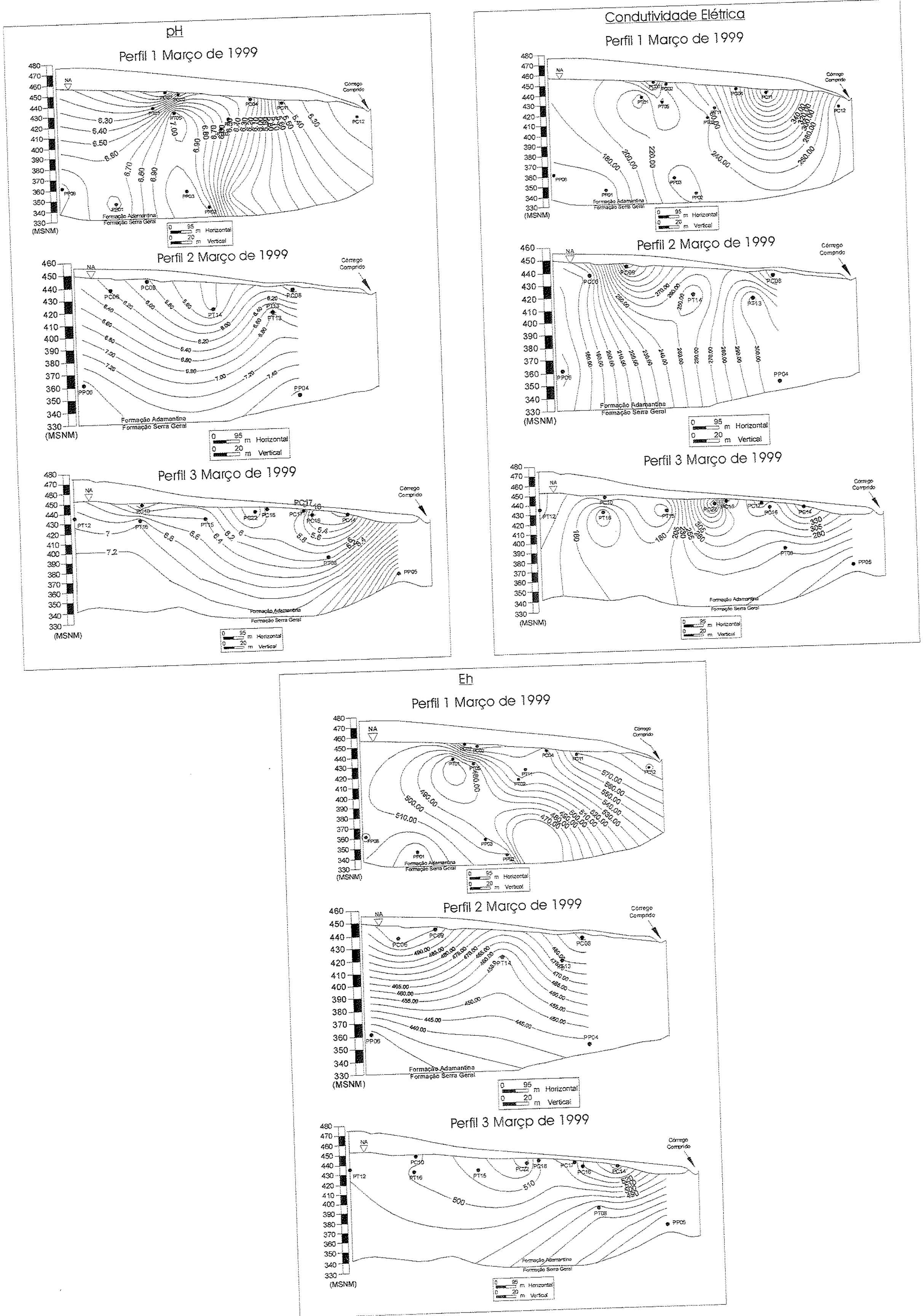

Figura 7.17.: Perfis de isoconcentrações para pH, condutividade elétrica $(\mathrm{mS} / \mathrm{cm})$ e Eh $(\mathrm{mV})$ 
Nota-se através do contorno das linhas de isoconcentração para alguns parâmetros, que em alguns perfis as águas subterrâneas dos poços tubulares (PT) possuem características de poços tubulares profundos da SABESP (PP). Esse fato pode ser observado nos poços PT-5 do Perfil 1, PT-13 do Perfil 2 e PT-12 e 16 do Perfil 3 que coincidentemente são os poços tubulares (PT) mais explorados. Os poços PT-12, 13 e 16 são utilizados para irrigar plantações e o PT-5 para encher a caixa d'água da fábrica de móveis da cidade de Urânia.

Ao comparar os perfis de diferentes campanhas de amostragem, não foi observada nenhuma variação química temporal significativa.

Para auxiliar na interpretação das variações dos parâmetros, as Tabelas 7.6., 7.7. e 7.8. apresentam as matrizes de correlação dos parâmetros químicos analisados na água para cada zona do aqüífero. Foram consideradas como correlacionado os pares cujo coeficiente de correlação linear possui nível de significância igual a 1\% (Davis, 1986).

$\mathrm{Na}$ zona rasa e de recarga (ZR) foi observada uma forte correlação positiva entre nitrato, cloreto, flúor, fosfato, sódio, cálcio, bário, estrôncio $e$ condutividade elétrica, indicando prováveis vazamentos da rede de esgoto, fossas sépticas e/ou contaminação por fertilizantes. Também podem ser observadas correlações positivas entre o $\mathrm{pH}$, a alcalinidade, o cálcio e o potássio devido à provável dissolução da matriz carbonática e de minerais carbonáticos e silicáticos.

Na zona intermediária (Zl) ainda ocorre correlação positiva entre o nitrato, cloreto, sódio e bário, que por sua vez possuem correlação negativa com o $\mathrm{pH} \mathrm{e}$ a alcalinidade, indicando a diminuição da contaminação e o aumento relativo da dissolução de minerais e da matriz. $\mathrm{O} \mathrm{pH}$ e a alcalinidade possuem correlação positiva com o cálcio, magnésio e estrôncio. Os cátions bário, magnésio e cálcio também apresentam correlação positiva. 
Nas zonas profundas e de descarga ocorre correlação positiva entre o nitrato e o cloreto que, por sua vez, possuem correlação negativa com o sódio e o pH. A alcalinidade, o pH, o cálcio, o magnésio, o estrôncio e a condutividade elétrica apresentam correlação positiva devido à dissolução de minerais. O magnésio e o sódio possuem correlação negativa indicando uma provável troca cationica entre os dois íons.

\begin{tabular}{|c|c|c|c|c|c|c|c|c|c|c|c|c|c|c|c|}
\hline & & & row & \& & 6 & $\%$ or & 80 & 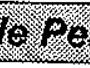 & $1050 \%$ & $g$ & $6 n g$, & ty & & & \\
\hline & $\mathrm{HCO}_{3}{ }^{\circ}$ & $\mathrm{SO}_{4}^{-2}$ & $\mathrm{Cr}$ & $\mathrm{NO}_{3}$ & $F$ & $\mathrm{PO}_{4}{ }^{-3}$ & $\mathrm{Na}^{+}$ & $\mathbf{K}^{+}$ & $\mathrm{Ca}^{+2}$ & $\mathrm{Mg}^{+2}$ & $\mathrm{Sr}^{+2}$ & $\mathrm{Ba}^{+2}$ & $\mathrm{pH}$ & Eh & C.E. \\
\hline $\mathrm{HCO}_{3-}$ & 1,00 & 0,22 & $-0,14$ & 0,13 & $-0,16$ & $-0,08$ & $-0,14$ & 0,45 & 0,49 & 0,17 & 0,43 & $-0,02$ & 0,71 & $-0,25$ & 0,15 \\
\hline $\mathrm{SO}_{4}^{-2}$ & & 1,00 & 0,01 & 0,10 & $-0,03$ & 0,01 & 0,04 & 0,40 & 0,00 & 0,34 & 0,11 & $-0,08$ & $-0,08$ & 0,06 & 0,05 \\
\hline $\mathrm{Cl}^{\circ}$ & & & 1,00 & 0,82 & 0,68 & 0,56 & 0,77 & 0,01 & 0,55 & 0,60 & 0,30 & 0,59 & $-0,22$ & $-0,09$ & 0,85 \\
\hline $\mathrm{NO}_{3}$ & & & & 1,00 & 0,60 & 0,30 & 0,54 & 0,33 & 0,81 & 0,83 & 0,58 & 0,79 & 0,03 & $-0,03$ & 0,89 \\
\hline $\mathrm{F}$ & & & & & 1,00 & 0,09 & 0,57 & $-0,02$ & 0,39 & 0,50 & 0,25 & 0,48 & $-0,18$ & 0,08 & 0,64 \\
\hline $\mathrm{PO}_{4}^{-3}$ & & & & & & 1,00 & 0,34 & $-0,09$ & 0,17 & 0,04 & 0,03 & 0,09 & $-0,07$ & 0,06 & 0,31 \\
\hline $\mathrm{Na}^{+}$ & & & & & & & 1,00 & 0,15 & 0,16 & 0,29 & 0,04 & 0,33 & 0,22 & 0,17 & 0,60 \\
\hline $\mathrm{K}^{+}$ & & & & & & & & 1,00 & 0,26 & 0,42 & 0,24 & 0,22 & 0,20 & $-0,05$ & 0,17 \\
\hline $\mathrm{Ca}^{* 2}$ & & & & & & & & & 1,00 & 0,70 & 0,75 & 0,60 & 0,37 & $-0,07$ & 0,75 \\
\hline $\mathrm{Mg}^{+2}$ & & & & & & & & & & 1,00 & 0,57 & 0,73 & $-0,05$ & 0,07 & 0,76 \\
\hline $\mathrm{Sr}^{+2}$ & & & & & & & & & & & 1,00 & 0,48 & 0,36 & $-0,12$ & 0,49 \\
\hline $\mathrm{Ba}^{+2}$ & & & & & & & & & & & & 1,00 & $-0,06$ & 0,09 & 0,69 \\
\hline pH & & & & & & & & & & & & & 1,00 & $-0,14$ & $-0,01$ \\
\hline Eh & & & & & & & & & & & & & & 1,00 & $-0,18$ \\
\hline C.E. & & & & & & & & & & & & & & & 1,00 \\
\hline
\end{tabular}

Os valores em itálico e negrito indicam correlaçóes com intervalo de significância de $95 \%$, sendo considerado 79
dados para cada parâmetro. C.E. - Condutividade elétrica $(\mu \mathrm{S} / \mathrm{cm})$

Eh $\sim(\mathrm{mV})$ 


\begin{tabular}{|c|c|c|c|c|c|c|c|c|c|c|c|c|c|c|c|}
\hline & $\mathrm{HCO}_{3}{ }^{\circ}$ & $\mathrm{SO}_{4}{ }^{-2}$ & $\mathrm{Cl}^{\circ}$ & $\mathrm{NO}_{3}{ }^{\circ}$ & $F^{-}$ & $\mathrm{PO}_{4}^{-{ }^{3}}$ & $\mathrm{Na}^{+}$ & $\mathrm{K}^{+}$ & $\mathrm{Ca}^{+2}$ & $\mathrm{Mg}^{+2}$ & $\mathrm{Sr}^{+2}$ & $\mathrm{Ba}^{+2}$ & $\mathrm{pH}$ & Eh & C.E. \\
\hline $\mathrm{HCO}_{3}$ & 1,00 & $-0,48$ & $-0,54$ & $-0,51$ & 0,13 & $-0,09$ & $-0,69$ & $-0,08$ & 0,82 & 0,58 & 0,66 & 0,02 & 0,70 & 0,18 & 0,42 \\
\hline $\mathrm{SO}_{4}^{-2}$ & & 1,00 & 0,84 & 0,55 & $-0,20$ & $-0,26$ & 0,87 & $-0,20$ & $-0,15$ & $-0,05$ & $-0,03$ & 0,19 & $-0,75$ & $-0,36$ & 0,27 \\
\hline $\mathrm{Cl}^{\circ}$ & & & 1,00 & 0,77 & $-0,10$ & $-0,14$ & 0,90 & 0,09 & $-0,11$ & 0,07 & $-0,07$ & 0,38 & $-0,79$ & -0.28 & 0,37 \\
\hline $\mathrm{NO}_{3}{ }^{\circ}$ & & & & 1,00 & 0,14 & 0,12 & 0,57 & 0,39 & 0,02 & 0.27 & 0,06 & 0,56 & $-0,56$ & $-0,27$ & 0,44 \\
\hline$F^{*}$ & & & & & 1,00 & 0,09 & $-0,24$ & 0,16 & 0,28 & 0,47 & 0,18 & 0,13 & 0,28 & $-0,30$ & 0,29 \\
\hline $\mathrm{PO}_{4}{ }^{3}$ & & & & & & 1,00 & $-0,27$ & $-0,02$ & $-0,04$ & $-0,10$ & $-0,02$ & $.0,23$ & 0,13 & 0,13 & 0,17 \\
\hline $\mathrm{Na}^{+}$ & & & & & & & 1,00 & $-0,08$ & $-0,40$ & $-0,22$ & $-0,33$ & 0,16 & $-0,84$ & $-0,28$ & 0,11 \\
\hline $\mathrm{K}^{+}$ & & & & & & & & 1,00 & 0,13 & 0,22 & 0.17 & 0,75 & 0,02 & $-0,02$ & 0,30 \\
\hline $\mathrm{Ca}^{+2}$ & & & & & & & & & 1,00 & 0,86 & 0,81 & 0,38 & 0,45 & 0,04 & 0,77 \\
\hline $\mathrm{Mg}^{+2}$ & & & & & & & & & & 1,00 & 0,65 & 0,46 & 0,29 & $-0,19$ & 0,80 \\
\hline $\mathrm{Sr}^{+2}$ & & & & & & & & & & & 1,00 & 0,34 & 0,19 & $-0,05$ & 0,65 \\
\hline $\mathrm{Ba}^{+2}$ & & & & & & & & & & & & 1,00 & $-0,02$ & -0.13 & 0,66 \\
\hline $\mathrm{pH}$ & & & & & & & & & & & & & 1,00 & 0,28 & 0,04 \\
\hline Eh & & & & & & & & & & & & & & 1,00 & $-0,21$ \\
\hline C.E. & & & & & & & & & & & & & & & 1,00 \\
\hline
\end{tabular}

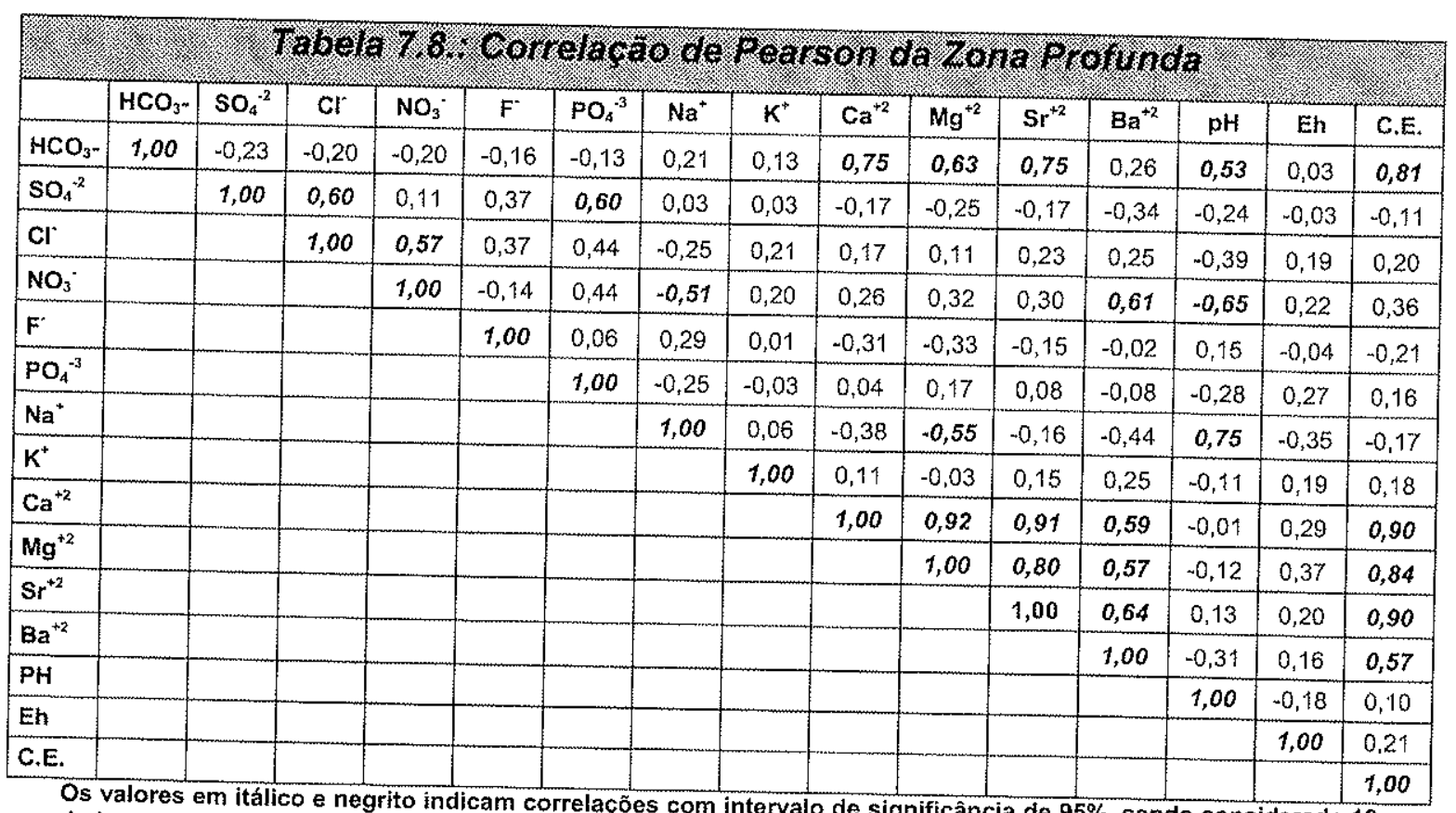

dados para cada parâmetro.

C.E, - Condutividade elétrica $(\mu \mathrm{S} / \mathrm{cm})$

Eh $-(\mathrm{mV})$ 


\subsubsection{Amostragem em diferentes tempos de bombeamento e estratificada}

As amostras de água, coletadas em tempos de bombeamento préestabelecidos foram realizadas para verificar a existência de variações nas concentrações dos íns em águas de diferentes profundidades (tubos de fluxo). Sabe-se que o bombeamento contínuo do poço faz com que exista tendência de capturar tubos de fluxo do aqüífero mais profundo e portanto, de águas mais velhas, com maior tempo de contato água-rocha. Através do modelo conceitual de circulação das águas subterrâneas, é possivel visualizar que os poços onde as águas foram amostradas em diferentes tempos de bombeamento, localizamse na área de recarga (PP-2) e descarga do aqüífero (PP-4).

A partir dos resultados da amostragem de água nos dois poços (Figuras 7.18. e 7.19.) é possível concluir que houve um aumento das concentrações de sódio e do $\mathrm{pH}$ com o tempo de bombeamento, este aumento pode ser devido ao fato deste cátion não participar de importantes reações de precipitação e troca catiônicas uma vez. que os ions bivalentes são mais adsorvidos pela fase sólida que os monovalentes. Observa-se também que as concentrações de cloreto e nitrato tendem a diminuir com o aumento do tempo de bombeamento, indicando contaminação superficial do aqüífero por estes íons. As concentrações de potássio, magnésio, zinco, bário, estrôncio, cálcio, bicarbonato e condutividade elétrica sofreram uma certa diminuição com o aumento do tempo de bombeamento.

A Figura 7.20. mostra os resultados das coletas estratificadas nos poços PP-1, 6 e 8, em junho de 1999. Observa-se que as amostras apresentaram as mesmas concentrações em todas as profundidades, não havendo qualquer tipo de variação dos resultados, esse fato ocorre também na campanha de maio de 1999 , onde foi efetuada coleta a 24 e 48 horas depois da limpeza dos poços PP. 6 e 8. Esses resultados são atribuídos ao fato dos poços coletados estarem situados em zonas de recarga onde há um movimento vertical da água subterrânea preferencial dentro do poço, e com isso coletou-se amostras de águas mais superficiais. 


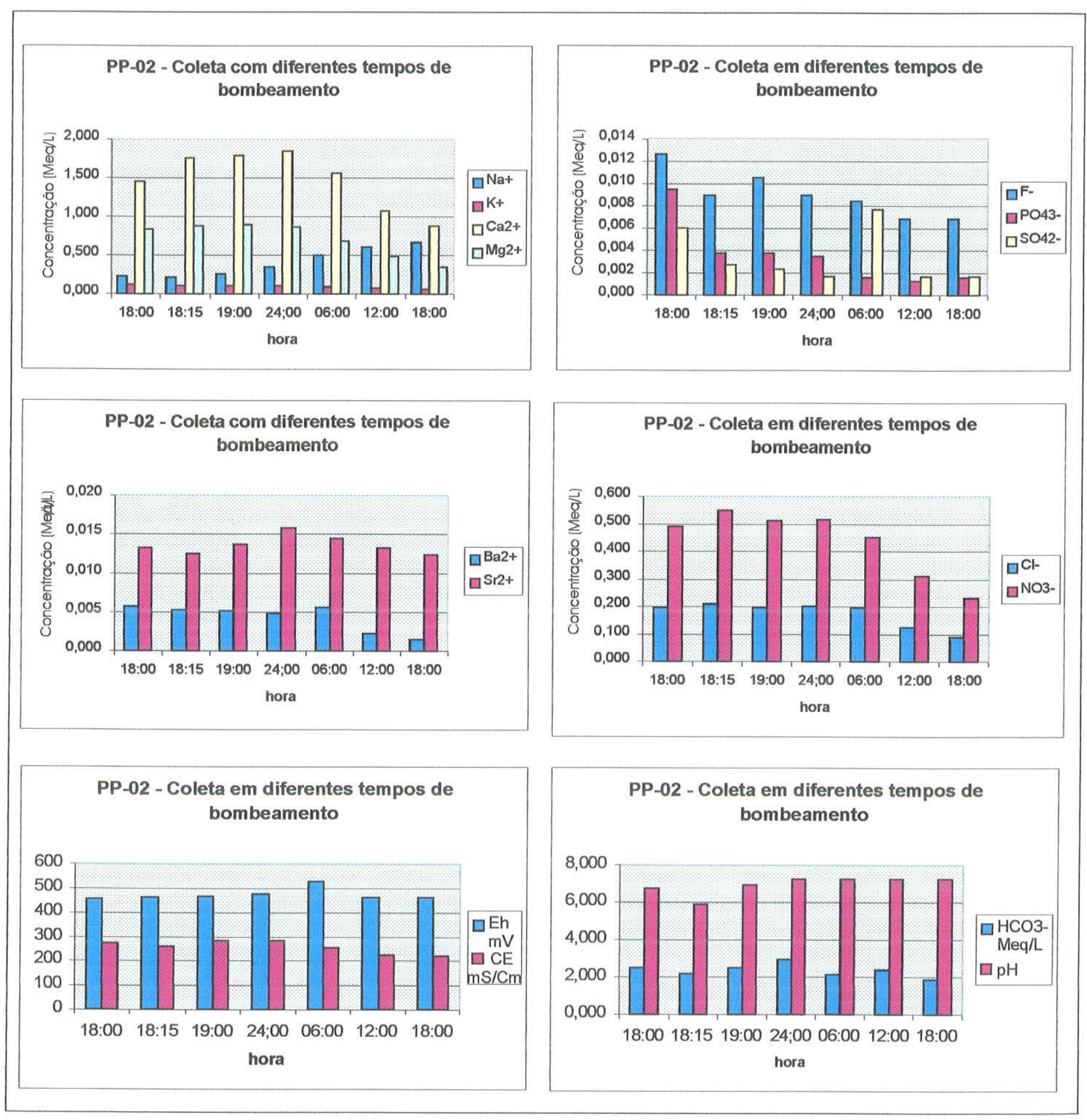

Figura 7.18.: Gráficos das coletas em diferentes tempos de bombeamento para o PP-02 


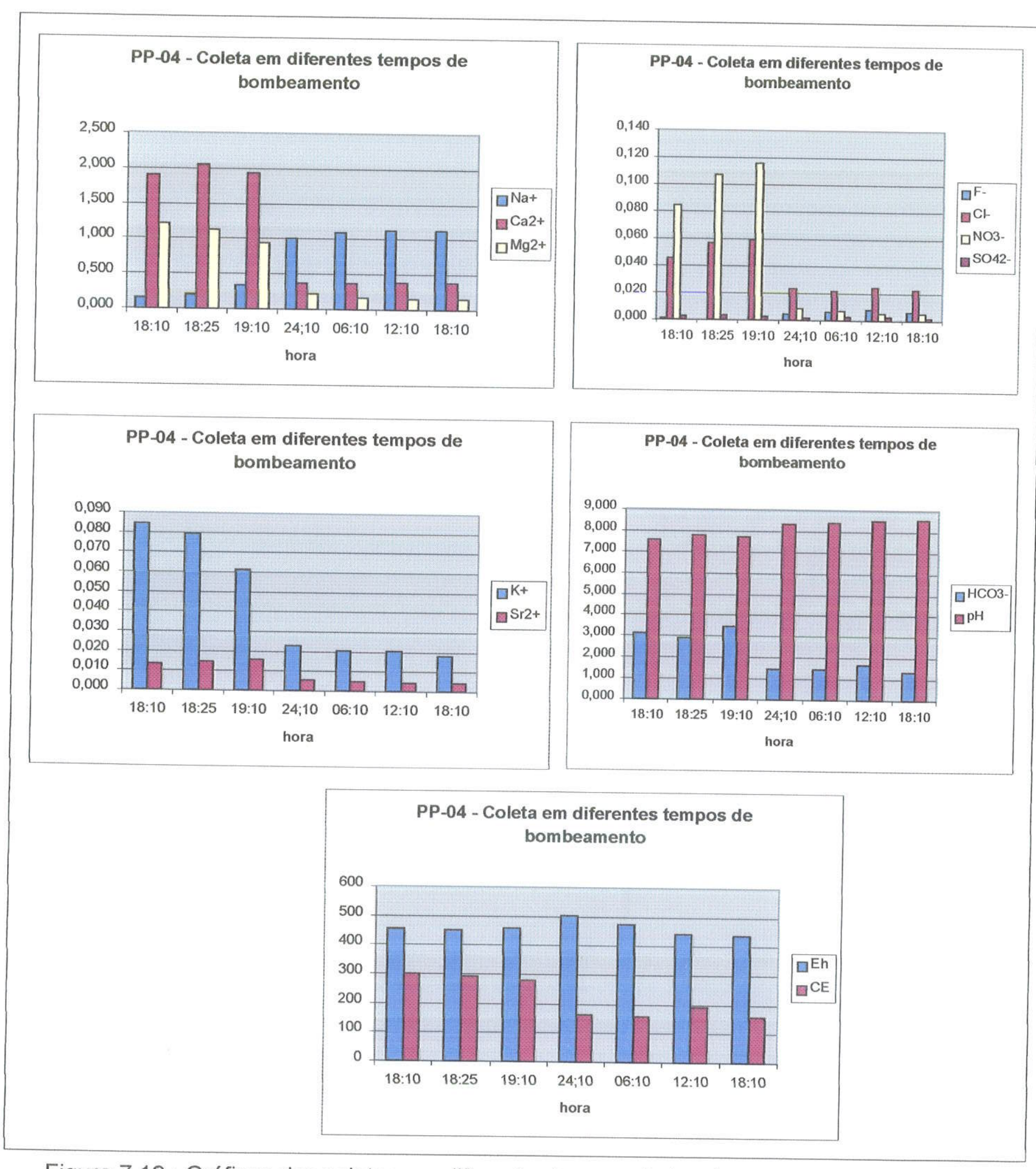

Figura 7.19.: Gráficos das coletas em diferentes tempos de bombeamento para o PP-04 


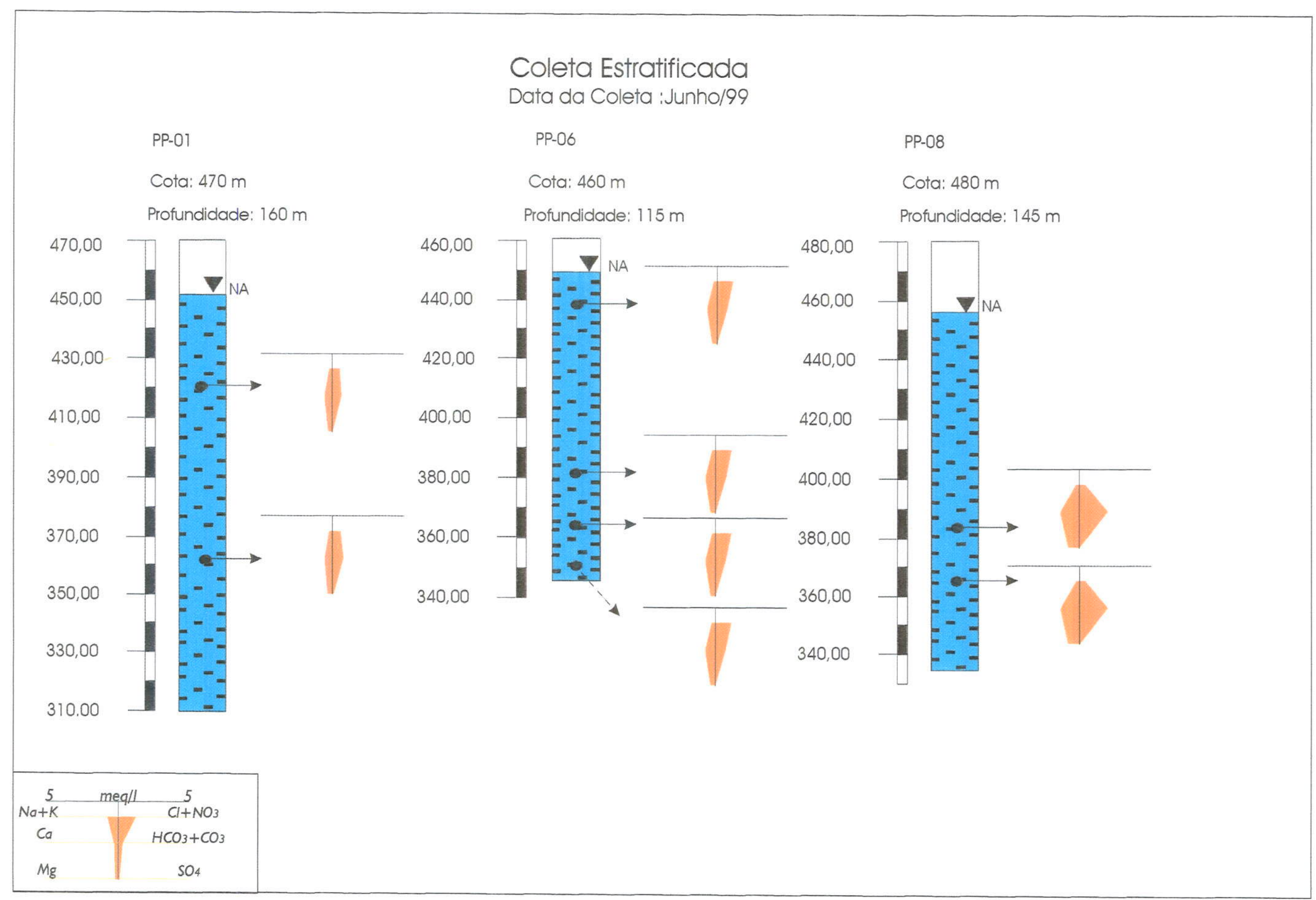




\subsection{Interação água - fase sólida}

Através dos dados apresentados nos itens anteriores foi possivel caracterizar separadamente a fase sólida e a água subterrânea, porém para a determinação do modelo hidrogeoquímico conceitual é necessário a determinação dos processos de interação entre duas fases. Em Urânia, esses processos são basicamente as reações de precipitação/dissolução e troca catiônica. As técnicas de tratamento de dados utilizadas para a determinação destes processos são descritas nos próximos itens.

\subsubsection{Diagramas de estabilidade}

Os diagramas de estabilidade mineral são figuras bidimensionais comumente utilizados para determinação da estabilidade de minerais aluminossilicáticos. Esses diagramas possuem campos de estabilidade para determinados minerais, que são separados por linhas que expressam o equilíbrio químico entre eles. Uma das grandes vantagens da utilização destes diagramas para se estudar os fenômenos de precipitação e dissolução de minerais aluminossilicáticos é que não é necessário plotar concentrações de alumínio, uma vez que normalmente este ín não é detectado em análises químicas de água subterrânea, impedindo o cálculo de índice de saturação para estes minerais.

Assumindo que a existência de minerais aluminossilicáticos nos sedimentos da Formação Adamantina achou-se necessário determinar quais eram os possíveis minerais estáveis. Desta forma foram feitos três diagramas de estabilidade para os sistemas $\mathrm{K}_{2} \mathrm{O}-\mathrm{Al}_{2} \mathrm{O}_{3}-\mathrm{H}_{2} \mathrm{O}, \mathrm{Na}_{2} \mathrm{O}-\mathrm{Al}_{2} \mathrm{O}_{3}-\mathrm{SiO}_{2}-\mathrm{H}_{2} \mathrm{O}$ e CaO$\mathrm{Al}_{2} \mathrm{O}_{3}-\mathrm{SiO}_{2}-\mathrm{H}_{2} \mathrm{O}$ para a temperatura a $25^{\circ} \mathrm{C}$ (Figuras 7.21., 7.22. e 7.23.).

$\mathrm{Na}$ Figura 7.21. pode-se observar que o K-feldspato, a caulinita e a gibsita são os minerais em equilíbrio, na Figura 7.22. é a Na-beidelita, a caulinita e a gibsita, enquanto que na Figura 7.23. apenas a Ca-beidelita, a caulinita e a gibsita encontram-se em equilíbrio. 
Através desses diagramas de estabilidade pode-se notar que as águas da zona profunda e de descarga (ZP) estão próximas ao limite superior do campo da caulinita quando não ultrapassam para o campo do feldspato e ilita, enquanto que as águas da zona rasa e de descarga (ZR) restringem-se principalmente ao campo de estabilidade da caulinita e gibsita, ultrapassando para a ilita apenas no caso do diagrama da Figura 7.23.. As águas da zona intermediária (ZI) ficam entre as da ZP e ZR sendo estável com a apenas com a caulinita e gibsita nos diagramas das Figuras 7.21. e 7.22. enquanto que no diagrama da Figura 7.23. a ilita tem a maioria dos pontos. Com isso pode-se dizer que com o aparecimento de estabilidade de minerais primários nas $Z P$ e de minerais secundários na $Z R$, indica que os processos de intemperismo químico são menos pronunciados na ZP do que na ZR. 


\begin{tabular}{|c|c|}
\hline$\triangle$ Out/2000 & \multirow{3}{*}{ ZR - Zona Rasa } \\
\hline A Abr/2000 & \\
\hline A Jun/1999 & \\
\hline - Out/2000 & \multirow{3}{*}{ ZR - Zona Intermediária } \\
\hline - Abr/2000 & \\
\hline - Jun/1999 & \\
\hline - Out $/ 2000$ & \multirow{3}{*}{ ZR - Zona Profunda } \\
\hline - Abr/2000 & \\
\hline " Jun/1999 & \\
\hline$\longrightarrow$ & Sentido da evolução \\
\hline
\end{tabular}

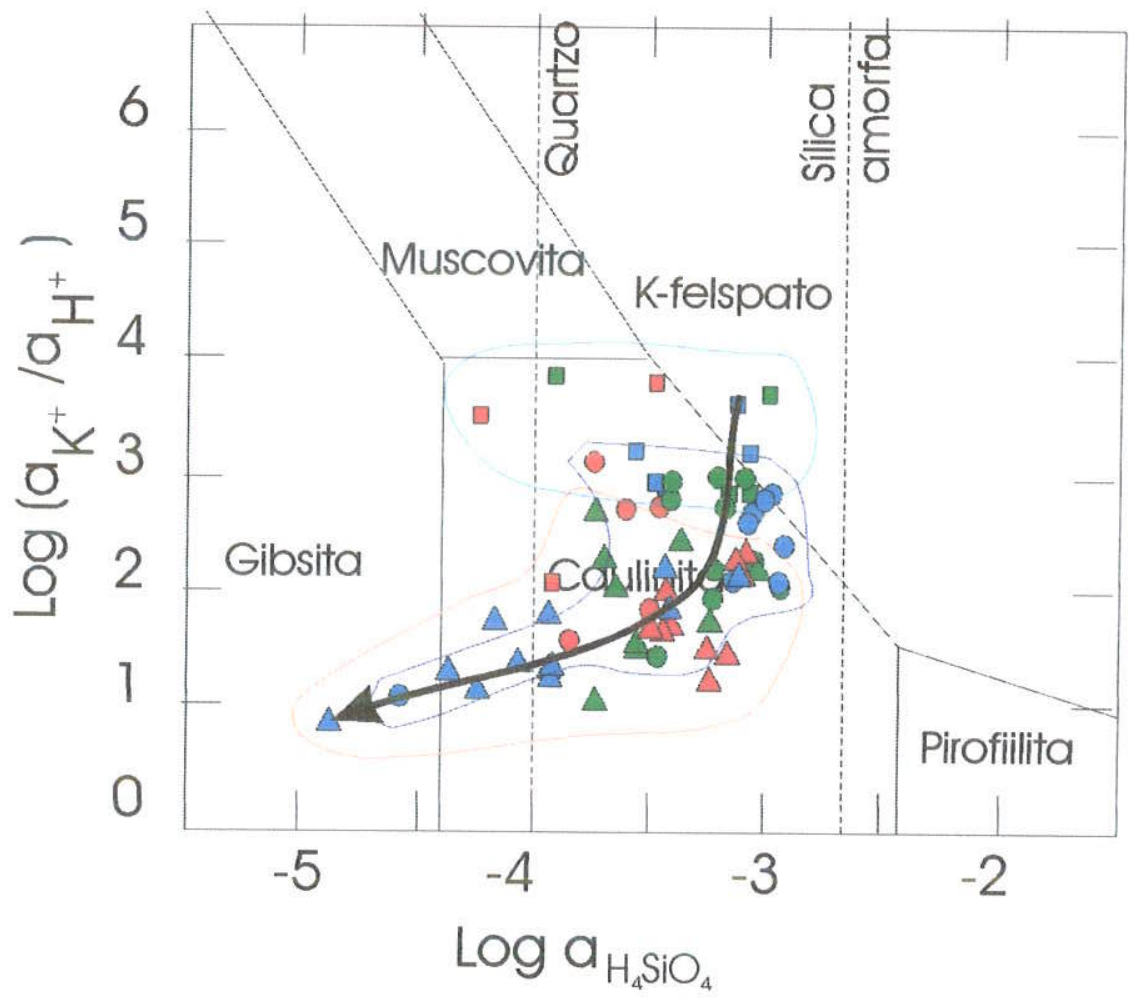

Figura 7.21.: Diagrama de estabilidade $\mathrm{K}_{2} \mathrm{O}-\mathrm{Al}_{2} \mathrm{O}_{3}-\mathrm{SiO}_{2}-\mathrm{H}_{2} \mathrm{O}$ a $25^{\circ} \mathrm{C}$ 


\begin{tabular}{|c|c|}
\hline$\triangle$ Out/2000 & \multirow{3}{*}{ ZR - Zona Rasa } \\
\hline Abr/2000 & \\
\hline A Jun/1999 & \\
\hline - Out/2000 & \multirow{3}{*}{ ZR - Zona Intermediária } \\
\hline - Abr/2000 & \\
\hline - Jun/1999 & \\
\hline - Out/2000 & \multirow{3}{*}{ ZR - Zona Profunda } \\
\hline - Abr/2000 & \\
\hline " Jun/1999 & \\
\hline$\longrightarrow$ & Sentido da evolução \\
\hline
\end{tabular}

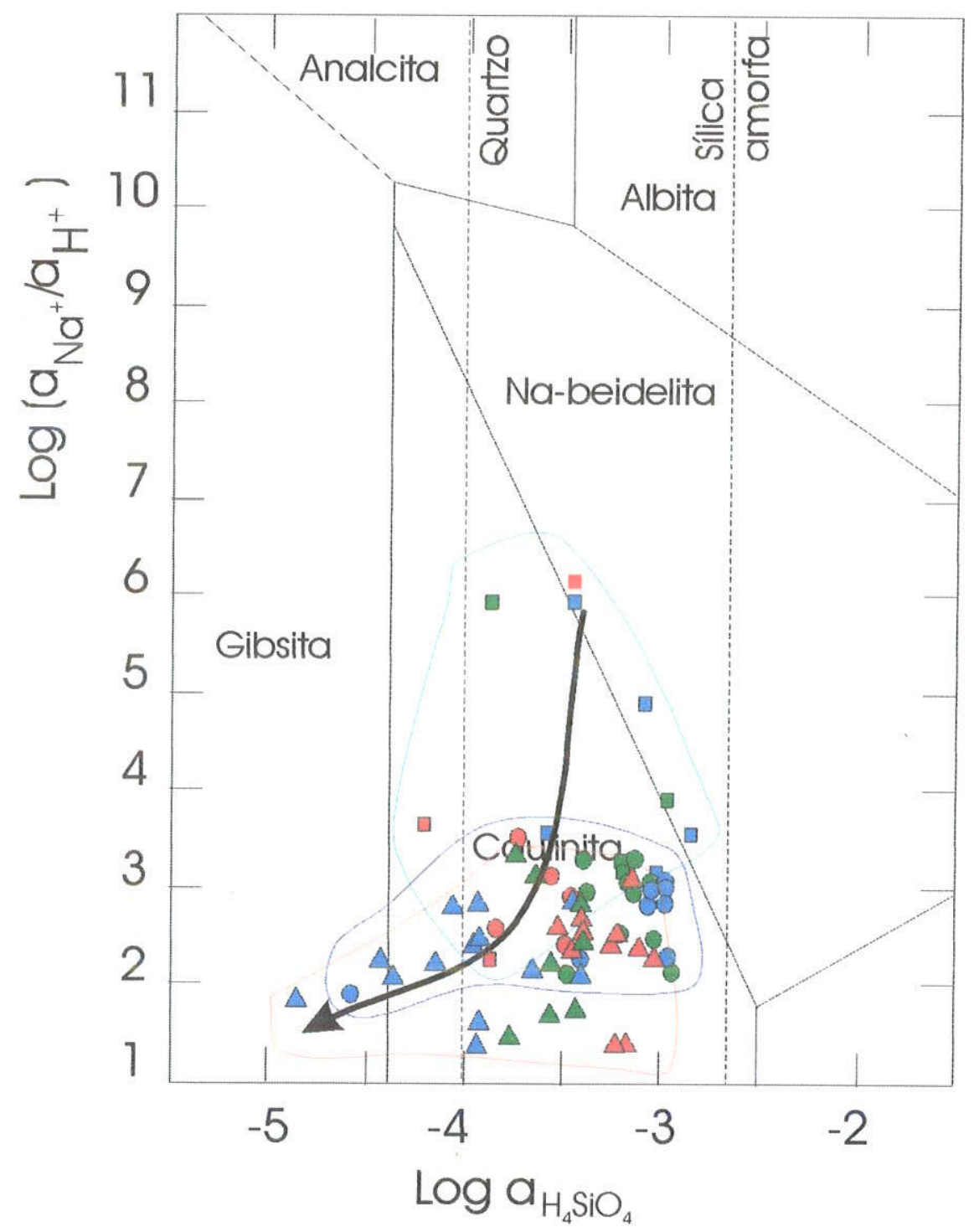

Figura 7.22.: Diagrama de estabilidade $\mathrm{Na}_{2} \mathrm{O}-\mathrm{Al}_{2} \mathrm{O}_{3}-\mathrm{SiO}_{2}-\mathrm{H}_{2} \mathrm{O}$ a $25^{\circ} \mathrm{C}$ 


\begin{tabular}{|c|c|}
\hline A Out/2000 & \multirow{3}{*}{ ZR - Zona Rasa } \\
\hline A Abr/2000 & \\
\hline A Jun/1999 & \\
\hline - Out/2000 & \multirow{3}{*}{ ZR - Zona Intermediária } \\
\hline - Abr/2000 & \\
\hline - Jun/1999 & \\
\hline - Out/2000 & \multirow{3}{*}{ ZR - Zona Profunda } \\
\hline Abr/2000 & \\
\hline "' Jun/1999 & \\
\hline$\longrightarrow$ & Sentido da evolução \\
\hline
\end{tabular}

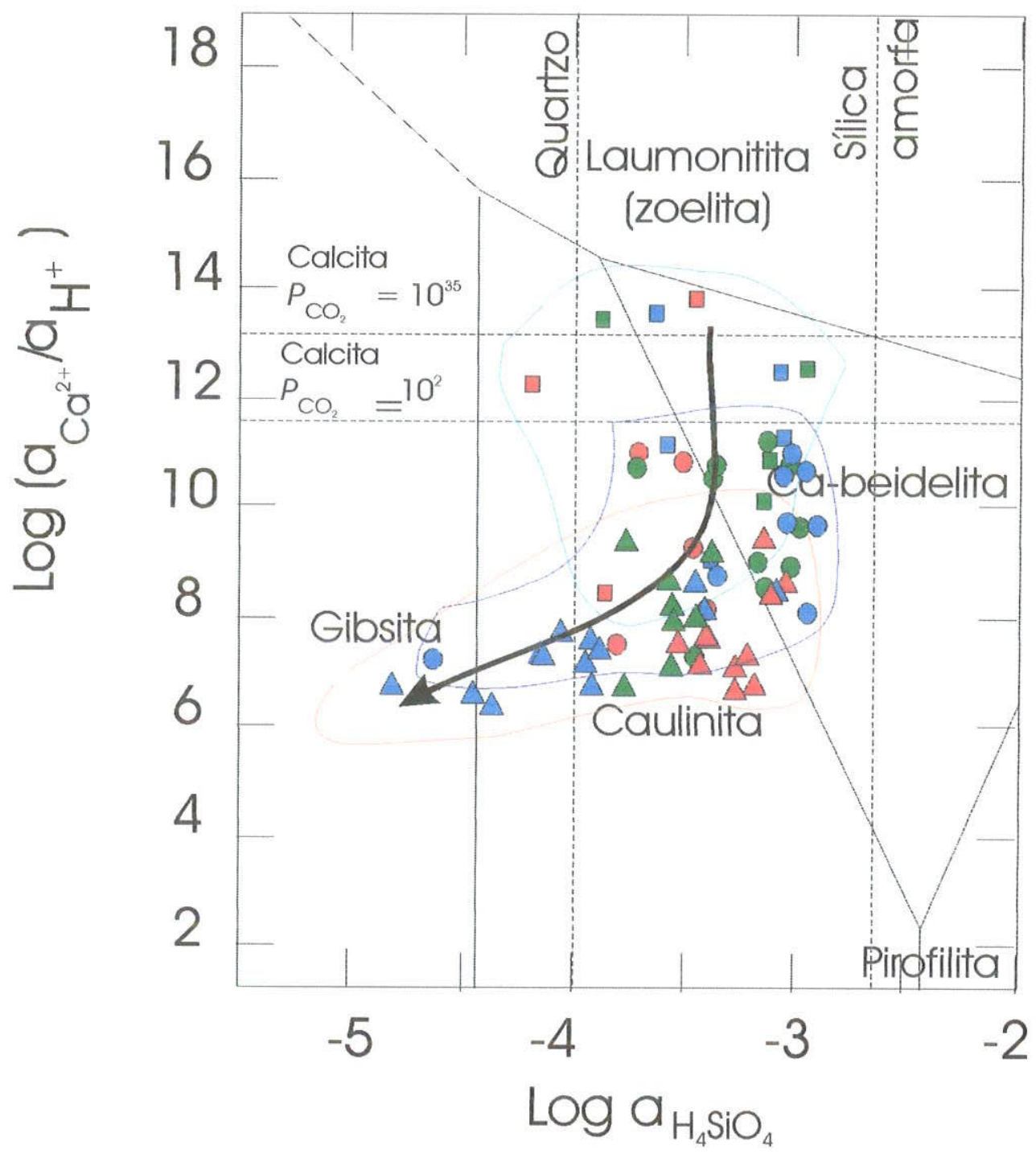

Figura 7.23.: Diagrama de estabilidade $\mathrm{CaO}-\mathrm{Al}_{2} \mathrm{O}_{3}-\mathrm{SiO}_{2}-\mathrm{H}_{2} \mathrm{O}$ a $25^{\circ} \mathrm{C}$ 


\subsubsection{Cálculo dos índices de saturação}

O índice de saturação é um parâmetro que serve como auxílio para detectar a ocorrência de reações de precipitação (índice de saturação positivo) ou dissolução (índice de saturação negativo). O cálculo é feito a partir de análises da composição química da água, não sendo possível obter este parâmetros para os minerais cujas espécies químicas não tenham sido detectadas, tal como alumínio e ferro que tendem a se preservar na fase sólida. Desta forma, não são possíveis os cálculos para minerais aluminossilicatos, argilominerais e minerais que contenham ferro.

A Figura 7.24. mostra os índices de saturação para os minerais quartzo, calcita e dolomita, onde é possível observar que o quartzo possui condições favoráveis à precipitação em todo o perfil, mas os valores são mais positivos na ZP do que na ZR, enquanto que a calcita e a dolomita possuem em todos os três perfis condições de dissolução, apresentando valores mais negativos na ZP e valores menos negativos na $Z R$.

A partir da análise dos índices de saturação pode-se afirmar que os minerais compostos por cálcio e/ou magnésio, como a calcita e dolomita, tem indícios de maior dissolução na $Z R$ do que na $Z P$, enriquecendo a água nestes íns ao longo do perfil. O quartzo apresenta-se em condições de precipitação em todo o perfil, porém ele tem maior chances de se alterar na $Z R$ do que na ZP. 
Calcita

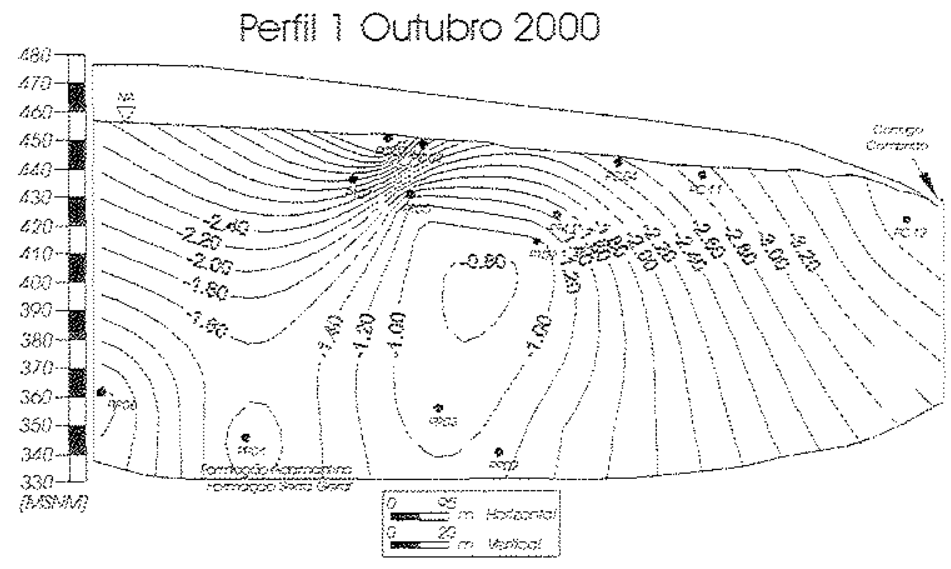

Perfil 2 Outubro 2000

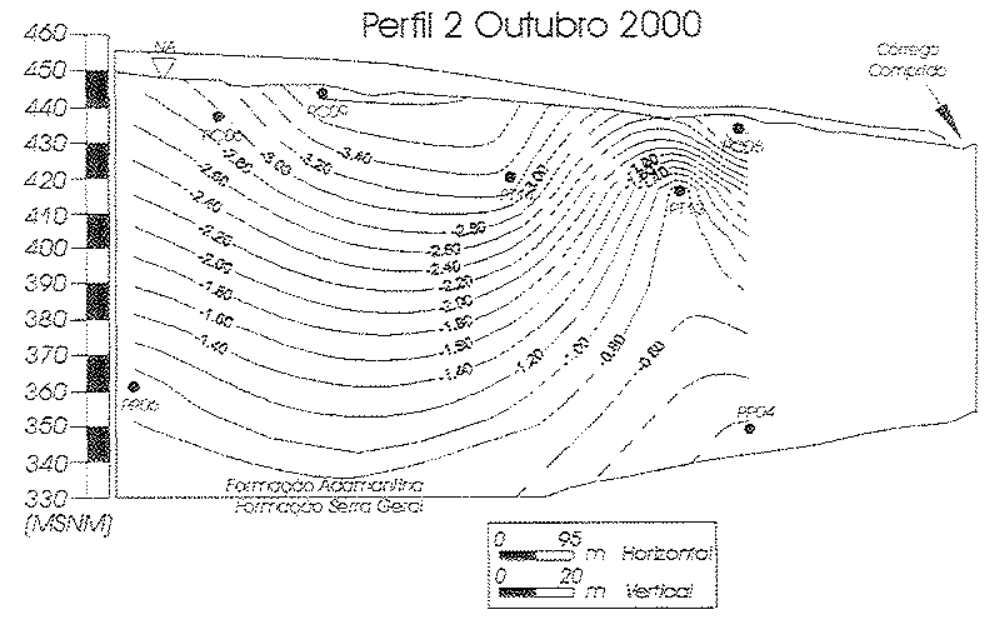

Perfil 3 Abril de 2000

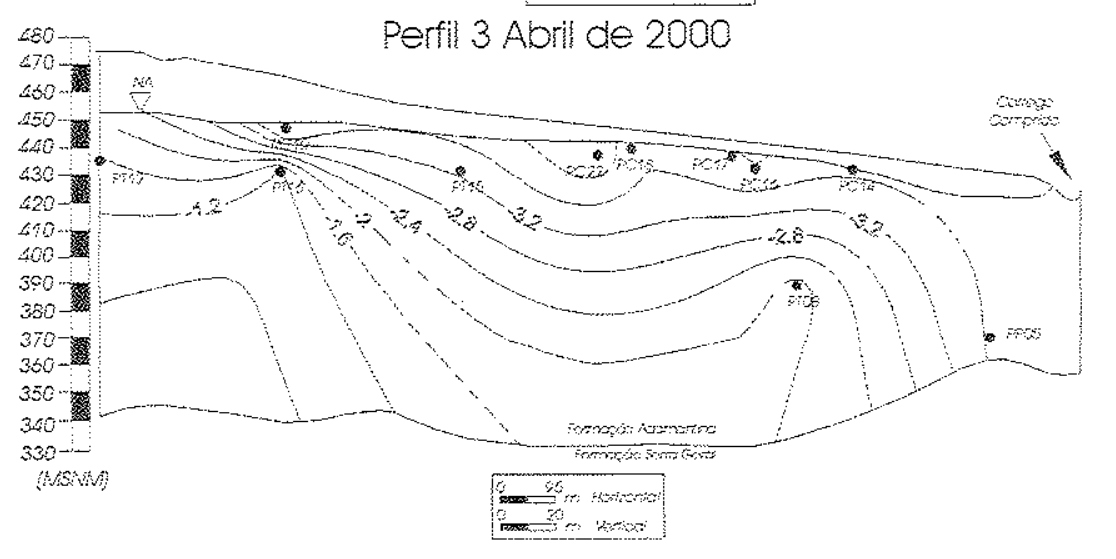

Dolomita

Perfil 1 Outubro 2000

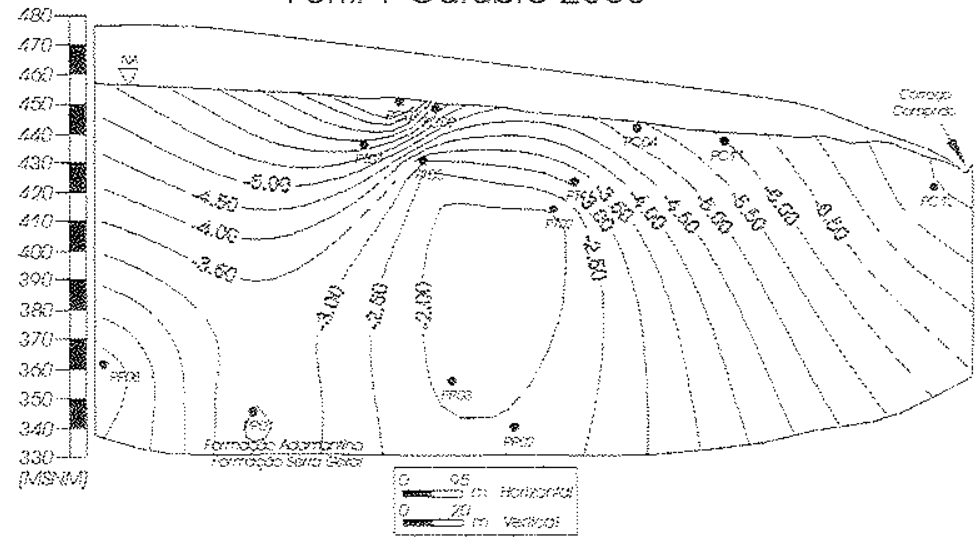

Perfil 2 Outubro 2000
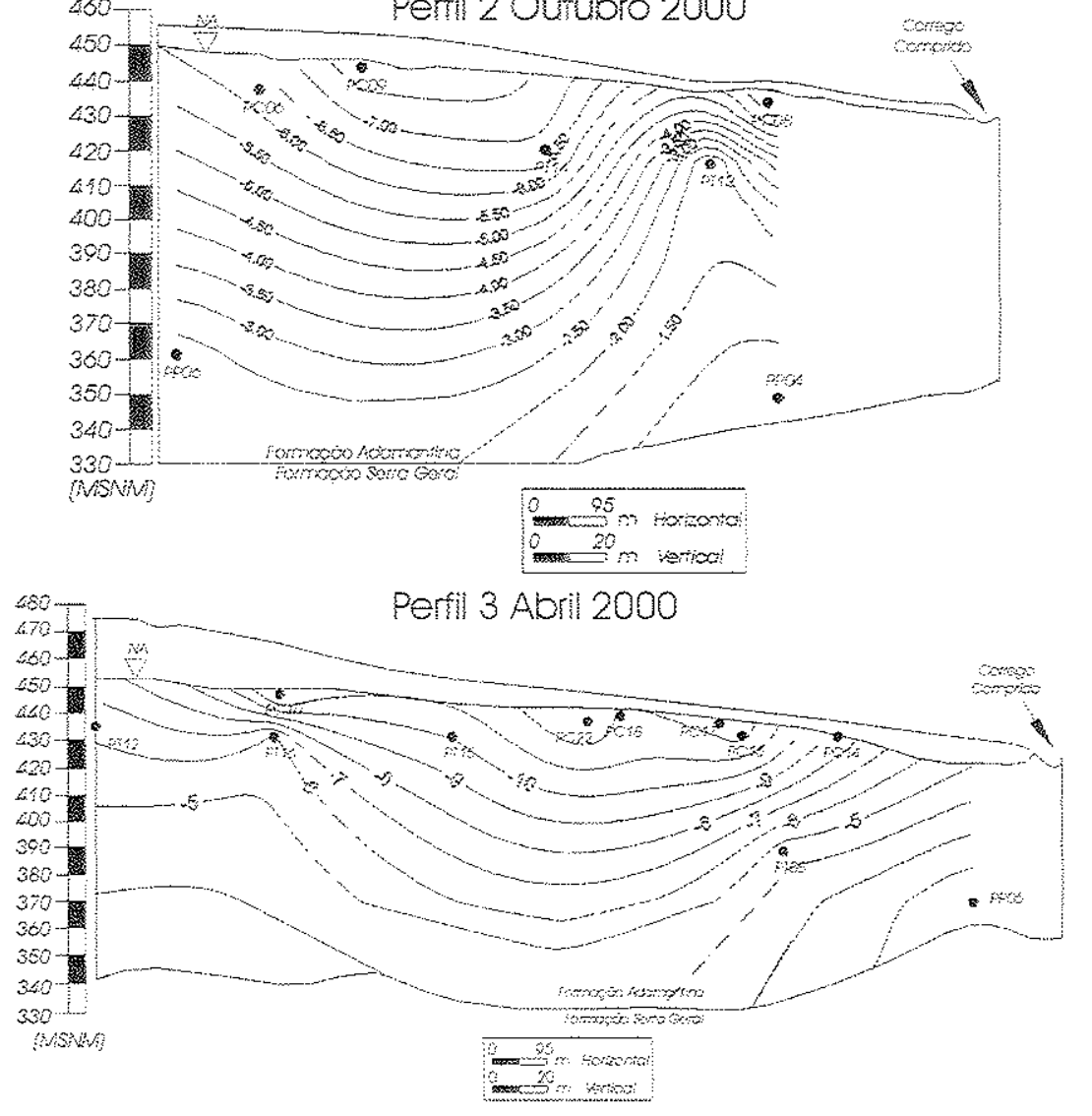

Quartzo
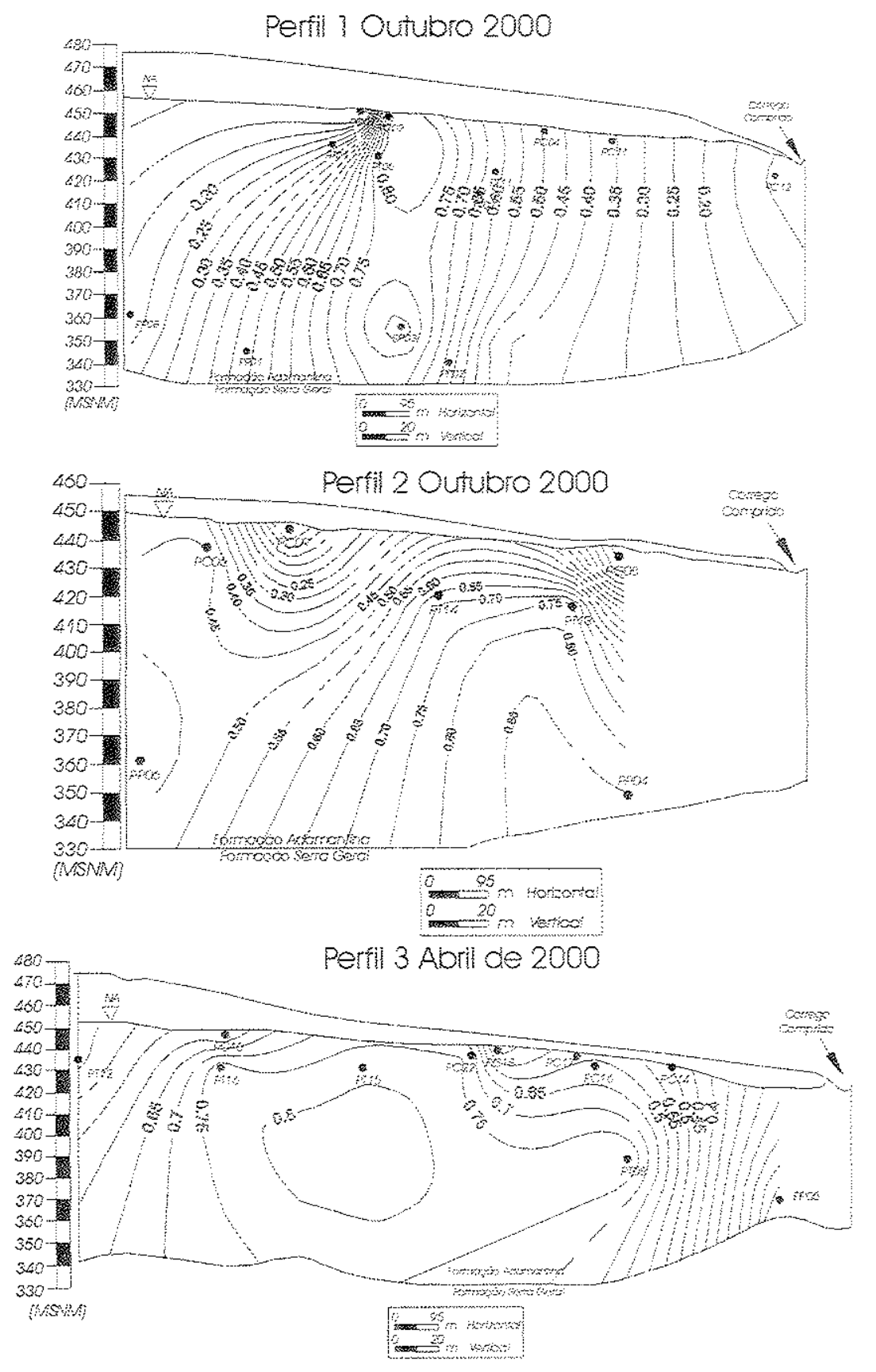

Figura 7.24.: Peris de índice de saturação para quarzo, calcita e dolomita 


\subsection{Modelo conceitual hidrogeoquímico}

Através dos itens anteriores foi possivel determinar que a água subterrânea encontra-se em contato com sedimentos arenosos compostos principalmente por quartzo, feldspatos (K-feldspato, albita e anortita), anfibólios e piroxênios cálcicos magnesianos, granada, calcita, goetita, hematita, montmorilonita cálcica e caulinita. Quimicamente o sedimento é composto por $\mathrm{SiO}_{2}(76 \%$ a $78 \%$ da massa), seguido pelo ferro e alumínio ( $4 \%$ a $10 \%)$, CaO $(3,5 \%), \operatorname{MgO}(1,5 \%), \mathrm{K}_{2} \mathrm{O}(1 \%)$ e $\mathrm{Na}_{2} \mathrm{O}(0,3 \%)$.

Ao longo do perfil hidrodinâmico da área de estudo é possivel observar uma evolução química da zona de recarga (ZR) para a zona profunda ou de descarga (ZP). As águas subterrâneas da ZR são principalmente compostas por sódio, potássio, nitrato e cloreto enquanto que as águas profundas são compostas por cálcio e bicarbonato, com exceção do ponto de descarga PP-5 que é sódico e bicarbonato. As águas da zona intermediárias (ZI) são compostas por uma mistura das águas da ZR e da ZP, sendo sódicas, cálcicas, cloretadas, nitratadas e bicarbonatadas

Devido às concentrações anômalas de nitrato e cloreto nas águas rasas, acredita-se em uma provável contaminação do aqüífero superficial por vazamento de fossa séptica e/ou da rede pública de captação de esgoto e por fertilizantes. Esse tipo de contaminação também acarretaria no aumento de sódio e potássio na água e desta forma grande parte da concentração desses cátions encontrada na $Z R$, seja causada por esse tipo de contaminação e não por processos de dissolução/precipitação de minerais.

Uma forma de identificar o quanto à contaminação mencionada influencia as concentrações de sódio, nitrato e cloreto para as três zonas do aqüífero, foi desenvolvido o perfil da Figura 7.25., onde mostra as porcentagens de variação da concentraçăo do ponto pela concentração inicial $\left(\mathrm{C} / \mathrm{C}_{0}\right)$. Para a realização da Figura 7.25. foram escolhidos os pontos PC-9, PT-14 e PP-4, representando respectivamente $Z R$, $Z l$ e $Z P$, do perfil 2. Considerou-se como $C_{0}$, as concentrações medidas no poço PC-9 por obter as maiores concentrações de 
cloreto e nitrato, ou seja, perto de uma fonte de contaminação. As demais porcentagens foram normatizadas a partir das concentrações do poço PC-9, para cada parâmetro. As concentrações de cloreto são maiores na ZR e vai diminuindo coma a profundidade. Sendo o cloreto um ín conservativo, o seu decréscimo é atribuido apenas a processos de dispersão hidráulica, não sendo adsorvido ou desadsorvido por nenhuma espécie sólida presente no sedimento.

Da mesma forma que o cloreto, os demais parâmetros físico-químicos, representados na Figura 7.25. apresentam um decréscimo em suas concentrações em função da profundidade, a exceção do sódio que diminui da ZR para a Zl e volta a aumentar na ZP. Comparando as taxas de dispersão do cloreto com os demais parâmetros nota-se que, além da dispersão hidráulica, outros fenômenos também devem ser considerados para explicar o comportamento das espécies. Esses fenômenos serão descritos para cada ín nos próximos parágrafos.

Ocorre diminuição nas concentrações de sódio e potássio das águas da $Z R$ para a ZI. As concentrações relativamente mais elevadas desses dois cátions nas águas da ZR estão relacionadas, à contaminação por vazamentos de fossas e/ou da rede de esgoto e/ou por fertilizantes.

A concentrações de potássio tendem a decrescer da ZR para a ZP. As concentrações, mais altas de potássio na ZR são causadas pela contaminação mencionada anteriormente e provável dissolução de K-feldspato. Como o potássio é um ín que tem como característica se fixar na fase sólida acredita-se que o seu decréscimo em relação à profundidade seja causado por trocas catiônicas. O processo de liberação do potássio do sedimento para a água seria a dissolução incongruente de $K$ - feldspato para caulinita através da reação da Equação 07. 


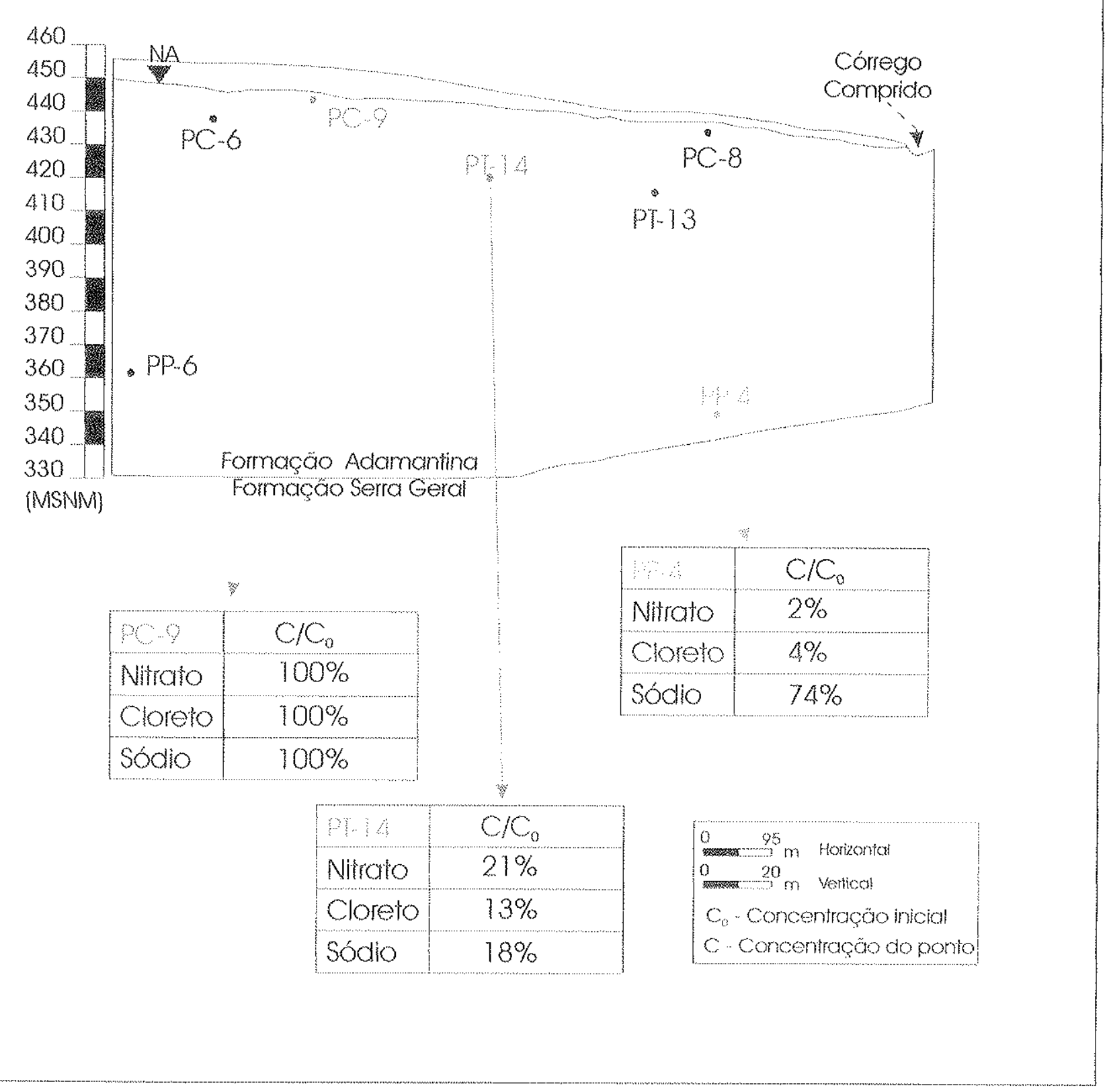

Figura 7.25.:Perfila da taxa de dispersáo do cloreto, nitrato e sódio 
A ocorrência desta reação no aqüifero estudado, pode ser confirmada através do diagrama de estabilidade mineral da Figura 7.21., onde nota-se que os pontos referentes às águas da ZR estão na parte inferior do campo da caulinita e que os pontos referentes às águas da $Z P$, situados na parte superior do campo da caulinita e no campo do K-feldspato. Com isso tem-se um indicativo da tendência do K-feldspato se intemperizar em caulinita liberando o potássio ao longo do fluxo da água subterrânea da ZR para a ZP.

$O$ decréscimo de sódio das águas $Z R$ para as da Zl está relacionada à dispersão e dissolução de feldspatos sódicos (albita) com troca catiônica. Esse fato ocorre pois o sódio apresenta porcentagem de dispersão próxima ao do cloreto, como demonstra a Figura 7.23., porém um pouco maior indicando um acréscimo deste ín. Quando a água subterrânea chega na Zl e flui para a ZP ocorre aumento na concentração de sódio, desta forma acredita-se que de alguma forma o sódio não sofre mais influências de troca catiônicas e ocorra a dissolução de feldspatos sódicos para caulinita através da reação da Equação 5.

Essa evolução pode ser observada através da Figura 7.23. que mostra uma tendência dos pontos relacionados às águas da ZP estarem próximos ao campo dos minerais primários mais ricos em sódio (albita) enquanto os pontos referentes às águas da ZR encontram-se no campo da caulinita.

A ausência de pontos no campo de estabilidade da albita deve-se ao fato de que este mineral é um feldspato sódico e que segundo a série de Goldich (Figura 4.1.) para intemperismo de minerais silicáticos, este tipo de feldspato é mais susceptivel ao intemperismo que o feldspato potássico. Desta forma todo o feldspato sódico teria sido intemperizado em minerais secundários para a illita e caulinita.

Os cátions, cálcio e magnésio, possuem comportamentos semelhantes. Ambos aumentam de concentração da ZR para a ZI devido trocas catiônicas e a provável dissolução de minerais (ca-montmorilonita, calcita e anfibólios e piroxênios cálcicos e magnesianos) e matriz carbonática presente nos 
sedimentos da Formação Adamantina, através das reações das Equações 01, 03 e 12.

Em alguns casos da ZI para a ZP o cálcio, o magnésio diminui e o sódio aumenta (Perfil 3). Este fato está relacionado à troca iônica entre o cálcio e magnésio por sódio. Essa troca ocorre pois cátions monovalentes tendem a ser substituído por cátions bivalentes (Hem, 1985). Pode-se confirmar esta observação através dos cálculos de índice de troca de base (icb) que é o desequilíbrio entre o cloreto e alcalinos através da fórmula:

$$
i c b=\frac{r C l-r(\mathrm{Na}+\mathrm{K})}{r \mathrm{Cl}} \quad \text { Equação } 14
$$

O cálculo de icb para os poços PC-9, PT-14 e PP-4, representando as três zonas do aqüífero, encontramse na Tabela 7.9., onde é possivel observar que os valores aumentam da ZR para a ZI e diminuem da ZI para ZP. De acordo com Custodio \& Llamas (1976), os valores de icb tendem a decrescer, quando ocorre a existência de troca entre cálcio e magnésio por sódio.

\begin{tabular}{|c|c|c|c|}
\hline \multicolumn{4}{|c|}{ 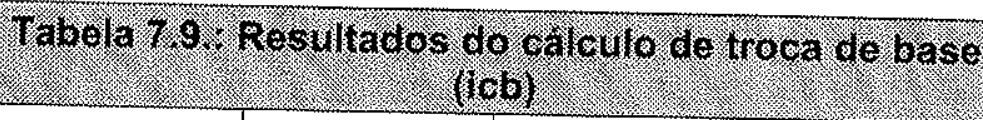 } \\
\hline Poço & PC.9/ZR & PT-14/ZI & PP.4/ZP \\
\hline $\mathrm{Icb}$ & $-0,55$ & 0,19 & $-27,35$ \\
\hline
\end{tabular}

Quanto aos ânions, observa-se que os valores de nitrato decrescem drasticamente da ZR para a ZP. Quando se compara com a porcentagem de dispersão do nitrato com a do cloreto, nota-se que a dispersão do nitrato é maior. Desta forma, além de dispersão, o nitrato pode estar sofrendo um incremento de outras fontes durante o fluxo da água subterrânea, como a evolução de nitrogênio orgânico para nitrato.

O aumento de bicarbonato na água deve-se a dissolução de minerais carbonáticos. Observa-se que o grande aumento da concentração deste ânion da ZR para a ZP coincide como aumento dos cátions cálcio e magnésio.

Observa-se que o $\mathrm{pH}$ tende a aumentar das águas mais rasas para as mais profundas e de descarga. Esse aumento está relacionado ao consumo de 
$\mathrm{H}^{+}$ao longo da linha de fluxo da água subterrânea com a dissolução dos carbonatos e dos aluminossilicatos.

A condutividade elétrica (CE) tende a diminuir da ZR para a ZP. Os altos valores de CE nas águas da $Z R$ são devido às concentrações anômalas dos ions relacionados à contaminação por vazamentos de fossas sépticas e/ou rede de esgoto e/ou fertilizantes. Ao longo do fluxo em direção às zonas mais profundas do aqüifero a influência da contaminação vai diminuindo e a CE também diminui como conseqüência. Observa-se nas Tabelas 7.6. e 7.8. que na ZR e Zl a CE é correlacionada com íons associados à contaminação antropica enquanto que na ZP a CE esta correlacionada à alcalinidade, $\mathrm{pH}$ e cátions relacionados à dissolução de minerais.

O Eh também tende a diminuir da ZR para a ZP, porém sua queda confirma a tendência das águas mais profundas serem menos oxidadas que as águas mais rasas.

Na Tabela 7.10. está representado um resumo das interpretações de dados obtidas neste trabalho para os três diferentes tipos de zonas.

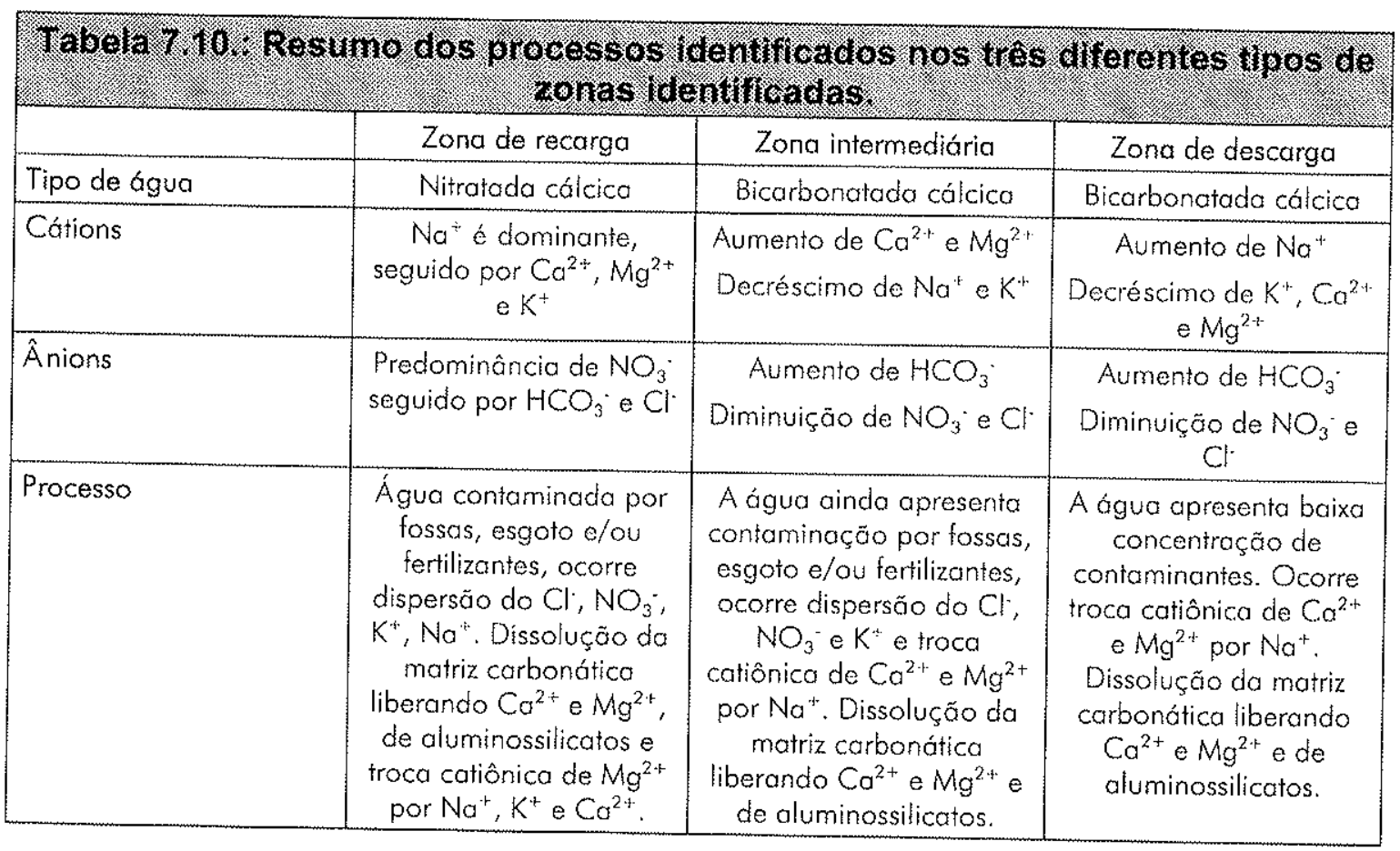




\section{CONCLUSÕES}

Os estudos mineralógicos dos sedimentos da Formação Adamantina na cidade de Urânia constituem de arenitos granulometricamente finos, composto principalmente por quartzo, montmorilonita cálcica, feldspatos (sódicos, cálcicos e potássicos), anfibólio e piroxênio cálcicos e magnesianos, carbonato (calcita e matriz carbonática), granada, caulinita, ilmenita, dentre outros minerais pesados.

Os sedimentos quimicamente são compostos por $\mathrm{SiO}_{2}(76 \%$ a $78 \%$ da massa), seguido pelo ferro e alumínio ( $4 \%$ a $10 \%$ da massa), $\mathrm{CaO}(3,5 \%$ da massa), $\mathrm{MgO}(1,5 \%), \mathrm{K}_{2} \mathrm{O}$ (1\% da massa) e $\mathrm{Na}_{2} \mathrm{O}(0,3 \%$ da massa). As concentrações de alguns cátions são baixas e próximas ao limite de detecção.

A capacidade de troca de cátions indicou valores de cerca de 16 e 170 meq/100 g, mostrando que a montmorilonita é o principal material adsorvente. A ordem de adsorção dos principais cátions de base é $\mathrm{Ca}, \mathrm{Mg}, \mathrm{H}$, Na e K.

As águas do aqüífero são divididas em zonas hidrogeoquímicas distintas, sendo a primeira denominada de zona rasa ou de recarga (ZR), representadas por poços cacimbas e com águas cloretadas cálcicas. A terceira é representada pelos poços profundos da SABESP e áreas de descarga (ZP), apresentando águas bicarbonatadas cálcicas ou magnesianas, a segunda zona seria uma intermediária às outras duas mencionadas (ZI). Essa evolução química se deve à presença de contaminação por fossas e/ou fertilizantes que deslocaram as análises das águas mais rasas de bicarbonatadas para cloro-nitratadas. Os ânions predominantes nas águas subterrâneas do Sistema Aqüifero Bauru no local são o bicarbonato, cloreto e nitrato. Quanto aos cátions o predomínio é o cálcico, havendo quantidade considerável de mistas.

A composição mineralógica dos sedimentos presentes na área contribui significativamente para a presença destes íons: os minerais carbonáticos e aluminossicáticos, são as principais fontes de enriquecimento iônico do meio aqüifero. Os processos identificados como controladores da composição química da água foram: a contaminação superficial do aqüifero por ações antropogênicas causando a ocorrência de elevadas concentrações de nitrato e 
cloreto, as reações de dissolução de quartzo, carbonatos e aluminossilicatos e formação de caulinita e formas criptocristalinas de sílica e calcita e reações de adsorção/troca iônica.

A evolução hidrogeoquímica das águas subterrâneas na área de estudo apresenta uma tendência de modificação química acompanhando a resultante de fluxo das águas subterrâneas em direção aos córregos Comprido e Matadouro (áreas de descarga). As águas tendem a ficar relativamente mais ricas em sódio e bicarbonato. 


\section{REFERÊNCIAS BIBLIOGRÁFICAS}

ALLISON, J. D.; BROWN, D. S.; NOVO-GRADAK, K. J. - 1991 MINTEQA2/PRODEFA2 - A Geochemical assessment model for environmental system. Version 3.0 - User's Manual. EPA Office of Research and Development. EPA/600/3-91/021.100p.

ALMODOVAR, M. L. N. - 1995 - Estudo da Anomalia de Cromo nas Águas Subterrâneas da Região Noroeste do Estado de São Paulo. São Paulo, 101 p. (Dissertação de Mestrado) - Instituto de Geociências Universidade de São Paulo.

ALMODOVAR, M. L. N. - 2000 - A origem natural da poluição por cromo no Aqüífero Adamantina, municipio de Urânia (SP) 212 p. Tese de Doutorado - Instituto de Geociências - Universidade de São Paulo.

ALVES, D. B. - 1990 - Influência dos tratamentos de dispersão de amostras na análise dos argilominerais por difração de raio $X$. Aplicação nos folhelhos cretáceos do flanco noroeste da bacia da foz do amazonas. Tese de doutoramento - Universidade Federal do Rio de Janeiro.

APPELO, C. A. \& POSTMA, D. - 1993 - Geochemistry, Groundwater and Pollution. A. A. Baukema, Brookfield, Vt. 536p.

BARCHA, S. F. - 1980 - Aspectos Geológicos e Províncias Hidrogeológicas da Formação Bauru na Região Norte-Ocidental do Estado de São Paulo, São José do Rio Preto. São José do Rio Preto, 209 p. Tese de Livre Docência - Inst. De Biociências, Letras e Exatas, Universidade Paulista.

BRANDT NETO, M. - 1977 - Estratigrafia da Formação Bauru na Região do Baixo Tieté, São Paulo. Dissertação de Mestrado, Inst. Geoc., USP.

BRANDT NETO, M.; PETRI, S.; COIMBRA, A. M. - 1984 - Argilominerais do Grupo Bauru: Considerações Genéticas. In: Simpósio Regional de Geologia, 5., São Paulo. Atas. São Paulo, SBG - Núcleo São Paulo. V.1, p. $61-74$.

BRANDT NETO, M.; BARELLI, N.; BARCGA, S. F.; COIMBRA, A. M. - 1987 Ocorrência de Analcina em Sedimentos da Formação Adamantina em Macedônia, Estado de São Paulo, uma Evidência de Hidrotermalismo no Grupo Bauru (no prelo).

CAMPOS, H. C. N. S. - 1987 - Contribuição do Estudo Hidrogeoquímico do Grupo Bauru no Estado de São Paulo. Dissertação de Mestrado Instituto de Geociências/USP. 
CAMPOS, H. C. N. S. - 1993 - Caracterização e Cartografia das Províncias Hidrogeoquímica do Estado de São Paulo. São Paulo, 177p. Tese de Doutorado - Instituto de Geociências/USP.

COIMBRA, A. M. - 1976 - Arenitos da Formação Bauru: estudo de áreas-fontes. Dissertação de Mestrado, Inst. Geoc., São Paulo, 2 v.

CUSTODIO, E. G. \& LLAMAS, M. R. - 1976 - Hidrologia Subterranea. Barcelona, Omega, 2 v.

DAEE - Departamento de Água e Energia Elétrica - 1974 - Estudo de Águas Subterrâneas; Regiäo Administrativa 6, Ribeirão Preto-SP, Geopesquisadore - Tahal, 2 v.

DAEE - Departamento de Água e Energia Elétrica - 1976 - Estudo de Águas Subterrâneas; Regiões Administrativas 7, 8 e 9 (Bauru, São José do Rio Preto e Araçatuba), São Paulo-ENCO, 4 v.

DAEE - Departamento de Água e Energia Elétrica - 1979 - Estudo de Águas Subterrâneas; Regiões Administrativas 10 e 11 (Presidente Prudente e Marília), São Paulo, 3 v.

DAEE - Departamento de Água e Energia Elétrica - 1988 - Águas Subterrâneas: Reservas Estratégicas. Água e Energia.DAEE5(13):13-23.

DAVIS, J. C. - 1973 - Statistics and data analysis in geology. Willey, New York. 550 p.

DEUTSCH, W. J. - 1997 - Groundwater Geochemistry - Fundamentals and Applications to Contamination. Lewis Publishers, 221p.

DREVER, J. - 1988 - The Chemical of Natural Waters. Prentice Hall. Englewood Cliffs, NJ. 604p.

FERNANDES, L. A. - 1998 - Estratigrafia e Evolução Geológica da Parte Oriental da Bacia Bauru (Ks, Brasil). Dissertação de Doutorado, Inst. Geoc., USP.

HEM, J. D. -1985 - Study and Interpretation of the Chemical Characteristics of Natural Water. U.S. Geologycal Survey Supply Paper, v.2254.

HIRATA, R.; BASTOS, C.; ROCHA, G. - 1997 - Mapeamento da Vulnerabilidade a Poluição dos Aqüíferos do Estado de São Paulo. Secretaria do Meio Ambiente do Estado de São Paulo. São Paulo, 2 v. 
HIRATA, R. C. A.;RODOLFI, G. - 1993 - Presença de cromo nas águas subterrâneas em Urânia. São Paulo, Secretaria do Meio Ambiente/Instituto Geológico. 24p. (Relatório Técnico).

ICDD (International Center for Difraction Data). - 1995 - Power diffraction file: PDF-2 Database Sets 1-45. Pennsylvania, ICDD. (CD-ROM).

IGC (INSTITUTO DE GEOGRÁFICO E CARTOGRÁFICO) \& DAEE (DEPARTAMENTO DE ÁGUAS E ENERGIA ELÉTRICA) - 1996 Unidades Hidrográficas de Gerenciamento de Recursos Hídricos do Estado de São Paulo - Escala 1.1000.000. Plano Estadual de Recursos Hídricos/Plano Cartográfico so Estado de São Paulo.

JANASI, V. A.; ANDRADE, S.; ULBRICH, H. H. G. J. - 1996 - A correção de drift instrumental em ICP-AES com espectrômetro seqüencial e análises de elementos maiores, menores e traços em rochas. Boletim IG-USP, Série Científica, v. 26, p. 45-58.

MEZZALIRA, S.; SALATI, E; MATSUI, E; BOTELHO, P.F.; VIEIRA, P.C. - 1979 - Contribuição Geoquímica ao estudo das Águas da Formação Bauru na Bacia do Rio São José dos Dourados, SP. Na. Acad. Bras. Cienc. 51 (4): $677-694$.

PALMER, C. \& CHERRY, J. - 1984 - Geochemical Evolution of Groundwater in Sequences of Sedimentary Rocks: J. Hydrol.75:27-65.

PARKHURST, D. L. - 1995 - User's guide to PHREEQC, a computr model for speciation, reaction path, advective transport and inverse Geochemical calculations. U. S. Geological Survey.

RAIJI, B. van \& QUAGGIO, J. A. - 1983. Métodos de análise de solo para fins de fertilidade. Boletim Técnico 81. Instituto Agronômico de Campinas. Campinas - SP.

ROCHA, G. A.; BERTACHIN!, A. C,; CAMPOS, H. C. N. S.; CAIXETA, J. B. 1982 - Tentativa de Zoneamento das Características Hidráulicas e Hidroquímicas do Aqüífero Bauru. In: Encontro de Geologia e Hidrogeologia do Grupo Bauru no Estado de São Paulo, 1., São Paulo, SBG/ABAS. p. 37-57.

ROSS, J. L. C.; MOROZ, I. C. - 1997 - Mapa Geomorfológico do Estado de São Paulo - escala 1:500.000. Convênio FFLCH USP (Faculdade de Filosofia, Letras e Ciências Humanas) e IPT (Laboratório de Cartografia Geotécnica - DIGEO). 
ROSSATO, F.M. - 1999 - Modelação Matemática bidimensional na definição de zona de captura de poços no Aqüífero Adamantina, Município de Urânia, noroeste do Estado de São Paulo. Monografia de Trabalho de Formatura. Instituto de Geociências - USP.

SOARES, P. C.; LANDIM, P. M. B.; FÚLFARO, V. J.; SOBREIRO NETO, A. F. . 1980 - Ensaio de Caracterização Estratigráfica do Cretáceo no Estado de São Paulo. Ver. Bras. Geoc., 10: 177.

TALTASSE, P. - 1968 - Os Fácies Hidroquímica no Estado de São Paulo. In: $22^{\circ}$ Congr. Bras. Geol., Belo Horizonte. Anais.. 1:263-266.

TRUESDELL, A. H. \& JONES, B. R. - 1973 - WATEC, a computer program for calculating chemical equilibria of natural water. US Geological Survey, National Techinical Information Service, PB-220 264.

WUTKE, A. C. P.; CAMARGO, O. A. - 1972 - Adsorção e Troca lônica. In: MONIZ, A. C. (org) - Elementos de Pedologia. Editora Universidade de São Paulo, p111-147. 
Anexo 1

\author{
Cadastro dos Poços e \\ Medição de Nível D’água
}




\section{Cadastro de poços cacimbas de Urânia}

\begin{tabular}{|c|c|c|c|c|c|c|c|c|c|}
\hline Poço & Proprietário & Endereço & $\begin{array}{c}\text { Diàm. } \\
(\mathrm{m})\end{array}$ & $\begin{array}{c}\text { Prof. } \\
\text { (m) }\end{array}$ & $\begin{array}{c}\text { N.água } \\
(\mathrm{m})\end{array}$ & $\begin{array}{l}\text { Uso da } \\
\text { água }\end{array}$ & $\begin{array}{l}\text { Equip. } \\
\text { bomb. }\end{array}$ & $\begin{array}{l}\text { Provável } \\
\text { ano perf. }\end{array}$ & Observaçōes \\
\hline PC 01 & $\begin{array}{l}\text { Raul Cardoso da } \\
\text { Silva } \\
\end{array}$ & $\begin{array}{l}\text { R. Esperança, } \\
264 \\
\end{array}$ & 1,20 & 13,0 & $\begin{array}{c}\text { poço } \\
\text { lacrado }\end{array}$ & Bebem & Sim & 1994 & $\begin{array}{c}\text { Poço tampado com laje de concreto. Quintal de terra ao redor do } \\
\text { poço }\end{array}$ \\
\hline PC 02 & Jacob Azol & R. Rio Preto,572 & 1,10 & 16,0 & 12,8 & Nāo bebem & Sim & 1992 & $\begin{array}{c}\text { Poço tampado com laje de concreto. Quintal de terra com } 20 \mathrm{~cm} \text { de } \\
\text { cimento ao redor do poço }\end{array}$ \\
\hline $\mathrm{PC} 03$ & $\begin{array}{c}\text { Antônio Peres } \\
\text { Paiares }\end{array}$ & $\begin{array}{l}\text { Av. Brasil, } \\
687 \\
\end{array}$ & 1,00 & 15,0 & 12,0 & Nāo bebem & $\operatorname{sim}$ & 1994 & Poço tampado com laje de concreto. Quintal cimentado. \\
\hline PC 04 & Antônio Ruiz & $\begin{array}{c}\text { Av. Brasil, } \\
785 \\
\end{array}$ & 1,35 & 16,0 & 14,1 & Não bebem & $\operatorname{Sim}$ & 1990 & $\begin{array}{l}\begin{array}{l}\text { Poço tampado com laje de concreto. Quintal de terra ao redor } \\
\text { do poço. }\end{array} \\
\text {. }\end{array}$ \\
\hline PC 05 & $\begin{array}{c}\text { Flaminio Flávio } \\
\text { Estal }\end{array}$ & $\begin{array}{l}\text { R. Guanabara, } \\
389 \\
\end{array}$ & 1,00 & 10,0 & 8,0 & Bebem & $\operatorname{Sim}$ & 1997 & Poço lacrado com laje de concreto. Quintal cimentado. \\
\hline PC 06 & Joāo Gasqui & $\begin{array}{l}\text { R. Esperança, } \\
219 \\
\end{array}$ & 1,00 & 15,0 & 9,0 & Não bebem & $\operatorname{Sin}$ & 1989 & $\begin{array}{l}\text { Poço tampado com faje de concreto. Quintal de terra ao fedor } \\
\text { do poço. Utiliza-se esterco animal na horta. }\end{array}$ \\
\hline PC 07 & Inácio Gonçalves & $\begin{array}{l}\text { R. Rio Preto, } \\
200\end{array}$ & 1,20 & 16,0 & $\$ 2,9$ & Bebem & $\operatorname{Sim}$ & 1993 & $\begin{array}{l}\text { Poço tampado com laje de concreto. Quintal todo calçado. O } \\
\text { vizinho possui uma horta. }\end{array}$ \\
\hline PC 08 & Rossini & $\begin{array}{l}\text { R. Benedito D. } \\
\text { Mendes, } 235\end{array}$ & 0,85 & 5,2 & 3,3 & Não be bem & $\operatorname{Sim}$ & 1990 & Poço tampado com laje de concreto. Quintal todo cimentado. \\
\hline PC 09 & Antônio Beltrami & $\begin{array}{l}\text { Av. Presidente } \\
\text { Kennedy, } 227\end{array}$ & 1,20 & 9,0 & 6,5 & Nāo bebem & $\operatorname{Sim}$ & & $\begin{array}{l}\text { Poço tampado com laje de concreto. Quintal todo cimentado. Os } \\
\text { atuais moradores vivem nesta casa a dois anos. }\end{array}$ \\
\hline PC 10 & $\begin{array}{l}\text { José Cartos } \\
\text { Chaves }\end{array}$ & R. Ceará, 159 & 1,00 & 18,0 & 16,0 & Năo bebem & $\operatorname{Sim}$ & 1997 & $\begin{array}{l}\text { Poço lacrado. Quintal de terra ao redor } \\
\text { do poço. }\end{array}$ \\
\hline$P C 11$ & Anorí de Fátima & R. Tanabi, 287 & 1,20 & 15,0 & 12,0 & Não bebem & Sim & & Poço tampado com laje de concreto. Quintal todo cimentado. \\
\hline PC 12 & $\begin{array}{l}\text { Laurito Roque } \\
\text { Nunes }\end{array}$ & $\begin{array}{l}\text { R. Maranhão, } \\
230\end{array}$ & 1,20 & 8,1 & 7.1 & Nāo bebem & $\operatorname{sim}$ & 1992 & $\begin{array}{l}\text { Poço tampado com várias tábuas e com } 50 \mathrm{~cm} \text { de azulejo ao redor. } \\
\text { Existe uma fossa com cota topográfica maior do que a do poço. }\end{array}$ \\
\hline
\end{tabular}




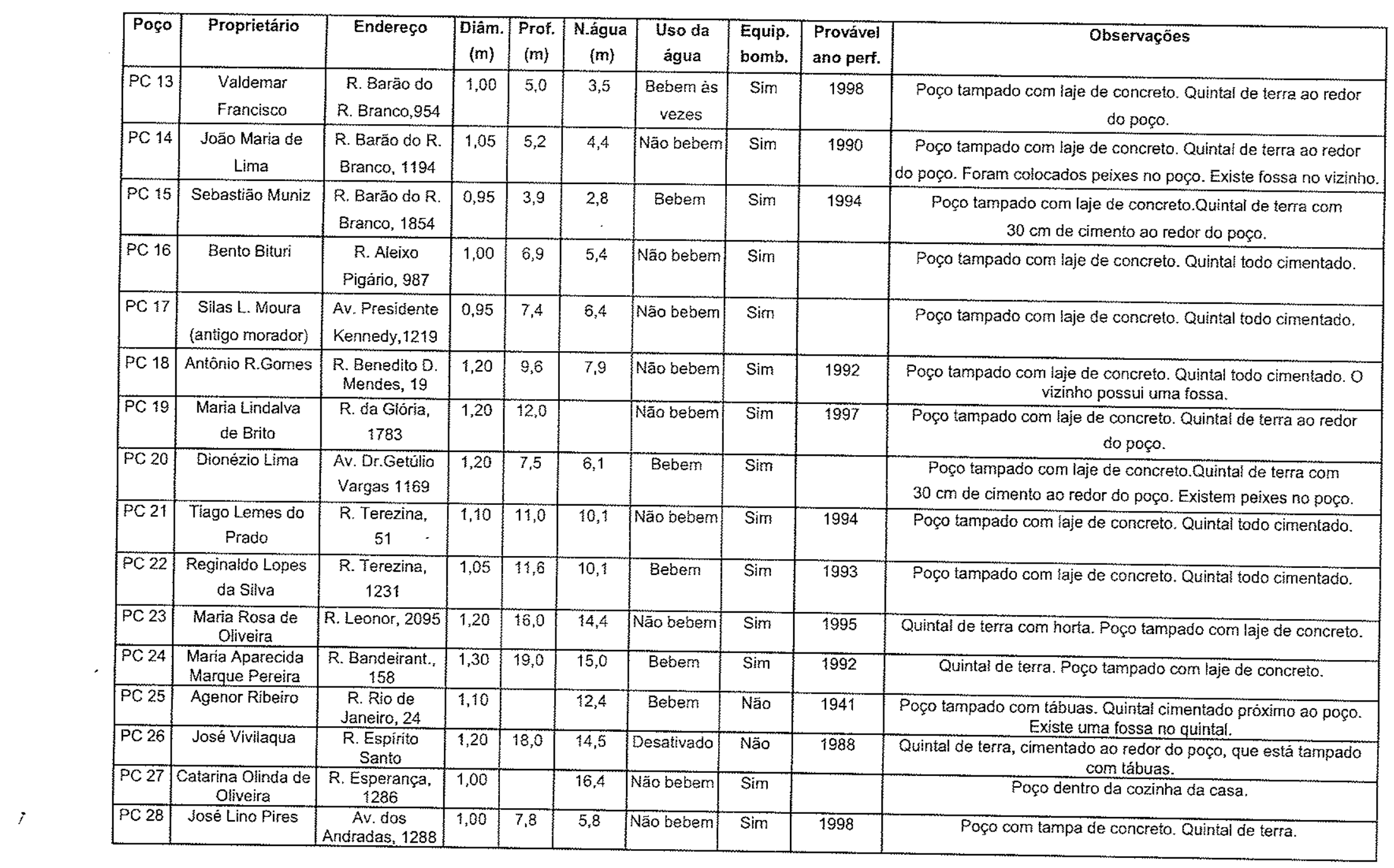


Cadastro de poços tubulares particulares de Urânia.

\begin{tabular}{|c|c|c|c|c|c|c|c|c|c|c|}
\hline Poço & Proprietário & Endereço & $\begin{array}{l}\text { Prof. } \\
\text { (m) }\end{array}$ & $\begin{array}{c}\text { N.água } \\
(\mathrm{m})\end{array}$ & $\begin{array}{l}\text { Vazâo } \\
\left(\mathrm{m}^{3} / \mathrm{h}\right)\end{array}$ & $\begin{array}{c}\text { Tubo } \\
\text { encam. }(\mathrm{m})\end{array}$ & $\begin{array}{l}\text { Provável } \\
\text { ano perf. }\end{array}$ & $\begin{array}{c}\text { Firma } \\
\text { perfuradora }\end{array}$ & $\begin{array}{l}\text { Uso da } \\
\text { água }\end{array}$ & Observaçōes \\
\hline PT 01 & Mário Akamatsu & R. Jales, 443 & 50,0 & 30,0 & 1,5 & 22,0 & 1992 & & Não bebem & Quintal de terra. Utilizou-se esterco animal na horta. \\
\hline PT 02 & Jorge Tadashi & R. Natal, 1384 & 59,0 & 27,0 & 0,7 & 9,0 & 1996 & $\begin{array}{c}\text { Contratada da } \\
\text { Jima }\end{array}$ & Bebem & Quintal cimentado ao redor do poço \\
\hline PT 03 & $\begin{array}{l}\text { Wilson Fernandes } \\
\text { dos Santos }\end{array}$ & $\begin{array}{c}\text { R. } 21 \text { de } \\
\text { Novembro, } 489\end{array}$ & 50,0 & 12,0 & 2,0 & 27,0 & 1995 & $\begin{array}{l}\text { Firma de Sta. } \\
\text { Clara do Oeste }\end{array}$ & Nấo bebem & $\begin{array}{l}\text { Quintal cimentado ao redor do poço. } \\
\text { Poço com cobertura de concreto. }\end{array}$ \\
\hline PT 04 & $\begin{array}{l}\text { Francisco Airton } \\
\text { Saracuza }\end{array}$ & Av. Brasil, 995 & 50,0 & & 1,3 & 16,0 & 1996 & Franzini & Não bebem & $\begin{array}{l}\text { Quintal cimentado ao redor do poço. } \\
\text { Poço com cobertura de concreto. }\end{array}$ \\
\hline PT 05 & $\begin{array}{c}\text { Alírio Fazzio (fábrica } \\
\text { de móveis) }\end{array}$ & $\begin{array}{l}\text { Rod. Euclides da } \\
\text { Cuniha, km } 549,5\end{array}$ & $\begin{array}{l}\text { aprox. } \\
180\end{array}$ & & & & 1966 & & Bebem & $\begin{array}{l}\text { Quando o atual proprietário comprou o terreno o } \\
\text { poço já existia. Existe uma fossa próxima ao poco. }\end{array}$ \\
\hline PT 06 & $\begin{array}{c}\text { Almindo Gitti } \\
\text { (Posto fpiranga) }\end{array}$ & Av. Brasit, 684 & 60,0 & & 2,0 & 60,0 & 1993 & & Não bebem & Quintal cimentado ao redor do poço \\
\hline PT 07 & Auto Posto Urânia & $\begin{array}{c}\text { R. Barão do } \\
\text { Rio Branco, } 133\end{array}$ & 60,0 & & 3,6 & 24,0 & 1997 & Gima (Jales) & Nâo bebem & $\begin{array}{l}\text { Quintal nâo cimentado ao redor do poço. A água } \\
\text { do poço vai direto para a caixa d'água. }\end{array}$ \\
\hline PT 08 & Ozirio Barison & $\begin{array}{l}\text { Av. Presidente, } \\
\text { Chácar. Boa } \\
\text { Vista }\end{array}$ & 100,0 & & 10,0 & 17,0 & 1991 & $\begin{array}{c}\text { Firma } \\
\text { (Tabapuā) }\end{array}$ & Bebem & $\begin{array}{l}\text { Quintal nâo cimentado ao redor do poço. Utililiza-se } \\
\text { esterco animal na horta. }\end{array}$ \\
\hline PT09 & $\begin{array}{l}\text { Adelino Gitti (Auto } \\
\text { Posto Texaco) }\end{array}$ & Av. Brasil, 10 & 100,00 & & 10,0 & 100,00 & 1988 & & Bebem & $\begin{array}{l}\text { Quintal de terra.Quando o poço foi construido, } \\
\text { apresentou } 0,03 \text { mg/L de cromo. }\end{array}$ \\
\hline PT 10 & $\begin{array}{c}\text { Sta. Casa da Miser. } \\
\text { (Sr. Jacinto) }\end{array}$ & $\begin{array}{c}\text { R. da Glória, } \\
218\end{array}$ & 80,00 & 50,00 & & & 1993 & \begin{tabular}{|l|} 
Darson Zagato \\
(Fernandópolis)
\end{tabular} & Não bebem & $\begin{array}{l}\text { Caixa de concreto ao redor do poço. Quintal de } \\
\text { terra. A água do poço vai p/ a caixa d'água. }\end{array}$ \\
\hline PT 11 & Adail Amorin & $\begin{array}{l}\text { R. da Saudade, } \\
595\end{array}$ & 60,00 & & 2,5 & 28,00 & 1997 & $\begin{array}{c}\text { Água Rasa } \\
\text { (Jales) }\end{array}$ & Não bebem & Caixa de concreto ao redor do poço. Quintal de terra. \\
\hline PT 12 & Luís Carlos de More & $\begin{array}{c}\text { Final da R. Bom } \\
\text { Jesus }\end{array}$ & 52,00 & 27,00 & 0,9 & 30,00 & 1994 & & Bebem & Quintal de terra ao redor do poço. \\
\hline PT 13 & Urbano Scapin & R. Tanabi, 287 & 48,00 & 1,80 & 6,0 & 12,00 & 1993 & $\begin{array}{c}\text { Frazini Bombas } \\
\text { (Jales) }\end{array}$ & Bebem & Quintal cimentado ao redor do poço \\
\hline PT 14 & Clube dos 100 & $\begin{array}{c}\text { R. Barão do Rio } \\
\text { Branco, } 546\end{array}$ & 45,00 & & 1,8 & 42,00 & 1995 & $\begin{array}{c}\text { Frazini Bombas } \\
\text { (Jales) }\end{array}$ & Bebem & $\begin{array}{l}\text { Terreno nāo cimentado ao redor do poço. Existe uma } \\
\text { fossa ativada na sauna. }\end{array}$ \\
\hline PT 15 & Jorge Yaguiu & R. São Paulo, 15 & 40,00 & & & 8,00 & 1989 & & Bebem & Quintal de terra ao redor do poço. \\
\hline PT 16 & Antônio Vila & R. Dona Leonor & 60,00 & 13,00 & 2,6 & 40,00 & 1997 & $\begin{array}{c}\text { Agua Rasa } \\
\text { (Jales) }\end{array}$ & Não bebem & $\begin{array}{l}\text { Quintal de terra ao redor do poço. Utiliza-se esterco } \\
\text { animal na horta. }\end{array}$ \\
\hline
\end{tabular}


Cadastro de poços tubulares da SABESP de Urânia

N.E.: nivel estático; N.D.: nivel dinâmico

\begin{tabular}{|c|c|c|c|c|c|c|c|c|c|c|c|c|c|}
\hline Poço & Endereço & $\begin{array}{c}\text { Coord. } \\
\text { N-S/E-W }\end{array}$ & $\begin{array}{l}\text { Cota } \\
\text { (m) }\end{array}$ & $\begin{array}{l}\text { Prof. } \\
\text { (m) }\end{array}$ & $\begin{array}{l}\text { N.E. } \\
\text { (m) }\end{array}$ & $\begin{array}{l}\text { N.D. } \\
\text { (m) }\end{array}$ & $\begin{array}{l}\text { Vazão } \\
\text { (m3/h) }\end{array}$ & Geologia & $\begin{array}{c}\text { Filtros } \\
\text { de-até }(\mathrm{m})\end{array}$ & $\begin{array}{c}\text { Cimentaç. } \\
(\mathrm{m})\end{array}$ & $\begin{array}{l}\text { Ano de } \\
\text { perfur. }\end{array}$ & $\begin{array}{c}\text { Firma } \\
\text { perfuradora }\end{array}$ & Uso \\
\hline PP 01 & R. Goiás, 8 & $\begin{array}{c}7762 \\
536,88 \\
\end{array}$ & & 160,0 & 40,0 & 99,8 & 8,0 & $0,0-160,0$ G. Bauru & & & 1979 & & $\begin{array}{l}\text { Desativado } \\
\text { sem bomba }\end{array}$ \\
\hline PP 02 & R. Fortaleza & $\begin{array}{l}7761,8 \\
537,07\end{array}$ & & 155,0 & 50,0 & 83,8 & 15,0 & $0,0-155,0$ G. Bauru & & & 1979 & & $\begin{array}{l}\text { Desativado, } \\
\text { com bomba }\end{array}$ \\
\hline PP 03 & Av. da Saudade & $\begin{array}{c}7761,9 \\
537,2 \\
\end{array}$ & & 150,0 & 32,0 & 90,2 & 8,0 & $0,0-150,0$ G. Bauru & & & & & $\begin{array}{l}\text { Desativado, } \\
\text { com bomba }\end{array}$ \\
\hline PP 04 & $\begin{array}{l}\text { R. Bened. Duarte Mendes } \\
\text { com Barão do Rio Branco }\end{array}$ & $\begin{array}{l}7761,3 \\
537,36 \\
\end{array}$ & 450 & 109,2 & 24,0 & 69,8 & 18,0 & $\begin{array}{c}\text { 0,0-102,6 G. Bauru } \\
\text { 102,6-109,2 S. Geral }\end{array}$ & $\begin{array}{c}69,22 \\
109,21 \\
\end{array}$ & $0,00-18,00$ & 1979 & $\begin{array}{c}\text { Waldemar Georg. } \\
\text { e Cia Ltda. }\end{array}$ & $\begin{array}{l}\text { Desativado, } \\
\text { com bomba }\end{array}$ \\
\hline PP 05 & $\begin{array}{l}\text { Próximo à Lagoa de } \\
\text { tratamento de esgoto }\end{array}$ & $\begin{array}{l}7761,6 \\
538,2 \\
\end{array}$ & 430 & 75,0 & 4,6 & 60,5 & 13,7 & $\begin{array}{l}\text { 0,0-66,0 G. Bauru } \\
66,0-75,0 \text { S. Geral } \\
\end{array}$ & $\begin{array}{l}44,20 \\
65,90 \\
\end{array}$ & $0,00-10,00$ & 1979 & $\begin{array}{c}\text { Hidrotécnica Serv. } \\
\text { Geol. Ltda. } \\
\end{array}$ & $\begin{array}{c}\text { Destivado e } \\
\text { lacrado }\end{array}$ \\
\hline PP 06 & R. Goiás & $\begin{array}{l}7761,3 \\
535,6 \\
\end{array}$ & 460 & 120,0 & 10,0 & 96,4 & 17,2 & $\begin{array}{c}\text { 0,0-117,0 G. Bauru } \\
117,0-120,0 \text { S. Geral }\end{array}$ & $\begin{array}{c}59,81 \\
112,53\end{array}$ & $0,00-17,00$ & 1982 & $\begin{array}{c}\text { Hidrogesp Poços } \\
\text { Artesian.Com. Ltda. } \\
\end{array}$ & $\begin{array}{l}\text { Desativado, } \\
\text { sem bomba }\end{array}$ \\
\hline PP 08 & $\begin{array}{c}\text { Margem esquerda da } \\
\text { Rod. Euclides da Cunha }\end{array}$ & $\begin{array}{l}7762,4 \\
536,08 \\
\end{array}$ & 480 & 145,0 & 23,0 & 122,7 & 8,8 & $\begin{array}{c}\text { 0,0-138,0 G. Bauru } \\
138,0-145,0 \text { S. Geral }\end{array}$ & & $0,00-18,00$ & 1991 & Politi & \begin{tabular}{|l|} 
Desativado, \\
sem bomba
\end{tabular} \\
\hline PP 09 & $\begin{array}{c}\text { Próximo ao Córrego } \\
\text { Comprido }\end{array}$ & $\begin{array}{l}7763,4 \\
539,25\end{array}$ & 420 & 270,0 & & & 2,2 & $\begin{array}{c}\text { 0,0-67,6 G. Bauru } \\
67,6-270,0 \text { S. Geral }\end{array}$ & & $0,00-18,00$ & 1995 & Geoplan & $\begin{array}{c}\text { Não foi } \\
\text { explorado }\end{array}$ \\
\hline
\end{tabular}


Monitoramento do Nivel D'água

\begin{tabular}{|c|c|c|c|c|}
\hline Poço & Data da medição & Nive d'água & Cota & Carga Hdráulica \\
\hline PC-44 & $26 / 09 / 2001$ & 1,93 & 429,00 & 427,07 \\
\hline PC-02 & $26 / 09 / 2001$ & 14,47 & 465,56 & 451,08 \\
\hline PC-06 & $26 / 09 / 2001$ & 11,89 & 456,38 & 444,49 \\
\hline PC-34 & $26 / 09 / 2001$ & 11,80 & 456,60 & 444,80 \\
\hline PC-35 & $26 / 09 / 2001$ & 10,56 & 455,00 & 444,35 \\
\hline PC-25 & $26 / 09 / 2001$ & 13,13 & 451,36 & 438,22 \\
\hline PC-38 & $26 / 09 / 2001$ & 6,96 & 450,00 & 443,00 \\
\hline PC-45 & $26 / 09 / 2001$ & 13,63 & 460,74 & 447,11 \\
\hline PC-27 & $26 / 09 / 2001$ & 17,15 & 462,76 & 445,61 \\
\hline PC-26 & $26 / 09 / 2001$ & 18,48 & 465,83 & 446,82 \\
\hline PC-28 & $26 / 09 / 2001$ & 6,41 & 449,67 & 443,26 \\
\hline PC-40 & $26 / 09 / 2001$ & 7,22 & 450,00 & 442,78 \\
\hline PC-32 & $26 / 09 / 2001$ & 7,76 & 437,60 & 429,84 \\
\hline PC-29 & $26 / 09 / 2001$ & 8,15 & 444,17 & 436,02 \\
\hline PT-19 & $26 / 09 / 2001$ & 3,93 & 446,35 & 442,41 \\
\hline PC-09 & $26 / 09 / 2001$ & 6,97 & 451,17 & 444,2 \\
\hline PC-22 & $26 / 09 / 2001$ & 11,32 & 454,30 & 442,97 \\
\hline PC-24 & $26 / 09 / 2001$ & 17,02 & 468,88 & 441,18 \\
\hline PC-10 & $26 / 09 / 2001$ & 15,87 & 461,85 & 448,98 \\
\hline PC-101 & $26 / 09 / 2001$ & 11,38 & 460,00 & \\
\hline
\end{tabular}




\section{Anexo 2}

Resultados Analíticos dos Sedimentos 


\begin{tabular}{|c|c|c|c|c|c|c|c|}
\hline \multicolumn{8}{|c|}{ ANALISE GRANULOMETRICA POR PIPAGEM E PENEIRAMENTO } \\
\hline \multirow{2}{*}{\multicolumn{8}{|c|}{ GCUSP - GSA - LABSED }} \\
\hline & & & & & & & \\
\hline \multicolumn{8}{|c|}{$\frac{\text { Data: } 16 / 08 / 01}{\text { Amostra: EXP } 44-48}$} \\
\hline Amostra: EXP & $44-48$ & & & Massa Dis & spersar & 1 & \\
\hline \multicolumn{4}{|c|}{ Antes da separação granulométrica } & \multicolumn{4}{|c|}{ Após separação granulométrica } \\
\hline \multicolumn{3}{|c|}{ Massa total inicial - $\mathrm{Mi}(\mathrm{g})$} & 48 & \multicolumn{3}{|c|}{ Particulas $4000-0,062\langle\mathrm{~g}\rangle$} & 40,9 \\
\hline \multicolumn{3}{|c|}{ Massa dos seixos $(\mathrm{g})$} & 0 & \multicolumn{3}{|c|}{ Particulas menores $0,062(\mathrm{~g})$} & 9,145 \\
\hline \multicolumn{3}{|c|}{ Eliminação ataque quimico $(g)$} & 0 & \multicolumn{3}{|c|}{ Massa total final $-M f(g)$} & 50,045 \\
\hline \multicolumn{3}{|c|}{ Volume da proveta . Vp (ml) } & 1000 & \multicolumn{3}{|c|}{ Fator de correçäo - Mi/Mi } & 0,9591 \\
\hline \multicolumn{8}{|c|}{ PIPETAGEM } \\
\hline Granulometria & \multicolumn{2}{|c|}{ Tempo (min:s) } & M. total $(g)$ & M. frasco $(g)$ & M. alíquota (g) & M. suspens allq (g) & M. susp. Total (g) \\
\hline$(m m)$ & $10 \mathrm{~cm}$ & $20 \mathrm{~cm}$ & Mt & Mfr & Mt-Mfr-D & Ms & $\mathrm{Ms}^{*} \mathrm{Vp} / 20$ \\
\hline $0,062-0,031$ & $00: 29$ & $00: 58$ & 11,386 & 10,9557 & 0,1829 & 0,0581 & 2,905 \\
\hline $0,031-0,016$ & $01: 56$ & $03: 52$ & 7,7777 & 7,6529 & 0,1248 & 0,0314 & 1,57 \\
\hline $0,016-0,008$ & $07: 44$ & $15: 28$ & 7,8918 & 7,7984 & 0,0934 & 0,0244 & 1,22 \\
\hline $0,008-0,004$ & $31: 00$ & $62 ; 00$ & 7,9281 & 7,8591 & 0,069 & 0,0212 & 1,0595 \\
\hline$<0,004$ & $123 ; 00$ & $246 ; 00$ & 7,83381 & 7,786 & 0,0478 & 0,0478 & 2,3905 \\
\hline \multicolumn{2}{|c|}{ PENEIRAMENTO } & \multicolumn{6}{|c|}{ CALCULOS PARA CURVA ACUMULATIVA E HISTOGRAMA } \\
\hline Granulometria (mm) & Massa $(g)$ & M. corrig. (g) & Prp. Massa (\%) & Prp. Acumulada (\%) & Wenthwort & Krumbein (phi) & \\
\hline $4,000-2,830$ & 0,0000 & 0,0000 & 0,0000 & 0,0000 & grânulo & & \\
\hline $2,830-2,000$ & 2,9000 & 2,7800 & 5,7900 & 5,7900 & grânuio & & \\
\hline प & -1 & מn: & 15 & MY & 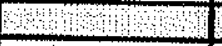 & & \\
\hline $2,000-1,410$ & 0,70 & 0,67 & 1,40 & 7,19 & areia $\mathrm{mt}$. grossa & & \\
\hline $1,410-1,000$ & 0,90 & 0,86 & 1,80 & 8,99 & areia mt. grossa & & \\
\hline $1,000 \sim 0,707$ & 0,60 & 0,58 & 1,20 & 10,19 & arela grossa & & \\
\hline $0,707-0,500$ & 0,80 & 0,77 & 1,60 & 11,79 & areia grossa & & \\
\hline $0,500-0,354$ & 2,20 & 2,11 & 4,40 & 16,19 & areia média & & \\
\hline $0,354-0,250$ & 5,80 & 5,56 & 11,59 & 27,78 & areia média & & \\
\hline $0,250-0,177$ & 10,20 & 9,78 & 20,38 & 48,16 & areia fina & & \\
\hline $0,177-0,125$ & 7,30 & 7,58 & 15,79 & 63,94 & arela fina & & \\
\hline $0,125-0,088$ & 6,50 & 6,23 & 12,99 & 76,93 & areia mt. fina & & \\
\hline $0,088-0,062$ & 2,40 & 2,30 & 4,80 & 81,73 & areia mt. fina & & \\
\hline$<0,002$ (fundo) & 0,00 & & & & silte/argila & & \\
\hline 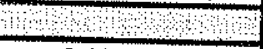 & 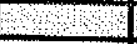 & 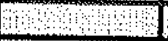 & 10 & 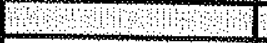 & \$ & & \\
\hline $0,062 \times 0,031$ & 2,905 & 2,79 & 5,80 & 87,53 & silte grosso & & \\
\hline $0,031-0,016$ & 1,57 & 1,51 & 3,14 & 90,67 & silte médio & & \\
\hline $0,016-0,008$ & 1,22 & 1,17 & 2,44 & 93,11 & sifte fino & & \\
\hline $0,008-0,004$ & 1,0595 & 1,02 & 2,12 & 95,22 & silte $\mathrm{mt}$. fino & & \\
\hline$<0,004$ & 2,3905 & 2,29 & 4,78 & 100,00 & argila & & \\
\hline Total & 50,05 & 48,00 & 100,00 & & & & \\
\hline
\end{tabular}




\begin{tabular}{|c|c|c|c|c|c|c|c|c|c|c|}
\hline \multicolumn{11}{|c|}{ PROGRAMA DE AVALIACAO DA FERTILIDADE DO SOLO } \\
\hline \multicolumn{11}{|c|}{ Análise química e CTC do solo } \\
\hline Data: & $19 / 03 / 2001$ & & & & & & & & & \\
\hline \multicolumn{2}{|c|}{ Amostras } & $M . O$ & $\mathrm{pH}$ & $\mathrm{K}$ & $\mathrm{Ca}$ & $\mathrm{Mg}$ & $\mathrm{H}+\mathrm{Al}$ & Al & $\mathrm{Na}$ & CTC \\
\hline Lab. & Solic. & $\mathrm{g} / \mathrm{dm}^{\mathrm{s}}$ & $\mathrm{CaCl}_{2}$ & & & & $\mathrm{nmol}_{\mathrm{c}} / \mathrm{K}$ & & & \\
\hline 392 & EXP22 & 5 & 5,2 & 2,3 & 22 & 25 & 14 & 1,2 & 4,3 & 63,3 \\
\hline 393 & EXP26 & 3 & 5,5 & 2,6 & 49 & 44 & 12 & 0.7 & 4,8 & 107,6 \\
\hline 394 & EXP30 & 2 & 5 & 2,4 & 24 & 28 & 13 & 1,1 & 4,4 & 67,4 \\
\hline 395 & EXP34 & 2 & 6,7 & 2,5 & 81 & 32 & 7 & 0,3 & 6,2 & 122,5 \\
\hline 396 & EXP40 & 2 & 6,9 & 2,4 & 88 & 30 & 7 & 0,3 & 6 & 127,4 \\
\hline 397 & EXP43 & 2 & 6,8 & 1,9 & 52 & 33 & 8 & 0,3 & 3,6 & 94,9 \\
\hline 398 & EXP52 & 2 & 6,9 & 1,5 & 48 & 15 & 7 & 0,3 & 3,3 & 71,5 \\
\hline 399 & EXP56 & 2 & 7,1 & 1,5 & 53 & 15 & 6 & 0,3 & 4,1 & 75,5 \\
\hline 400 & EXP60 & 2 & 7 & 1,6 & 56 & 15 & 6 & 0,3 & 5,2 & 78,6 \\
\hline 401 & EXP64 & 2 & 7,4 & 1,7 & 75 & 17 & 6 & 0,3 & 6,3 & 99,7 \\
\hline 402 & EXP78 & 2 & 7,4 & 1,4 & 60 & 12 & 7 & 0,3 & 7,3 & 80,4 \\
\hline 403 & EXP80 & 2 & 7,3 & 1,3 & 52 & 9 & 7 & 0,3 & 8,1 & 69,3 \\
\hline 404 & EXP44a48 & 2 & 7,3 & 3 & 235 & 65 & 7 & 0,3 & 12,4 & 310 \\
\hline 405 & ESC10 & 2 & 7,3 & 0,6 & 43 & 9 & 8 & 0,3 & 1,7 & 60,6 \\
\hline 406 & ESC14 & 2 & 6,2 & 2,8 & 84 & 18 & 12 & 0,3 & 7,5 & 116,8 \\
\hline 407 & ESC17 & 2 & 6,4 & 2,4 & 58 & 39 & 13 & 0,3 & 5,5 & 112,4 \\
\hline 408 & ESC20 & 2 & 6,6 & 4,3 & 174 & 53 & 8 & 0,3 & 11,8 & 239,3 \\
\hline 409 & ESC24 & 2 & 7,1 & 3,5 & 158 & 47 & 7 & 0,3 & 11,1 & 215,5 \\
\hline 410 & ESC28 & 2 & 7,3 & 2,3 & 107 & 28 & 7 & 0,3 & 7,3 & 144,3 \\
\hline 411 & ESC 32 & 2 & 7,3 & 2,2 & 84 & 25 & 7 & 0,3 & 7 & 118,2 \\
\hline 412 & ESC36 & 2 & 7,4 & 2,4 & 98 & 26 & 6 & 0,3 & 8,2 & 132,4 \\
\hline 413 & ESC40 & 2 & 7,3 & 2 & 74 & 21 & 6 & 0,3 & 7 & 103 \\
\hline 414 & ESC44 & 2 & 7,4 & 2,3 & 82 & 27 & 6 & 0,3 & 8,7 & 117,3 \\
\hline 415 & ESC52 & 2 & 7,5 & 2,4 & 96 & 24 & 6 & 0,3 & 9,7 & 128,4 \\
\hline 416 & ESC60 & 2 & 7,3 & 0,7 & 18 & 4 & 7 & 0,3 & 1,7 & 29,7 \\
\hline
\end{tabular}


LABORATÓRIO DE QUIMICA E ICP-AES

\begin{tabular}{|c|c|c|c|c|c|c|c|c|c|c|c|c|c|c|c|c|c|c|c|}
\hline \multicolumn{20}{|c|}{ uimica do solo } \\
\hline Data: & $19 / 3 / 2001$ & & & & & & & & & & & & & & & & & & \\
\hline \multicolumn{2}{|c|}{ Amostras } & $\% \mathrm{SiO}_{2}$ & $\% \mathrm{Al}_{2} \mathrm{O}_{3}$ & $\% \mathrm{Fe}_{2} \mathrm{O}_{3}$ & $\% \mathrm{MgO}$ & $\% \mathrm{CaO}$ & $\% \mathrm{Na}_{2} \mathrm{O}$ & $\% \mathrm{~K}_{2} \mathrm{O}$ & $\% \mathrm{P}_{2} \mathrm{O}_{5}$ & $\%$ Mno & & & & & & & & & \\
\hline Lab. & Solic. & & & & & & & & & & $\% \mathrm{TiO}_{2}$ & \%Total & $\% \mathrm{H}_{2} \mathrm{O}$ & $8 \mathrm{a}(\mathrm{ppm})$ & $\mathrm{La}(\mathrm{ppm})$ & $\operatorname{sr}(\mathrm{ppm})$ & $V(p p m)$ & $Y(\mathrm{ppm})$ & $\mathrm{Zr}(\mathrm{ppm})$ \\
\hline $\mathrm{LI}-145$ & EXP22 & 82,99 & 5.12 & 5.68 & 0,59 & 0.16 & 0,06 & 1,01 & $<0,01$ & & & & & & & & & & \\
\hline $41-146$ & EXP26 & 82.46 & 5.1 & 5,15 & 0,93 & 0,24 & 0,09 & 1.31 & $<0,01$ & $\frac{0,1}{0,14}$ & 1,64 & 99,82 & 0,86 & 324 & 29 & 28 & 119 & 13 & 272 \\
\hline LI-148 & EXP30 & 65.74 & 6.25 & 20,14 & 0.17 & 0.1 & 0.03 & 0,18 & 0.01 & $\frac{0,14}{0,04}$ & 1,59 & 99,53 & 1,16 & 341 & 38 & 45 & 98 & 17 & 234 \\
\hline$L-149$ & EXP34 & 74,82 & 5.02 & 5.32 & 2.06 & 4,19 & 0.42 & 1,3 & 0,07 & $\frac{0,04}{0,1}$ & 1.25 & 99,12 & 0,87 & 38 & 30 & $<5$ & 376 & 12 & 300 \\
\hline$L:-150$ & EXP40 & 79.53 & 4,5 & 5,09 & 1.78 & 2,55 & 0.36 & 1,32 & 0,07 & $\frac{0,1}{0,11}$ & 1.82 & 99,51 & 1.1 & 823 & 37 & 281 & 136 & 19 & 264 \\
\hline LI-151 & EXP43 & 84,82 & 3.93 & 4,4 & 0,86 & 0,46 & 0,18 & 1,25 & 0,04 & 0,11 & 1,77 & 99,95 & 0.77 & 709 & 32 & 130 & 127 & 18 & 271 \\
\hline$L i-154$ & EXP52 & 68,37 & 4.44 & 6,73 & 2.48 & 7,74 & 0,39 & 1,27 & 0.05 & 0,14 & 1,58 & 99,64 & 0,88 & 406 & 32 & 52 & 104 & 19 & 254 \\
\hline 나- 155 & EXP56 & 85,18 & 3,38 & 3,29 & 1,27 & 1,88 & 0,24 & 1 & $<0,01$ & 0,06 & 2,49 & 99,88 & 0,91 & 442 & 27 & 253 & 183 & 18 & 478 \\
\hline L. -156 & EXP60 & 84,2 & 3 & 2,77 & 1,08 & 3,51 & 0,3 & 1,05 & $<0,01$ & 0,06 & 1,06 & 99,8 & 0,92 & 305 & $<15$ & 103 & 73 & $<10$ & 196 \\
\hline $4-157$ & EXP64 & 78,22 & 3,83 & 3,36 & 1,43 & 5,19 & 0.45 & 1.2 & 0,04 & & 0,83 & 100,32 & 0,83 & 312 & 26 & 157 & 67 & $<10$ & 142 \\
\hline Ll-158a & EXP78 & 83,57 & 3,45 & 2.86 & 1,35 & 2,86 & 0,53 & 1.13 & 0,04 & $\frac{0,07}{0,06}$ & 0.99 & 99,5 & 0,97 & 374 & 22 & 221 & 89 & 13 & 156 \\
\hline $11-158 b$ & EXP78 & 83,62 & 3.47 & 2,96 & 1,34 & 2,92 & 0.54 & 1,14 & 0,04 & $\frac{0,06}{0,06}$ & 0,82 & 99,16 & 0,79 & 352 & 25 & 152 & 75 & 12 & 161 \\
\hline LI-159 & EXP30 & 84,03 & 3,45 & 2,7 & 1,36 & 3,09 & 0.56 & 1,13 & 0,04 & 0,06 & 0,81 & 99,39 & 0,79 & 340 & 24 & 148 & 69 & 12 & 150 \\
\hline Li-152 & EXP44348 & 43,48 & 5,28 & 4,77 & 4,6 & 20 & 0.03 & 1,33 & $\frac{0,04}{0.07}$ & 0.06 & 0.76 & 99,81 & 0,56 & 369 & 29 & 181 & 68 & 12 & 137 \\
\hline ti-160 & ESC10 & 87.81 & 2,93 & 3,2 & 0,19 & 0,97 & 0,05 & 0,22 & $\frac{0.07}{<0.01}$ & 0,08 & 1,1 & 99,8 & 2,56 & 309 & 38 & 549 & 64 & 16 & 127 \\
\hline Li-161 & ESC14 & 81,87 & 5,04 & 5.81 & 0,98 & 0,32 & 0,1 & 1,21 & $\frac{<0,07}{<0,01}$ & 0,04 & 1.12 & 98,69 & 0,42 & 68 & $<15$ & 30 & 91 & $<10$ & 241 \\
\hline Li-162a & ESC17 & 65,12 & 6,55 & 20,03 & 0.49 & 0,22 & 0,07 & 0,52 & $\frac{<0,01}{0,01}$ & 0,14 & 1,75 & 100,09 & 1,34 & 356 & 30 & 38 & 144 & 20 & 294 \\
\hline Li-162b & ESC17 & 65,25 & 6,45 & 20.06 & 0,49 & 0,22 & 0,07 & 0,54 & $\frac{0,01}{0,01}$ & 0.07 & 1,27 & 99,33 & 0,85 & 144 & $\angle 15$ & 20 & 441 & 12 & 272 \\
\hline LL-163 & ESC20 & 68,68 & 8,83 & 10 & 2.02 & 1.3 & 0.28 & 2.04 & $\frac{0,01}{0,1}$ & 0,07 & 1,26 & 99,39 & 0.85 & 142 & $<15$ & 19 & 429 & 12 & 264 \\
\hline Lif-164 & ESC24 & 69,74 & 6.06 & 6,21 & 1,85 & 5,49 & 0,3 & 1,7 & $\frac{0,1}{0,08}$ & 0,16 & 1,93 & 100,54 & 3,99 & 529 & 44 & 79 & 208 & 33 & 343 \\
\hline$[\mathrm{l}-147$ & ESC28 & 72.19 & 4,97 & 6,74 & 1,91 & 5,01 & 0,3 & 1,3 & $\frac{0,08}{0,06}$ & 0.13 & 1,67 & 99,84 & 1,74 & 452 & 38 & 157 & 133 & 25 & 291 \\
\hline L1-165 & $\overline{E S C 32}$ & 75,1 & 4,33 & $4,6 \overline{6}$ & 1,81 & 5,58 & 0.35 & 1,25 & $\frac{0,06}{0,06}$ & C.18 & 2,14 & 99,24 & 0,77 & 450 & 35 & 136 & 151 & 27 & 473 \\
\hline LI-169 & ESC36 & 74,9 & 4,87 & 6.88 & 2,14 & 3,82 & 0.37 & 1,27 & $\frac{0,06}{0,05}$ & 0,11 & 1,21 & 99,37 & 0,82 & 527 & 24 & 156 & 94 & 19 & 168 \\
\hline $4 \mid-166$ & ESC40 & 79,39 & 4.43 & 5,08 & 1,94 & 2,77 & 0,42 & 1,31 & $\frac{0,05}{0,05}$ & 0.17 & 2,44 & 99,82 & 0,86 & 409 & 26 & 121 & 177 & 24 & 437 \\
\hline$L[-167$ & ESC44 & 77.1 & 4,49 & 5,81 & 2,2 & 3,57 & 0,45 & 1,34 & $\frac{0,05}{0,06}$ & 0,11 & 1.79 & 99,47 & 0,72 & 454 & 21 & 126 & 123 & 17 & 271 \\
\hline $41-153 a$ & ESC52 & 86.09 & 2,98 & 3,73 & 1,19 & 1,56 & 0.22 & 0,92 & $\frac{0,06}{0,02}$ & 0,13 & 2,18 & 99.84 & 0,76 & 484 & 27 & 160 & 152 & 18 & 380 \\
\hline $41-153 b$ & ESC52 & 86,56 & 2,96 & 3,71 & 1,19 & 1,53 & 0,22 & 0,91 & $\frac{0,02}{<0,01}$ & 0,08 & 1.45 & 99,91 & 0.53 & 301 & 32 & 71 & 97 & $<10$ & 283 \\
\hline $41-168$ & ESC60 & 90,18 & 3,12 & 2.89 & 0.27 & 0,43 & 0,11 & 0.11 & & 0,08 & 1,44 & 100,26 & 0,53 & 294 & 16 & 76 & 93 & $<10$ & 262 \\
\hline branco & & $<0,02$ & $<0.01$ & $<0,01$ & $<0.01$ & 0.15 & $<0.01$ & 0,04 & $\frac{<0,01}{<0,01}$ & 0.05 & 1,49 & 100,2 & 0.45 & 29 & $<15$ & 19 & 91 & $<10$ & 597 \\
\hline & & & & & & & & & & $<0,01$ & $<0,01$ & 0.19 & & $<10$ & $<15$ & 7 & $<15$ & $<10$ & $\angle 25$ \\
\hline
\end{tabular}




\section{Difração de Raio X}

\begin{tabular}{|c|c|}
\hline \multicolumn{2}{|r|}{ Legenda } \\
\hline Identificação da amostra & Descrição \\
\hline EXP 44-48m (total) & Amostra total \\
\hline ESC 10 (total) & Amostra total \\
\hline ESC 17 (total) & Amostra total \\
\hline ESC 20 (total) & Amostra total \\
\hline ESC 24 (total) & Amostra total \\
\hline ESC 32 (total) & Amostra total \\
\hline ESC 34 (total) & Amostra total \\
\hline ESC 36 (total) & Amostra total \\
\hline ESC 40 (total) & Amostra total \\
\hline ESC 52 (total) & Amostra total \\
\hline ESC 14 (total) & Amostra total \\
\hline ESC 60 (total) & Amostra total \\
\hline EXP 0-30 (total) & Amostra total \\
\hline EXP 22 (total) & Amostra total \\
\hline EXP 26 (total) & Amostra total \\
\hline EXP 28 (total) & Amostra total \\
\hline EXP 40 (total) & Amostra total \\
\hline EXP 43 (total) & Amostra total \\
\hline EXP 44 (total) & Amostra total \\
\hline EXP 52 (total) & Amostra total \\
\hline EXP 56 (total) & Amostra total \\
\hline EXP 60 (total) & Amostra total \\
\hline EXP 64 (total) & Amostra total \\
\hline EXP 78 (total) & Amostra total \\
\hline ESP 80 (total) & Amostra total \\
\hline 44 pesados & Amostra de minerais pesados ponto EXP \\
\hline 52 pesados & Amostra de minerais pesados ponto ESC \\
\hline 32 magnéticos & Amostra de minerais magnéticos ponto ESC \\
\hline 44 magnéticos & Amostra de minerais magnéticos ponto EXP \\
\hline 56 pesados & Amostra de minerais pesados ponto EXP \\
\hline 32 pesados & Amostra de minerais pesados ponto ESC \\
\hline 80 magnéticos & Amostra de minerais magnéticos ponto EXP \\
\hline 20 pesados & Amostra de minerais pesados ponto ESC \\
\hline 20 magnéticos & Amostra de minerais magnéticos ponto ESC \\
\hline 80 pesados & Amostra de minerais pesados ponto EXP \\
\hline 56 magnéticos & $\begin{array}{c}\text { Amostra de minerais magnéticos ponto EXP } \\
\text { profundidade } 52 \mathrm{~m}\end{array}$ \\
\hline 56 pesados & $\begin{array}{c}\text { Amostra de minerais pesados ponto ESC } \\
\text { profundidade } 52 \mathrm{~m}\end{array}$ \\
\hline exp520_004mm & Amostra ESC-52m fração $<0,004 \mathrm{~mm}$ \\
\hline $\exp 44 \quad 480 \quad 004 \mathrm{~mm}$ & Amostra EXP-44-48m fração $<0,004 m m$ \\
\hline $\exp 320 \quad 004 \mathrm{~mm}$ & Amostra ESC-32m fração $<0,004 \mathrm{~mm}$ \\
\hline $\exp 560004 \mathrm{~mm}$ & Amostra EXP-56m fração $<0,004 \mathrm{~mm}$ \\
\hline $\exp 200 \quad 004 \mathrm{~mm}$ & Amostra ESC-20m fração $<0,004 \mathrm{~mm}$ \\
\hline $\exp 800-004 \mathrm{~mm}$ & Amostra EXP-80m fração $<0,004 m m$ \\
\hline
\end{tabular}



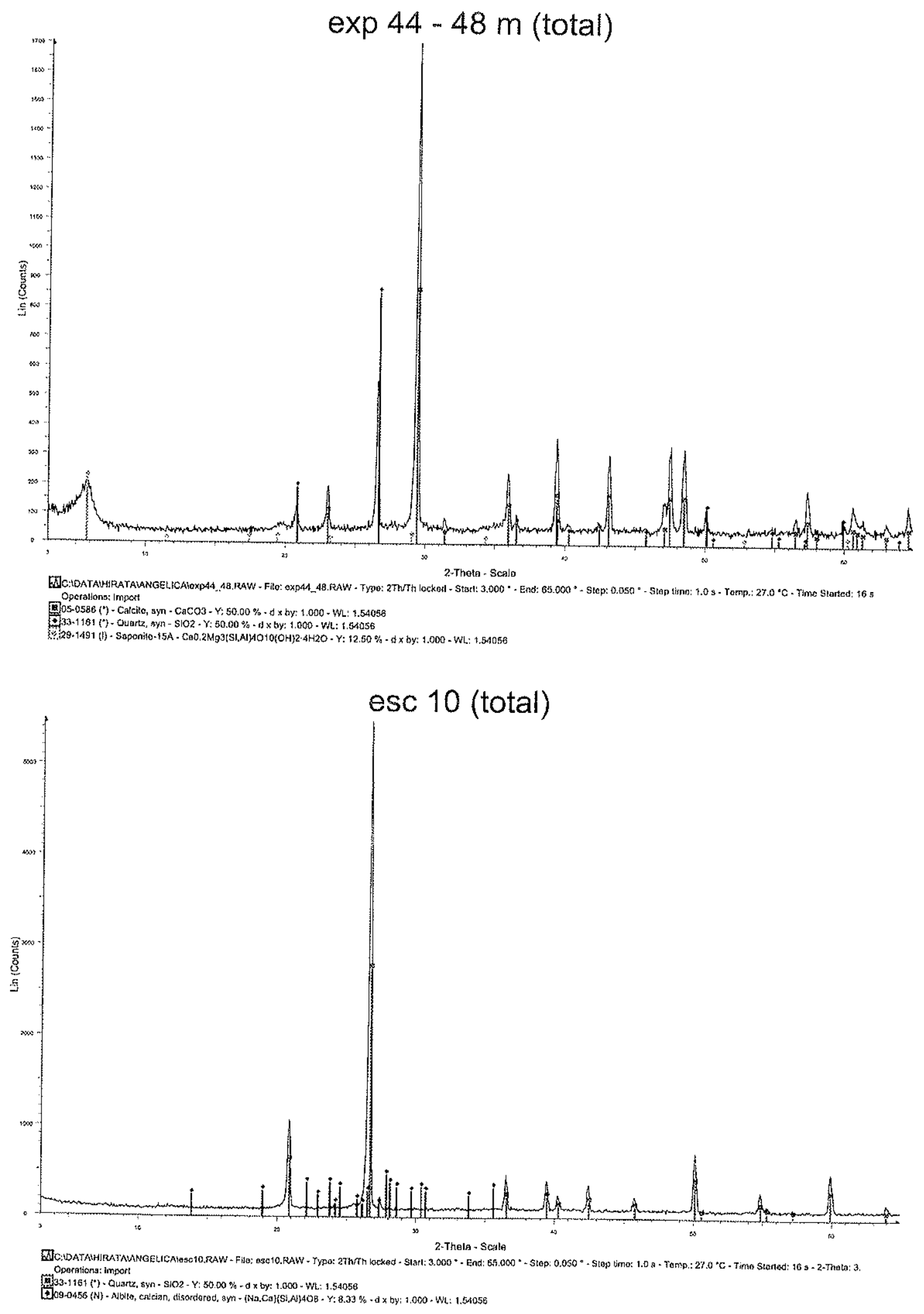


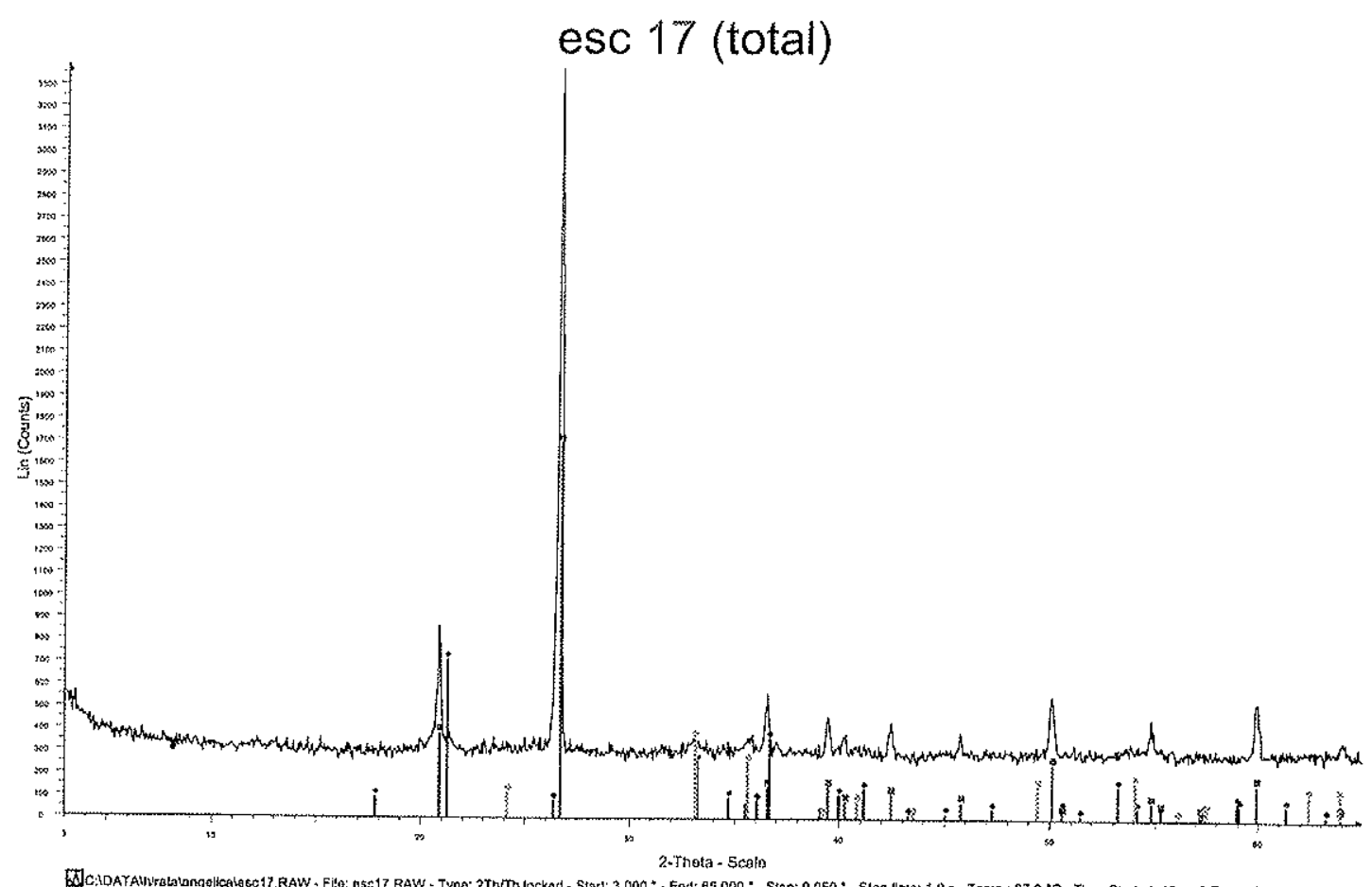

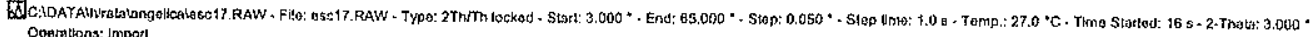
Operations: Impart

W.

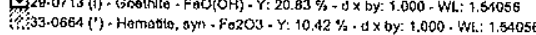

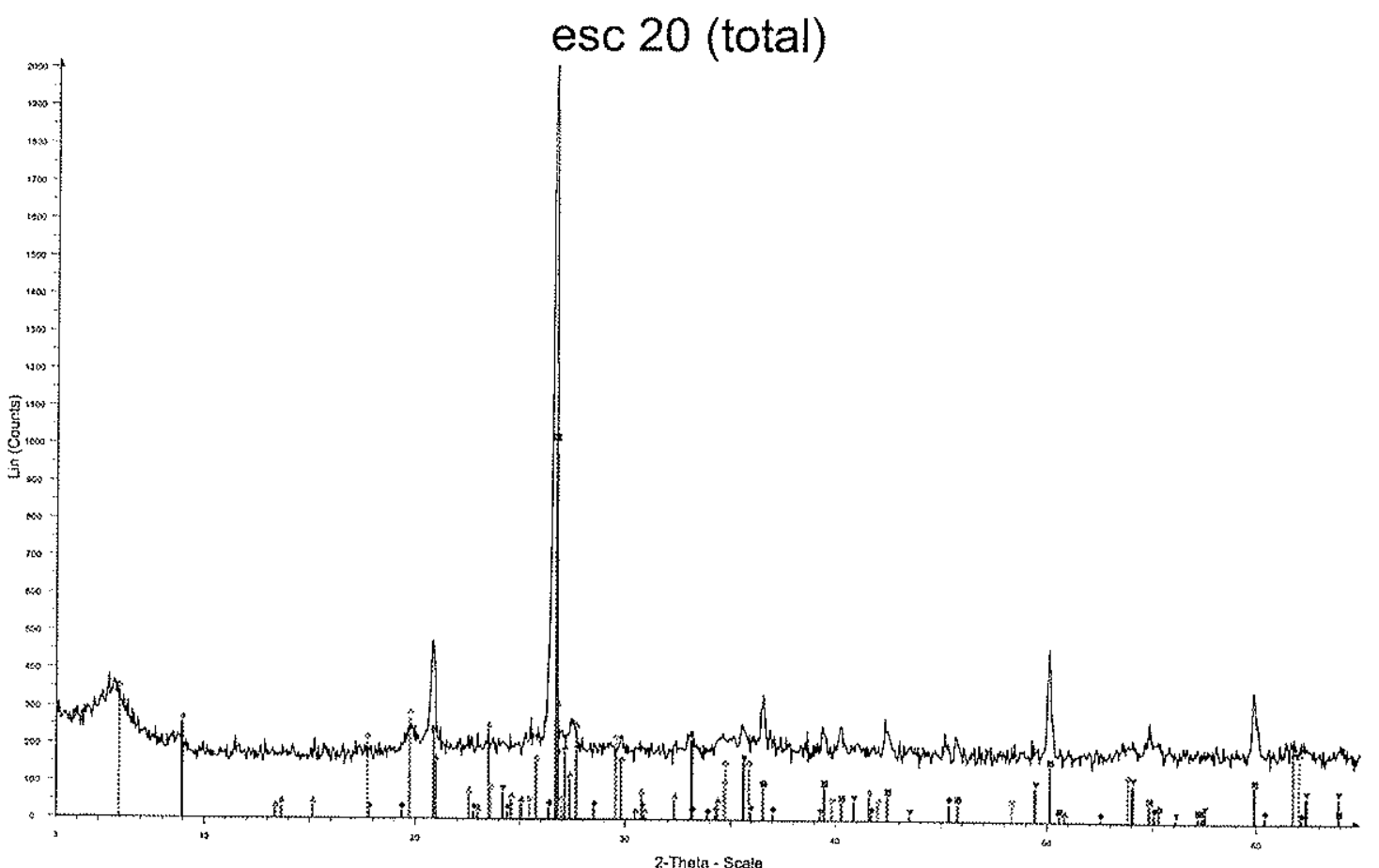

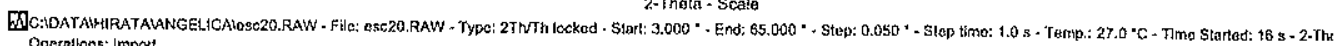
Opersitons: Impost

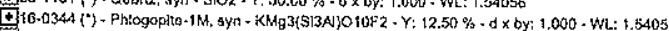

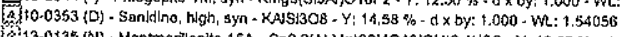

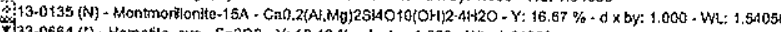

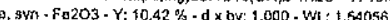




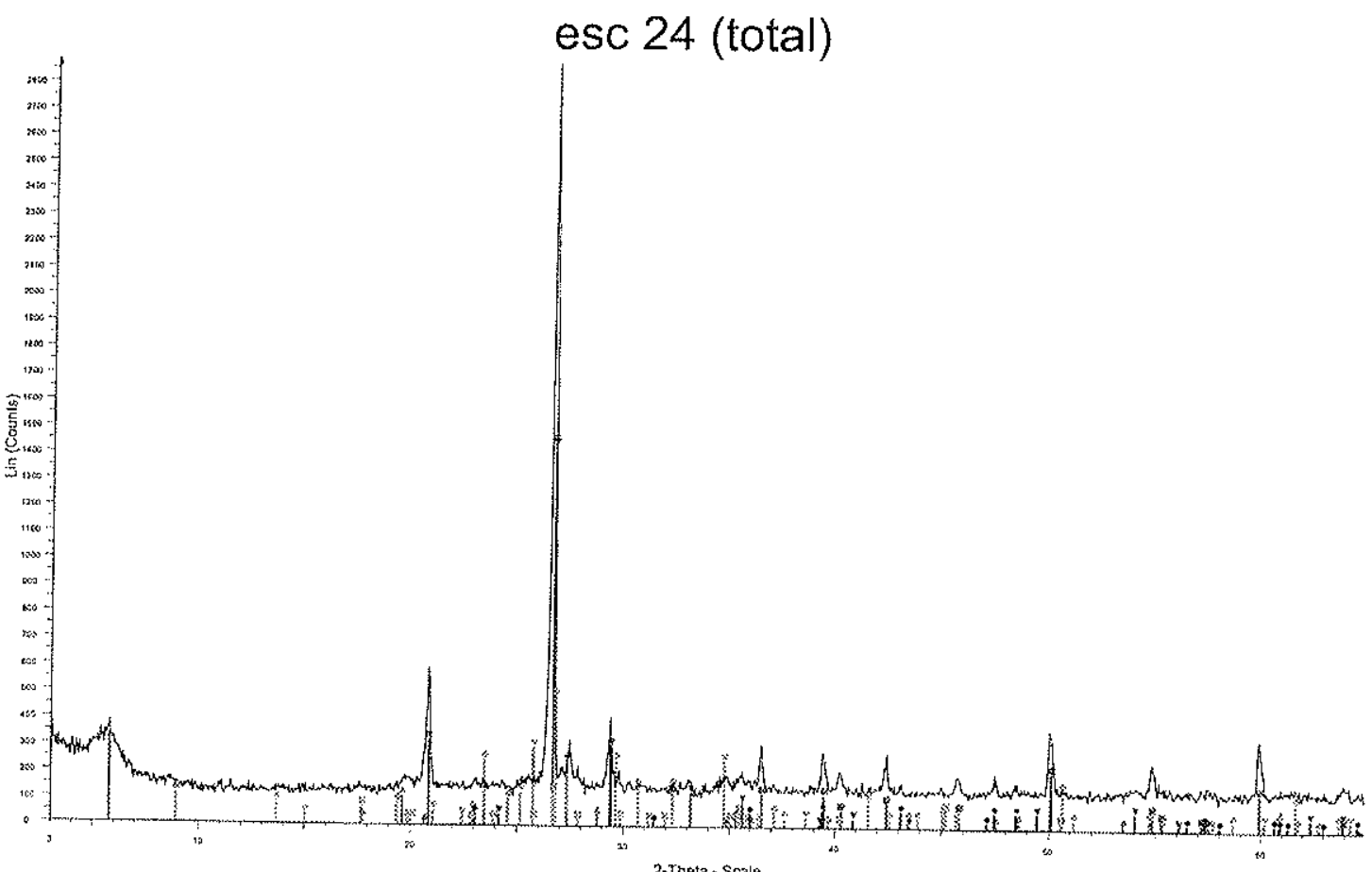

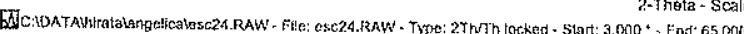

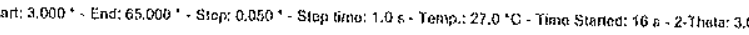

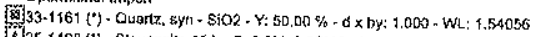

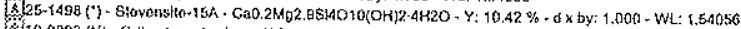

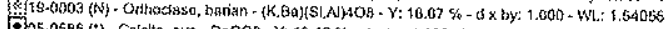

g.

W

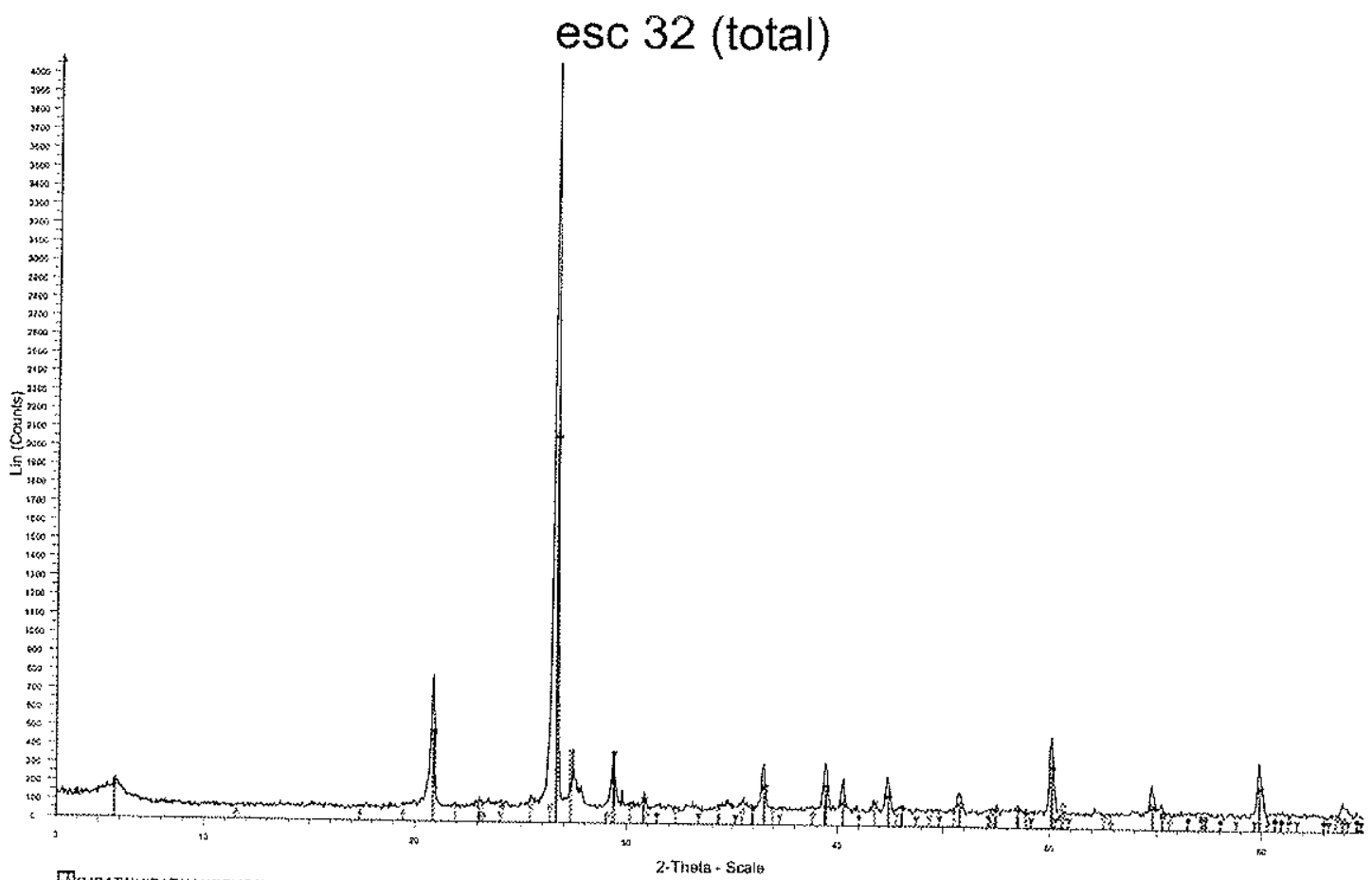

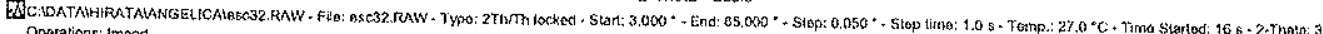

Oporations: import

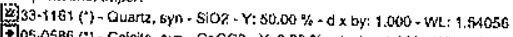

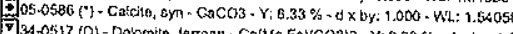

(1)

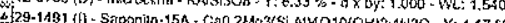



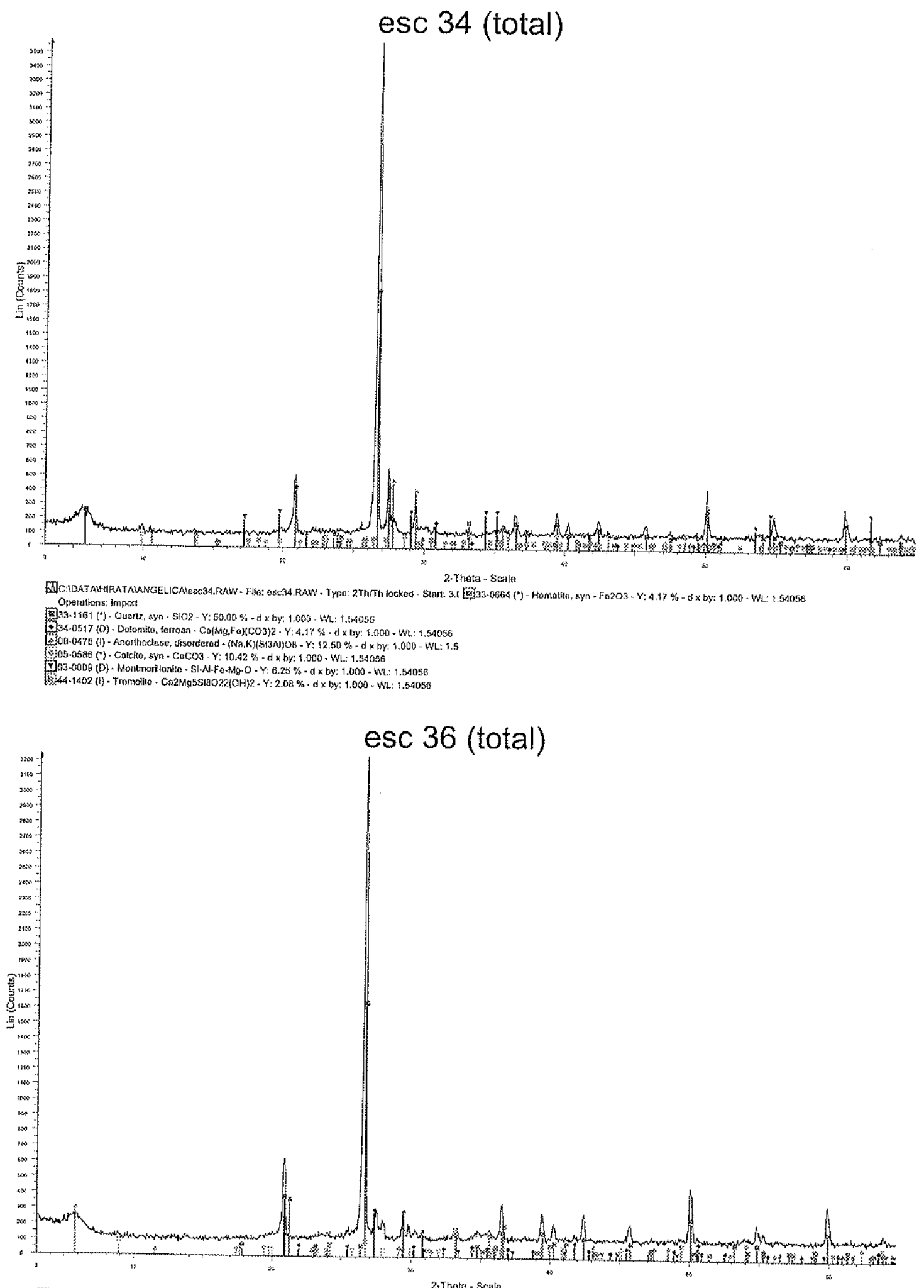

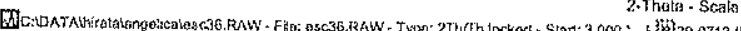

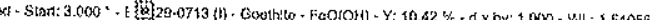

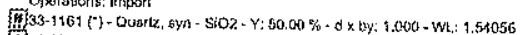

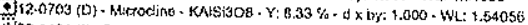

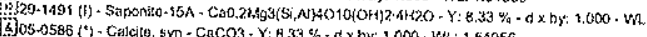

Y) 340577 (1) - Don

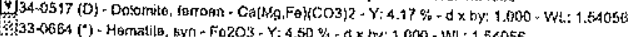



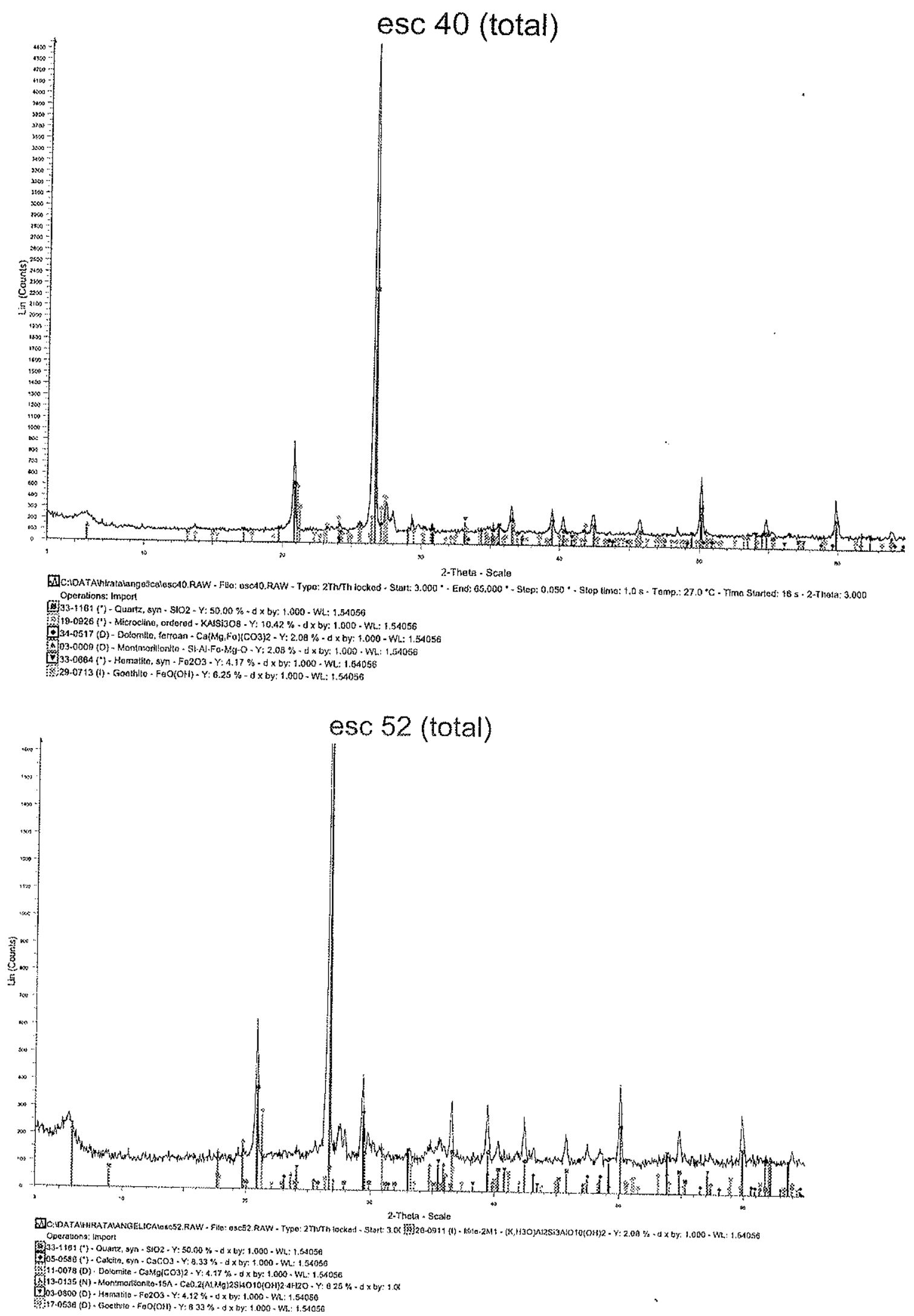


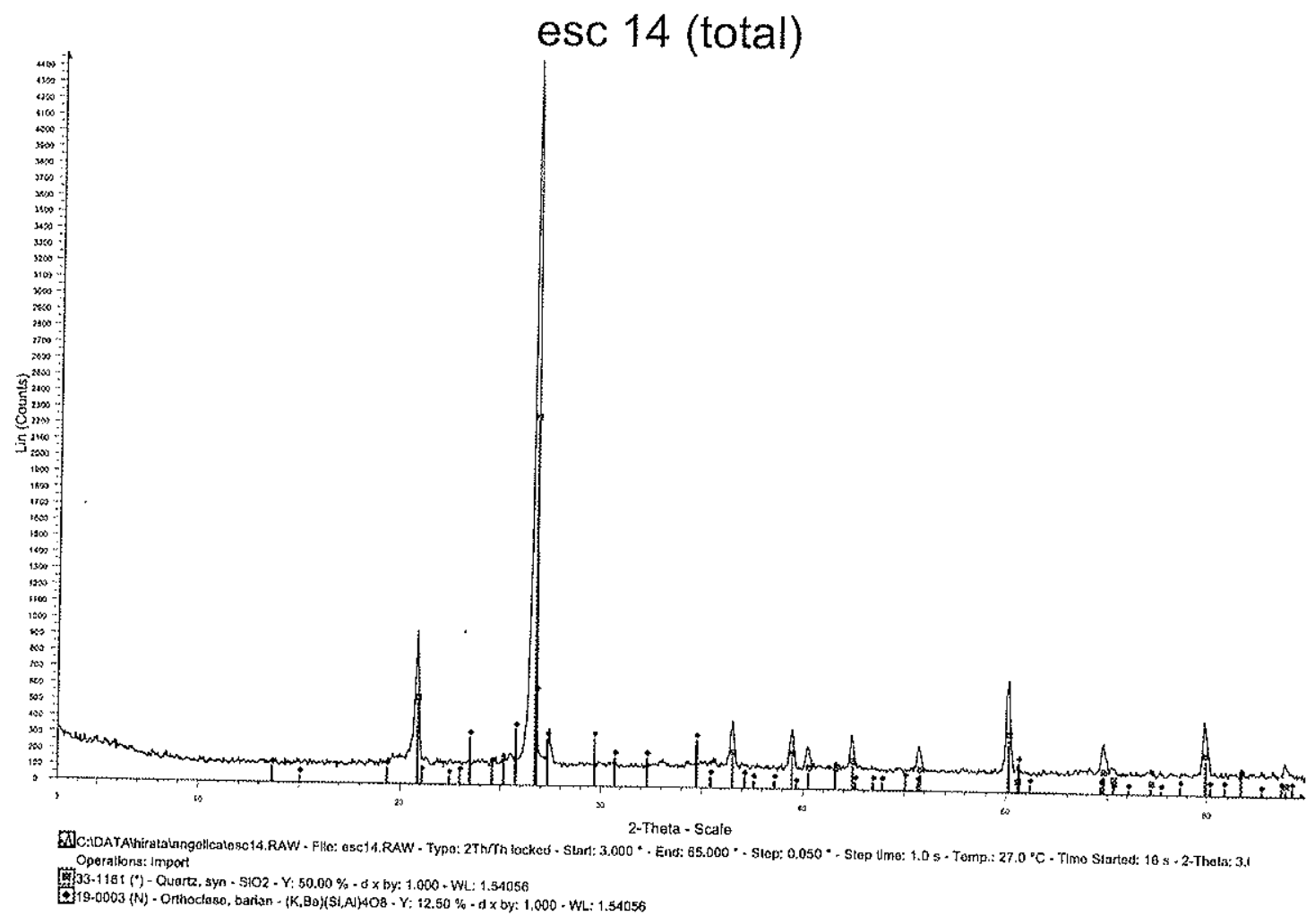




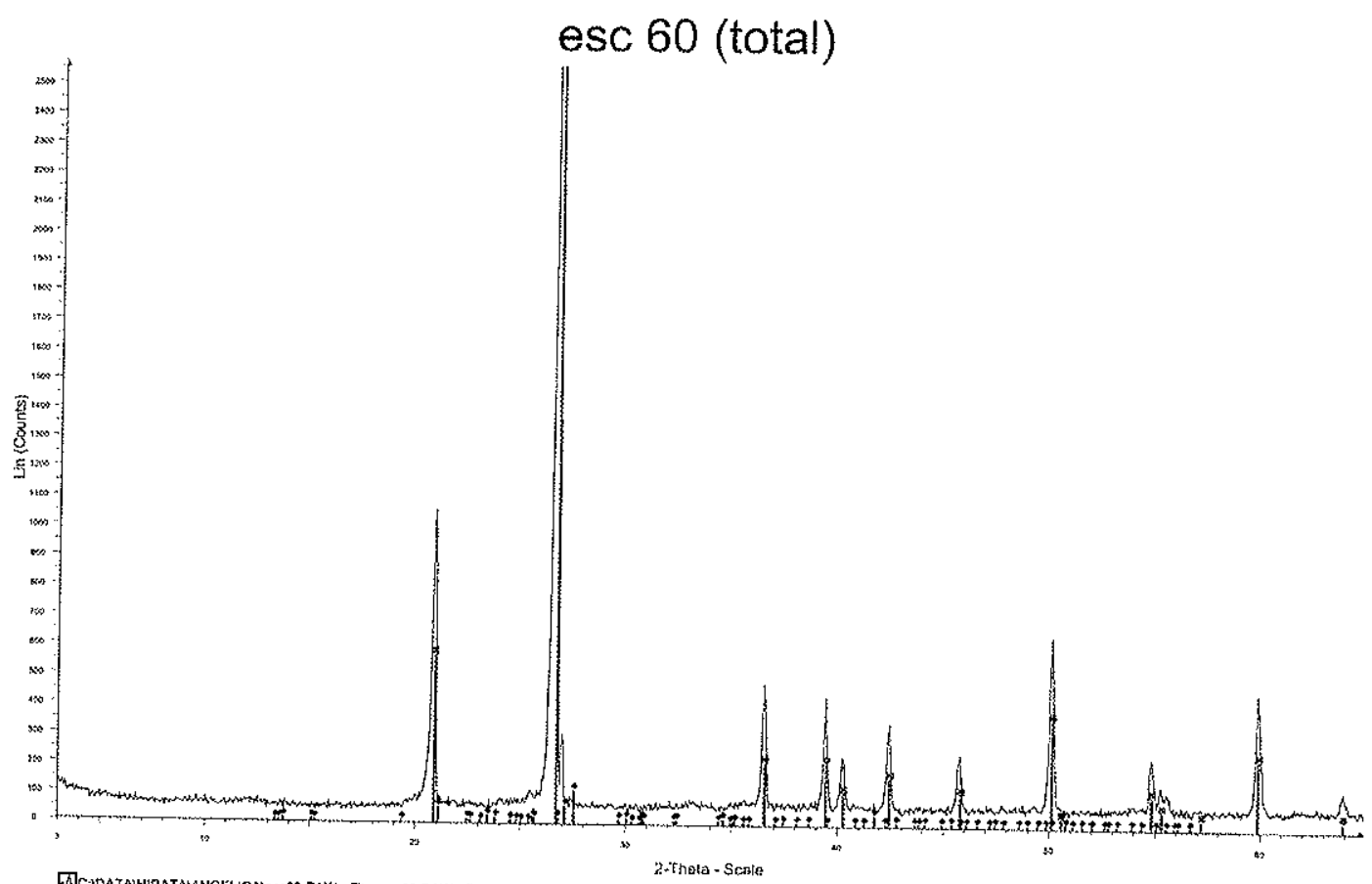

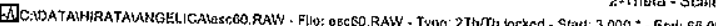

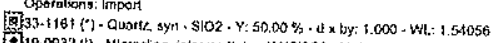

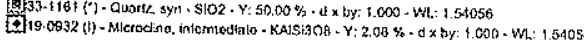

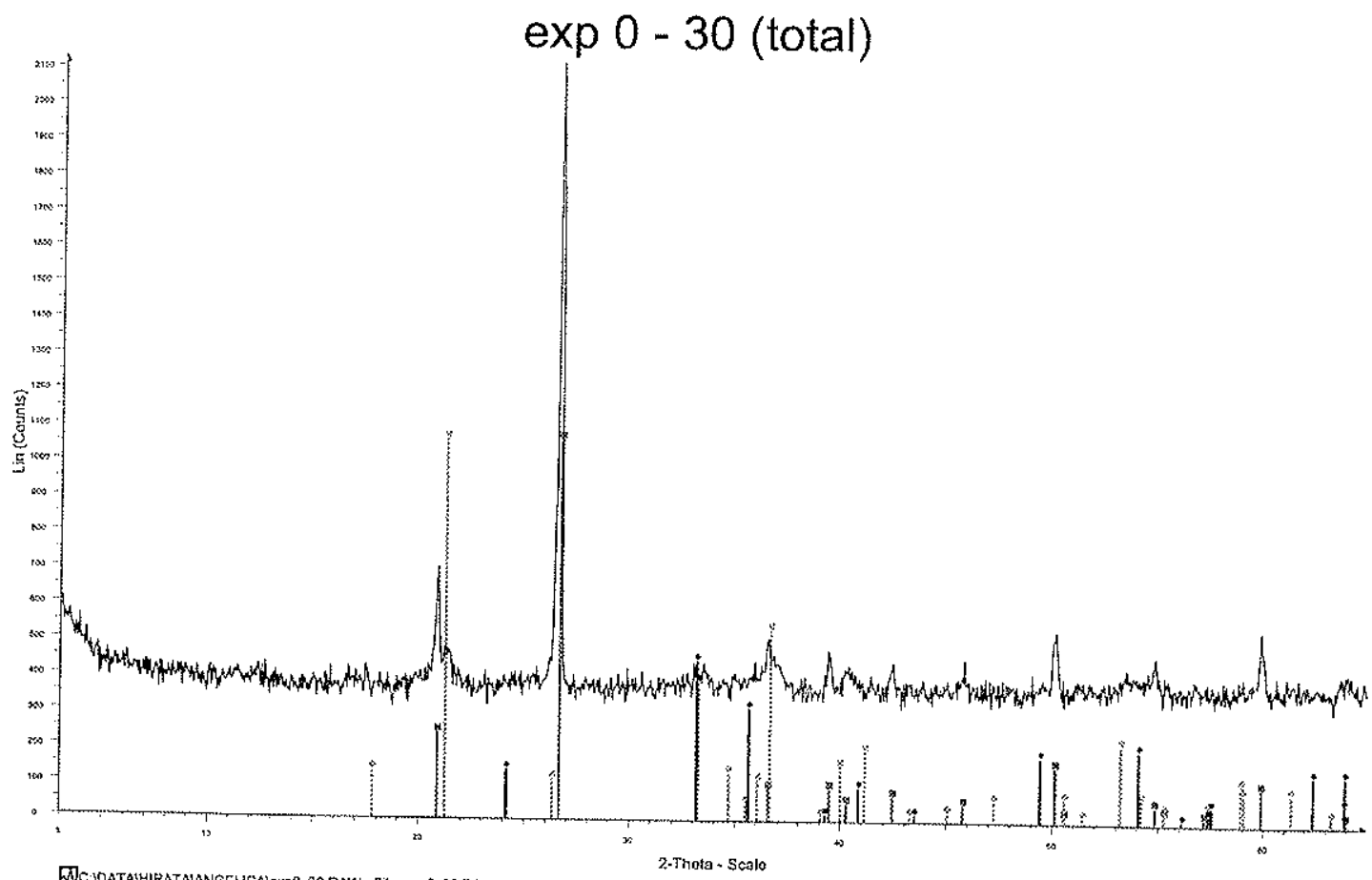

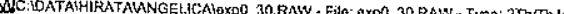

年

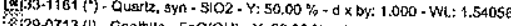

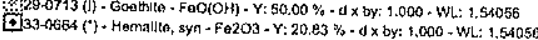




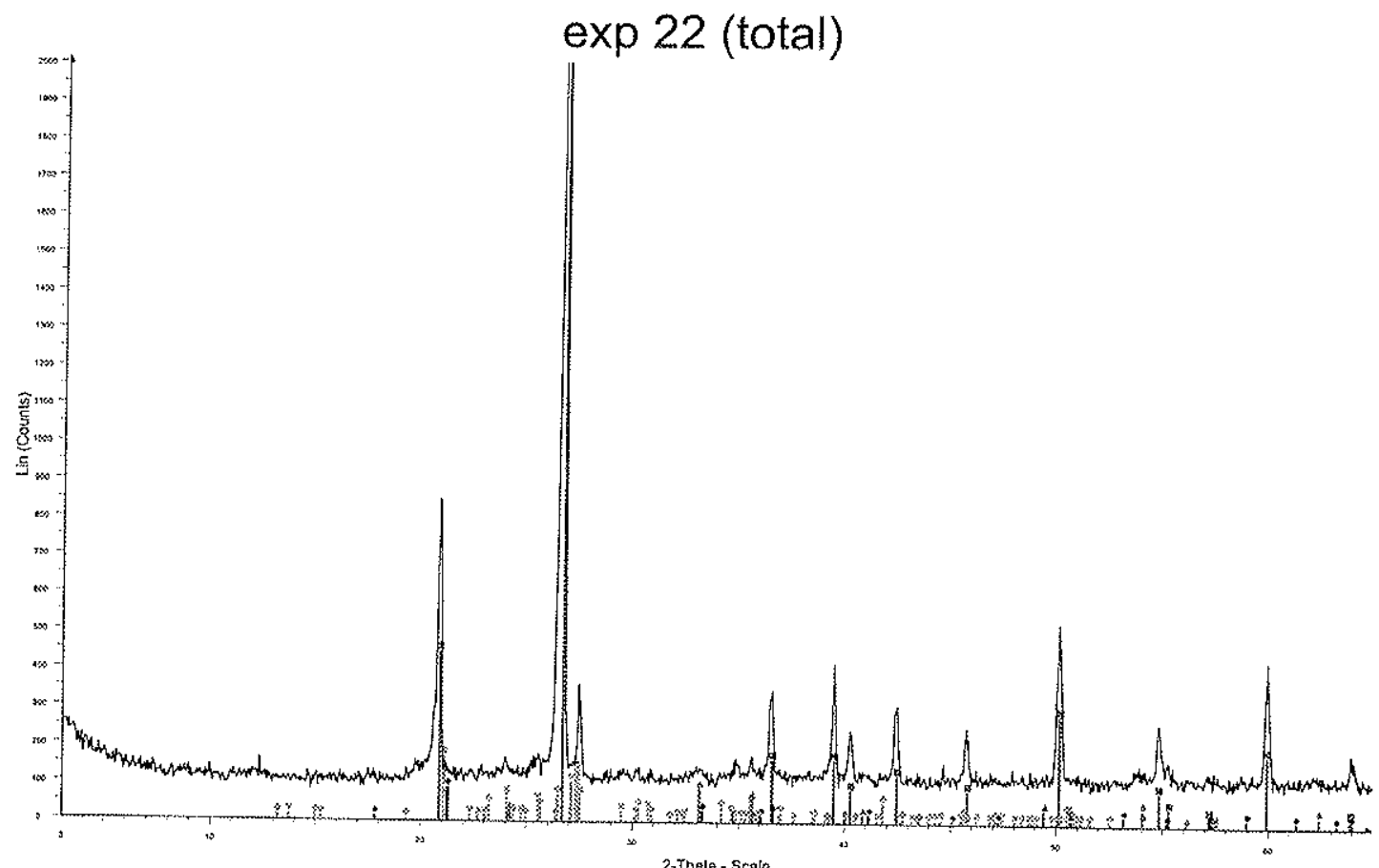

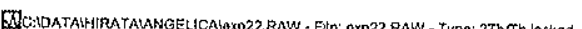

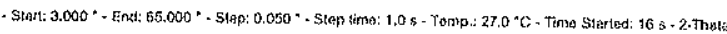
罗33.1161 (') - Ouart

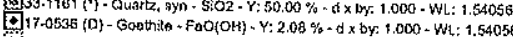

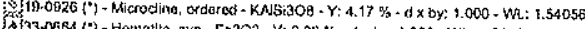

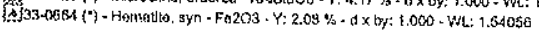

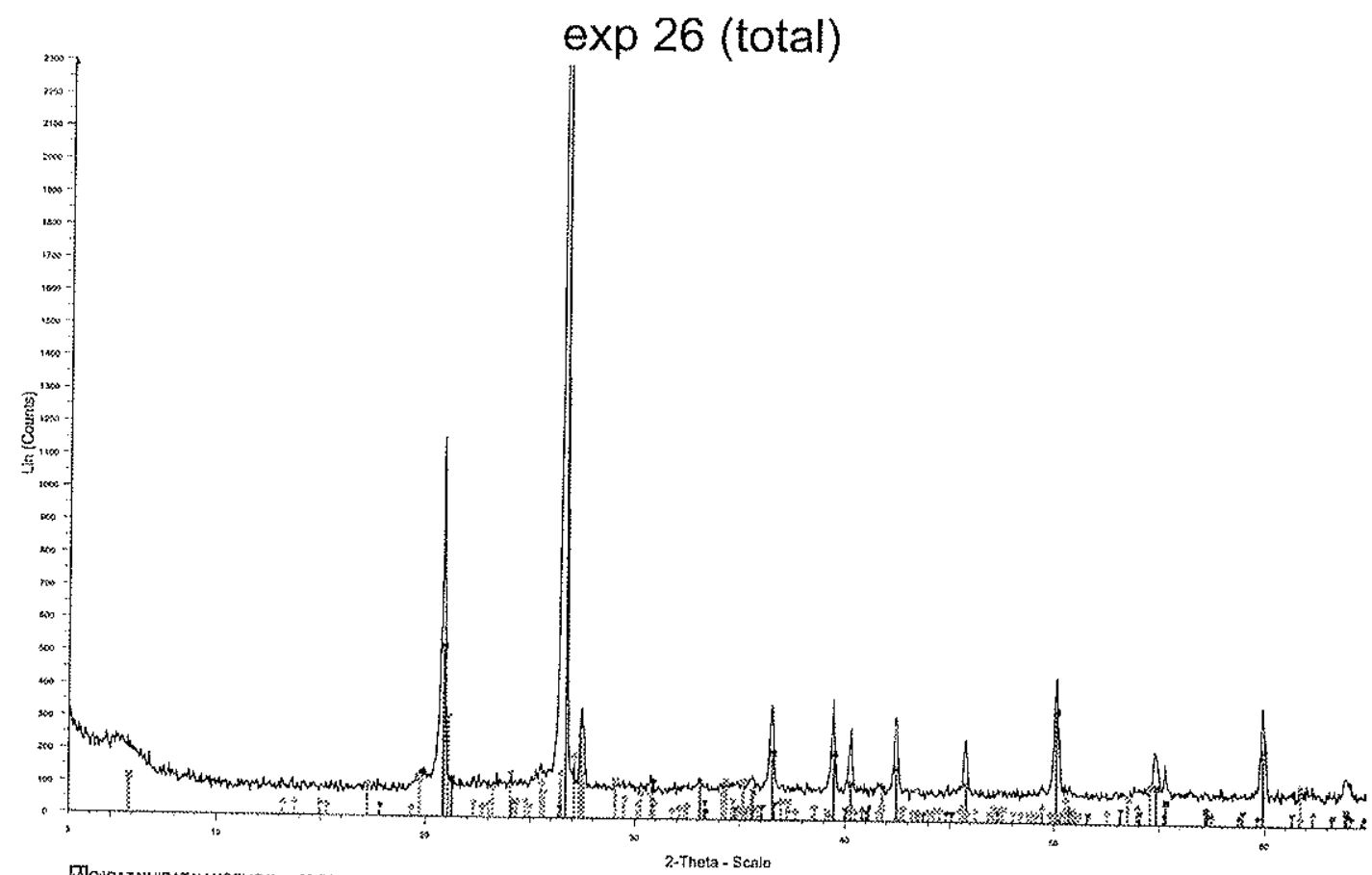

Wperatens: Impart

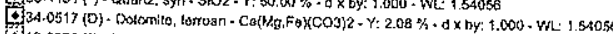

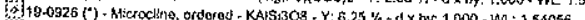

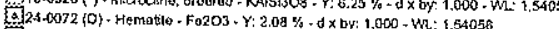

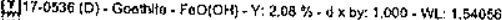

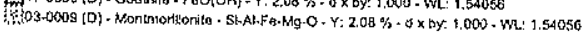




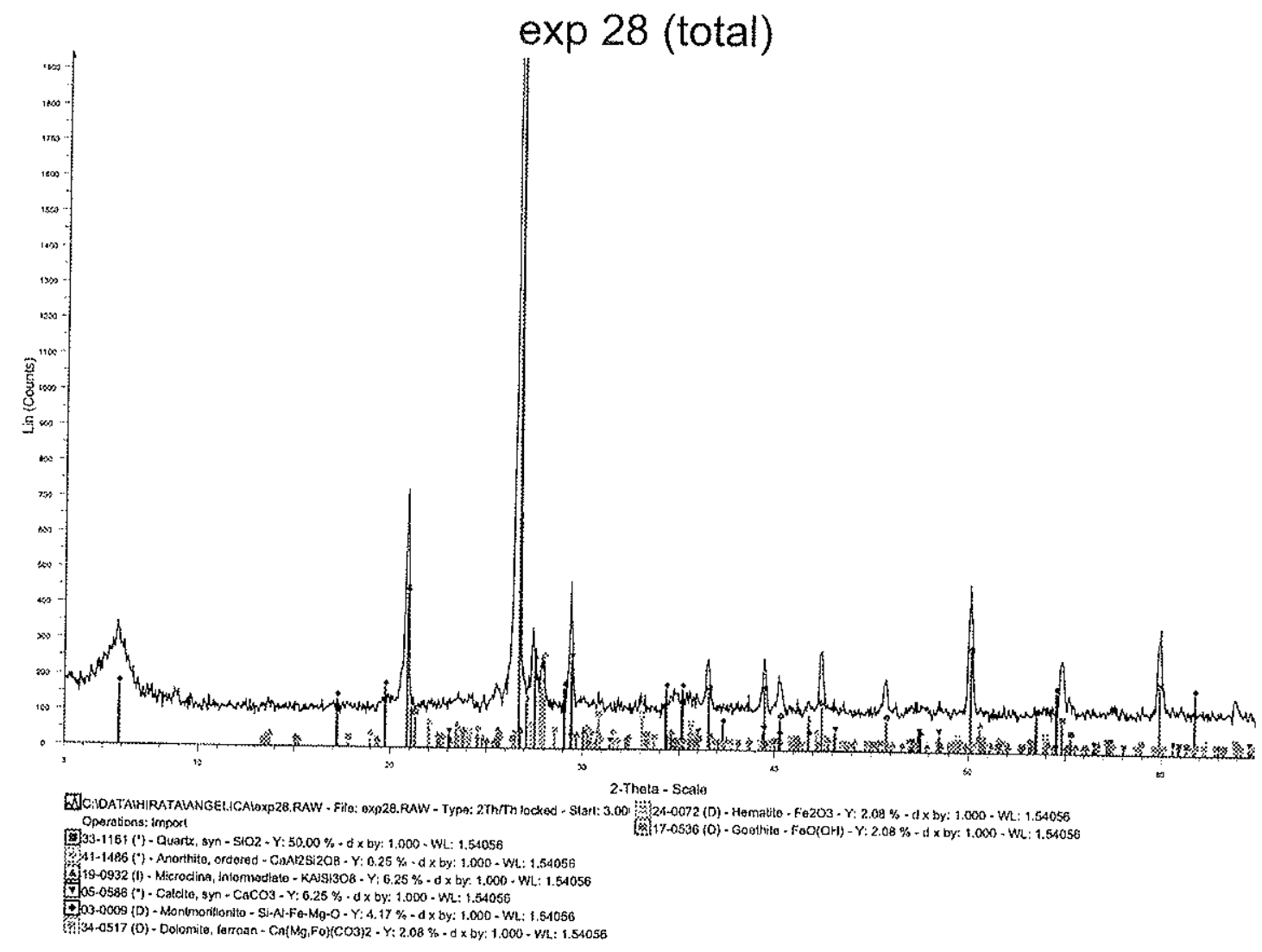



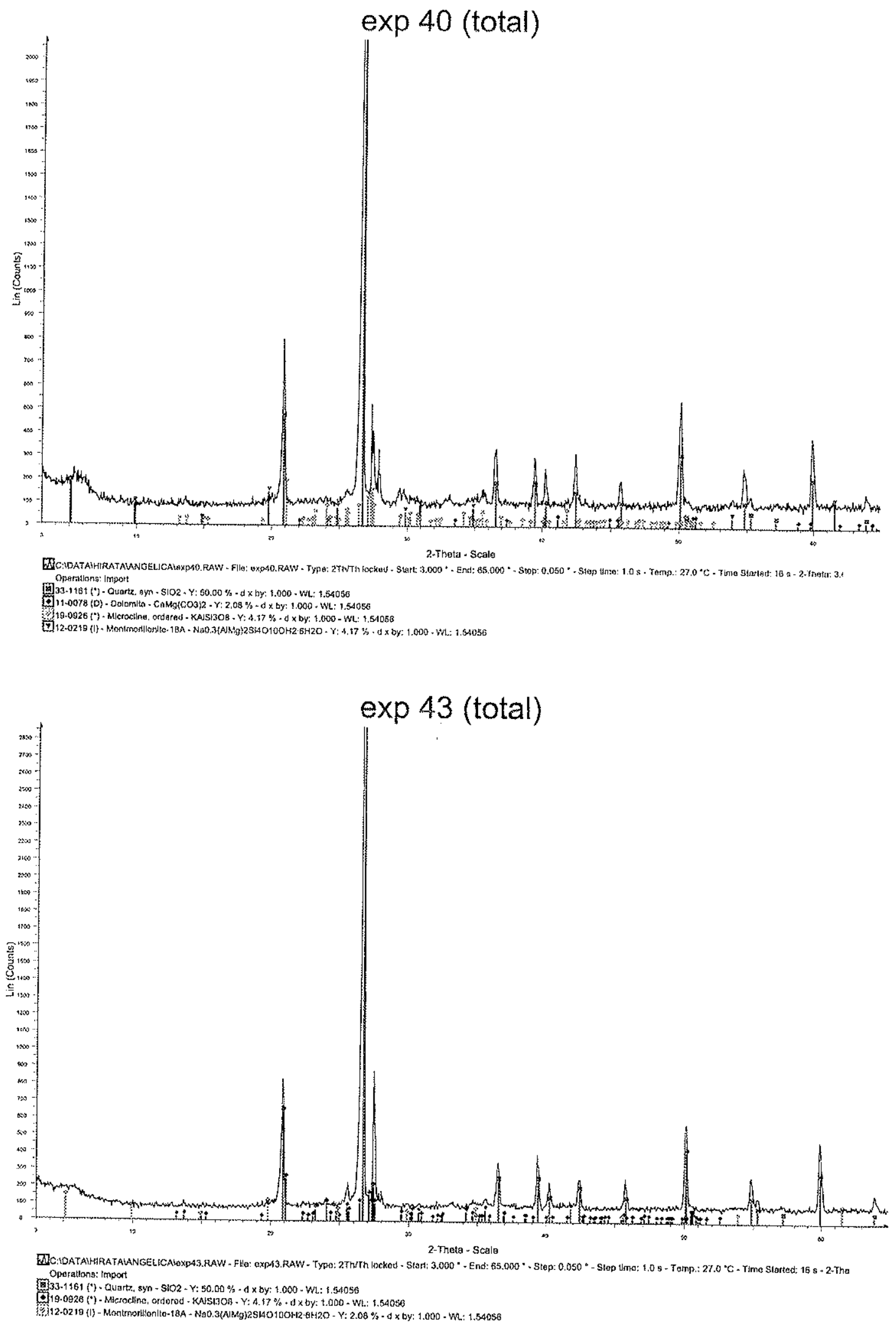

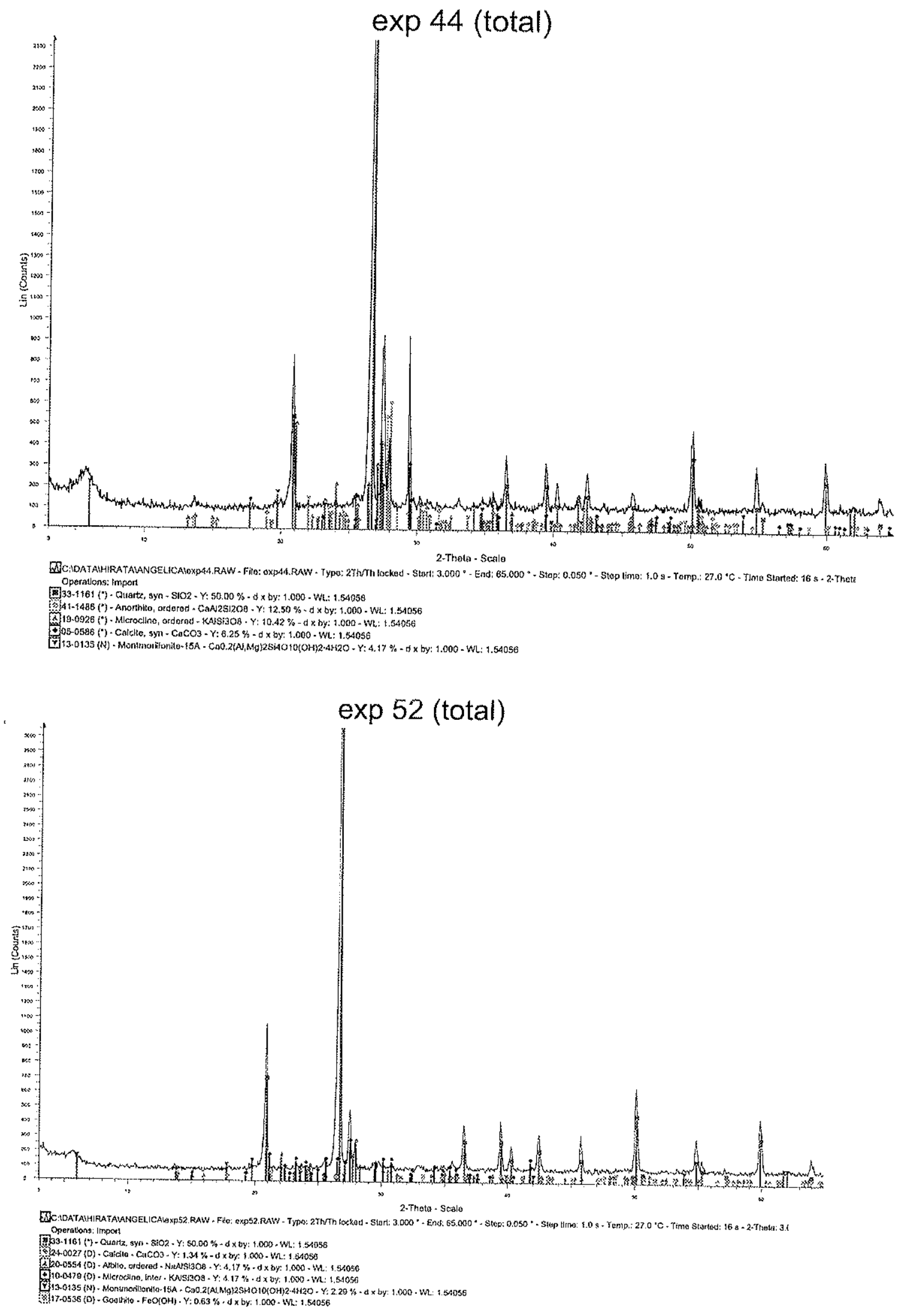

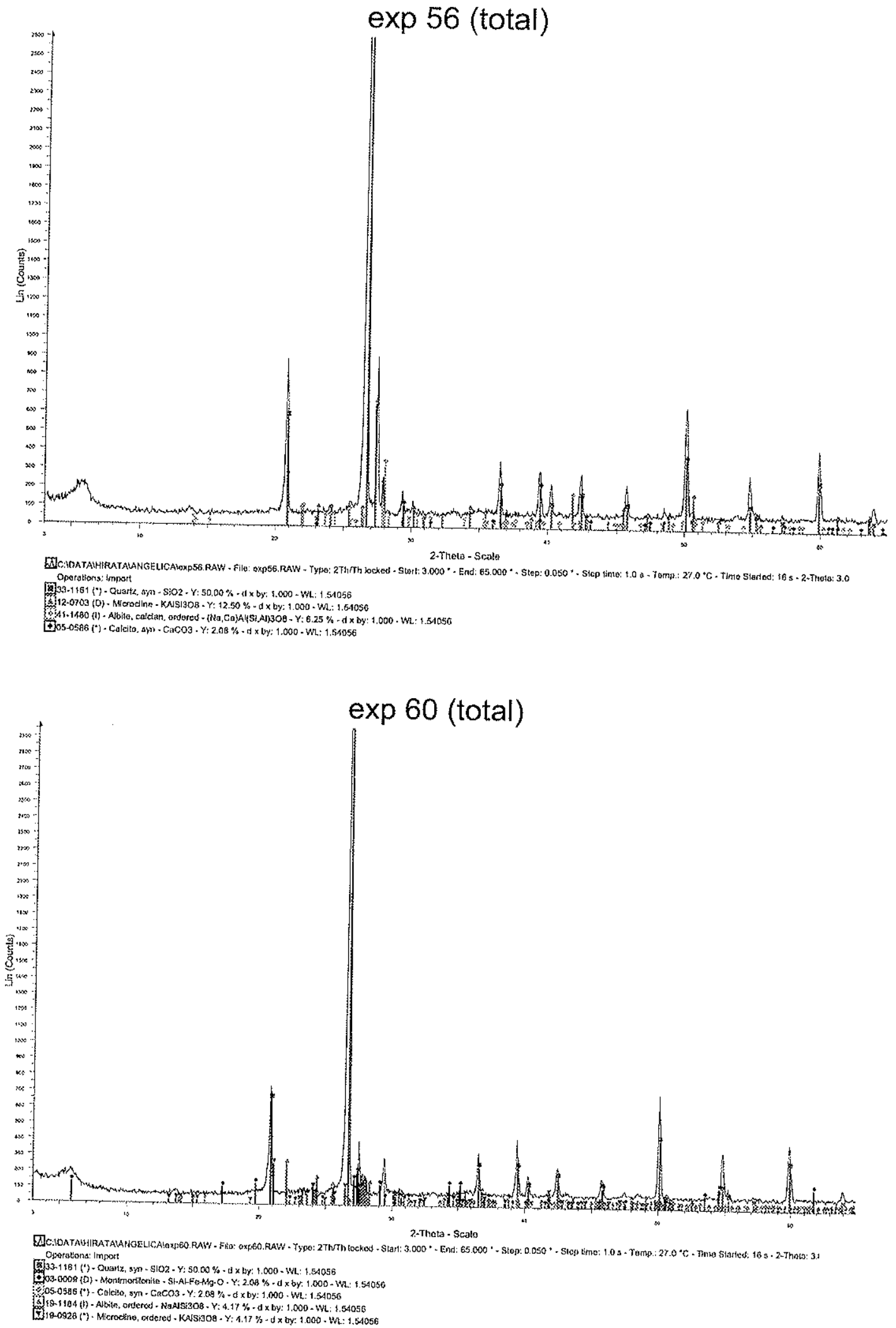

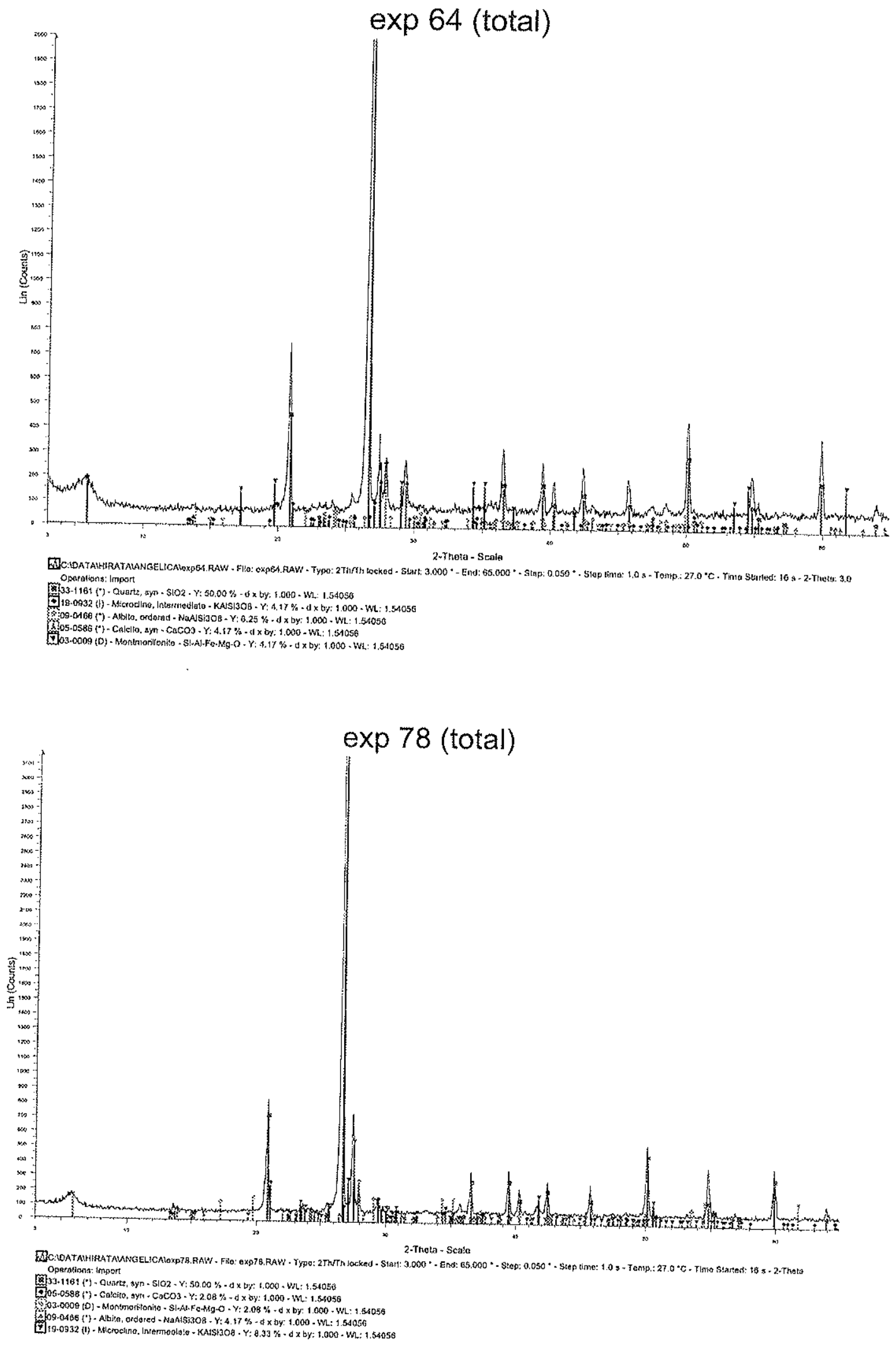

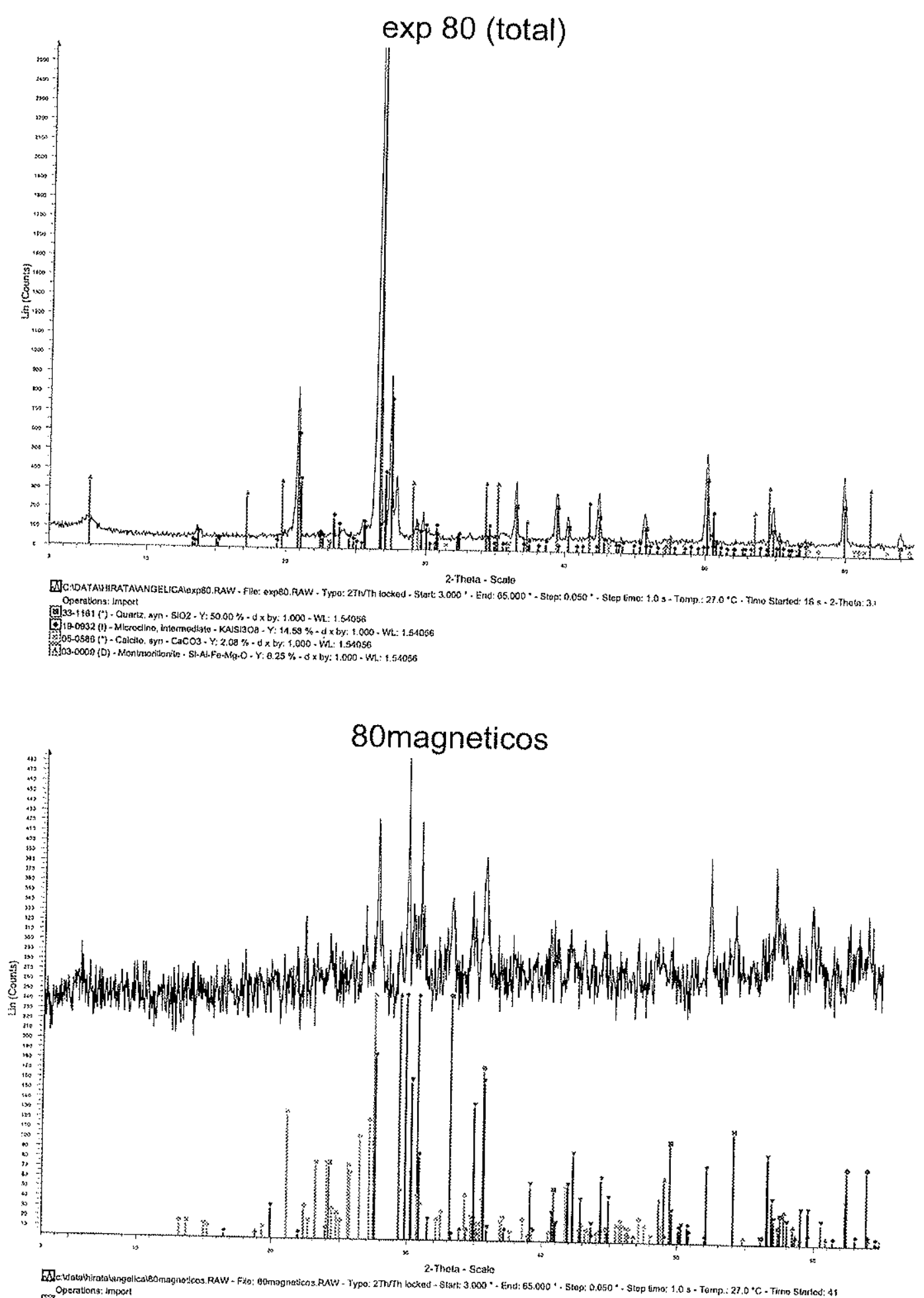

Operattons: Import

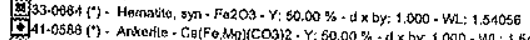

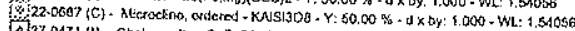

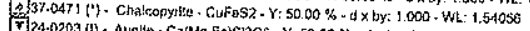

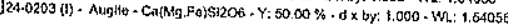



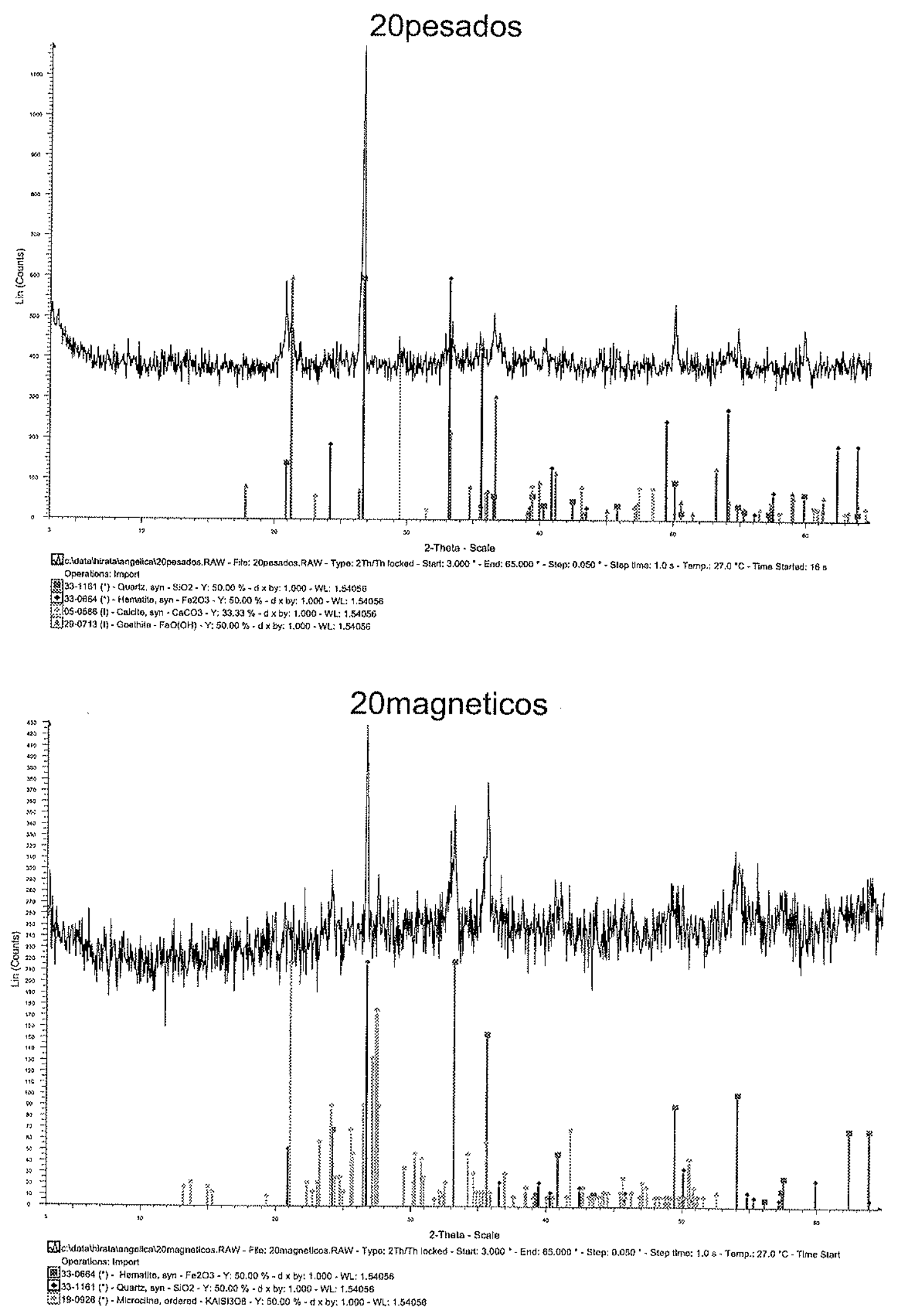

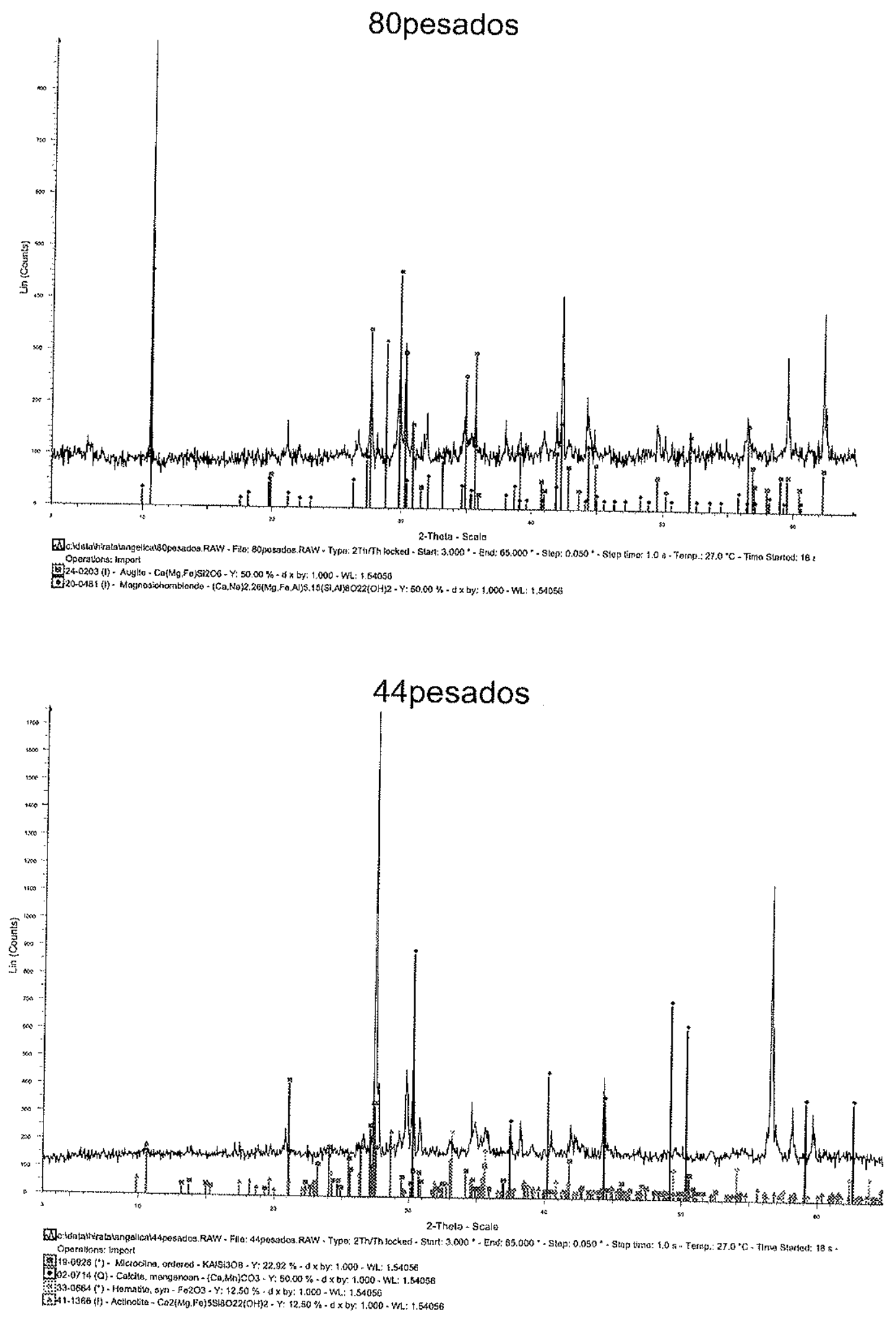

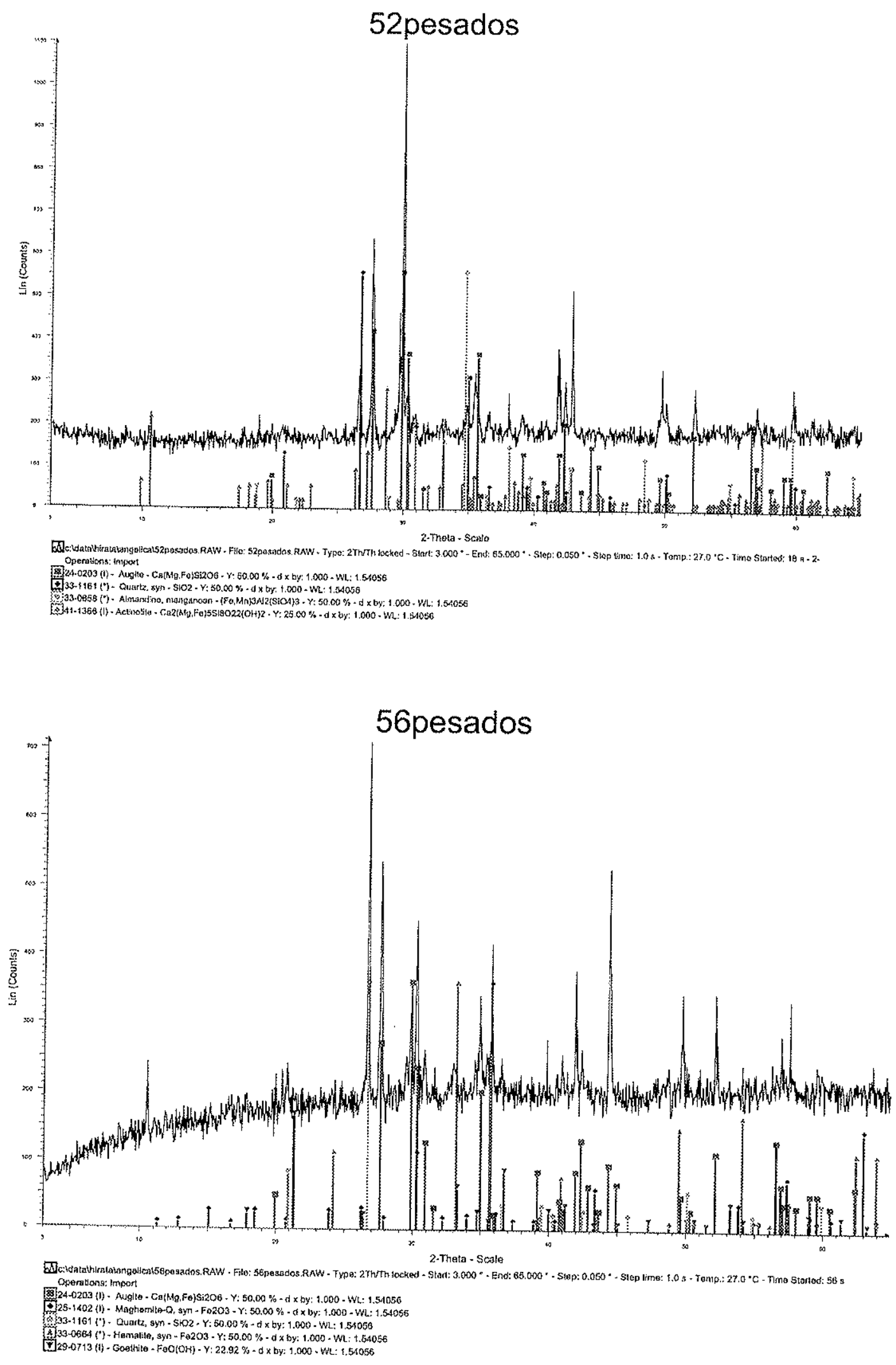

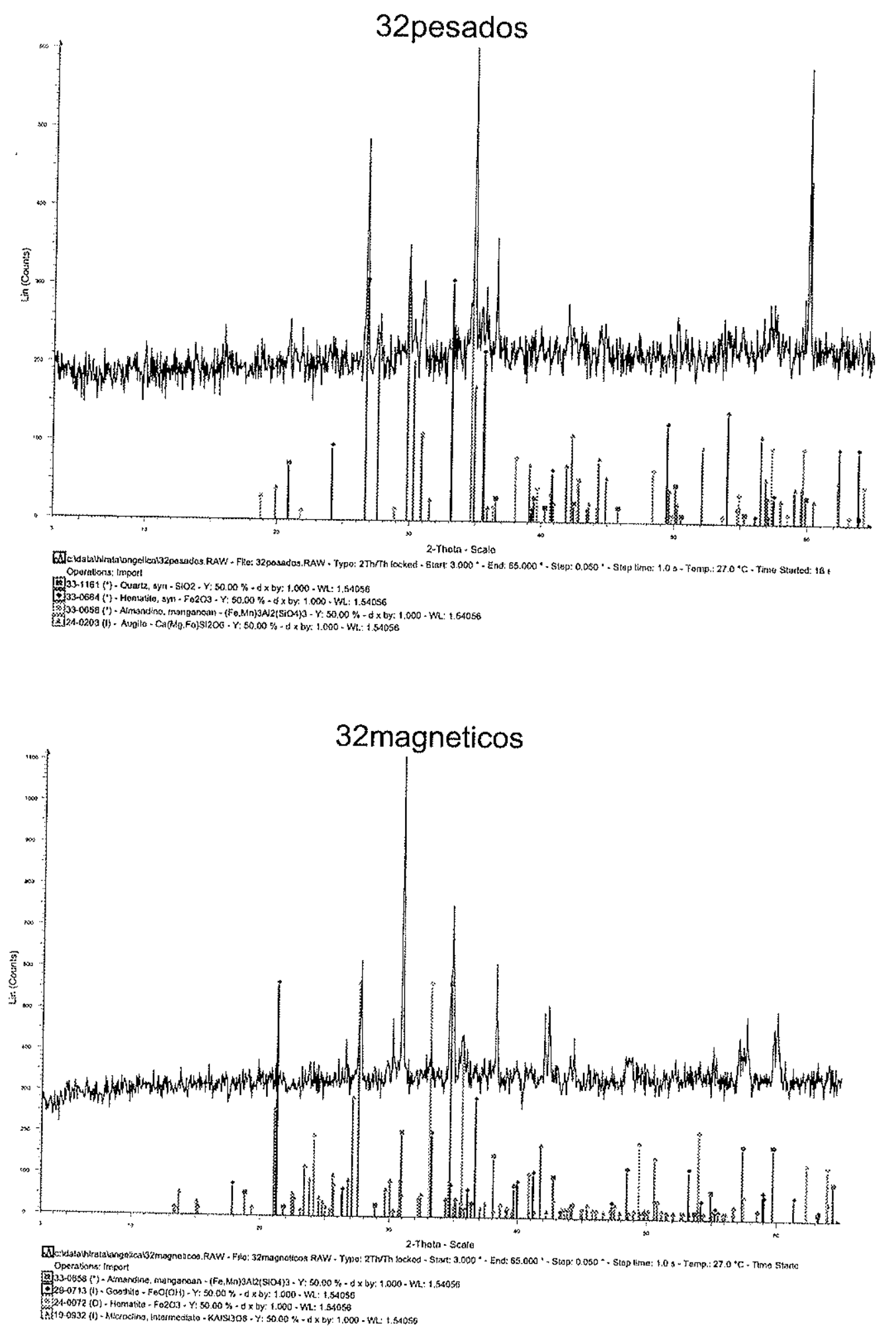

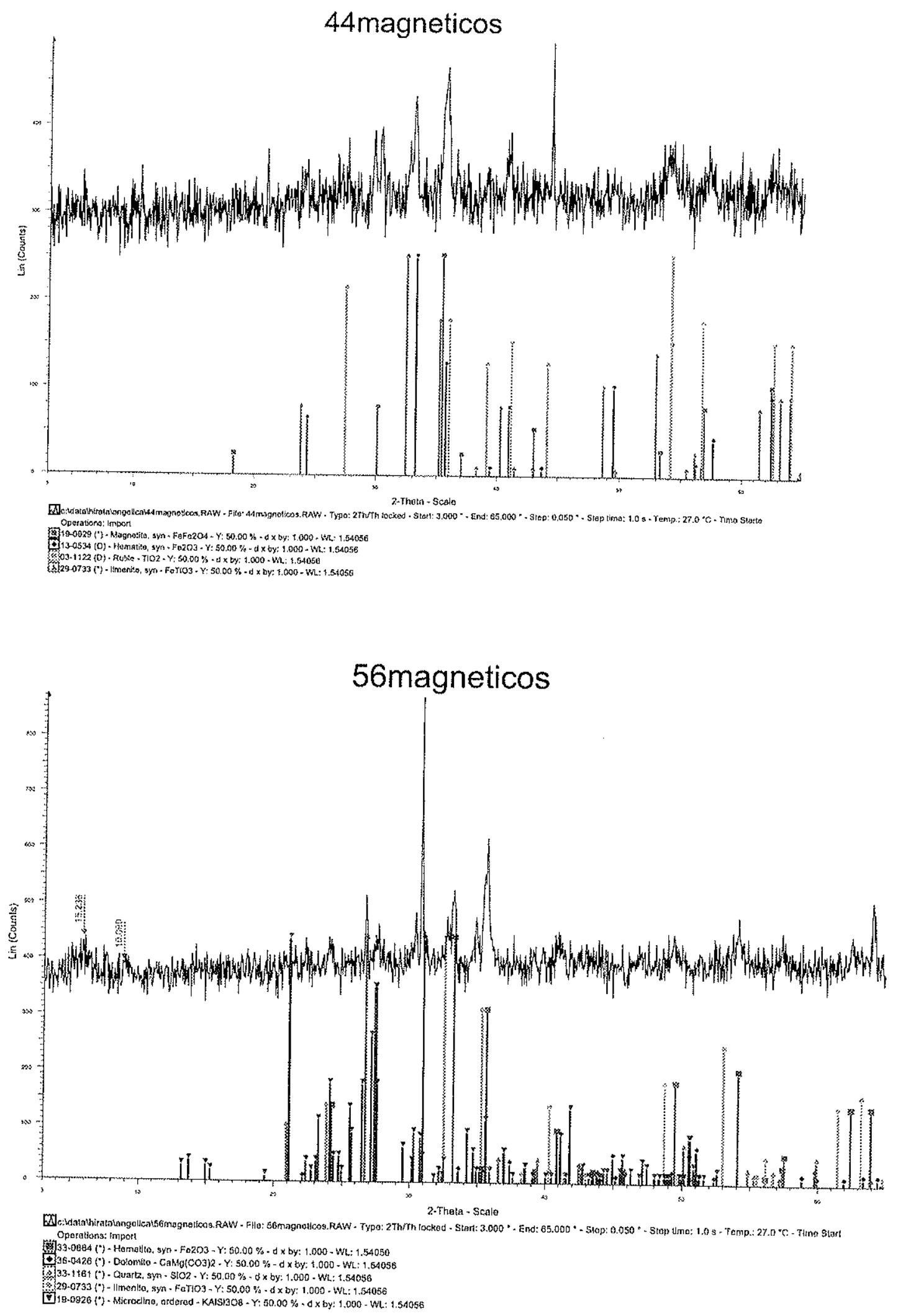

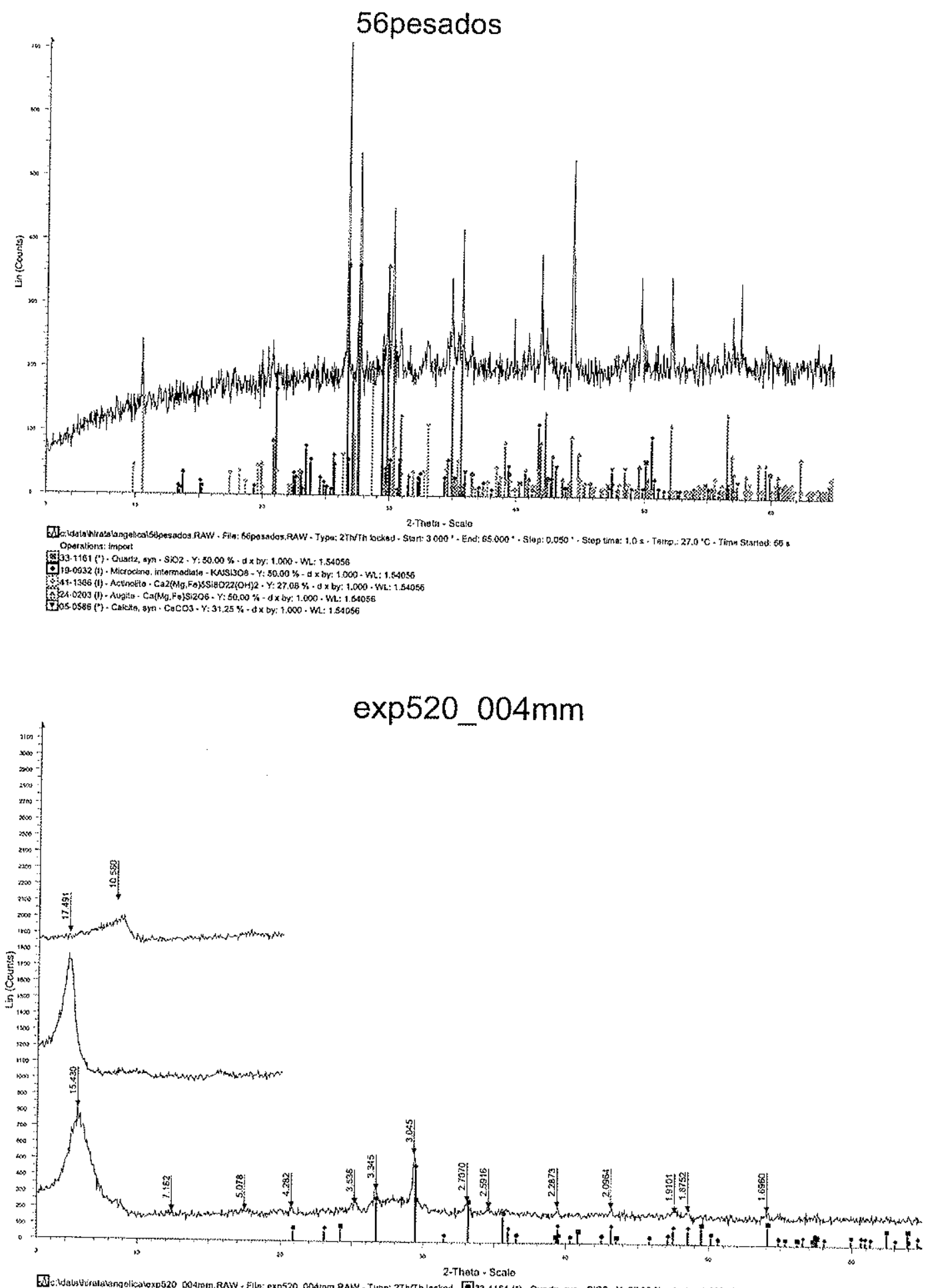

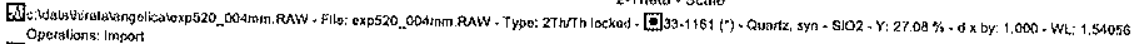

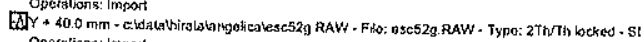

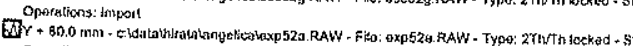

Operalleng: impert

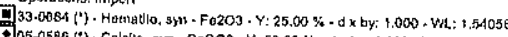

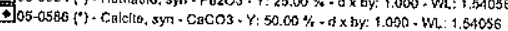



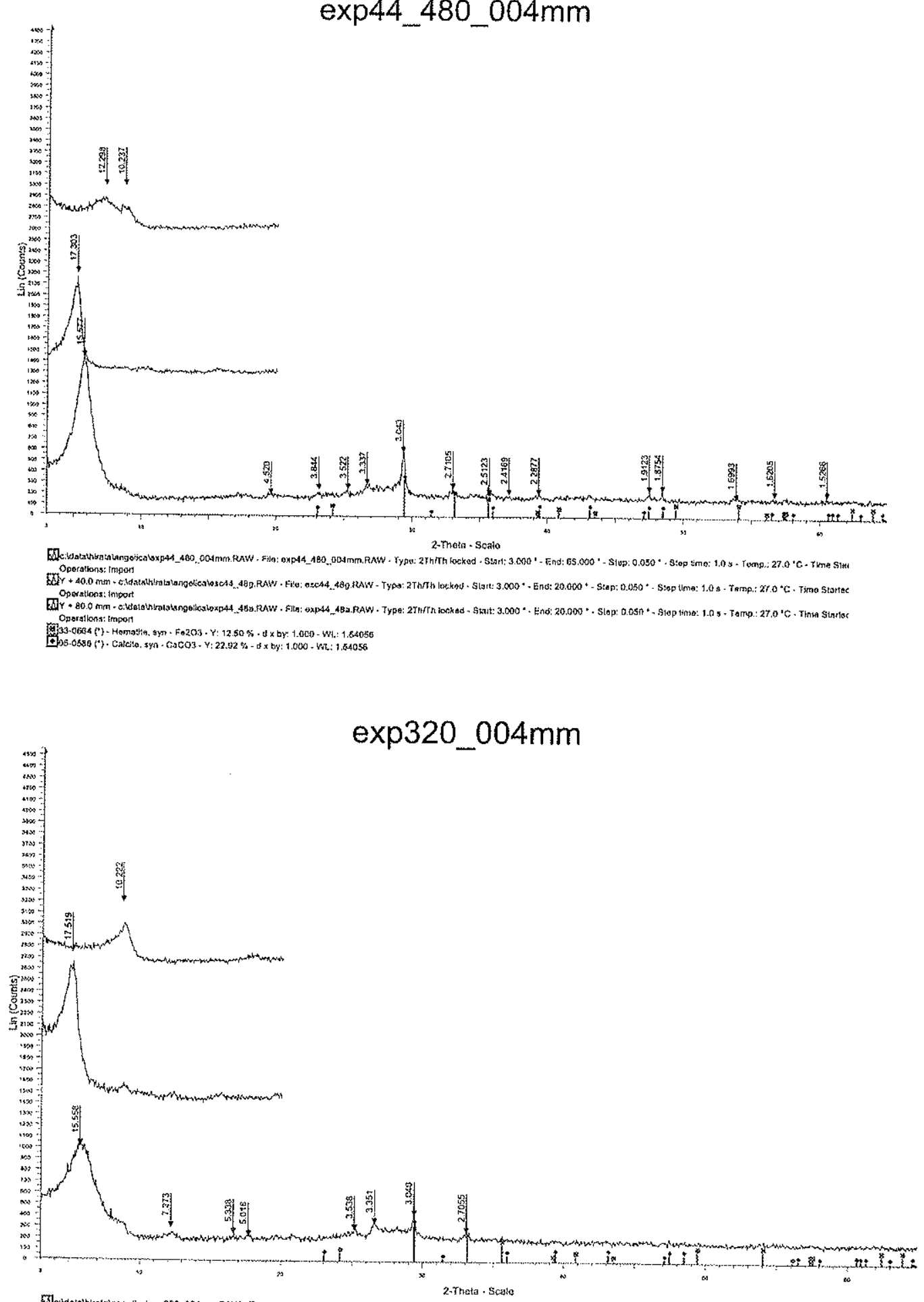

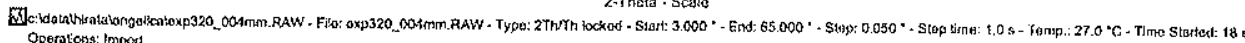

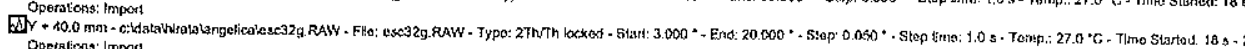

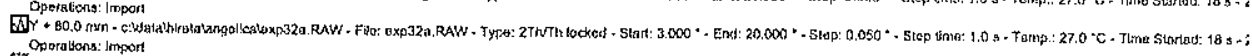

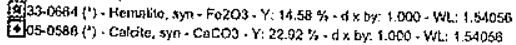




\section{exp560_004mm}
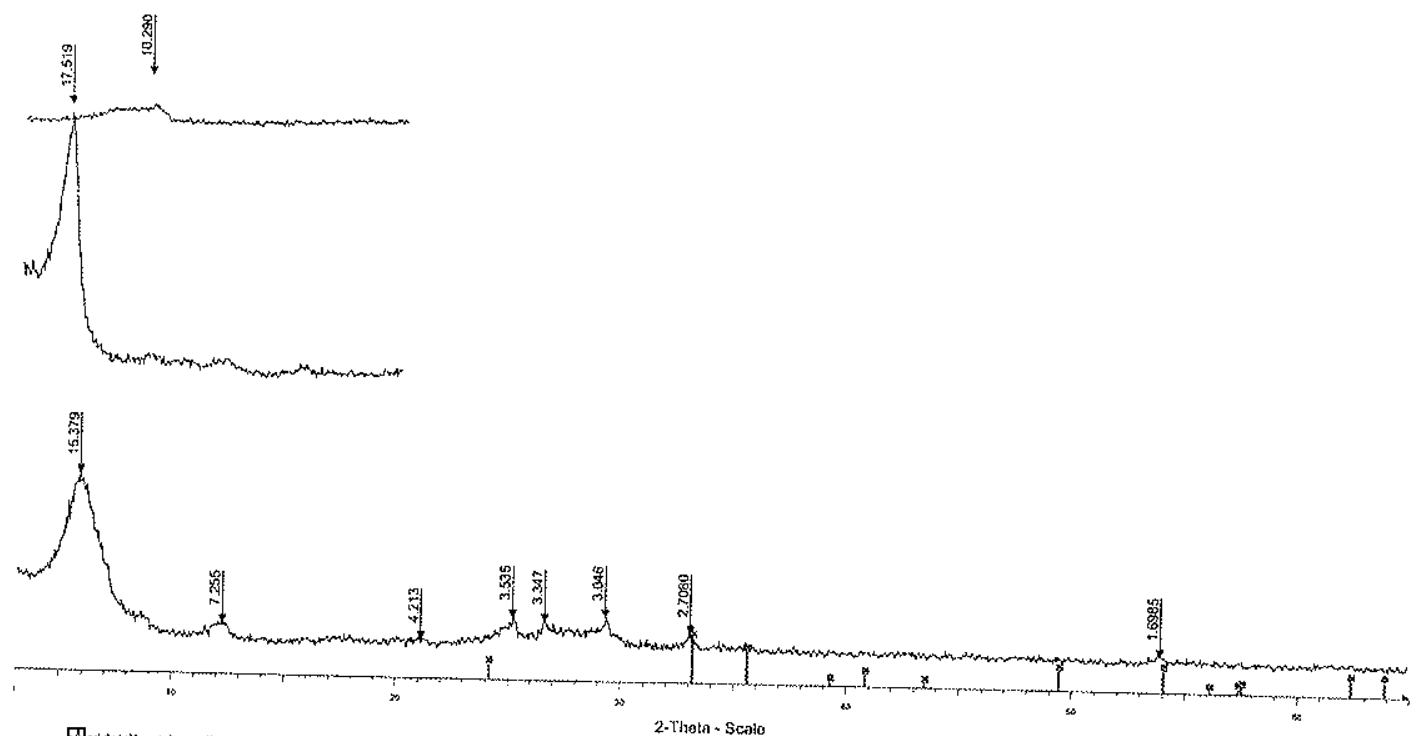

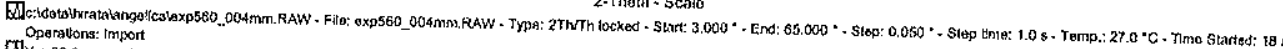

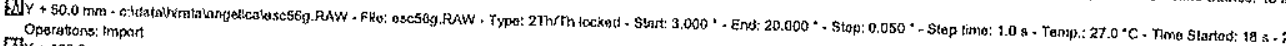
Operatons: mpast

Operattons: - treport

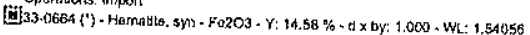

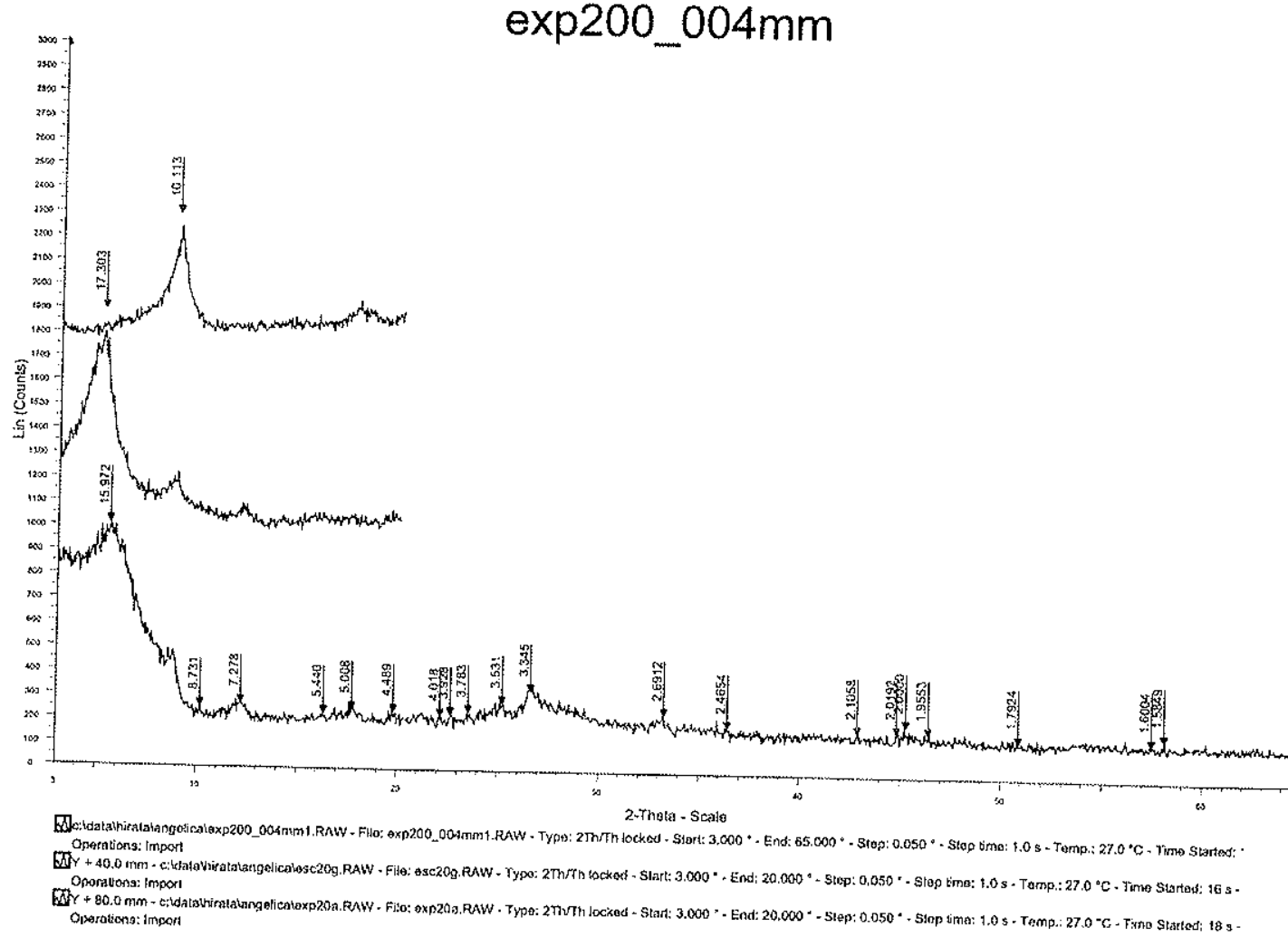




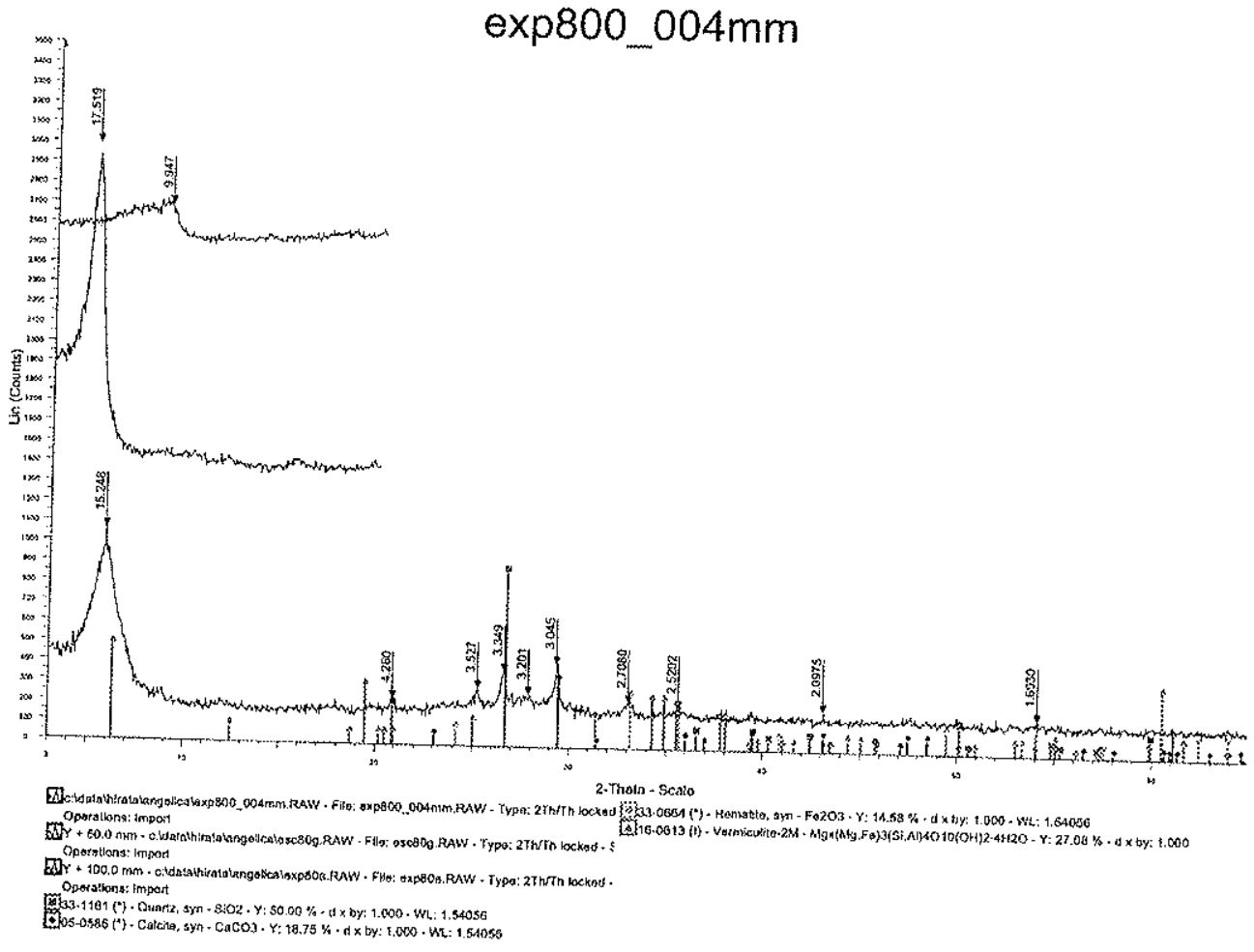




\section{Anexo 3}

Resultados Analíticos da Água Subterrânea 


\begin{tabular}{|c|c|c|c|c|c|c|c|c|c|c|c|c|c|c|c|c|c|c|c|c|c|c|c|}
\hline Poço & Coleta & $\mathrm{Na}+$ & $\mathrm{K}+$ & $\mathrm{Ca2+}$ & $\mathrm{Mg} 2+$ & Fe total & $\mathrm{Mn} 2+$ & Al3 3 & $\mathrm{Ba} 2+$ & $\mathrm{S} 2+$ & Ni2 $\div$ & $\mathrm{Cu} 2+$ & $\mathrm{Zn} 2+$ & Cr total & $\mathrm{Fm}$ & Cl- & NO2- & $\mathrm{Br}$ - & NO3- & PO43- & SO42- & HCO3- & Erro Analitico \\
\hline \multirow[t]{6}{*}{$P C-02$} & $17 / 06 / 1998$ & 13,00 & 16,00 & 17,80 & 6,80 & al & al & al & 0,31 & 14,00 & ai & a! & 0,02 & a! & 0,01 & 9,83 & 0,03 & 0,12 & 63,07 & 0,01 & 0,36 & \begin{tabular}{|l|} 
na \\
\end{tabular} & 35,59 \\
\hline & $26 / 11 / 1998$ & 5,00 & 6.50 & 14,65 & 7,35 & al & at & 0,19 & 0,38 & 0,10 & ai & a! & 0,04 & al & 0,04 & 10,94 & 0,03 & 0,01 & 66,29 & 0,02 & 0,30 & 30,50 & $-3,78$ \\
\hline & $11 / 03 / 1999$ & 5,50 & 6.40 & 19,35 & 7.75 & 0,06 & 0,01 & 0,14 & 0,34 & 0.18 & al & af & a! & 0,01 & 0,05 & 11,16 & 0,05 & 0.01 & 69,41 & 0,04 & 0,49 & 36,60 & $-0,35$ \\
\hline & $21 / 06 / 1999$ & 7,20 & 6,70 & 21,10 & 7.10 & al & 0,01 & ai & 0,05 & 0,18 & 0.02 & al & 0,02 & 0,02 & 0,08 & 15,28 & a! & 0,01 & 85,31 & 0,14 & 0,67 & 30,50 & $-4,50$ \\
\hline & $14 / 04 / 2000$ & 4,90 & 7,00 & 19,50 & 9,75 & al & $\mathrm{al}$ & al & 0,48 & 0,19 & al & al & a! & al & 0,07 & 17,79 & al & al & 90,81 & 0,04 & 0,29 & 19,65 & $-2,69$ \\
\hline & $10 / 10 / 2000$ & 9,60 & 7.00 & 20,95 & 9.75 & al & 0,03 & $a$ & 0,49 & 0,18 & al & a! & at & 0,01 & 0,04 & 12,38 & al & at & 60,70 & 0.13 & 0,21 & 17,66 & 20,29 \\
\hline \multirow[t]{6}{*}{$\mathrm{PC}-04$} & $17 / 06 / 1998$ & 38,00 & 16,50 & 28,70 & 7,65 & ai & al & a! & 0,44 & 0,24 & al & al & 0,01 & al & 0,02 & 21,30 & 0,03 & 0,01 & 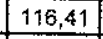 & 0,01 & 0,55 & na & 24,95 \\
\hline & 26/11/1998 & 20,50 & 6,50 & 23.00 & 7,45 & 0,02 & al & 0,10 & 0,40 & 0,16 & al & al & 0,01 & al & 0,05 & 22,23 & 0,11 & 0,10 & 113,24 & 0,02 & 0,61 & 45,75 & $-6,30$ \\
\hline & $11 / 03 / 1999$ & 19,50 & 6,40 & 31,20 & 8.10 & 0,04 & 0,01 & 0,09 & 0,34 & 0,38 & a! & a! & $\mathrm{al}$ & 0,01 & 0,07 & 20,67 & 0,03 & 0,01 & 99,65 & 0,04 & 0,58 & 51,85 & 3,23 \\
\hline & $21 / 06 / 1999$ & 19,00 & 7,30 & 41,80 & 7,70 & 0,01 & al & a! & 0,41 & 0,33 & 0.01 & al & a! & 0,02 & 0,09 & 27,07 & al & al & 126,12 & 0,13 & 0.81 & 57,95 & $-0,34$ \\
\hline & $14 / 04 / 2000$ & 17,50 & 5,90 & 33,30 & 7.70 & 0,10 & 0,02 & al & 0,23 & 0,25 & al & al & 0,01 & al & 0,05 & 26,45 & al & al & 80,26 & 0,05 & 0,57 & 52,41 & 5,01 \\
\hline & $10 / 10 / 2000$ & 18,00 & 6,10 & 16,85 & 4.80 & al & al & $a$ & 0,19 & 0.15 & al & al & al & al & 0,04 & 12,38 & $\mathrm{al}$ & a! & 75,58 & 0,03 & 7,02 & 35,33 & $-7,75$ \\
\hline \multirow[t]{6}{*}{$P C-06$} & $17 / 06 / 1998$ & 7,40 & 14,00 & 22,90 & 3,55 & al & al & al & 0,19 & 0,11 & al & ai & 0,04 & a! & 0.15 & 6,43 & 0,02 & 0,09 & 38,26 & 0,06 & 0,59 & na & 44,14 \\
\hline & $26 / 11 / 1998$ & 3,90 & 5,50 & 9,30 & 2,35 & a! & al & al & 0,11 & 0,04 & a! & 0,02 & 0,02 & al & 0,01 & 3,72 & 0,01 & 0,01 & 34,07 & 0,02 & 0,14 & 39,65 & $-14,78$ \\
\hline & $10 / 03 / 1999$ & 5,00 & 7,90 & 25,05 & 4,45 & al & 0,01 & 0,06 & 0,18 & 0,19 & $\mathrm{al}$ & a! & 0,02 & 0,01 & 0,03 & 8,82 & 0,01 & 0,01 & 55,81 & 0,04 & 0,47 & 51,85 & 0,97 \\
\hline & 21/06/1999 & 4.20 & 6.90 & 18,10 & 2,80 & ai & 0,01 & al & 0,19 & 0.13 & 0,01 & 0,10 & 0,27 & 0,02 & 0,12 & 7,74 & al & 0,00 & 51,64 & 0,08 & 0,51 & 45,75 & $-9,27$ \\
\hline & $14 / 04 / 2000$ & 4,70 & 7,40 & 20,85 & 4,85 & al & al & al & 0,19 & 0,14 & al & 0,02 & 0,03 & al & 0,01 & 8,34 & al & al & 69,40 & 0.03 & 0,19 & 32,76 & $-1,51$ \\
\hline & $10 / 10 / 2000$ & 4,50 & 7,00 & 17.05 & 3,75 & al & al & $a$ & 0,19 & 0,11 & al & 0,02 & 0,01 & $\mathrm{al}$ & 0,01 & 5.23 & al & al & 62,54 & 0,02 & 0,14 & 26,26 & $-1,61$ \\
\hline \multirow[t]{6}{*}{$P C-07$} & 18/06/1998 & 14,50 & 27,00 & 3,80 & 2,60 & al & al & al & 0,18 & $3 !$ & at & al & at & al & 0,02 & 2,52 & 0,02 & 0,08 & 48,21 & 0,01 & 0,10 & na & 33,88 \\
\hline & $27 / 11 / 1998$ & 3,90 & 5,50 & 9,30 & 2,35 & a! & al & a! & 0,11 & 0,04 & al & 0,02 & 0,02 & a! & 0,01 & 3,72 & 0.01 & 0,01 & 37,07 & 0,02 & 0,14 & 9,15 & 6,27 \\
\hline & $10 / 03 / 1999$ & 5,00 & 7,90 & 25,05 & 4.45 & al & 0,01 & 0,06 & 0,18 & 0.19 & $\mathrm{al}$ & al & 0,02 & 0,01 & 0.03 & 8,82 & 0,01 & 0,01 & 55,81 & 0,04 & 0,47 & 12,20 & 20,19 \\
\hline & \begin{tabular}{|l|}
$22 / 06 / 1999$ \\
\end{tabular} & 4,20 & 6,90 & 18,10 & 2.80 & al & 0,01 & al & 0,19 & 0,13 & 0.01 & 0,10 & 0,27 & 0,02 & 0,12 & 7,74 & al & 0,00 & 51,64 & 0,08 & 0,51 & 3,05 & 14,85 \\
\hline & $14 / 04 / 2000$ & 3,60 & 6,60 & 5,85 & 4,90 & a! & 0,02 & al & 0,25 & 0,09 & 0,01 & al & al & 0,02 & 0,01 & 2,30 & ai & al & 51,03 & 0,06 & 0,06 & 3,79 & 3,76 \\
\hline & $10 / 10 / 2000$ & 2,10 & 3,80 & 6,55 & 4,30 & a! & 0,02 & $a$ & 0,30 & 0,06 & al & al & al & 0,01 & 0,03 & 3,33 & a! & a! & 54,70 & 0,02 & 0,08 & 3,84 & $-8,65$ \\
\hline \multirow[t]{6}{*}{$P C-08$} & $18106 / 4998$ & 25,00 & 14,50 & 10,00 & 7,05 & a! & 0,09 & al & 0,24 & af & a! & $\mathrm{al}$ & 0,01 & al & 0.25 & 17,08 & 0,06 & 0.02 & 68,56 & 0,02 & 3,71 & na & 20,46 \\
\hline & 24/11/19998 & 18,50 & 7,30 & 7,40 & 6,90 & 0,04 & 0,09 & 0.35 & 0,18 & 0,04 & at & 0,01 & 0,01 & al & 0,04 & 14,13 & 0,04 & 0,02 & 55,72 & 0,02 & 7,34 & 30,50 & \\
\hline & $10 / 03 / 1999$ & 20,00 & 10,00 & 11,55 & 7,95 & 0,01 & 0,09 & 0,09 & 0,30 & 0,10 & a! & al & al & 0,01 & 0,05 & 14,51 & 0,07 & 0,02 & 65,11 & 0,05 & 2,46 & 36,60 & 31 \\
\hline & $21 / 06 / 1999$ & 18,50 & 9,40 & 10,80 & 6,00 & at & 0,08 & $\mathrm{a}^{\mathrm{a}}$ & 0,19 & 0,20 & 0,02 & 0,01 & al & 0.01 & 0,04 & 16,93 & $\mathrm{al}$ & 0,02 & 68,78 & 0,20 & 3,58 & 39,65 & $-5,24$ \\
\hline & $14 / 04 / 2000$ & 22,00 & 10,20 & 12,20 & 9,55 & 0,02 & 0,11 & al & 0,16 & 0,09 & al & al & a! & at & 0,07 & 20,75 & al & al & 90,25 & 0,03 & 4,97 & 29,48 & $-0,20$ \\
\hline & $10 / 50 / 2000$ & 20,00 & 7,40 & 9,45 & 8.25 & at & 0.11 & $a$ & 0,21 & 0,08 & af & al & al & al & 0,05 & 22,38 & al & $\mathrm{al}$ & 73,83 & 0,05 & 2,48 & 20,18 & 0,22 \\
\hline \multirow[t]{5}{*}{ PC-09 } & \begin{tabular}{|l|}
$18 / 06 / 1998$ \\
\end{tabular} & 24,00 & 2,20 & 14,10 & 4,45 & a! & 0,04 & al & 0,21 & 0,08 & a! & a! & 0,01 & al & 0,13 & 27,46 & 0,07 & 0,01 & 59,05 & 0.01 & 0,64 & na & 10,89 \\
\hline & 24/11/1998 & 29,00 & 2,20 & 17,40 & 6,35 & 0,02 & 0,06 & af & 0,33 & 0,13 & a! & 0,04 & 0,00 & al & 0,23 & 35,66 & 0,07 & 0,12 & 84,27 & 0,02 & 1.00 & 12,20 & 2,24 \\
\hline & $10 / 03 / 1999$ & 29,00 & 2,40 & 34,70 & 8.10 & al & 0,05 & 0,13 & 0.48 & 0,28 & 0,01 & al & $a^{i}$ & 0,01 & 0.08 & 38,10 & 0,05 & 0,01 & 95,44 & 0,02 & 0,64 & 24,40 & 10,58 \\
\hline & $21 / 06 / 1999$ & 22,50 & 2,40 & 24,10 & 5,80 & al & 0,05 & al & 0,31 & 0,09 & 0,02 & al & al & 0,01 & 0,04 & 40,65 & al & 0,00 & 97,62 & 0,44 & 0,97 & 21,35 & $-6,49$ \\
\hline & $10 / 10 / 2000$ & 31,00 & 2,30 & 6,10 & 2,10 & $\mathrm{al}$ & al & $a$ & 0,08 & 0,06 & at & ai & al & 0,01 & 0,08 & 32,09 & ai & $\mathrm{al}$ & 108,91 & 0.02 & 0,71 & 9,93 & $-20,21$ \\
\hline \multirow[t]{6}{*}{ PC-10 } & \begin{tabular}{|l|l|}
$19 / 06 / 1998$ \\
\end{tabular} & 15,50 & 5,00 & 9,25 & 1,35 & 0,08 & 0,03 & af & al & 0.09 & a! & $\mathrm{al}$ & 0,01 & a! & 0.15 & 6,02 & 0,03 & 0,01 & 35.31 & 0,01 & 0,89 & na & 28,64 \\
\hline & $25 / 41 / 1998$ & 15,00 & 4.40 & 17,40 & 6,35 & 0,02 & 0,06 & at & 0.33 & 0.13 & al & 0,01 & 0,01 & al & 0,07 & 4,71 & 0,01 & 0,01 & 27,92 & 0,05 & 0,40 & 33,55 & 30,79 \\
\hline & 103/1999 & 14,20 & 4,20 & 5,25 & 1,60 & 0,16 & 0,02 & 0,09 & 0,10 & 0.09 & a! & al & $\mathrm{al}$ & 0,01 & 0,06 & 6,25 & 0,03 & 0,03 & 37,35 & 0,06 & 0,26 & 21,35 & 0,09 \\
\hline & $21 / 06 / 1999$ & 13,60 & 4,70 & 7.80 & 1,00 & 0.01 & 0,06 & $\mathrm{a!}$ & 0.05 & 0,34 & 0,01 & al & 0,10 & 0,01 & 0,03 & 6,58 & al & 0,01 & 37,22 & 0,07 & 0,46 & 21,35 & 2,09 \\
\hline & $14 / 04 / 2000$ & 12,80 & 4,00 & 2,65 & 1.05 & a! & 0.01 & a! & 0,04 & 0,03 & al & al & al & al & 0,02 & 6,50 & at & al & 35,03 & 0,01 & 0,13 & 6,55 & 1,15 \\
\hline & $10 / 10 / 2000$ & 12,00 & 4,10 & 3,65 & 7,00 & a! & al & a & 0,05 & 0,05 & a! & af & al & al & 0,02 & 5,70 & al & $\mathrm{al}$ & 31,08 & 0,03 & 0,15 & 7,05 & 6,60 \\
\hline
\end{tabular}




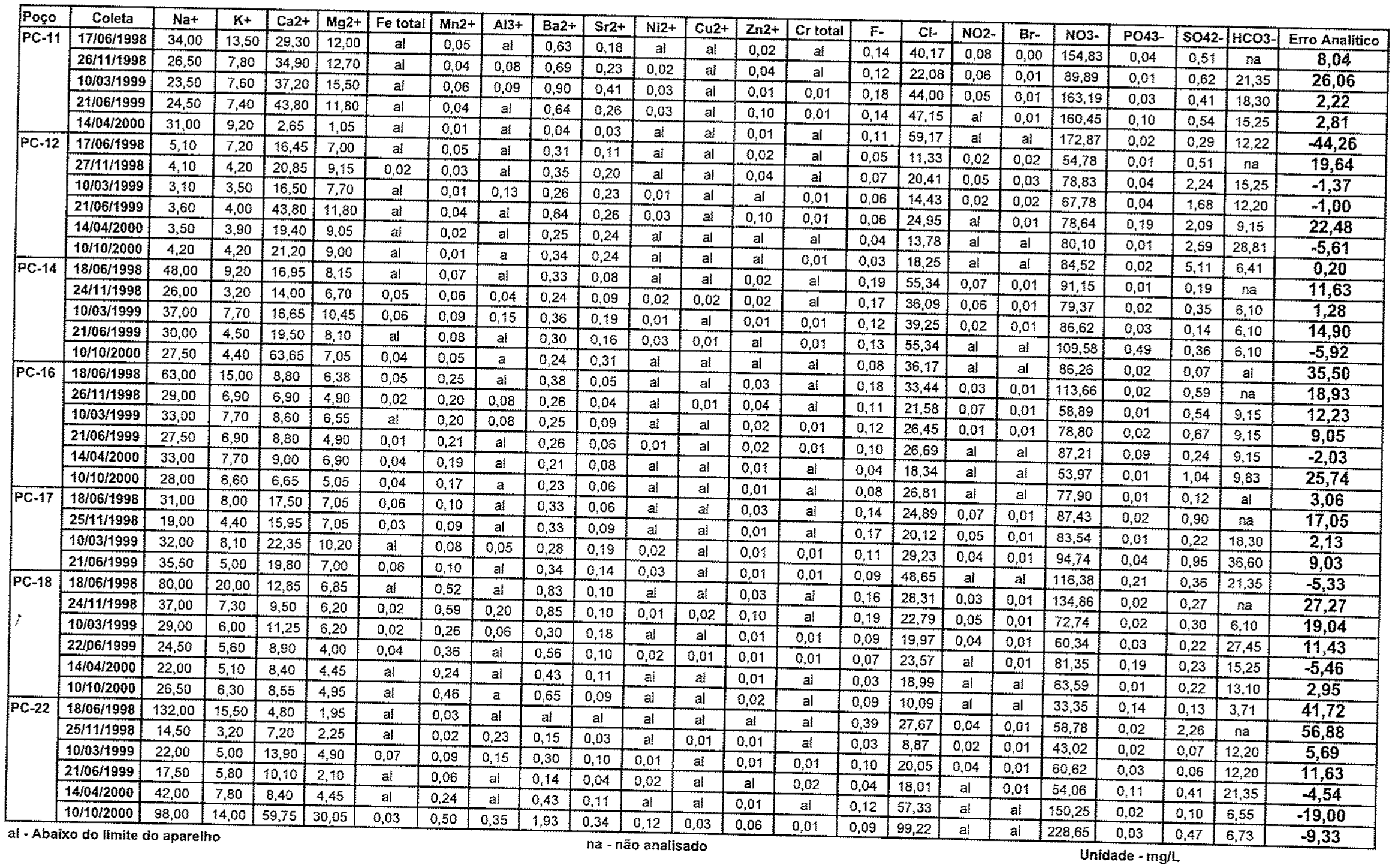




\begin{tabular}{|c|c|c|c|c|c|c|c|c|c|c|c|c|c|c|c|c|c|c|c|c|c|c|}
\hline Poço & Coleta & $\mathrm{Na}+$ & $K+$ & $\mathrm{Ca} 2+$ & $\mathrm{Mg2+}$ & $\mathrm{Fe}$ total & $\mathrm{Mn} 2+$ & $\mathrm{Al} 3 \mathrm{t}$ & $\mathrm{Ba2}+$ & $\mathrm{Sr} 2 \%$ & $\mathrm{Ni2}+$ & $\mathrm{Zn} 2+$ & Cr total & $\mathrm{F}-$ & $\mathrm{Cl}-$ & NO2- & Br- & NO3- & PO43- & SO42- & $\mathrm{HCO}-$ & Erro Analitico \\
\hline \multirow[t]{5}{*}{ PT-01 } & $17 / 06 / 1998$ & 7,00 & 7,80 & 17,15 & 8,70 & \begin{tabular}{|l|}
$\mathrm{al}$ \\
\end{tabular} & al & al & 0,49 & 0,14 & al & 0,01 & al & 0,14 & 11,98 & al & 0,14 & 59,67 & 0,04 & 0,17 & na & 22,70 \\
\hline & $26 / 11 / 1998$ & 7,30 & 6,20 & 18,75 & 7,45 & a! & al & 0,11 & 0,45 & 0,06 & a! & 0,01 & 0,01 & 0,14 & 10,09 & 0,03 & 0,01 & 46,19 & 0,01 & 0,56 & 42,70 & 7,81 \\
\hline & $11 / 03 / 1999$ & 6,50 & 6,40 & 16,75 & 8,05 & a! & al & 0,90 & 0,39 & 0.16 & al & 0,02 & 0,01 & 0,33 & 12,98 & 0,07 & 0,02 & 61,32 & 0,05 & 0,14 & 36,60 & 1,90 \\
\hline & $21 / 06 / 1999$ & 6,50 & 6,20 & 17,50 & 7,60 & 0,07 & al & 0,14 & 0,43 & 0,15 & al & a! & 0,02 & 0,04 & 12,83 & al & al & 67,06 & 0.21 & 0,14 & 39,65 & $-3,30$ \\
\hline & $14 / 04 / 2000$ & 6.40 & 6.20 & 17,55 & 9,30 & a) & af & al & 0,48 & 0,15 & a! & al & 0,01 & 0,02 & 9,08 & al & a! & 36,78 & 0,29 & 0,05 & 31,12 & 20,76 \\
\hline \multirow{6}{*}{ PT-02 } & \begin{tabular}{|c|}
$17 / 06 / 1998$ \\
\end{tabular} & 7,60 & 10,40 & 30,60 & 8,90 & a! & a! & al & 0,28 & 0,34 & al & 0,01 & a! & 0,11 & 3,19 & al & al & 13,23 & 0,00 & 0,09 & $\mathrm{na}$ & 80,43 \\
\hline & $26 / 11 / 1998$ & 4,30 & 4,90 & 34,00 & 9,65 & 0,01 & al & 0,09 & 0,29 & 0,21 & al & 0,01 & 0,01 & 0,10 & 3,40 & 0,01 & 0,01 & 14,39 & 0,05 & 0,09 & 210,45 & $-14,56$ \\
\hline & $11 / 03 / 1999$ & 4,00 & 4,60 & 29,40 & 9,90 & a! & a! & 0,06 & 0,26 & 0,36 & al & 0,01 & 0,01 & 0,08 & 4,28 & 0,01 & 0,01 & 18.44 & 0,04 & 0,06 & 134,20 & $-0,61$ \\
\hline & 21/06/1999 & 3,80 & 4,80 & 38,90 & 8,70 & al & al & al & 0,25 & 0,38 & a! & 0,02 & 0,02 & 0,07 & 5,41 & al & at & 18,60 & 0,18 & 0,08 & 167,75 & $-2,74$ \\
\hline & $14 / 04 / 2000$ & 3,90 & 4,70 & 39,70 & 21,70 & al & al & a! & 0,25 & 0,38 & al & 0,01 & 0,02 & 0,11 & 4,99 & a! & $\mathrm{al}$ & 19,23 & 0,15 & 0,10 & 137,58 & 19,91 \\
\hline & $10 / 10 / 2000$ & 2,00 & 2,50 & 31,00 & 11,55 & al & a! & $a$ & 0,25 & 0,34 & al & at & 0,02 & 0,11 & 4,86 & a! & 0,01 & 18,44 & 0,20 & 0,09 & 157,37 & $-6,45$ \\
\hline \multirow[t]{6}{*}{ PT-05 } & $17 / 06 / 1998$ & 4,30 & 5,80 & 19,35 & 4,90 & al & al & $\mathrm{al}$ & 0,23 & 0,16 & a! & 0,04 & al & 0,28 & 1,54 & al & $\mathrm{al}$ & 22,12 & 0,29 & 0,20 & na & 59,99 \\
\hline & $26 / 11 / 1998$ & 2,60 & 3,70 & 18,65 & 6.40 & 0,01 & al & 0,14 & 0,23 & $0,1\}$ & $\mathrm{al}$ & 0,04 & al & 0,19 & 1,23 & al & 0,00 & 15,84 & 0,07 & 0,06 & 109,80 & $-10,95$ \\
\hline & 10/03/1999 & 2,60 & 3,60 & 19,65 & 7,20 & af & al & 0,05 & 0.23 & 0,21 & at & 0,05 & 0,01 & 0,03 & 1,79 & al & 0,01 & 35,07 & 0,21 & 0,01 & 79,30 & $-3,50$ \\
\hline & $21 / 06 / 1999$ & 2,50 & 3,60 & 20,80 & 6,40 & af & al & a! & 0,23 & 0,19 & al & 0,03 & 0,02 & 0,18 & 2,53 & al & al & 34,81 & 0,49 & 0,06 & 91,50 & $-9,75$ \\
\hline & $14 / 04 / 2000$ & 2,40 & 3,50 & 21,15 & 8,10 & al & $\mathrm{al}$ & al & 0,09 & 0,21 & al & al & 0,02 & 0,28 & 2,06 & a! & at & 32,59 & 0,62 & 0,06 & 83,53 & $-1,67$ \\
\hline & $10 / 10 / 2000$ & 2,60 & 3,70 & 20,35 & 7,60 & al & a! & $a$ & 0.24 & 0,15 & a! & 0,06 & 0,02 & 0,29 & 2,19 & al & $\mathrm{al}$ & 34,79 & 0,54 & 0,05 & 86.71 & 1,38 \\
\hline \multirow[t]{5}{*}{ PT -08} & 18/06/1998 & 4,30 & 5,80 & 19,35 & 4,90 & al & a! & al & 0,29 & 0,16 & a! & 0,04 & al & 0,30 & 8,36 & 0,00 & 0,01 & 70,39 & 0,20 & 0,11 & na & 10,22 \\
\hline & $27 / 11 / 1998$ & 4,70 & 4,00 & 22,45 & 10,90 & a! & a! & 0,28 & 0,24 & 0,10 & a! & 0,10 & 0,01 & 0.18 & 3,78 & 0,01 & 0,01 & 35,41 & 0,07 & 0,07 & 109,80 & $-2,60$ \\
\hline & $10 / 03 / 1999$ & 4,50 & 4,10 & 25,10 & 11,50 & 0,05 & 0,01 & 0,40 & 0,20 & 0,20 & al & 0,08 & 0,01 & 0,27 & 7,46 & 0,04 & 0,01 & 60,10 & 0,08 & 0,15 & 85,40 & $-0,83$ \\
\hline & $22 / 06 / 1999$ & 4.40 & 4,00 & 32,40 & 10,60 & at & a! & al & 0,25 & 0,19 & al & 0,07 & 0,02 & 0,13 & 8,03 & $\mathrm{al}$ & a! & 65,36 & 0,55 & 0,07 & 97,60 & $-1,96$ \\
\hline & $14 / 04 / 2000$ & 4,70 & 4,30 & 37,20 & 13,15 & 0,04 & 0,01 & $\mathrm{al}$ & 0,31 & 0,20 & al & 0,09 & 0,02 & 0,39 & 9,49 & al & al & 67,66 & 0,32 & 0,09 & 85,17 & 7,94 \\
\hline \multirow[t]{6}{*}{$P T-11$} & $18 / 06 / 1998$ & 2,50 & 2,60 & 22,00 & 7,50 & al & al & al & 0,30 & 0,19 & al & 0,08 & al & 0,17 & 5,58 & 0,00 & 0,01 & 57,59 & 0,04 & 0,31 & na & 26,57 \\
\hline & $24 / 11 / 199 \mathrm{~B}$ & 5,30 & 4,70 & 18,55 & 6,15 & 0,33 & al & 0,34 & 0,31 & 0,12 & a! & 0,23 & al & 0,10 & 7,88 & 0,01 & 0,01 & 64,94 & 0,02 & 0,31 & 73,20 & $-14,53$ \\
\hline & 10/03/1999 & 5,30 & 4,90 & 19,10 & 6,60 & al & al & 0,05 & 0,25 & 0,20 & a! & 0,07 & 0,01 & 0,12 & 7,04 & 0,02 & 0,13 & 80,25 & 0,03 & 0,33 & 45,75 & $-1,78$ \\
\hline & $21 / 06 / 1999$ & 6,10 & 4,80 & 19,50 & 5,60 & a! & al & al & 0,29 & 0,21 & 0,02 & 0,11 & 0,01 & 0,05 & 8,31 & al & $\mathrm{al}$ & 61,41 & 0,26 & 0,51 & 57.95 & $-8,96$ \\
\hline & $14 / 04 / 2000$ & 5,30 & 4,60 & 20,50 & 7,70 & al & al & a! & 0,33 & 0,20 & 0,02 & $\mathrm{al}$ & 0,02 & 0,07 & 7,31 & a) & a! & 59,51 & 0,11 & 0,76 & 44,22 & 2,58 \\
\hline & $10 / 10 / 2000$ & 5,30 & 4,80 & 19,90 & 7,10 & a! & $\mathrm{a!}$ & $a$ & 0.28 & 0,16 & al & al & 0,02 & 0,07 & 7,44 & a! & $\mathrm{al}$ & 59,80 & 0,18 & 0,80 & 48,17 & $-1,28$ \\
\hline \multirow{6}{*}{ PT-12 } & $18 / 06 / 1998$ & 15,00 & 11,20 & 15,30 & 4,55 & a) & al & al & 0,18 & 0,06 & a! & al & 0,02 & 0,19 & 1,10 & al & 0,01 & 2,24 & 0,15 & 0,06 & na & 92,31 \\
\hline & $24 / 11 / 1998$ & 5,90 & 3,60 & 13,45 & 5,20 & al & al & 0,19 & 0,18 & 0,05 & $\mathrm{al}$ & 0,03 & 0.02 & 0,19 & 0,94 & $\mathrm{al}$ & 0,01 & 1,78 & 0.01 & 0,15 & 115,90 & $-14,33$ \\
\hline & $10 / 03 / 1999$ & 3,80 & 2,60 & 10,00 & 3,25 & al & at & 0,08 & 0,10 & 0,05 & al & al & 0,02 & 0,18 & 0,39 & 0,01 & 0,01 & 1,46 & 0,06 & 0,05 & 67,10 & $-6,31$ \\
\hline & $21 / 06 / 1999$ & 4,50 & 3,90 & 14,07 & 4,40 & al & al & $\mathrm{al}$ & 0,16 & 0,08 & af & a! & 0,04 & 0,08 & 1,73 & a! & $\mathrm{al}$ & 2,87 & 0,14 & 0,04 & 109,80 & $-46,45$ \\
\hline & $14 / 04 / 2000$ & 4,70 & 3,10 & 14,60 & 6,00 & al & ai & al & 0,14 & 0,06 & $\mathrm{al}$ & $\mathrm{al}$ & 0,02 & 0,13 & 1,02 & al & 0.01 & 3,09 & 0,03 & 0,05 & 72,07 & 8,71 \\
\hline & $10 / 10 / 2000$ & 4,90 & 3,40 & 13,75 & 5.45 & al & al & $a$ & 0,11 & 0,06 & al & a! & 0,03 & 0,17 & 1,19 & al & al & 4,08 & 0,04 & 0,04 & 93,14 & $-6,44$ \\
\hline
\end{tabular}




\begin{tabular}{|c|c|c|c|c|c|c|c|c|c|c|c|c|c|c|c|c|c|c|c|c|c|c|}
\hline Poço & \begin{tabular}{|l|} 
Coleta \\
\end{tabular} & $\mathrm{Na}+$ & $\mathrm{K}+$ & $\mathrm{Ca} 2+$ & $\mathrm{Mg} 2+$ & Fe total & Mn2+ & $\mathrm{Al} 3 \div$ & $\mathrm{Ba} 2+$ & Sr2+ & $\mathrm{Ni} 2+$ & $\mathrm{Zn} 2+$ & \begin{tabular}{|c|} 
Cr total \\
\end{tabular} & $F_{-}$ & $\mathrm{Cl}-$ & NO2- & $\mathrm{Br}$ & NO3- & PO43- & SO42- & $\mathrm{HCO}_{-}$ & Erro Analitico \\
\hline \multirow[t]{6}{*}{ PT-13 } & $19 / 06 / 1998$ & 3,60 & 5,10 & 44,38 & 11,60 & \begin{tabular}{|l|} 
al \\
\end{tabular} & a! & al & 0,26 & 0,34 & $\mathrm{al}$ & a) & al & 0,05 & 5,39 & 0,02 & 0,00 & 21,53 & 0,07 & \begin{tabular}{|l|}
0,17 \\
\end{tabular} & na & 74,44 \\
\hline & $25 / 11 / 1998$ & 3,10 & 3,60 & 38,80 & 10,25 & al & al & 0,08 & 0,25 & 0,19 & al & al & 0,01 & 0,01 & 6,52 & 0,02 & 0,01 & 24,86 & 0,01 & 0,15 & 183,00 & $-8,53$ \\
\hline & 10/03/1999 & 2,40 & 3,20 & 37,30 & $\$ 1,70$ & al & $a$ & a! & 0,21 & 0,36 & al & al & 0,02 & 0,22 & 4,30 & 0.01 & 0,02 & 17,31 & 0,01 & 0,07 & 183,00 & $-6,07$ \\
\hline & $21 / 06 / 1999$ & 2,30 & 3,30 & 49,30 & 10,70 & 0,01 & al & at & 0,24 & 0,36 & al & ai & 0,03 & 0,05 & 6,90 & al & $\mathrm{al}$ & 69,40 & 0,39 & 1,70 & 198,25 & $-13,18$ \\
\hline & $14 / 04 / 2000$ & 2,40 & 3,30 & 64,80 & 12,55 & 0,01 & al & al & 0,25 & 0,36 & a! & al & 0,02 & 0,02 & 6.11 & al & al & 24,74 & 0,05 & 0,07 & 170,34 & 14,06 \\
\hline & $10 / 10 / 2000$ & 2,50 & 3,60 & 39,30 & 13,40 & al & a! & $a$ & 0,26 & 0,33 & al & al & 0,03 & 0,01 & 5,90 & a! & a! & 27,14 & 0,24 & 0,07 & 193,60 & $-4,88$ \\
\hline \multirow{6}{*}{ PT-14 } & $17 / 06 / 1998$ & 28,00 & 5,80 & 11,85 & 4,90 & 0,21 & 0,03 & al & 0,25 & 0,11 & al & $\mathrm{al}$ & $\mathrm{al}$ & 0,04 & 17,32 & 0,03 & 0,01 & 55,58 & 0,02 & 0,88 & 183,06 & 25,69 \\
\hline & $26 / 11 / 1998$ & 13,20 & 2,70 & 14,40 & 6,10 & 0,07 & 0,04 & 0,09 & 0,26 & 0,09 & 0,01 & al & al & 0,06 & 23,29 & 0,08 & 0,02 & 69,31 & 0,02 & 1,28 & 15,25 & $-4,37$ \\
\hline & 10/03/1999 & 13,40 & 2,90 & 17,55 & 7,30 & 0,06 & 0,04 & al & 0,19 & 0,18 & al & $\mathrm{al}$ & 0,01 & 0,11 & 20,94 & 0,09 & 0,01 & 69,04 & 0,03 & 2,17 & 15,25 & 3,32 \\
\hline & $21 / 06 / 1999$ & 30,00 & 4,50 & 17,70 & 6,20 & 0,07 & 0,04 & al & 0,25 & 0,15 & 0,02 & af & 0,01 & 0,06 & 23,74 & al & a! & 69,04 & 0,39 & 1,70 & 12,20 & 16,31 \\
\hline & $14 / 04 / 2000$ & 12,20 & 2,90 & 17,75 & 8,40 & 0,06 & 0,04 & at & 0,26 & 0,15 & al & al & a! & 0,05 & 24,80 & al & al & 71,55 & 0,01 & 2,05 & 9,83 & 3,14 \\
\hline & $10 / 10 / 2000$ & 11,20 & 2,90 & 16,45 & 6,90 & $\mathrm{al}$ & 0,03 & $a$ & 0,24 & 0,14 & al & al & 0,01 & 0,04 & 24,37 & al & a! & 70,13 & 0,42 & 1,27 & 25,62 & $-7,59$ \\
\hline \multirow[t]{6}{*}{ PT-15 } & $17 / 06 / 1998$ & 10,20 & 5,90 & 4,70 & 3,05 & $\mathrm{al}$ & a! & al & al & $\mathrm{al}$ & al & 0,02 & al & 0,15 & 6,58 & 0,02 & 0,07 & 29,15 & 0,27 & 0,15 & na & 23,00 \\
\hline & $27 / 11 / 1998$ & 6,90 & 4,00 & 9,05 & 5,30 & 0,04 & a! & 0,05 & 0,14 & $\mathrm{al}$ & $\mathrm{al}$ & 0,02 & 0,01 & 0,04 & 4,83 & 0,01 & 0,00 & 20,20 & 0,02 & 0,08 & 42,70 & 5,46 \\
\hline & $10 / 03 / 1999$ & 6,50 & 3,70 & 7,05 & 4,35 & al & al & 0,09 & 0,04 & a! & al & al & 0,02 & 0,09 & 6,12 & 0,03 & 0,02 & 28,87 & 0,05 & 0,11 & 21,35 & 4,83 \\
\hline & $21 / 06 / 1999$ & 6,10 & 3,60 & 7,10 & 3,50 & al & al & al & 0,06 & 0,03 & al & at & 0,02 & 0,02 & 9,18 & al & al & 37,29 & 0,85 & 0,13 & 15,25 & $-6,47$ \\
\hline & $14 / 04 / 2000$ & 5,80 & 3,20 & 6,45 & 4,35 & al & a! & at & 0,06 & 0,03 & a! & af & $a !$ & 0,03 & 5,53 & $\mathrm{al}$ & 0,04 & 27,96 & 0,23 & 0,04 & 19,65 & 3,92 \\
\hline & $10 / 10 / 2000$ & 5,80 & 3,40 & 5,85 & 3,80 & $\mathrm{al}$ & al & $a$ & 0,09 & 0,03 & al & al & 0,02 & 0,08 & 4,30 & al & $\mathrm{al}$ & 22,95 & 0,43 & 0,07 & 22,48 & 3,72 \\
\hline \multirow[t]{6}{*}{ PT-16 } & $18 / 06 / 1998$ & 7,80 & 5,40 & 21,90 & 2,65 & al & a! & al & 0,21 & 0,10 & al & $a$ & al & 0,17 & 0,65 & 0,01 & 0,00 & 2,12 & 0,01 & 0,09 & na & 93,14 \\
\hline & $24 / 11 / 1998$ & 3,90 & 2,90 & 23,00 & 5,40 & 0.01 & al & $\mathrm{a!}$ & 0,21 & 0,08 & a! & al & 0,02 & 0,21 & 1,19 & $\mathrm{al}$ & 0,01 & 1,73 & 0,01 & 0,25 & 155,55 & $-17,56$ \\
\hline & $10 / 03 / 1999$ & 3,90 & 2,90 & 21,50 & 5,90 & al & al & 0,05 & 0,14 & 0,15 & al & al & 0,03 & 0,12 & 0,36 & 0,01 & 0,02 & 2,56 & 0,09 & 0,07 & 128,10 & $-8,73$ \\
\hline & $21 / 06 / 1999$ & 4,10 & 2,90 & 19,70 & 4,90 & 0,01 & $\mathrm{al}$ & a! & 0,16 & 0,13 & al & 21 & 0,04 & 0,01 & 1,70 & al & $\mathrm{al}$ & 5,30 & 0,17 & 0,10 & 131,15 & $-16,35$ \\
\hline & $14 / 04 / 2000$ & 3,90 & 2,90 & 22,70 & 7,05 & $\mathrm{al}$ & al & $\mathrm{al}$ & 0,15 & 0,15 & a! & $\mathrm{al}$ & $\mathrm{al}$ & 0,07 & 0,51 & a! & 0,01 & 2,84 & 0,03 & 0,06 & 111,37 & 1,84 \\
\hline & $10 / 10 / 2000$ & 4,20 & 3,30 & 23,20 & 6,35 & $\mathrm{al}$ & a! & $a$ & 0,20 & 0,14 & 0,01 & 0,01 & 0,03 & 0,16 & 0,77 & al & al & 2,68 & 0,02 & 0,13 & 128,47 & $-5,48$ \\
\hline
\end{tabular}




\begin{tabular}{|c|c|c|c|c|c|c|c|c|c|c|c|c|c|c|c|c|c|c|c|c|c|c|c|}
\hline Poço & Coleta & $\mathrm{Na}+$ & $\mathrm{K}+$ & $\mathrm{Ca} 2+$ & Mg2 & Fe total & $\mathrm{Mn} 2+$ & $\mathrm{Al} 3+$ & $\mathrm{Ba} 2+$ & $\mathrm{S} r 2+$ & $\mathrm{Cu} 2+$ & $\operatorname{Zn} 2+$ & Cr total & $F_{-}$ & $\mathrm{Cl}-$ & $\mathrm{NO} 2-$ & $\mathrm{Br}_{\mathrm{-}}$ & $\mathrm{NO}_{-}$ & PO43. & SO42- & $\mathrm{HCO}-$ & $1 \mathrm{co3}$ & Erro Analítico \\
\hline PP-01 & $19 / 06 / 1998$ & 2,10 & 3,30 & 11,30 & 2,10 & 0,11 & 0,02 & al & al & al & af & 3,90 & al & 0,17 & 1,50 & 0,04 & 0,02 & 10,58 & 0,02 & 0,19 & 67,10 & al & $-12,21$ \\
\hline metros & $23 / 11 / 1998$ & 3,10 & 16,00 & 7,90 & 3,55 & 0,01 & 0,01 & 0,06 & 0,14 & 0,04 & at & 2,24 & al & 0,25 & 7,23 & 0,03 & 0,01 & 13,48 & 0,02 & 0,15 & 47,21 & al & 3,83 \\
\hline 46,80 & $09 / 03 / 1999$ & 3,00 & 3.50 & 9,45 & 3,60 & 0,06 & 0.01 & 0,03 & 0,11 & 0,13 & al & 0,95 & 0,01 & 0,19 & 1,69 & 0,01 & 0,15 & 16,51 & 0,05 & 0,08 & 45,75 & al & $-2,38$ \\
\hline 106,5 & $09 / 03 / 1999$ & 3,00 & 3,50 & 9,60 & 3,50 & 0,06 & $\mathrm{al}$ & 0,05 & 0,23 & 0,13 & a! & 0,04 & 0,01 & 0,18 & 1.57 & $\mathrm{a}$ & 0,01 & 17,13 & 0,10 & 0,07 & 45,75 & al & $-3,86$ \\
\hline 46,8 & $23 / 06 / 1999$ & 2,80 & 3,80 & 9,60 & 3,10 & 0.03 & 0,02 & al & 0,11 & 0,06 & al & 0,40 & 0,02 & 0,13 & 2,45 & al & al & 18,31 & 1,02 & 0,56 & 39,65 & al & $-4,57$ \\
\hline \multirow{2}{*}{106,5} & $23 / 06 / 1999$ & 2,70 & 3,80 & 9,60 & 3,10 & 0,05 & $0,0 t$ & at & 0,11 & 0,06 & al & 0,02 & 0.02 & 0,11 & 2,03 & al & $a$ & 18,49 & 1,21 & 0,43 & 42,70 & at & $-7,61$ \\
\hline & $10 / 10 / 2000$ & 3,30 & 4,00 & 9,45 & 3,95 & al & a! & $a$ & 0,13 & 0,10 & at & 4,85 & 0,01 & 0,30 & 2,07 & al & $\mathrm{al}$ & 20,66 & 0,02 & 0,06 & 51,39 & $a !$ & $-2,32$ \\
\hline \multirow[t]{2}{*}{ PP-02 } & 19/06/1998 & 37,00 & 2,30 & 30,70 & 4,35 & $a !$ & al & $\mathrm{al}$ & al & 0,31 & al & 0,03 & 0,08 & 0,21 & 1,24 & 0,02 & 0,01 & 2,86 & 0,02 & 0,18 & 118,95 & 6,00 & 27,14 \\
\hline & 24/11/1998 & 22,00 & 1,80 & 9,10 & 2.65 & 0,01 & al & 0,05 & 0,06 & 0,18 & at & 0,08 & 0,06 & 0.25 & 2,45 & al & 0,00 & 6,94 & 0.03 & 0.19 & 112,85 & $\mathrm{al}$ & $-9,53$ \\
\hline horas & $09 / 03 / 1999$ & 5,50 & 4,50 & 40,10 & 10,20 & 0,01 & $\mathrm{al}$ & 0.04 & 0,38 & 0,71 & al & 0,47 & 0,01 & 0.24 & 7.11 & 0,04 & 0,01 & 30,43 & 0.04 & 0,16 & 125,05 & a! & 7,96 \\
\hline $18: 00$ & 13/05/1999 & 5,10 & 4,60 & 29,10 & 10,20 & 0,01 & 0,01 & a! & 0,39 & 0,58 & a! & 1,02 & 0,02 & 0,24 & 7,00 & al & 0,02 & 30,47 & 0,30 & 0,29 & 152,50 & af & $-9,04$ \\
\hline 18:15 & $13 / 05 / 1999$ & 5,00 & 4,40 & 35,10 & 10,60 & 0,03 & a! & al & 0,36 & 0,55 & $a$ & 0,64 & 0,02 & 0,17 & 7,45 & $\mathrm{al}$ & al & 34,02 & 0,12 & 0.13 & 134,20 & at & 0,34 \\
\hline 19:00 & 13/05/1999 & 6,00 & 4,40 & 35,70 & 10,80 & al & a! & al & 0,35 & 0,60 & at & 0,56 & 0,02 & 0.20 & 7,01 & al & 0,02 & 31,71 & 0,12 & 0,11 & 152,50 & af & $-2,29$ \\
\hline $24 ; 00$ & $13 / 05 / 1999$ & 7,90 & 4,20 & 37,10 & 10,50 & al & al & at & 0,33 & 0,69 & al & 0.39 & 0.03 & 0,17 & 7,10 & al & $\mathrm{al}$ & 31,99 & 0,11 & 0,08 & 179,95 & al & $-6,96$ \\
\hline 06:00 & $14 / 05 / 1999$ & 11,40 & 3,40 & 31,20 & 8,20 & al & al & al & 0,38 & 0,63 & al & 0,24 & 0,04 & 0,16 & 6,95 & at & al & 28,09 & 0,05 & 0,37 & 131,15 & a! & 0,49 \\
\hline$\{2 ; 00$ & $14 / 05 / 4999$ & 13,80 & 2,80 & 21,50 & 5,90 & $\mathrm{a}$ & al & af & 0,15 & 0,58 & al & 0,16 & 0,06 & 0,13 & 4,3 & $\mathrm{al}$ & 0,01 & 19,37 & 0,04 & 0,08 & 143,35 & af & $-10,72$ \\
\hline \multirow[t]{3}{*}{ 18:00 } & $14 / 05 / 1999$ & 15,40 & 2,30 & 17,50 & 4,20 & at & at & al & 0.10 & 0,54 & al & 0.10 & 0,09 & 0,13 & 3,1 & at & 0,01 & 14,12 & 0,05 & 0,08 & 112,85 & a! & $-5,00$ \\
\hline & 23/06/1999 & 4,40 & 4,80 & 29,60 & 9,80 & 0,32 & a! & al & 0,04 & 0,51 & 0,01 & 0,82 & 0,03 & 0,16 & 9,49 & al & al & 38,01 & 1,49 & 0,91 & 118,95 & al & $-4,51$ \\
\hline & $14 / 04 / 2000$ & 5,70 & 4,50 & 40,60 & 11,20 & 0,02 & at & af & 0,33 & 0,53 & al & 0,39 & 0,01 & 0,17 & 6,51 & $\mathrm{al}$ & 0,01 & 29,01 & 0,01 & 0,07 & 134,30 & al & 7,70 \\
\hline \multirow[t]{6}{*}{$P P-03$} & $19 / 06 / 1998$ & 29,00 & 25,00 & 30,70 & 4,35 & al & $\mathrm{al}$ & al & 0,26 & 0.53 & al & al & 0,02 & 0,11 & 3,19 & 0,03 & 0,01 & 23,50 & 0,02 & 0,27 & 201,30 & a! & 0,36 \\
\hline & 24/11/4998 & 4,70 & 3,90 & 40,20 & 9,50 & al & al & 0,19 & 0,29 & 0,54 & al & 0,08 & 0,06 & 0,15 & 3,80 & $\mathrm{al}$ & 0,01 & 26,70 & 0,02 & 0,27 & 179,95 & at & $-5,51$ \\
\hline & $09 / 03 / 1999$ & 4,30 & 3,90 & 30,20 & 8,90 & al & al & 0,08 & 0,40 & 0,63 & al & 0,01 & 0,02 & 0,20 & 4,39 & al & 0,01 & 25,88 & 0,13 & 0,12 & 128,10 & al & $-1,94$ \\
\hline & $23 / 06 / 1999$ & 4,40 & 4,60 & 22,80 & 8,60 & 0.10 & 0,01 & al & 0,26 & 0,30 & al & 0,06 & 0,02 & 0,27 & 9,61 & at & al & 51,47 & 1.02 & 0,62 & 88.45 & a! & $-9,12$ \\
\hline & $14 / 04 / 2000$ & 4,40 & 4,30 & 49,40 & 9,60 & 0,01 & al & al & 0,30 & 0,29 & al & 0,04 & al & 0,28 & 6,52 & at & 0,01 & 41,53 & 0,16 & 0,08 & 78 & al & 24,52 \\
\hline & $10 / 10 / 2000$ & 4,70 & 4,40 & 27,60 & 9,80 & $\mathrm{al}$ & al & $\mathrm{a}$ & 0,28 & 0,55 & ai & 0,02 & 0,02 & 0.20 & 5,41 & al & al & 33,20 & 0,04 & 0,11 & 102,77 & al & 2,70 \\
\hline \multirow{14}{*}{$\begin{array}{l}\text { PP-04 } \\
\text { horas } \\
09: 10 \\
15: 00 \\
18: 10 \\
18: 25 \\
19: 10 \\
24: 10 \\
06: 10\end{array}$} & $19 / 06 / 1998$ & 35,00 & 1,30 & 8,45 & 1,85 & al & at & a! & $\mathrm{al}$ & 0,16 & al & al & 0.09 & 0,22 & 0,97 & 0,01 & 0,01 & 0,31 & 0,01 & 0,13 & 146,40 & 9,00 & $-6,73$ \\
\hline & $24 / 11 / 1998$ & 28,00 & 0,07 & 6,75 & 1,85 & $\mathrm{a}$ & al & 0,41 & 0,03 & 0,10 & al & al & 0,07 & 0.15 & 0,93 & al & 0,00 & 0,41 & 0,02 & 0,16 & 109,80 & 9,00 & $-2,30$ \\
\hline & $09 / 03 / 4999$ & 12,40 & 2,80 & 40,50 & 10,30 & 0,01 & al & 0,06 & 0,18 & 0,61 & al & 0,02 & 0,03 & 0,11 & 2.44 & 0,02 & 0,02 & 6,77 & 0,04 & 0,17 & 213,50 & a! & $-2,54$ \\
\hline & $09 / 03 / 1999$ & 27,00 & 0,70 & 8,05 & 2,10 & 0.02 & al & 0,03 & 0,09 & 0,20 & al & al & 0,08 & 0,16 & 0.74 & $\mathrm{al}$ & 0,60 & 0.42 & 0,01 & 0.12 & 70,15 & 18,00 & 19,66 \\
\hline & $13 / 05 / 1999$ & 3,50 & 3,30 & 37,90 & 14,60 & 0,02 & at & al & 0,13 & 0,58 & al & 0,05 & 0,04 & 0.01 & 1,61 & at & 0,01 & 5.22 & 0,01 & \begin{tabular}{l|l|}
0,12 \\
\end{tabular} & 192,15 & al & 1,01 \\
\hline & $13 / 05 / 1999$ & 4,80 & 3,10 & 40,90 & 13,60 & 0,04 & al & al & 0.14 & 0,64 & at & 0,02 & 0,04 & al & 1,99 & al & 0,01 & 6,61 & 0.03 & 0.18 & 176,90 & al & 6,17 \\
\hline & $13 / 05 / 1999$ & 7.70 & 2,40 & 38,80 & 11,50 & al & at & al & 0,08 & 0.69 & al & 0,02 & 0.04 & at & 2,11 & al & 0,20 & 7,15 & 0,04 & 0,14 & 210,45 & al & $-4,79$ \\
\hline & $14 / 05 / 1999$ & 23,00 & 0,90 & 7,40 & 2,60 & at & al & a! & al & 0,23 & $\mathrm{al}$ & al & 0,11 & 0.08 & 0,82 & af & 0,00 & 0,55 & 0,01 & 0,10 & 88,45 & 12,00 & 4,18 \\
\hline & $14 / 05 / 1999$ & 25,00 & 0,80 & 7,40 & 2,10 & a! & a! & a) & al & 0,21 & al & al & 0.11 & 0,11 & 0,76 & al & 0,00 & 0,41 & 0,04 & 0,11 & 88,45 & 9,00 & 5,53 \\
\hline & $14 / 05 / 1999$ & 26,00 & 0,80 & 7,60 & & a! & al & al & at & 0,19 & al & al & 0,11 & 0.15 & 0,86 & al & 0,01 & 0,33 & 0,04 & 0,11 & 100,65 & 9.00 & 0,21 \\
\hline & $14 / 05 / 1999$ & 26.00 & 0,70 & 7,60 & 1,80 & at & al & al & a! & 0,19 & al & al & 0,12 & 0,11 & 0,79 & al & 0,00 & 0,34 & 0,04 & 0,07 & \begin{tabular}{|l|}
82,35 \\
\end{tabular} & 12,00 & 9,81 \\
\hline & $23 / 06 / 4999$ & 2,50 & 3,70 & 46,70 & 14,20 & 0.01 & al & al & 0.14 & 0,59 & at & 0,03 & 0,04 & 0,01 & 2,59 & al & $\mathrm{al}$ & 7,18 & 0,38 & 0.11 & 210,45 & al & 0,94 \\
\hline & $\$ 4 / 04 / 2000$ & 3,50 & 3,50 & 49,40 & 15,65 & al & a & at & 0.10 & 0,60 & al & 0,03 & 0,02 & 0,01 & 1.81 & al & 0,01 & 5,89 & 0,02 & 0,04 & 196,54 & al & 8,71 \\
\hline & $10 / 10 / 2000$ & 23,00 & 1,90 & 15,25 & 5,40 & al & $a$ & $a$ & 0.06 & 0,29 & al & $a !$ & 0,05 & 0,06 & 1.31 & a & 0.01 & 2,51 & 0,03 & 0,05 & 138,10 & al & $-1,76$ \\
\hline
\end{tabular}




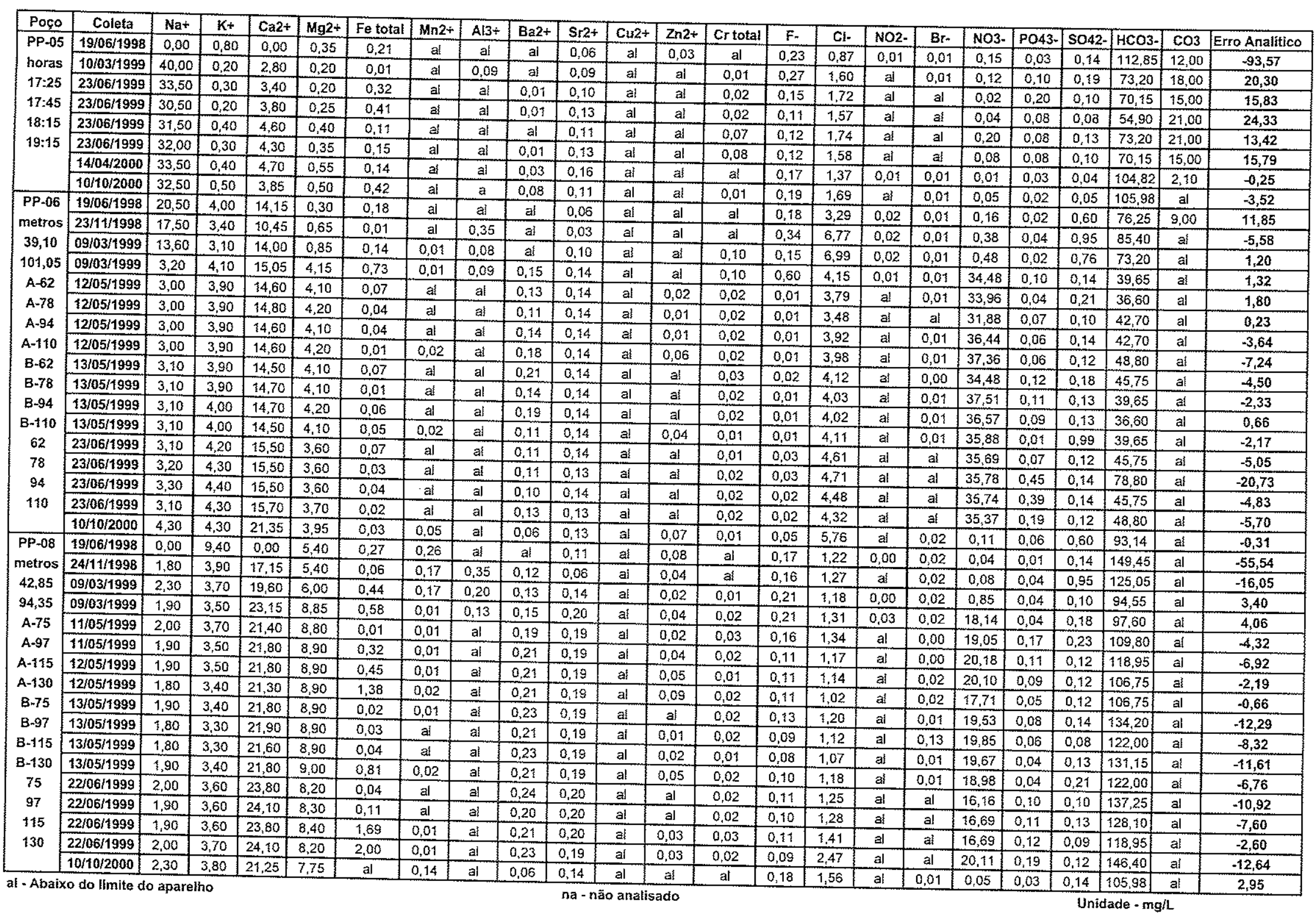




\begin{tabular}{|c|c|c|c|c|c|c|c|}
\hline Poço & Coleta & $\mathrm{T} \operatorname{ar}(\mathrm{C})$ & T água (C) & $\mathrm{pH}$ & $\mathrm{Eh}(\mathrm{mV})$ & $02(\mathrm{mg} / \mathrm{L})$ & C.E. $(\mathrm{ms} / \mathrm{cm})$ \\
\hline \multirow[t]{6}{*}{ PC-02 } & $17 / 06 / 1998$ & 25,40 & 25,40 & 6,45 & 485 & 6,30 & 241,00 \\
\hline & $26 / 11 / 1998$ & 37,10 & 26,70 & 6,30 & 561 & 2,80 & 219,00 \\
\hline & $11 / 03 / 1999$ & 30,00 & 28,20 & 6,22 & 503 & 4,36 & 237,00 \\
\hline & 21/06/1999 & 18,30 & 18,20 & 6,53 & 549 & 6,10 & 269,00 \\
\hline & $14 / 04 / 2000$ & 27,80 & 27,40 & 5,92 & 516 & na & 254,00 \\
\hline & $10 / 10 / 2000$ & 27,40 & 27,00 & 5,96 & 386 & na & 236,00 \\
\hline \multirow[t]{6}{*}{ PC.04 } & $17 / 06 / 1998$ & 23,00 & 24,10 & 6,42 & 471 & 5,38 & 390,00 \\
\hline & 26/11/1998 & 35,70 & 27,20 & 6,35 & 536 & 2,42 & 332,00 \\
\hline & $11 / 03 / 1999$ & 27,00 & 26,70 & 6,32 & 490 & 3,69 & 358,00 \\
\hline & $21 / 06 / 1999$ & 26,70 & 26,20 & 6,67 & 504 & 3,10 & 394,00 \\
\hline & $14 / 04 / 2000$ & 28,00 & 28,00 & 6,25 & 456 & $\mathrm{na}$ & 300,00 \\
\hline & $10 / 10 / 2000$ & 29,60 & 29,00 & 6,05 & 336 & na & 279,00 \\
\hline \multirow[t]{6}{*}{ PC-06 } & $17 / 06 / 1998$ & 33,00 & 26,40 & 6,49 & 491 & 0,74 & 203,00 \\
\hline & $26 / 11 / 1998$ & 28,30 & 21,60 & 5,94 & 524 & 1,17 & 120,80 \\
\hline & $10 / 03 / 1999$ & 32,00 & 27,00 & 6,19 & 504 & 3,49 & 227,00 \\
\hline & $21 / 06 / 1999$ & 22,70 & 22,60 & 6,24 & 519 & 3,60 & 183,00 \\
\hline & $14 / 04 / 2000$ & 34,00 & 28,10 & 5,98 & 551 & na & 205,00 \\
\hline & $10 / 10 / 2000$ & 29,10 & 29,00 & 5,72 & 318 & na & 174,00 \\
\hline \multirow[t]{6}{*}{$P C-07$} & $18 / 06 / 1998$ & 20,80 & 22,90 & 5,86 & 501 & 6,46 & 126,60 \\
\hline & $27 / 11 / 1998$ & 26,40 & 22,40 & 5,82 & 570 & 3,05 & 148,30 \\
\hline & $10 / 03 / 1999$ & 27,50 & 26,80 & 5,56 & 530 & 4,76 & 124,00 \\
\hline & $22 / 06 / 1999$ & 16,90 & 17,40 & 5,53 & 568 & 6,10 & 121,00 \\
\hline & $14 / 04 / 2000$ & 28,00 & 27,10 & 5,19 & 497 & na & 124,00 \\
\hline & $29 / 01 / 1900$ & 29,40 & 29,00 & 5,46 & 358 & na & 121,00 \\
\hline \multirow[t]{6}{*}{ PC-08 } & $18 / 06 / 1998$ & 32,40 & 27,20 & 5,88 & 490 & 0,70 & 252,00 \\
\hline & $24 / 11 / 1998$ & 36,40 & 29,20 & 5,82 & 547 & 1,04 & 227,00 \\
\hline & $10 / 03 / 1999$ & 35,10 & 32,40 & 5,71 & 491 & 1,20 & 254,00 \\
\hline & $21 / 06 / 1999$ & 24,60 & 24,70 & 5,88 & 542 & 2,40 & 241,00 \\
\hline & $14 / 04 / 2000$ & 27,00 & 24,50 & 5,66 & 493 & na & 281,00 \\
\hline & $10 / 10 / 2000$ & 29,30 & 29,00 & 5,53 & 431 & na & 249,00 \\
\hline \multirow[t]{5}{*}{ PC-09 } & $18 / 06 / 1998$ & 31,00 & 27,50 & 5,92 & 524 & 0,69 & 255,00 \\
\hline & $24 / 11 / 1998$ & 38,30 & 28,50 & 5,70 & 553 & 1,54 & 317,00 \\
\hline & 10/03/1999 & 33,70 & 31,00 & 5,84 & 500 & 3,34 & 386,00 \\
\hline & $21 / 06 / 1999$ & 27,70 & 26,20 & 5,96 & 527 & 3,50 & 337,00 \\
\hline & $10 / 10 / 2000$ & 27,00 & 27,00 & 5,70 & 325 & na & 320,00 \\
\hline \multirow[t]{6}{*}{$\mathrm{PC}-10$} & $19 / 06 / 1998$ & 25,20 & 25,20 & 6,28 & 513 & 0,65 & 167,50 \\
\hline & $25 / 11 / 1998$ & 30,30 & 24,40 & 6,27 & 564 & 2,88 & 132,70 \\
\hline & $10 / 03 / 1999$ & 29,60 & 29,10 & 5,79 & 497 & 4,79 & 125,00 \\
\hline & $21 / 06 / 1999$ & 19,30 & 19,50 & 6,62 & 474 & 4,50 & 135,00 \\
\hline & $14 / 04 / 2000$ & 28,00 & 27,70 & 5,64 & 541 & na & 102,00 \\
\hline & $10 / 40 / 2000$ & 30,10 & 30,00 & 5,60 & 421 & na & 98,10 \\
\hline \multirow[t]{5}{*}{ PC-11 } & $17 / 06 / 1998$ & 26,70 & 25,10 & 5,69 & 494 & 5,60 & 463,00 \\
\hline & $26 / 11 / 1998$ & 35,70 & 23,50 & 5,83 & 580 & 2,63 & 330,00 \\
\hline & $10 / 03 / 1999$ & 27,00 & 27,40 & 5,40 & 523 & 4,23 & 512,00 \\
\hline & $21 / 06 / 1999$ & 25,00 & 25,10 & 5,79 & 519 & 3,20 & 486,00 \\
\hline & $14 / 04 / 2000$ & 28,80 & 29,50 & 5,76 & 531 & na & 518,00 \\
\hline \multirow[t]{6}{*}{$\mathrm{PC}-12$} & $17 / 06 / 1998$ & 26,70 & 25,40 & 5,07 & 503 & 4,63 & 224,00 \\
\hline & $27 / 11 / 1998$ & 32,50 & 24,40 & 5,78 & 595 & 2,97 & 270,00 \\
\hline & $10 / 03 / 1999$ & 37,20 & 36,50 & 5,12 & 535 & 4,65 & 202,00 \\
\hline & $21 / 06 / 1999$ & 24,40 & 25,00 & 5,47 & 539 & 3,10 & 256,00 \\
\hline & $14 / 04 / 2000$ & 28,00 & 26,20 & 5,22 & 544 & na & 229,00 \\
\hline & $10 / 10 / 2000$ & 27,30 & 27,00 & 5,25 & 399 & na & 247,00 \\
\hline
\end{tabular}




\begin{tabular}{|c|c|c|c|c|c|c|c|}
\hline Poço & Coleta & $\mathrm{T} \operatorname{ar}(\mathrm{C})$ & T água (C) & $\mathrm{pH}$ & $\operatorname{Eh}(\mathrm{mV})$ & $\mathrm{O} 2(\mathrm{mg} / \mathrm{L})$ & C.E. $(\mathrm{mS} / \mathrm{cm})$ \\
\hline \multirow[t]{5}{*}{ PC-14 } & $18 / 06 / 1998$ & 27,50 & 26,70 & 4,82 & 471 & 5,28 & 369,00 \\
\hline & $24 / 11 / 1998$ & 37,10 & 30,60 & 5,20 & 572 & 2,23 & 307,00 \\
\hline & $10 / 03 / 1999$ & 35,00 & 28,40 & 4,92 & 557 & 3,19 & 408,00 \\
\hline & $21 / 06 / 1999$ & 24,80 & 24,50 & 4,98 & 555 & 3,10 & 389,00 \\
\hline & $10 / 10 / 2000$ & 30,00 & 30,00 & 4,83 & 371 & na & 287 \\
\hline \multirow[t]{6}{*}{$P C-16$} & $18 / 06 / 1998$ & 33,00 & 28,10 & 5,15 & 493 & 1,07 & 360,00 \\
\hline & $26 / 11 / 1998$ & 28,50 & 18,60 & 5,35 & 565 & 1,63 & 257,00 \\
\hline & $10 / 03 / 1999$ & 28,50 & 27,60 & 5,10 & 530 & 2,15 & 303,00 \\
\hline & 21/06/1999 & 21,90 & 22,00 & 5,07 & 489 & 2,40 & 301,10 \\
\hline & $14 / 04 / 2000$ & 27,00 & 24,90 & 5,43 & 495 & na & 289,00 \\
\hline & $10 / 10 / 2000$ & 29,60 & 29,00 & 4,96 & 413 & na & 248,00 \\
\hline \multirow[t]{4}{*}{$\mathrm{PC}-17$} & $18 / 06 / 1998$ & 28,00 & 27,10 & 5,57 & 458 & 3,58 & 325,00 \\
\hline & 25/11/1998 & 37,90 & 21,10 & 5,89 & 513 & 1,48 & 295,00 \\
\hline & $10 / 03 / 1999$ & 29,70 & 27,30 & 5,84 & 515 & 1,89 & 355,00 \\
\hline & $21 / 06 / 1999$ & 20,90 & 21,00 & 5,92 & 354 & 4,10 & 394,00 \\
\hline \multirow[t]{6}{*}{$P C-18$} & $18 / 06 / 1998$ & 29,50 & 24,80 & 6,00 & 474 & 5,62 & 380,00 \\
\hline & $24 / 11 / 1998$ & 38,00 & 30,60 & 5,27 & 530 & 1,57 & 320,00 \\
\hline & $10 / 03 / 1999$ & 31,30 & 28,30 & 5,92 & 506 & 3,19 & 243,00 \\
\hline & $22 / 06 / 1999$ & 12,40 & 12,90 & 5,69 & 554 & 8,00 & 253,00 \\
\hline & $14 / 04 / 2000$ & 34,00 & 27,20 & 5,63 & 558 & na & 210,00 \\
\hline & $10 / 10 / 2000$ & 30,00 & 30,00 & 5,19 & 418 & na & 249,00 \\
\hline \multirow[t]{6}{*}{$\mathrm{PC}-22$} & $18 / 06 / 1998$ & 28,90 & 26,40 & 5,71 & 505 & 0,72 & 234,00 \\
\hline & $25 / 11 / 1998$ & 29,70 & 24,50 & 5,75 & 593 & 2,40 & 156,50 \\
\hline & $10 / 03 / 1999$ & 29,30 & 28,90 & 5,37 & 535 & 4,04 & 243,00 \\
\hline & $21 / 06 / 1999$ & 20,70 & 20,50 & 5,35 & 493 & 4,10 & 184,00 \\
\hline & $14 / 04 / 2000$ & 28,00 & 27,90 & 5,18 & 515 & na & 470,00 \\
\hline & $10 / 10 / 2000$ & 29,00 & 29,00 & 5,29 & 475 & na & 245,00 \\
\hline \multirow[t]{5}{*}{ PT-01 } & $17 / 06 / 1998$ & 25,50 & 25,50 & 6,15 & 488 & 5,90 & 249,00 \\
\hline & $26 / 11 / 1998$ & 30,10 & 27,70 & 6,62 & 465 & 4,27 & 233,00 \\
\hline & $11 / 03 / 1999$ & 29,60 & 29,40 & 6,19 & 494 & 4,50 & 257,00 \\
\hline & $21 / 06 / 1999$ & 21,10 & 21,00 & 6,49 & 537 & 6,30 & 235,00 \\
\hline & $14 / 04 / 2000$ & 27,80 & 27,00 & 6,04 & 516 & na & 235,00 \\
\hline \multirow[t]{6}{*}{ PT-02 } & $17 / 06 / 1998$ & 25,70 & 25,50 & 6,76 & 508 & 6,75 & 268,00 \\
\hline & $26 / 11 / 1998$ & 28,80 & 27,10 & 6,92 & 531 & 3,57 & 246,00 \\
\hline & $11 / 03 / 1999$ & 34,00 & 30,10 & 6,62 & 487 & 5,85 & 233,00 \\
\hline & $21 / 06 / 1999$ & 21,00 & 21,60 & 6,69 & 523 & 4,90 & 266,00 \\
\hline & $14 / 04 / 2000$ & 28,00 & 27,40 & 6,65 & 532 & na & 254,00 \\
\hline & $10 / 10 / 2000$ & 27,40 & 27,00 & 6,84 & 357 & na & 267,00 \\
\hline \multirow[t]{6}{*}{ PT-05 } & $17 / 06 / 1998$ & 24,50 & 24,90 & 6,97 & 514 & 8,03 & 198,20 \\
\hline & $26 / 11 / 1998$ & 26,40 & 23,70 & 7,52 & 481 & 3,86 & 186,00 \\
\hline & $10 / 03 / 1999$ & 30,40 & 30,10 & 7,08 & 478 & 6,14 & 194,90 \\
\hline & $21 / 06 / 1999$ & 22,30 & 26,80 & 7,09 & 528 & 5,10 & 192,00 \\
\hline & $14 / 04 / 2000$ & 28,00 & 25,60 & 7,01 & 513 & na & 192,00 \\
\hline & $10 / 10 / 2000$ & 27,50 & 27,00 & 6,98 & 324 & na & 188,00 \\
\hline \multirow[t]{5}{*}{ PT.08 } & $18 / 06 / 1998$ & 28,00 & 23,60 & 6,68 & 512 & 0,73 & 294,00 \\
\hline & $27 / 11 / 1998$ & 33,30 & 22,00 & 7,18 & 477 & 2,61 & 251,00 \\
\hline & $10 / 03 / 1999$ & 31,70 & 28,10 & 6,15 & 466 & 4,16 & 234,00 \\
\hline & $22 / 06 / 1999$ & 26,80 & 30,40 & 6,95 & 520 & 3,10 & 258,00 \\
\hline & $14 / 04 / 2000$ & 34,10 & 28,00 & 7,02 & 493 & na & 294,00 \\
\hline
\end{tabular}




\begin{tabular}{|c|c|c|c|c|c|c|c|}
\hline Poço & Coleta & $\mathrm{T} \operatorname{ar}(\mathrm{C})$ & Tágua (C) & $\mathrm{pH}$ & Eh (mV) & $02(\mathrm{mg} / \mathrm{L})$ & C.E. $(\mathrm{ms} / \mathrm{cm})$ \\
\hline \multirow[t]{6}{*}{ PT-11 } & 18/06/1998 & 26,00 & 26,20 & 6,13 & 493 & 5,45 & 223,00 \\
\hline & $24 / 11 / 1998$ & 27,40 & 25,70 & 6,40 & 410 & 3,78 & 216,00 \\
\hline & $10 / 03 / 1999$ & 31,80 & 24,60 & 5,97 & 494 & 4,48 & 211,00 \\
\hline & $21 / 06 / 1999$ & 17,80 & 17,90 & 6,25 & 526 & 5,20 & 223,00 \\
\hline & $14 / 04 / 2000$ & 26,00 & 26,90 & 6,14 & 488 & $\mathrm{na}$ & 214,00 \\
\hline & $10 / 10 / 2000$ & 26,10 & 26,00 & 6,99 & 491 & $\mathrm{na}$ & 157,10 \\
\hline \multirow[t]{6}{*}{ PT-12 } & $18 / 06 / 1998$ & 25,50 & 26,10 & 6,99 & 491 & 0,70 & 157,10 \\
\hline & $24 / 11 / 1998$ & 31,60 & 20,50 & 7,17 & 531 & 3,97 & 137,30 \\
\hline & $10 / 03 / 1999$ & 26,80 & 26,50 & 6,92 & 491 & 6,31 & 93,30 \\
\hline & 21/06/1999 & 20,10 & 20,20 & 7,14 & 462 & 6,00 & 140,30 \\
\hline & $14 / 04 / 2000$ & 28,00 & 28,00 & 7,03 & 514 & $\mathrm{na}$ & 139,00 \\
\hline & $10 / 10 / 2000$ & 24,90 & 24,00 & 6,66 & 375,00 & na & 137,70 \\
\hline \multirow[t]{6}{*}{ PT-13 } & $19 / 06 / 1998$ & 24,50 & 23,80 & 6,78 & 459 & 5,76 & 318,00 \\
\hline & 25/11/1998 & 27,30 & 21,30 & 7,17 & 532 & 2,83 & 265,00 \\
\hline & $10 / 03 / 1999$ & 30,00 & 29,30 & 6,82 & 480 & 5,24 & 279,00 \\
\hline & $21 / 06 / 1999$ & 24,20 & 24,00 & 7,05 & 514 & 4,10 & 315,00 \\
\hline & $14 / 04 / 2000$ & 26,70 & 26,20 & 6,12 & 464 & na & 300,00 \\
\hline & $10 / 10 / 2000$ & 27,50 & 27,00 & 6,95 & 359 & na & 298,00 \\
\hline \multirow[t]{6}{*}{ PT-14 } & $17 / 06 / 1998$ & 29,00 & 28,20 & 5,34 & 502 & 0,70 & 258,00 \\
\hline & $26 / 11 / 1998$ & 27,50 & 25,30 & 5,50 & 495 & 1,58 & 240,00 \\
\hline & $10 / 03 / 1999$ & 29,20 & 28,80 & 5,34 & 453 & 2,44 & 264,00 \\
\hline & $21 / 06 / 1999$ & 14,30 & 14,50 & 5,51 & 519 & 3,70 & 238,00 \\
\hline & $14 / 04 / 2000$ & 26,70 & 28,00 & 5,30 & 496 & na & 244,00 \\
\hline & $10 / 10 / 2000$ & 27,10 & 26,80 & 5,26 & 354 & 6,10 & 225,00 \\
\hline \multirow[t]{6}{*}{ PT-15 } & $17 / 06 / 1998$ & 27,00 & 26,50 & 5,96 & 494 & 0,66 & 107,90 \\
\hline & $27 / 11 / 1998$ & 29,10 & 24,90 & 6,36 & 515 & 3,13 & 155,00 \\
\hline & $10 / 03 / 1999$ & 25,00 & 26,00 & 6,41 & 514 & 2,43 & 112,60 \\
\hline & $21 / 06 / 1999$ & 18,50 & 17,80 & 5,84 & 474 & 4,00 & 129,70 \\
\hline & $14 / 04 / 2000$ & 34,00 & 27,10 & 5,94 & 536 & $\mathrm{na}$ & 110,00 \\
\hline & $10 / 10 / 2000$ & 27,10 & 27,00 & 6,02 & 417 & na & 103,30 \\
\hline \multirow[t]{6}{*}{ PT-16 } & $18 / 06 / 1998$ & 23,50 & 25,10 & 6,83 & 491 & 0,58 & 203,00 \\
\hline & $24 / 11 / 1998$ & 31,80 & 21,80 & 7,02 & 547 & 4,04 & 186,30 \\
\hline & $10 / 03 / 1999$ & 27,70 & 27,20 & 6,97 & 502 & 5,90 & 256,20 \\
\hline & $21 / 06 / 1999$ & 19,60 & 19,70 & 6,85 & 476 & 5,50 & 178,30 \\
\hline & $14 / 04 / 2000$ & 28,00 & 27,90 & 6,82 & 547 & na & 187,00 \\
\hline & $10 / 10 / 2000$ & 25,50 & 25,00 & 6,55 & 401 & na & 128,47 \\
\hline \multirow{2}{*}{$\begin{array}{l}\text { PP.01 } \\
\text { metros }\end{array}$} & $19 / 06 / 1998$ & 25,60 & 25,90 & 6,76 & 517 & 0,48 & 118,30 \\
\hline & $23 / 11 / 1998$ & 32,40 & 28,90 & 7,04 & 539 & 0,01 & 114,20 \\
\hline 46,80 & $09 / 03 / 1999$ & 36,10 & 35,90 & 6,55 & 497 & 5,10 & 144,00 \\
\hline 106,5 & $09 / 03 / 1999$ & 36,90 & 36,10 & 6,52 & 509 & 6,66 & 103,00 \\
\hline 46,8 & $23 / 06 / 1999$ & 22,90 & 23,00 & 6,43 & 540 & 5,30 & 100,90 \\
\hline \multirow[t]{2}{*}{106,5} & $23 / 06 / 1999$ & 23,00 & 23,10 & 6,37 & 524 & 5,80 & 105,80 \\
\hline & $10 / 10 / 2000$ & 28,90 & 28,00 & 6,85 & 317 & na & 123,00 \\
\hline
\end{tabular}




\begin{tabular}{|c|c|c|c|c|c|c|c|}
\hline Poço & Coleta & $\mathrm{T} \operatorname{ar}(\mathrm{C})$ & $r$ água (C) & $\mathrm{pH}$ & $\mathrm{Eh}(\mathrm{mV})$ & $02(\mathrm{mg} / \mathrm{L})$ & C.E. $(\mathrm{mS} / \mathrm{cm})$ \\
\hline \multirow[t]{2}{*}{ PP-02 } & $19 / 06 / 1998$ & 27,00 & 25,20 & 8,46 & 464 & 0,65 & 149,80 \\
\hline & $24 / 11 / 1998$ & 29,30 & 26,90 & 8,07 & 502 & 2,92 & 159,90 \\
\hline horas & $09 / 03 / 1999$ & 29,00 & 28,50 & 6,98 & 478 & 4,50 & 248,00 \\
\hline $18: 00$ & $13 / 05 / 1999$ & na & 25,00 & 6,76 & 457 & 4,29 & 276,00 \\
\hline $18: 15$ & $13 / 05 / 1999$ & na & 24,60 & 6,85 & 460 & 4,05 & 261,00 \\
\hline $19: 00$ & $13 / 05 / 1999$ & na & 24,50 & 6,92 & 464 & 4,00 & 281,00 \\
\hline $24 ; 00$ & $13 / 05 / 1999$ & na & 16,00 & 7,24 & 476 & 4,90 & 285,00 \\
\hline 06:00 & $14 / 05 / 1999$ & na & 21,50 & 7,28 & 528 & 4,40 & 256,00 \\
\hline $12: 00$ & $14 / 05 / 1999$ & na & 25,00 & 7,27 & 463 & 3,70 & 226,00 \\
\hline \multirow[t]{3}{*}{$18: 00$} & $14 / 05 / 1999$ & na & 24,00 & 7,23 & 462 & 3,40 & 220,00 \\
\hline & $23 / 06 / 1999$ & 25,30 & 25,70 & 6,68 & 508 & 3,50 & 275,00 \\
\hline & $14 / 04 / 2000$ & 27,80 & 27,60 & 6,85 & 575 & na & 275,00 \\
\hline \multirow[t]{6}{*}{ Pp.03 } & $19 / 06 / 1998$ & 27,50 & 25,30 & 7,64 & 478 & 0,73 & 291,00 \\
\hline & 24/11/1998 & 29,90 & 28,10 & 7,77 & 491 & 3,60 & 288,00 \\
\hline & $09 / 03 / 1999$ & 29,50 & 28,00 & 7,11 & 475 & 5,06 & 249,00 \\
\hline & $23 / 06 / 1999$ & 24,60 & 25,70 & 6,66 & 508 & 3,70 & 272,00 \\
\hline & $14 / 04 / 2000$ & 31,10 & 28,60 & 6,93 & 500 & na & 229,00 \\
\hline & $10 / 10 / 2000$ & 25,80 & 25,00 & 7,10 & 334 & na & 253,00 \\
\hline$P P=04$ & $19 / 06 / 1998$ & 27,00 & 25,50 & 8,78 & 452 & 0,64 & 158,70 \\
\hline horas & $24 / 11 / 1998$ & 29,20 & 26,80 & 8,72 & 505 & 3,47 & 158,30 \\
\hline $09: 10$ & $09 / 03 / 1999$ & 28,80 & 27,50 & 7,87 & 443 & 3,02 & 265,00 \\
\hline $15: 00$ & $09 / 03 / 1999$ & 34,00 & 29,30 & 8,54 & 445 & 3,70 & 138,00 \\
\hline $18: 10$ & $13 / 05 / 1999$ & na & 24,10 & 7,57 & 453 & 3,70 & 301,00 \\
\hline $18: 25$ & $13 / 05 / 1999$ & na & 24,10 & 7,76 & 452 & 3,00 & 290,00 \\
\hline $19: 10$ & $13 / 05 / 1999$ & na & 25,00 & 7,69 & 457 & 2,60 & 279,00 \\
\hline $24 ; 10$ & $14 / 05 / 1999$ & na & 16,00 & 8,32 & 502 & 4,30 & 161,00 \\
\hline $06: 10$ & $14 / 05 / 1999$ & na & 21,10 & 8,37 & 476 & 3,40 & 159,00 \\
\hline $12: 10$ & $14 / 05 / 1999$ & na & 25,00 & 8,49 & 440 & 2,90 & 190,00 \\
\hline \multirow[t]{4}{*}{$18: 10$} & $14 / 05 / 1999$ & na & 26,40 & 8,53 & 437 & 3,10 & 160,00 \\
\hline & $23 / 06 / 1999$ & 23,80 & 23,80 & 7,65 & 491 & 3,30 & 309,00 \\
\hline & $14 / 04 / 2000$ & 31,10 & 28,60 & 7,74 & 568 & na & 290,00 \\
\hline & $10 / 10 / 2000$ & 25,40 & 25,00 & 7,91 & 355 & na & 204,00 \\
\hline \multirow{8}{*}{$\begin{array}{l}\text { PP.05 } \\
\text { hora }\end{array}$} & $19 / 06 / 1998$ & 26,50 & 24,80 & 9,16 & 460 & 0,61 & 147,90 \\
\hline & $10 / 03 / 1999$ & 35,40 & 34,70 & 9,13 & 427 & 3,87 & 157,00 \\
\hline & $23 / 06 / 1999$ & 22,30 & 22,20 & 9,01 & 440 & 4,10 & 160,00 \\
\hline & $23 / 06 / 1999$ & 22,20 & 22,10 & 9,10 & 425 & 3,20 & 163,00 \\
\hline & $23 / 06 / 1999$ & 22,00 & 22,10 & 8,88 & 465 & 3,60 & 122,00 \\
\hline & $23 / 06 / 1999$ & 21,60 & 21,50 & 8,90 & 443 & 3,50 & 159,40 \\
\hline & $14 / 04 / 2000$ & 28,00 & 30,00 & 8,79 & 392 & na & 160,00 \\
\hline & $10 / 10 / 2000$ & 25,30 & 25,00 & 8,74 & 361 & na & 158,00 \\
\hline
\end{tabular}




\begin{tabular}{|c|c|c|c|c|c|c|c|}
\hline Poço & Coleta & $T \operatorname{ar}(\mathrm{C})$ & $T$ água (C) & $\mathrm{pH}$ & $\mathrm{Eh}(\mathrm{mV})$ & $02(\mathrm{mg} / \mathrm{L})$ & C.E. $(\mathrm{mS} / \mathrm{cm})$ \\
\hline \multirow{2}{*}{$\begin{array}{l}\text { PP-06 } \\
\text { metros }\end{array}$} & $19 / 06 / 1998$ & 26,20 & 25,60 & 8,92 & 487 & 0,62 & 137,10 \\
\hline & $23 / 11 / 1998$ & 34,20 & 29,30 & 6,38 & 451 & 3,29 & 136,20 \\
\hline 39,10 & $09 / 03 / 1999$ & 34,20 & 33,10 & 7,69 & 427 & 2,34 & 133,00 \\
\hline 101,05 & $09 / 03 / 1999$ & 35,20 & 35,00 & 5,93 & 449 & 4,56 & 134,00 \\
\hline A-62 & $12 / 05 / 1999$ & na & 26,00 & 6,11 & 454 & 3,08 & 154,00 \\
\hline A.78 & $12 / 05 / 1999$ & na & 26,00 & 6,05 & 432 & 4,12 & 153,00 \\
\hline A-94 & $12 / 05 / 1999$ & na & 26,00 & 6,02 & 437 & 4,58 & 153,00 \\
\hline A-110 & $12 / 05 / 1999$ & na & 25,70 & 6,06 & 434 & 4,43 & 155,00 \\
\hline B-62 & $13 / 05 / 1999$ & na & 26,70 & 6,00 & 474 & 4,86 & 156,00 \\
\hline$B-78$ & $13 / 05 / 1999$ & na & 26,40 & 5,96 & 460 & 3,51 & 154,00 \\
\hline B-94 & $13 / 05 / 1999$ & na & 26,00 & 6,01 & 455 & 3,53 & 164,00 \\
\hline B-110 & $13 / 05 / 1999$ & na & 25,80 & 6,64 & 467 & 4,38 & 155,00 \\
\hline 62 & $23 / 06 / 1999$ & 17,60 & 19,20 & 6,17 & 482 & 4,60 & 156,00 \\
\hline 78 & $23 / 06 / 1999$ & 18,10 & 18,40 & 6,16 & 477 & 5,40 & 154,90 \\
\hline 94 & $23 / 06 / 1999$ & 21,30 & 21,40 & 5,96 & 475 & 5,80 & 155,00 \\
\hline \multirow[t]{2}{*}{110} & $23 / 06 / 1999$ & 22,90 & 23,00 & 6,02 & 480 & 4,10 & 155,50 \\
\hline & $10 / 10 / 2000$ & 29,80 & 29,00 & 7,14 & 345 & na & 158,00 \\
\hline \multirow{2}{*}{$\begin{array}{l}\text { PP.08 } \\
\text { metros }\end{array}$} & $19 / 06 / 1998$ & 23,80 & 23,90 & 7,74 & 160 & 0,47 & 171,20 \\
\hline & $24 / 11 / 1998$ & 27,50 & 27,20 & 7,63 & 513 & 1,49 & 162,50 \\
\hline 42,85 & $09 / 03 / 1999$ & 36,10 & 35,80 & 7,36 & 467 & 2,38 & 155,00 \\
\hline 94,35 & $09 / 03 / 1999$ & 34,10 & 33,60 & 6,84 & 476 & 7,12 & 193,00 \\
\hline A-75 & $11 / 05 / 1999$ & na & 27,00 & 6,83 & 429 & 6,43 & 205,00 \\
\hline A-97 & $11 / 05 / 1999$ & na & 24,80 & 6,76 & 421 & 4,60 & 206,00 \\
\hline$A \cdot 115$ & $12 / 05 / 1999$ & na & 24,90 & 6,74 & 486 & 4,22 & 207,00 \\
\hline$A-130$ & $12 / 05 / 1999$ & na & 24,30 & 6,63 & 491 & 4,53 & 205,00 \\
\hline B.75 & $13 / 05 / 1999$ & na & 24,90 & 6,62 & 473 & 4,15 & 205,00 \\
\hline B-97 & $13 / 05 / 1999$ & na & 25,10 & 6,65 & 460 & 4,03 & 207,00 \\
\hline$B \times 115$ & $13 / 05 / 1999$ & na & 24,80 & 6,65 & 447 & 4,24 & 207,00 \\
\hline B-130 & $13 / 05 / 1999$ & na & 16,00 & 6,65 & 428 & 4,15 & 209,00 \\
\hline 75 & $22 / 06 / 1999$ & 24,80 & 24,90 & 6,75 & 506 & 6,70 & 211,00 \\
\hline 97 & $22 / 06 / 1999$ & 22,80 & 22,80 & 6,73 & 498 & 5,00 & 215,00 \\
\hline 115 & $22 / 06 / 1999$ & 19,20 & 19,10 & 6,74 & 510 & 6,80 & 218,00 \\
\hline \multirow[t]{2}{*}{130} & $22 / 06 / 1999$ & 17,90 & 28,10 & 7,05 & 535 & 7,10 & 250,00 \\
\hline & $10 / 10 / 2000$ & 27,00 & 27,00 & 7,54 & 321 & na & 176,00 \\
\hline
\end{tabular}

na - não analisado 
Anexo 4

Análise Estatística 
Poços Cacimbas Particulares - PC

\begin{tabular}{|l|c|c|c|c|c|c|}
\hline & N & Média & Mediana & Minimo & Máximo & DP \\
\hline SO4 & 14 & 0,862 & 0,570 & 0,100 & 3,710 & 0,973 \\
\hline CL & 14 & 22,271 & 23,095 & 2,520 & 55,340 & 14,795 \\
\hline NO3 & 14 & 80,311 & 65,815 & 35,310 & 154,830 & 37,147 \\
\hline F & 14 & 0,141 & 0,145 & 0,013 & 0,390 & 0,101 \\
\hline PO4 & 14 & 0,018 & 0,014 & 0,006 & 0,060 & 0,015 \\
\hline NA & 14 & 37,893 & 28,000 & 5,100 & 132,000 & 34,482 \\
\hline K & 14 & 13,114 & 14,250 & 2,200 & 27,000 & 6,406 \\
\hline CA & 14 & 15,229 & 15,275 & 3,800 & 29,300 & 7,870 \\
\hline MG & 14 & 5,916 & 6,825 & 1,350 & 12,000 & 2,855 \\
\hline PH & 14 & 5,808 & 5,870 & 4,820 & 6,490 & 0,524 \\
\hline EH (mV) & 14 & 490,929 & 492,000 & 458,000 & 524,000 & 18,062 \\
\hline CE & 14 & 285,007 & 253,500 & 126,600 & 463,000 & 96,828 \\
\hline
\end{tabular}

Nov $/ 98$

\begin{tabular}{|l|c|c|c|c|c|c|}
\hline & N & Média & Mediana & Mínimo & Máximo & DP \\
\hline HCO3 & 14 & 20,696 & 16,775 & 6,100 & 45,750 & 13,060 \\
\hline SO4 & 14 & 0,591 & 0,375 & 0,070 & 2,240 & 0,590 \\
\hline CL & 14 & 17,646 & 20,265 & 3,720 & 36,090 & 10,563 \\
\hline NO3 & 14 & 66,061 & 69,515 & 27,920 & 113,240 & 24,532 \\
\hline F & 14 & 0,093 & 0,070 & 0,007 & 0,230 & 0,073 \\
\hline PO4 & 14 & 0,021 & 0,020 & 0,009 & 0,050 & 0,011 \\
\hline NA & 14 & 17,993 & 18,750 & 3,900 & 37,000 & 10,841 \\
\hline K & 14 & 5,350 & 5,500 & 2,200 & 7,800 & 1,776 \\
\hline CA & 14 & 14,839 & 14,325 & 6,900 & 34,900 & 7,780 \\
\hline MG & 14 & 6,289 & 6,525 & 2,250 & 12,700 & 2,803 \\
\hline PH & 14 & 5,805 & 5,820 & 5,200 & 6,350 & 0,357 \\
\hline EH (mV) & 14 & 557,357 & 562,500 & 513,000 & 595,000 & 24,963 \\
\hline CE & 14 & 245,164 & 263,500 & 120,800 & 332,000 & 77,923 \\
\hline
\end{tabular}

Mar/99

\begin{tabular}{|l|c|c|c|c|c|c|}
\hline & N & Média & Mediana & Mínimo & Máximo & DP \\
\hline HCO3 & 14 & 25,489 & 22,875 & 6,100 & 51,850 & 15,208 \\
\hline SO4 & 14 & 0,679 & 0,480 & 0,060 & 2,460 & 0,651 \\
\hline CL & 14 & 21,551 & 20,010 & 6,250 & 44,000 & 12,235 \\
\hline NO3 & 14 & 77,905 & 68,595 & 37,350 & 163,190 & 30,358 \\
\hline F & 14 & 0,082 & 0,075 & 0,030 & 0,180 & 0,041 \\
\hline PO4 & 14 & 0,036 & 0,040 & 0,020 & 0,060 & 0,011 \\
\hline NA & 14 & 19,843 & 21,000 & 3,100 & 37,000 & 11,634 \\
\hline K & 14 & 6,486 & 7,000 & 2,400 & 10,000 & 2,084 \\
\hline CA & 14 & 19,900 & 18,000 & 5,250 & 37,200 & 9,807 \\
\hline MG & 14 & 7,421 & 7,725 & 1,600 & 15,500 & 3,325 \\
\hline PH & 14 & 5,664 & 5,750 & 4,920 & 6,320 & 0,438 \\
\hline EH (mV) & 14 & 515,429 & 510,500 & 490,000 & 557,000 & 19,945 \\
\hline CE & 14 & 284,071 & 248,500 & 124,000 & 512,000 & 109,533 \\
\hline
\end{tabular}


Jun/99

\begin{tabular}{|l|c|c|c|c|c|c|}
\hline & N & Média & Mediana & Mínimo & Máximo & DP \\
\hline HCO3 & 13 & 22,758 & 21,350 & 3,050 & 57,950 & 16,501 \\
\hline SO4 & 13 & 0,872 & 0,510 & 0,230 & 3,580 & 0,946 \\
\hline CL & 13 & 26,795 & 24,950 & 6,580 & 55,340 & 16,526 \\
\hline NO3 & 13 & 88,611 & 85,310 & 37,220 & 160,450 & 33,903 \\
\hline F & 13 & 0,085 & 0,090 & 0,031 & 0,140 & 0,036 \\
\hline PO4 & 13 & 0,185 & 0,140 & 0,065 & 0,490 & 0,135 \\
\hline NA & 13 & 18,062 & 19,000 & 3,600 & 35,500 & 10,688 \\
\hline K & 13 & 5,977 & 6,700 & 2,400 & 9,400 & 1,830 \\
\hline CA & 13 & 22,031 & 19,500 & 7,800 & 43,800 & 13,109 \\
\hline MG & 13 & 6,215 & 6,000 & 1,000 & 11,800 & 3,252 \\
\hline PH & 13 & 5,873 & 5,880 & 4,980 & 6,670 & 0,543 \\
\hline EH (mV) & 13 & 514,846 & 527,000 & 354,000 & 568,000 & 55,502 \\
\hline CE & 13 & 289,162 & 269,000 & 121,000 & 486,000 & 108,618 \\
\hline
\end{tabular}

\section{Abr $/ 00$}

\begin{tabular}{|l|c|c|c|c|c|c|}
\hline & N & Média & Mediana & Mínimo & Máximo & DP \\
\hline HCO3 & 11 & 19,559 & 13,103 & 3,786 & 52,411 & 14,882 \\
\hline SO4 & 11 & 0,950 & 0,290 & 0,060 & 4,970 & 1,522 \\
\hline CL & 11 & 22,704 & 18,340 & 2,300 & 59,170 & 18,890 \\
\hline NO3 & 11 & 85,233 & 80,100 & 35,030 & 172,870 & 41,715 \\
\hline F & 11 & 0,051 & 0,040 & 0,009 & 0,120 & 0,038 \\
\hline PO4 & 11 & 0,026 & 0,015 & 0,007 & 0,060 & 0,018 \\
\hline NA & 11 & 17,909 & 17,500 & 3,500 & 42,000 & 13,399 \\
\hline K & 11 & 6,800 & 7,000 & 3,900 & 10,200 & 1,988 \\
\hline CA & 11 & 12,927 & 9,000 & 2,650 & 33,300 & 9,387 \\
\hline MG & 11 & 5,791 & 4,900 & 1,050 & 9,750 & 3,091 \\
\hline PH & 11 & 5,624 & 5,640 & 5,180 & 6,250 & 0,348 \\
\hline EH (mV) & 11 & 517,909 & 516,000 & 456,000 & 558,000 & 30,846 \\
\hline CE & 11 & 271,091 & 254,000 & 102,000 & 518,000 & 127,348 \\
\hline
\end{tabular}

\section{Out/00}

\begin{tabular}{|l|c|c|c|c|c|c|}
\hline & N & Média & Mediana & Mínimo & Máximo & DP \\
\hline HCO3 & 11 & 14,404 & 9,928 & 3,715 & 35,328 & 10,457 \\
\hline SO4 & 13 & 0,854 & 0,210 & 0,070 & 5,110 & 1,439 \\
\hline CL & 13 & 24,261 & 18,250 & 3,330 & 99,220 & 24,826 \\
\hline NO3 & 13 & 79,388 & 73,830 & 31,080 & 228,640 & 49,671 \\
\hline F & 13 & 0,052 & 0,041 & 0,012 & 0,090 & 0,028 \\
\hline PO4 & 13 & 0,048 & 0,030 & 0,014 & 0,140 & 0,046 \\
\hline NA & 13 & 22,992 & 18,000 & 2,100 & 98,000 & 24,569 \\
\hline K & 13 & 6,077 & 6,100 & 2,300 & 14,000 & 2,833 \\
\hline CA & 13 & 15,331 & 9,450 & 3,650 & 63,650 & 15,637 \\
\hline MG & 13 & 5,158 & 4,950 & 1,000 & 9,750 & 2,707 \\
\hline PH & 13 & 5,453 & 5,460 & 4,830 & 6,050 & 0,360 \\
\hline EH (mV) & 13 & 395,692 & 399,000 & 318,000 & 493,000 & 54,141 \\
\hline CE & 13 & 225,931 & 247,000 & 98,100 & 320,000 & 64,331 \\
\hline
\end{tabular}


Poços Tubulares Particulares - PT

Jun/98

\begin{tabular}{|l|c|c|c|c|c|c|}
\hline & $\mathrm{N}$ & Média & Mediana & Mínimo & Máximo & $\mathrm{DP}$ \\
\hline SO4 & 10 & 0,223 & 0,160 & 0,060 & 0,880 & 0,242 \\
\hline CL & 10 & 6,169 & 5,485 & 0,650 & 17,320 & 5,276 \\
\hline NO3 & 10 & 33,362 & 25,635 & 2,120 & 70,390 & 25,337 \\
\hline F & 10 & 0,160 & 0,160 & 0,040 & 0,300 & 0,085 \\
\hline PO4 & 10 & 0,109 & 0,055 & 0,003 & 0,290 & 0,110 \\
\hline NA & 10 & 9,030 & 7,300 & 2,500 & 28,000 & 7,612 \\
\hline K & 10 & 6,580 & 5,800 & 2,600 & 11,200 & 2,563 \\
\hline CA & 10 & 20,658 & 19,350 & 4,700 & 44,380 & 10,758 \\
\hline MG & 10 & 6,165 & 4,900 & 2,650 & 11,600 & 2,881 \\
\hline PH & 10 & 6,459 & 6,720 & 5,340 & 6,990 & 0,540 \\
\hline EH (mV) & 10 & 495,200 & 493,500 & 459,000 & 514,000 & 15,810 \\
\hline CE & 10 & 227,620 & 236,000 & 107,900 & 318,000 & 63,582 \\
\hline
\end{tabular}

Nov/98

\begin{tabular}{|l|c|c|c|c|c|c|}
\hline & $\mathbf{N}$ & Média & Mediana & Mínimo & Máximo & DP \\
\hline HCO3 & 10 & 105,835 & 109,800 & 15,250 & 210,450 & 63,897 \\
\hline SO4 & 10 & 0,300 & 0,150 & 0,060 & 1,280 & 0,377 \\
\hline CL. & 10 & 6,315 & 4,305 & 0,940 & 23,290 & 6,692 \\
\hline NO3 & 10 & 29,465 & 22,530 & 1,730 & 69,310 & 24,076 \\
\hline F & 10 & 0,122 & 0,120 & 0,006 & 0,210 & 0,071 \\
\hline PO4 & 10 & 0,029 & 0,019 & 0,008 & 0,070 & 0,025 \\
\hline NA & 10 & 5,720 & 5,000 & 2,600 & 13,200 & 3,037 \\
\hline K & 10 & 4,030 & 3,850 & 2,700 & 6,200 & 1,024 \\
\hline CA & 10 & 21,110 & 18,700 & 9,050 & 38,800 & 9,139 \\
\hline MG & 10 & 7,280 & 6,275 & 5,200 & 10,900 & 2,181 \\
\hline PH & 10 & 6,786 & 6,970 & 5,500 & 7,520 & 0,584 \\
\hline EH (mV) & 10 & 498,400 & 505,000 & 410,000 & 547,000 & 41,626 \\
\hline CE & 10 & 211,560 & 224,500 & 137,300 & 265,000 & 43,321 \\
\hline
\end{tabular}

Mar/99

\begin{tabular}{|l|c|c|c|c|c|c|}
\hline & N & Média & Mediana & Minimo & Máximo & DP \\
\hline HCO3 & 10 & 79,605 & 73,200 & 15,250 & 183,000 & 54,512 \\
\hline SO4 & 10 & 0,316 & 0,090 & 0,009 & 2,170 & 0,657 \\
\hline CL & 10 & 6,566 & 5,210 & 0,360 & 20,940 & 6,314 \\
\hline NO3 & 10 & 35,442 & 31,970 & 1,460 & 69,040 & 25,645 \\
\hline F & 10 & 0,155 & 0,120 & 0,030 & 0,330 & 0,093 \\
\hline PO4 & 10 & 0,065 & 0,050 & 0,013 & 0,210 & 0,056 \\
\hline NA & 10 & 5,290 & 4,250 & 2,400 & 13,400 & 3,175 \\
\hline K & 10 & 3,890 & 3,650 & 2,600 & 6,400 & 1,159 \\
\hline CA & 10 & 20,340 & 19,375 & 7,050 & 37,300 & 8,819 \\
\hline MG & 10 & 7,575 & 7,250 & 3,250 & 11,700 & 2,811 \\
\hline PH & 10 & 6,447 & 6,515 & 5,340 & 7,080 & 0,545 \\
\hline EH (mV) & 10 & 485,900 & 489,000 & 453,000 & 514,000 & 17,584 \\
\hline CE & 10 & 213,500 & 233,500 & 93,300 & 279,000 & 63,541 \\
\hline
\end{tabular}




\begin{tabular}{|l|c|c|c|c|c|c|}
\hline & $\mathrm{N}$ & Média & Mediana & Mínimo & Máximo & DP \\
\hline HCO3 & 10 & 92,110 & 94,550 & 12,200 & 198,250 & 62,420 \\
\hline SO4 & 10 & 0,454 & 0,115 & 0,042 & 1,700 & 0,671 \\
\hline CL & 10 & 8,036 & 7,465 & 1,700 & 23,740 & 6,578 \\
\hline NO3 & 10 & 43,114 & 49,350 & 2,870 & 69,400 & 26,914 \\
\hline F & 10 & 0,068 & 0,052 & 0,010 & 0,180 & 0,051 \\
\hline PO4 & 10 & 0,363 & 0,325 & 0,140 & 0,850 & 0,222 \\
\hline NA & 10 & 7,030 & 4,450 & 2,300 & 30,000 & 8,198 \\
\hline K & 10 & 4,160 & 3,950 & 2,900 & 6,200 & 0,951 \\
\hline CA & 10 & 23,697 & 19,600 & 7,100 & 49,300 & 12,679 \\
\hline MG & 10 & 6,960 & 6,300 & 3,500 & 10,700 & 2,596 \\
\hline PH & 10 & 6,586 & 6,770 & 5,510 & 7,140 & 0,560 \\
\hline EH (mV) & 10 & 507,900 & 519,500 & 462,000 & 537,000 & 26,639 \\
\hline CE & 10 & 217,530 & 229,000 & 129,700 & 315,000 & 57,842 \\
\hline
\end{tabular}

\begin{tabular}{|l|c|c|c|c|c|c|}
\hline & N & Média & Mediana & Mínimo & Máximo & DP \\
\hline HCO3 & 10 & 76,488 & 77,798 & 9,827 & 170,336 & 52,360 \\
\hline SO4 & 10 & 0,333 & 0,065 & 0,040 & 2,050 & 0,642 \\
\hline CL & 10 & 7,090 & 5,820 & 0,510 & 24,800 & 6,965 \\
\hline NO3 & 10 & 34,595 & 30,275 & 2,840 & 71,550 & 24,646 \\
\hline F & 10 & 0,117 & 0,070 & 0,020 & 0,390 & 0,123 \\
\hline PO4 & 10 & 0,184 & 0,130 & 0,010 & 0,620 & 0,190 \\
\hline NA & 10 & 5,170 & 4,700 & 2,400 & 12,200 & 2,796 \\
\hline K & 10 & 3,870 & 3,400 & 2,900 & 6,200 & 1,066 \\
\hline CA & 10 & 26,240 & 20,825 & 6,450 & 64,800 & 16,781 \\
\hline MG & 10 & 9,830 & 8,250 & 4,350 & 21,700 & 4,962 \\
\hline PH & 10 & 6,407 & 6,395 & 5,300 & 7,030 & 0,586 \\
\hline EH (mV) & 10 & 509,900 & 513,500 & 464,000 & 547,000 & 25,111 \\
\hline CE & 10 & 216,900 & 224,500 & 110,000 & 300,000 & 61,740 \\
\hline
\end{tabular}

Out/00

\begin{tabular}{|l|c|c|c|c|c|c|}
\hline & N & Média & Mediana & Mínimo & Máximo & DP \\
\hline HCO3 & 8 & 93,129 & 89,926 & 22,482 & 183,064 & 59,851 \\
\hline SO4 & 8 & 0,319 & 0,080 & 0,050 & 1,270 & 0,460 \\
\hline CL & 8 & 6,378 & 4,580 & 0,770 & 24,370 & 7,631 \\
\hline NO3 & 8 & 30,001 & 25,045 & 2,680 & 70,130 & 24,293 \\
\hline F & 8 & 0,117 & 0,095 & 0,014 & 0,290 & 0,088 \\
\hline PO4 & 8 & 0,259 & 0,220 & 0,020 & 0,540 & 0,189 \\
\hline NA & 8 & 4,813 & 4,550 & 2,000 & 11,200 & 2,941 \\
\hline K & 8 & 3,450 & 3,400 & 2,500 & 4,800 & 0,670 \\
\hline CA & 8 & 21,225 & 20,125 & 5,850 & 39,300 & 10,308 \\
\hline MG & 8 & 7,769 & 7,000 & 3,800 & 13,400 & 3,171 \\
\hline PH & 8 & 6,414 & 6,605 & 5,260 & 6,980 & 0,596 \\
\hline EH(mV) & 8 & 364,625 & 358,000 & 324,000 & 417,000 & 32,129 \\
\hline CE & 8 & 195,308 & 201,500 & 103,300 & 298,000 & 68,931 \\
\hline
\end{tabular}


Poços Profundos da SABESP - PP

\begin{tabular}{|l|c|c|c|c|c|c|}
\hline & N & Média & Mediana & Mínimo & Máximo & DP \\
\hline HCO3 & 7 & 124,614 & 118,950 & 67,100 & 201,300 & 46,169 \\
\hline SO4 & 7 & 0,236 & 0,180 & 0,130 & 0,600 & 0,168 \\
\hline CL & 7 & 1,754 & 1,240 & 0,870 & 3,290 & 1,035 \\
\hline NO3 & 7 & 5,371 & 0,310 & 0,040 & 23,500 & 8,856 \\
\hline F & 7 & 0,184 & 0,180 & 0,110 & 0,230 & 0,041 \\
\hline PO4 & 7 & 0,017 & 0,016 & 0,007 & 0,030 & 0,007 \\
\hline NA & 7 & 17,657 & 20,500 & 0,000 & 37,000 & 16,719 \\
\hline K & 7 & 6,586 & 3,300 & 0,800 & 25,000 & 8,605 \\
\hline CA & 7 & 13,614 & 11,300 & 0,000 & 30,700 & 12,825 \\
\hline MG & 7 & 2,671 & 2,100 & 0,300 & 5,400 & 2,045 \\
\hline PH & 7 & 8,209 & 8,460 & 6,760 & 9,160 & 0,860 \\
\hline EH (mV) & 7 & 431,143 & 464,000 & 160,000 & 517,000 & 121,486 \\
\hline CE & 7 & 167,714 & 149,800 & 118,300 & 291,000 & 56,841 \\
\hline
\end{tabular}

\begin{tabular}{|l|c|c|c|c|c|c|}
\hline & N & Média & Mediana & Mínimo & Máximo & DP \\
\hline HCO3 & 6 & 110,043 & 111,325 & 47,210 & 179,950 & 43,990 \\
\hline SO4 & 6 & 0,445 & 0,230 & 0,150 & 0,950 & 0,393 \\
\hline CL & 6 & 3,742 & 3,125 & 0,930 & 7,230 & 2,721 \\
\hline NO3 & 6 & 7,998 & 3,675 & 0,080 & 26,700 & 10,576 \\
\hline F & 6 & 0,217 & 0,205 & 0,150 & 0,340 & 0,077 \\
\hline PO4 & 6 & 0,028 & 0,025 & 0,015 & 0,040 & 0,011 \\
\hline NA & 6 & 12,850 & 11,100 & 1,800 & 28,000 & 11,122 \\
\hline K & 6 & 4,845 & 3,650 & 0,070 & 16,000 & 5,664 \\
\hline CA & 6 & 15,258 & 9,775 & 6,750 & 40,200 & 12,753 \\
\hline MG & 6 & 3,933 & 3,100 & 0,650 & 9,500 & 3,164 \\
\hline PH & 6 & 7,602 & 7,700 & 6,380 & 8,720 & 0,813 \\
\hline EH (mV) & 6 & 500,167 & 503,500 & 451,000 & 539,000 & 28,986 \\
\hline CE & 6 & 169,850 & 159,100 & 114,200 & 288,000 & 60,787 \\
\hline
\end{tabular}

\begin{tabular}{|l|c|c|c|c|c|c|}
\hline & N & Média & Mediana & Mínimo & Máximo & DP \\
\hline HCO3 & 7 & 107,621 & 94,550 & 45,750 & 213,500 & 55,230 \\
\hline SO4 & 7 & 0,226 & 0,160 & 0,080 & 0,760 & 0,239 \\
\hline LL & 7 & 3,629 & 2,440 & 1,180 & 7,110 & 2,559 \\
\hline NO3 & 7 & 11,577 & 6,770 & 0,120 & 30,430 & 12,760 \\
\hline F & 7 & 0,196 & 0,200 & 0,110 & 0,270 & 0,053 \\
\hline PO4 & 7 & 0,059 & 0,040 & 0,016 & 0,130 & 0,040 \\
\hline NA & 7 & 11,586 & 5,500 & 2,300 & 40,000 & 13,305 \\
\hline K & 7 & 3,100 & 3,500 & 0,200 & 4,500 & 1,392 \\
\hline CA & 7 & 22,379 & 19,600 & 2,800 & 40,500 & 14,900 \\
\hline MG & 7 & 5,721 & 6,000 & 0,200 & 10,300 & 4,280 \\
\hline PH & 7 & 7,527 & 7,360 & 6,550 & 9,130 & 0,834 \\
\hline EH (mV) & 7 & 459,143 & 467,000 & 427,000 & 497,000 & 27,169 \\
\hline CE & 7 & 193,000 & 157,000 & 133,000 & 265,000 & 57,859 \\
\hline
\end{tabular}


Jun/99

\begin{tabular}{|l|c|c|c|c|c|c|}
\hline & N & Média & Mediana & Mínimo & Máximo & DP \\
\hline HCO3 & 7 & 99,343 & 88,450 & 39,650 & 210,450 & 58,240 \\
\hline SO4 & 7 & 0,363 & 0,130 & 0,090 & 0,910 & 0,331 \\
\hline CL & 7 & 4,557 & 2,590 & 1,410 & 9,610 & 3,559 \\
\hline NO3 & 7 & 23,936 & 18,310 & 0,200 & 51,470 & 18,361 \\
\hline F & 7 & 0,117 & 0,120 & 0,005 & 0,270 & 0,088 \\
\hline PO4 & 7 & 0,597 & 0,380 & 0,070 & 1,490 & 0,574 \\
\hline NA & 7 & 7,229 & 3,100 & 1,900 & 31,500 & 10,743 \\
\hline K & 7 & 3,586 & 3,800 & 0,400 & 4,800 & 1,477 \\
\hline CA & 7 & 21,800 & 22,800 & 4,600 & 46,700 & 13,966 \\
\hline MG & 7 & 6,871 & 8,400 & 0,400 & 14,200 & 4,733 \\
\hline PH & 7 & 7,030 & 6,680 & 6,170 & 8,880 & 0,935 \\
\hline EH (mV) & 7 & 500,571 & 508,000 & 465,000 & 540,000 & 23,999 \\
\hline CE & 7 & 207,557 & 218,000 & 100,900 & 309,000 & 82,113 \\
\hline
\end{tabular}

\begin{tabular}{|l|c|c|c|c|c|c|}
\hline & N & Média & Mediana & Mínimo & Máximo & DP \\
\hline HCO3 & 4 & 128,571 & 119,563 & 78,617 & 196,542 & 50,703 \\
\hline SO4 & 4 & 0,058 & 0,055 & 0,040 & 0,080 & 0,021 \\
\hline NL & 4 & 4,053 & 4,160 & 1,370 & 6,520 & 2,849 \\
\hline F & 4 & 19,110 & 17,450 & 0,008 & 41,530 & 19,496 \\
\hline PO4 & 4 & 0,156 & 0,170 & 0,005 & 0,280 & 0,113 \\
\hline NA & 4 & 0,054 & 0,025 & 0,006 & 0,160 & 0,072 \\
\hline K & 4 & 11,775 & 5,050 & 3,500 & 33,500 & 14,511 \\
\hline CA & 4 & 3,175 & 3,900 & 0,400 & 4,500 & 1,900 \\
\hline MG & 4 & 36,025 & 45,000 & 4,700 & 49,400 & 21,291 \\
\hline PH & 4 & 9,250 & 10,400 & 0,550 & 15,650 & 6,340 \\
\hline EH (mV) & 4 & 5,578 & 7,335 & 6,850 & 8,790 & 0,903 \\
\hline CE & 4 & 238,500 & 252,000 & 160,000 & 290,000 & 58,866 \\
\hline
\end{tabular}

Out/00

\begin{tabular}{|l|c|c|c|c|c|c|}
\hline & N & Média & Mediana & Mínimo & Máximo & DP \\
\hline HCO3 & 6 & 99,561 & 104,379 & 51,386 & 138,101 & 28,072 \\
\hline SO4 & 6 & 0,168 & 0,085 & 0,050 & 0,600 & 0,215 \\
\hline CL & 6 & 2,967 & 1,880 & 1,310 & 5,760 & 2,046 \\
\hline NO3 & 6 & 9,430 & 1,310 & 0,050 & 33,200 & 14,155 \\
\hline F & 6 & 0,167 & 0,185 & 0,050 & 0,320 & 0,100 \\
\hline PO4 & 6 & 0,033 & 0,030 & 0,020 & 0,060 & 0,015 \\
\hline NA & 6 & 11,683 & 4,500 & 2,300 & 32,500 & 12,830 \\
\hline K & 6 & 3,075 & 3,900 & 0,050 & 4,400 & 1,742 \\
\hline CA & 6 & 16,458 & 18,250 & 3,850 & 27,600 & 8,724 \\
\hline MG & 6 & 5,225 & 4,675 & 0,500 & 9,800 & 3,253 \\
\hline PH & 6 & 7,547 & 7,340 & 6,850 & 8,740 & 0,694 \\
\hline EH (mV) & 6 & 338,833 & 339,500 & 317,000 & 361,000 & 17,938 \\
\hline CE & 6 & 178,667 & 167,000 & 123,000 & 253,000 & 45,005 \\
\hline
\end{tabular}


Histograma PC Março de 1999
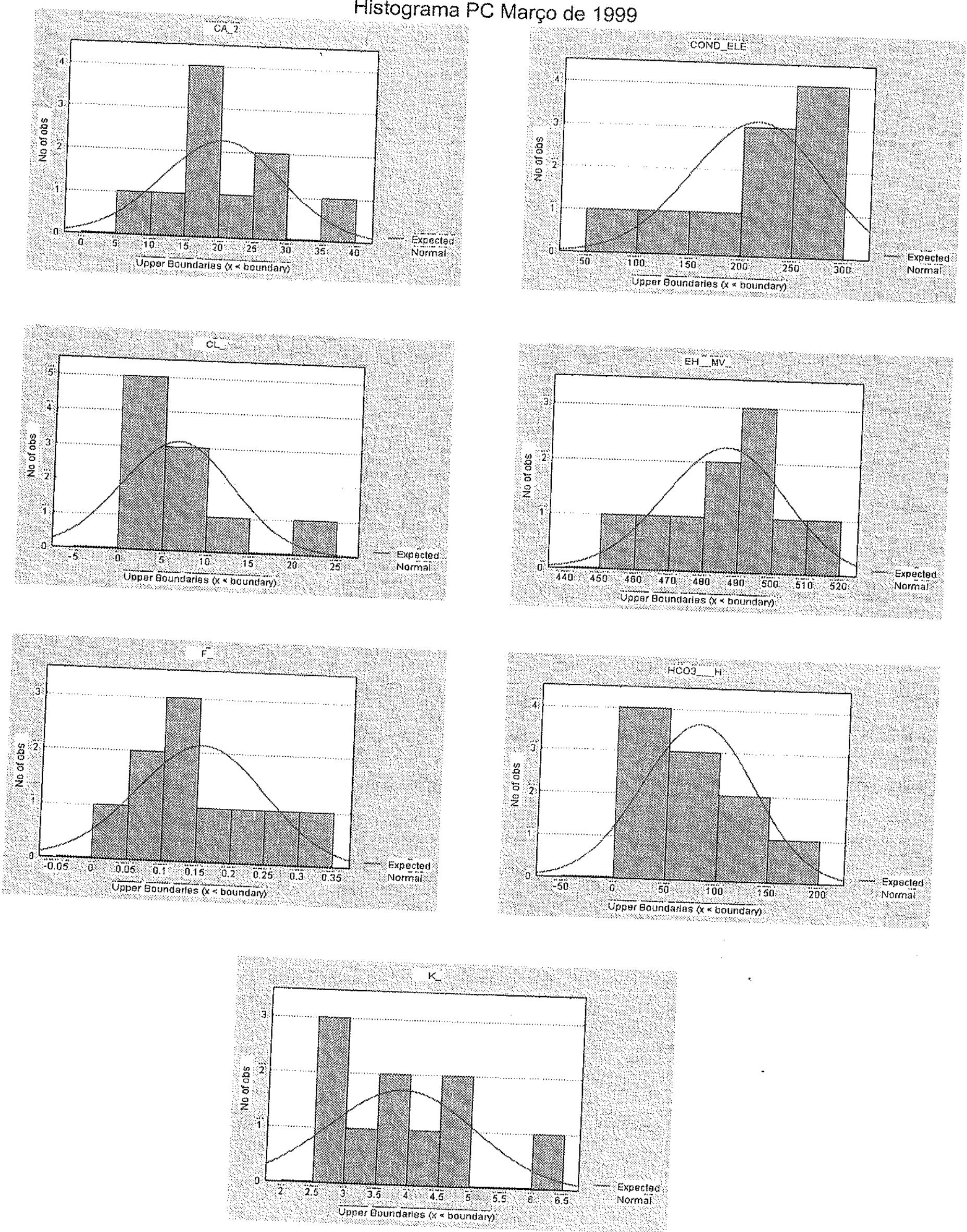
Histograma PT Outubro de 2000
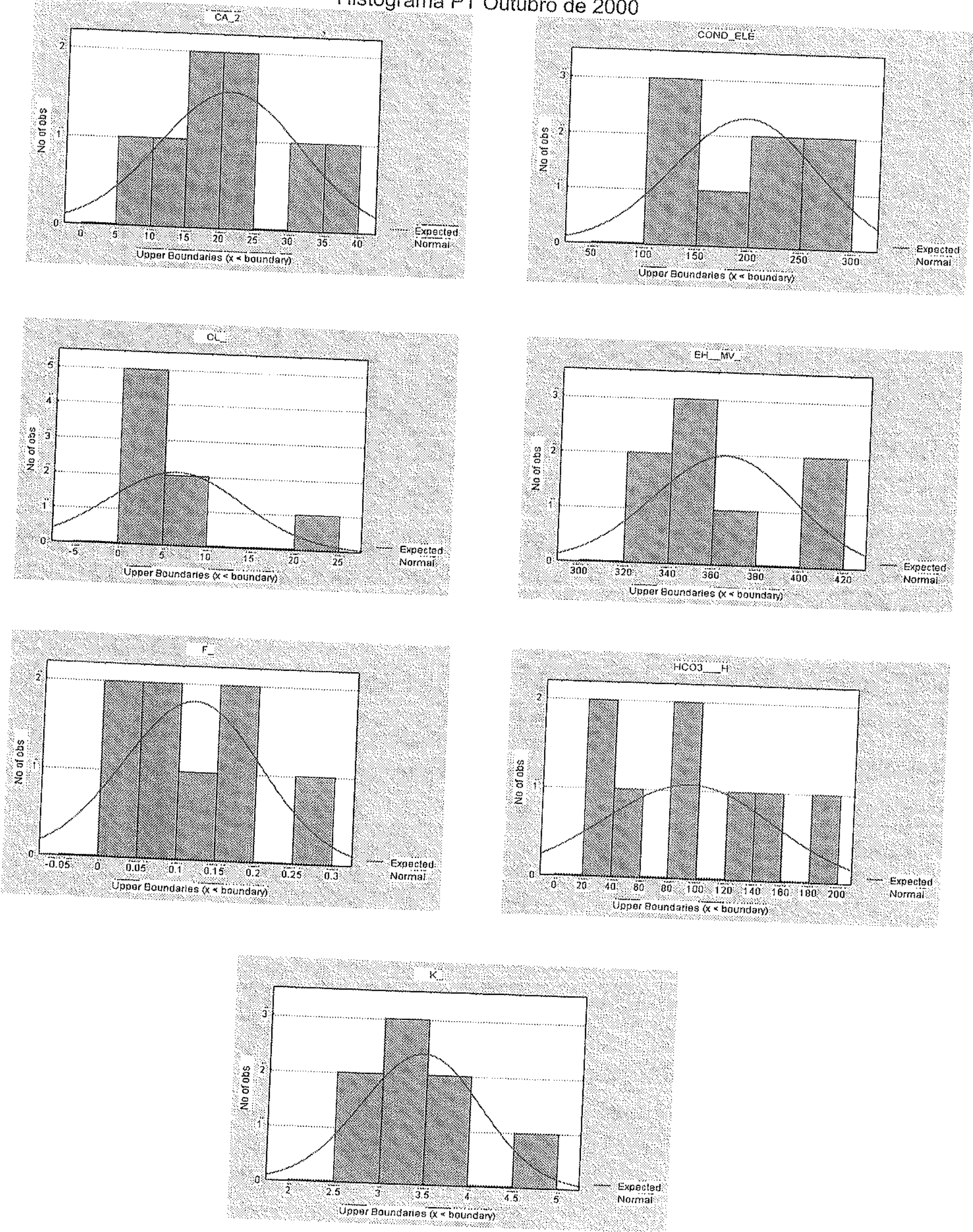
Histogramas PP Outubro de 1998
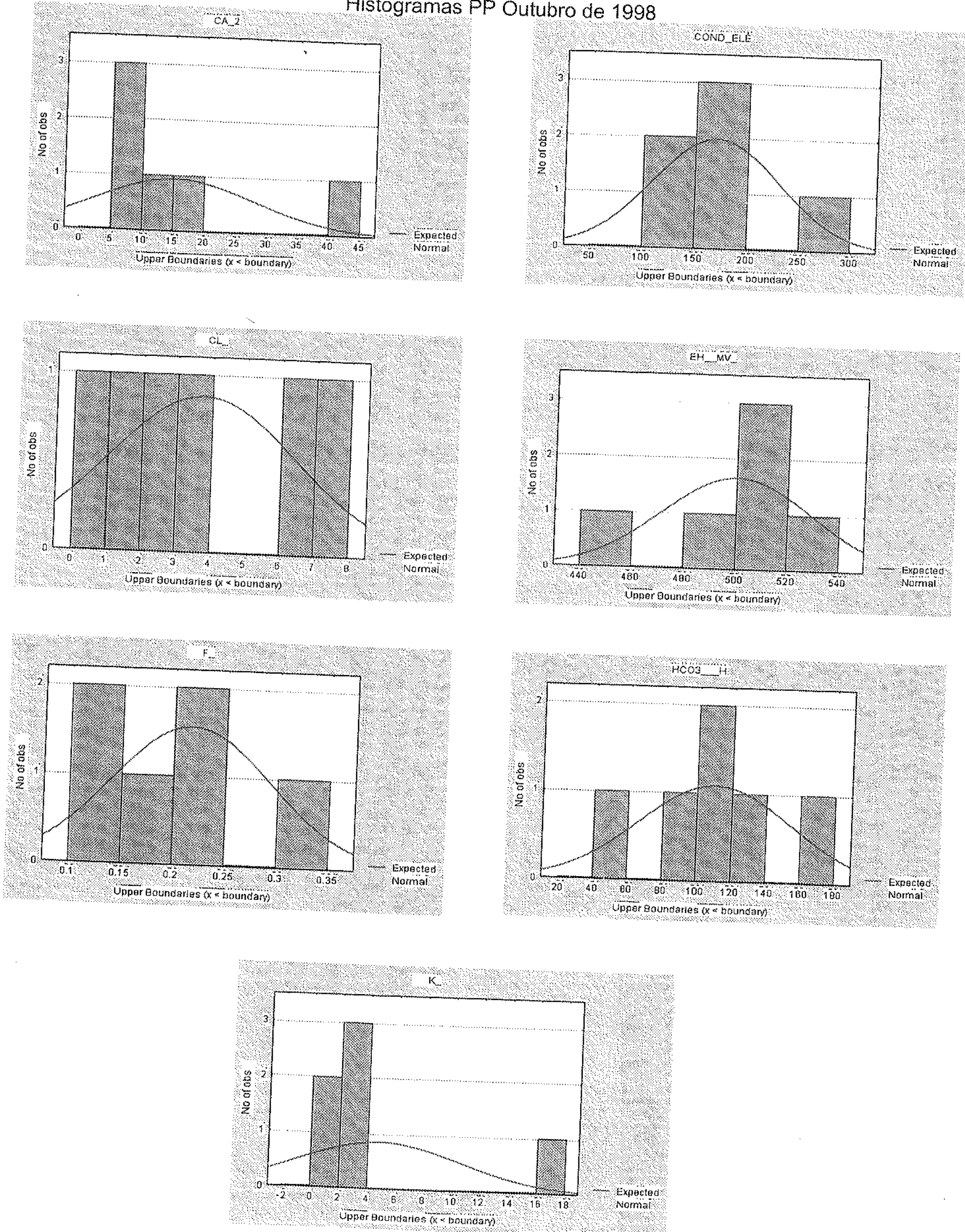